\title{
Analysis and design of a solar-combisystem for high solar fraction Canadian housing with diurnal and seasonal water-based thermal stores
}

\author{
by \\ Briana Paige Kemery, PEng \\ BEng, Mechanical Engineering, \\ Carleton University, 2009
}

A thesis submitted to the Faculty of Engineering and Design in partial fulfilment of the requirements for the degree of

Master of Applied Science in Sustainable Energy

Department of Mechanical and Aerospace Engineering Carleton University, Ottawa, Ontario, Canada May 2017

Copyright (c)

Briana Paige Kemery, 2017 


\section{Abstract}

The objectives of this work were three-fold. First, to aid in the design and construction of an experimental research facility, the Urbandale Centre for Home Energy Research in Ottawa, Canada. The facility was constructed as a single-detached residential building for the purpose of researching solar thermal energy technologies for buildings. Second, to develop a simulation model using TRNSYS, ESP-r, and a co-simulator program to predict system and building performance. Third, to use the simulation tool to size the diurnal storage system and establish a suitable control method for charging and discharging seasonal and diurnal thermal stores in conjunction with a solar thermal combisystem to meet the space heating and domestic hot water loads whilst achieving a high solar fraction.

An initial system design ( $\alpha$ case) was defined and the results analysed on a seasonal and diurnal basis with the primary metric being solar fraction. A parametric study was carried out to evaluate the selected $\alpha$ case inputs and an improved system design ( $\beta$ case) developed. The work concludes a solar fraction of $90 \%$ or better (neglecting space cooling) for an energy efficient home is possible, using diurnal and seasonal thermal storage to offset the supply-demand mismatch of solar availability and space heating in a Canadian climate. 


\title{
For
}

\author{
My parents \\ You set me loose on the world with more opportunities and experiences \\ than I could ask for
}

Joshua

Your humour cracks me up and your talent inspires me

\section{My grandparents}

For my engineering mind and the heart for hard work

The song bird, giraffe, and wonders unseen

All creatures sharing with you and me

Our planet we ought leave pristine 


\section{Acknowledgments}

My friend and supervisor, Ian, without whom I never would have began or finished this journey. It's been my pleasure to work and learn with you, ta.

I am grateful for my contemporaries who shared this journey with me. For your

support, your guidance, and most importantly your camaraderie, thank you. May we continue to prove excellence and a good time are not mutually exclusive,

Neil Saldanha, Geoffrey Johnson, Patrice Pinel, Andrea Pietila, Stephen

McMurtry, Courtney Edwards, Adam Wills, John Kopf, Sébastien

Brideau, Skai Edwards, Evan Boucher, and Fred Barrett.

Special mentions,

Steven Cains, for your encouragement, cleverness, and friendship.

Sputnik, Tuuli, and Raffi, for your constancy, hugs, and good humour.

$\mathrm{G}$, for tossing a life ring of challenge into my sea of boredom. 


\section{Contributions}

The design team whose support, brilliance, and good humour made the Urbandale Centre for Home Energy Research possible, my admiration and thanks!

Ian, Sheryl Boyle, Matthew Sachs, Ben Miranda, and Lucie Fontein.

I must express my gratitude for the excellent work of my colleagues to lay the groundwork for my research, and the countless times you lent your support or guidance. In particular,

Adam Wills, Geoffrey Johnson, Sébastien Brideau, and Skai Edwards.

For all your efforts supporting the Urbandale Centre for Home Energy Research, thank you.

Fred Barrett, Chris Weissflog, Sébastien Brideau, Geoffrey Johnson, Tom Mackintosh, Curtis Meister, Nina Dmytrenko, Mihai Mateescu, Ashley Hooker, Sarah Brown, Isabelle Kosteniuk. 


\section{Table of Contents}

Abstract $\quad$ ii

Acknowledgments $\quad$ iv

Contributions $\quad$ v

Table of Contents $\quad$ vi

List of Tables $\quad$ xi

List of Figures $\quad$ xiii

Nomenclature $\quad$ xvii

List of Symbols $\quad$ xix

1 Background 1

1.1 Seasonal thermal stores . . . . . . . . . . . . . . 4

1.2 Solar combisystems . . . . . . . . . . . . . . . 7

1.3 Single-scale residential systems . . . . . . . . . . . . . 8

1.4 Previous Work ......................... 10 


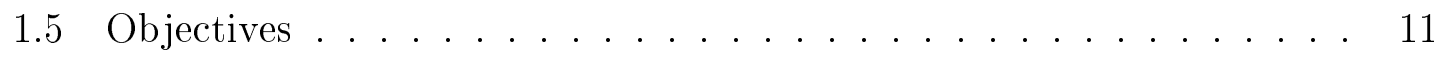

2 Simulation Methodology 14

2.1 Simulation Tools ........................ 14

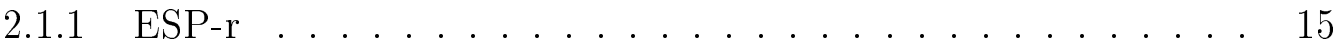

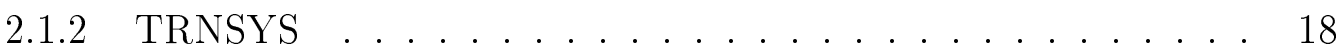

2.1.3 Co-simulator ........................ 19

2.2 Climate Data . . . . . . . . . . . . . . 20

2.3 ESP-r Model . . . . . . . . . . . . . . . . . 21

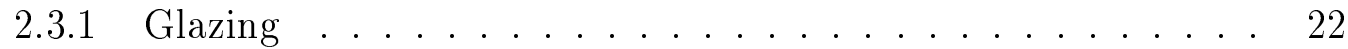

2.3.2 Building Envelope ................. 24

2.3.3 Infiltration and Ventilation ............. 27

2.3.4 Radiant Floor . . . . . . . . . . . . . . 28

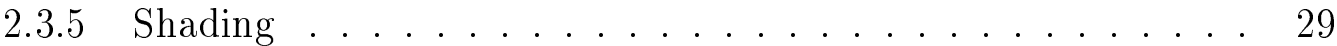

2.3.6 BASESIMP Calculations . . . . . . . . . . 30

2.4 TRNSYS Model . . . . . . . . . . . . . . 31

2.4.1 Charging and Discharging Systems . . . . . . . . . 31

2.4.2 Custom Type 266 Controller . . . . . . . . . . . . . 34

Type 266 Logic . . . . . . . . . . . . . 35

2.4.3 Diurnal and Seasonal Storage Tanks - Type 534 . . . . . . . 40

2.4.4 Evacuated Tube Solar Thermal Collector - Type 71 . . . . . 44

2.4.5 Heat Exchangers ................. 45

2.4.6 Working Fluids . . . . . . . . . . . . . . 46

2.4.7 Domestic Hot Water Data . . . . . . . . . . . . 46 
2.5 Ground Temperature Sensitivity Study . . . . . . . . . . . . . 47

2.6 Simulation period and time step . . . . . . . . . . . . 49

2.7 Model Verification . . . . . . . . . . . . . . 50

3 Experimental Work $\quad 51$

3.1 Urbandale Centre for Home Energy Research . . . . . . . . . . . . 51

3.1.1 Seasonal Thermal Store .............. 54

3.1.2 Diurnal Thermal Store . . . . . . . . . . . 57

3.1.3 Roth Radiant Floor Heating System . . . . . . . . . . . 58

3.1.4 Personal Contributions ................. 59

Facility Design and Management . . . . . . . . . 59

Solar Thermal Energy Stores . . . . . . . . . . 59

Instrumentation and Data Acquisition . . . . . . . . 60

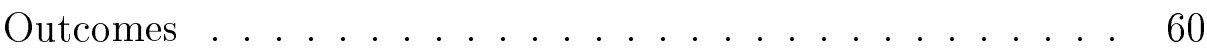

4 Simulation Results $\quad 62$

4.1 Concepts and Terminology .................. 63

$4.2 \quad \alpha$ Case Results . . . . . . . . . . . . . . . . 64

4.2.1 Annual Performance ............... 66

4.2.2 $\alpha$ Case Performance on Specific Days . . . . . . . . . . . . 69

Cloudy Summer Day - 8 August . . . . . . . . . . 70

Cloudy Spring Day - 12 May . . . . . . . . . . 77

Cloudy Autumn Day - 3 October . . . . . . . . . . 77

Cloudy Winter Day - 13 January . . . . . . . . . 78

Sunny Winter Day - 12 January . . . . . . . . . . 78

viii 
Sunny Spring Day -6 May . . . . . . . . . . . . 85

Sunny Summer Day - 13 August . . . . . . . . . . . . . 86

Sunny Autumn Day - 14 October . . . . . . . . . . . . 86

$4.2 .3 \quad \alpha$ Case Summary . . . . . . . . . . . . . . . . 87

4.3 Parametric Results . . . . . . . . . . . . . . . . . 88

$4.4 \quad \beta$ Case Results . . . . . . . . . . . . . . . . . . . 92

4.4 .1 Annual Performance . . . . . . . . . . . . . . . . . . 93

4.4 .2 Seasonal Cases . . . . . . . . . . . . . . . . . . 102

$4.4 .3 \quad$ Diurnal Cases . . . . . . . . . . . . . . . . . . . . . 105

4.5 Overall Ranking of Considered Cases . . . . . . . . . . . . . 108

5 Conclusions and Recommendations $\quad 110$

5.1 Conclusions . . . . . . . . . . . . . . . . . . . 111

5.2 Future Work . . . . . . . . . . . . . . . . . . . . . . 113

$\begin{array}{ll}\text { List of References } & 116\end{array}$

Appendix A Additional Results Plots 125

A.1 Cloudy Spring Day - 12 May . . . . . . . . . . . . . . . . . 125

A.2 Cloudy Autumn Day - 3 October . . . . . . . . . . . . . . 129

A.3 Cloudy Winter Day - 13 January . . . . . . . . . . . . . . . 133

A.4 Sunny Spring Day - 6 May . . . . . . . . . . . . . . . . . 137

A.5 Sunny Summer Day - 13 August . . . . . . . . . . . . . . . . 141

A.6 Sunny Autumn Day - 14 October . . . . . . . . . . . . . . . 145

A.7 STES $\alpha$ and $\beta$ Case Behaviour Comparison . . . . . . . . . 149 
B.1 Harmonizer Input File . . . . . . . . . . . . . . . . . . . 151

Appendix C ESP-r Input Files 152

C.1 Configuration ........................ 152

C.2 Alberta Infiltration Model . . . . . . . . . . . . . . . . . 156

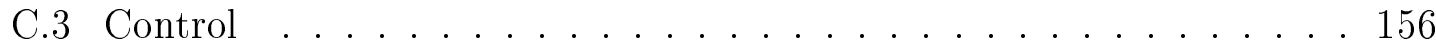

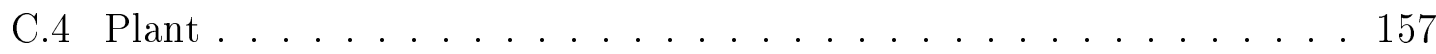

C.5 Air Flow Network . . . . . . . . . . . . . . . 158

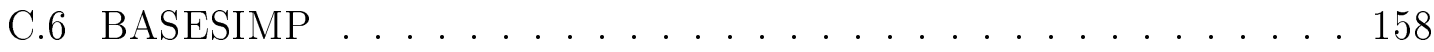

Appendix D Simulation Studio Architecture $\quad 159$

$\begin{array}{lll}\text { Appendix E TRNSYS Input Files } & 161\end{array}$

E.1 Custom Controller Type . . . . . . . . . . . . . . 161

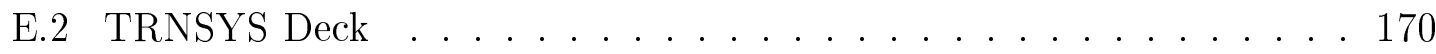

E.3 Apricus Solar Collectors . . . . . . . . . . . . . 190 


\section{List of Tables}

3 ESP-r Wall Materials and Construction . . . . . . . . . . . . 24

4 TRNSYS Types Used . . . . . . . . . . . . . . . . . . . . 31

5 Diurnal Store Inputs . . . . . . . . . . . . . . . . . . 44

6 Seasonal Store Inputs . . . . . . . . . . . . . . . . . . . . 44

$7 \quad$ Simulation Heat Exchangers Inputs $\ldots \ldots \ldots \ldots \ldots$

8 Working Fluids $\ldots \ldots \ldots \ldots \ldots \ldots$

9 Auxiliary Energy Use and Store Charging . . . . . . . . . 48

10 Annual Heat Loss and Averaged Store Temperatures _ . . . . . . 49

$11 \quad \alpha$ Case . . . . . . . . . . . . . . . . . . 65

12 Parametric Simulation Cases . . . . . . . . . . . . . . . 88

13 Parametric Cases Inputs . . . . . . . . . . . . . . . . . . 89

$14 \quad \beta$ Case . . . . . . . . . . . . . . . . . . 92

15 Energy Use . . . . . . . . . . . . . . . . . . . . . . 102

16 Energy Efficiency . . . . . . . . . . . . . . . . . . . . . 103

17 Store Temperatures and Heat Loss By Seasonal Parametric Case . . . 104

18 Energy-use . . . . . . . . . . . . . . . . . . . . . . 105

19 Charging Efficiency By Diurnal Parametric Case . . . . . . . . . . 106 
20 Store Temperatures and Heat Loss By Diurnal Parametric Case . . . 107

$21 \beta$ Case Rank Compared to Parametric Cases . . . . . . . . . . . . . . 109 


\section{List of Figures}

1 Observed Global Impacts of Climate Change . . . . . . . . . . . 2

2 Secondary Energy Use in Canada By Sector . . . . . . . . . . . 4

3 Global Horizontal Irradiation $\ldots \ldots \ldots \ldots$

4 Northern Hemisphere Solar Availability and SH Demand Mismatch . 6

5 Solar Thermal Charging Loop . . . . . . . . . . . . . . . . . 12

6 Simplified ESP-r Zone Model . . . . . . . . . . . . . . . . . 16

$7 \quad$ Simplified ESP-r Node Energy Balance $\ldots \ldots \ldots \ldots \ldots$

8 ESP-r Interface and House Model . . . . . . . . . . . . . . . . 21

9 Window-to-Wall Area by Orientation . . . . . . . . . . . 23

10 Rain screen System with Cascadia Clips and Z-girts . . . . . . . 25

11 Cedar Rain Screen Panel . . . . . . . . . . . . . . . . 26

12 ESP-r's Radiant Floor Heat Injection . . . . . . . . . . . . . 28

13 Simplified TRNSYS Solar Thermal Charging Components . . . . . 32

14 Simplified TRNSYS DHW and SH Components . . . . . . . . . 33

15 Custom TRNSYS Type - Thermal Store Charging Logic . . . . . . 37

16 Custom TRNSYS Type - Radiant Floor Heating Logic . . . . . . . 39

17 Type 534 Flow Mode 1 and Diurnal Store Node Layout . . . . . . . 43 
18 Urbandale Centre for Home Energy Research . . . . . . . . . . . . 52

19 Solar Collectors - Urbandale Centre for Home Energy Research . . . . 53

$2035 \mathrm{~m}^{3}$ Below-grade Seasonal Thermal Storage Tank . . . . . . . . . 55

21 Seasonal Store Diffuser Design . . . . . . . . . . . . . . 56

22 Three 450 L Diurnal Store Tanks . . . . . . . . . . . . . . 57

23 2nd Floor Radiant Floor Layout . . . . . . . . . . . . 58

24 ZCL Thermocouple Rack Installation . . . . . . . . . . . . 61

25 Energy Supplied by End-Use $(\alpha$ Case $) \ldots \ldots . \ldots . \ldots 67$

26 Energy Collected and Added to Thermal Stores ( $\alpha$ Case) $\ldots \ldots 7$

27 Seasonal Store Temperature Profile $(\alpha$ Case $) \ldots \ldots$. . . . . . . 68

28 Diurnal Store Temperature Profile $(\alpha$ Case $) \ldots \ldots$. . . . . . . 68

29 Cloudy Summer Day - Ambient Temperature and Irradiance . . . . . 70

30 Cloudy Summer Day - Store Behaviour . . . . . . . . . . . . 72

31 Cloudy Summer Day - DHW Loads . . . . . . . . . . . . . . 73

32 Cloudy Summer Day - Store Heat Loss . . . . . . . . . . . . . . . 74

33 Cloudy Summer Day - Store Stratification . . . . . . . . . . 76

34 Sunny Winter Day - Ambient Temperature and Irradiance . . . . . . 79

35 Sunny Winter Day - Store Behaviour . . . . . . . . . . . 81

36 Sunny Winter Day - Store Stratification . . . . . . . . . . . . 82

37 Sunny Winter Day - DHW Loads . . . . . . . . . . . . . 83

38 Thermal Store Heat Loss . . . . . . . . . . . . . . . 84

39 Annual Average Solar Fraction for Seasonal \& Diurnal Cases . . . . . 90

40 Energy Supplied by End-Use . . . . . . . . . . . . . . . . . . 94

41 Seasonal Store Temperatures . . . . . . . . . . . . . . . 95

xiv 
42 Diurnal Store Temperatures $\ldots \ldots \ldots \ldots$

43 Solar Fraction . . . . . . . . . . . . . . . . . . . . 98

44 Energy Collected and Added to Thermal Stores . . . . . . . . . . . 99

45 Zone Temperature . . . . . . . . . . . . . . . . . 100

46 DHW Delivery Temperature . . . . . . . . . . . . . . . . . . 101

47 Cloudy Spring Day - Ambient Temperature and Irradiance . . . . . . 125

48 Cloudy Spring Day - Store Behaviour . . . . . . . . . . . . 126

49 Cloudy Spring Day - DHW Loads . . . . . . . . . . . . . . 127

50 Cloudy Spring Day - Heat Loss ～. . . . . . . . . . . . . 127

51 Cloudy Spring Day - Store Stratification _ . . . . . . . . . . . 128

52 Cloudy Autumn Day - Ambient Temperature and Irradiance . . . . . 129

53 Cloudy Autumn Day - Store Behaviour . . . . . . . . . . . . . 130

54 Cloudy Autumn Day - DHW Loads . . . . . . . . . . . . . . . . . . 131

55 Cloudy Autumn Day - Heat Loss . . . . . . . . . . . . . . . 131

56 Cloudy Autumn Day - Store Stratification . . . . . . . . . . . 132

57 Cloudy Winter Day - Ambient Temperature and Irradiance . . . . . . 133

58 Cloudy Winter Day - Store Behaviour . . . . . . . . . . . . . . . 134

59 Cloudy Winter Day - DHW Loads . . . . . . . . . . . . . . . . 135

60 Cloudy Winter Day - Heat Loss . . . . . . . . . . . . . . 135

61 Cloudy Winter Day - Store Stratification . . . . . . . . . . . 136

62 Sunny Spring Day - Ambient Temperature and Irradiance . . . . . . 137

63 Sunny Spring Day - Store Behaviour _ . . . . . . . . . . . 138

64 Sunny Spring Day - DHW Loads _. . . . . . . . . . . . . . . 139

65 Sunny Spring Day - Heat Loss . . . . . . . . . . . . . . . . 139 
66 Sunny Spring Day - Store Stratification . . . . . . . . . . . . . 140

67 Sunny Summer Day - Ambient Temperature and Irradiance . . . . . . 141

68 Sunny Summer Day - Store Behaviour _ . . . . . . . . . . . . . . 142

69 Sunny Summer Day - DHW Loads . . . . . . . . . . . . . . . . . 143

70 Sunny Summer Day - Heat Loss . . . . . . . . . . . . . . . . 143

71 Sunny Summer Day - Store Stratification . . . . . . . . . . . . . . 144

72 Sunny Autumn Day - Ambient Temperature and Irradiance . . . . 145

73 Sunny Autumn Day - Store Behaviour . . . . . . . . . . . . 146

74 Sunny Autumn Day - DHW Loads . . . . . . . . . . . . . . . 147

75 Sunny Autumn Day - Heat Loss . . . . . . . . . . . . . . . . . 147

76 Sunny Autumn Day - Store Stratification . . . . . . . . . . . . . 148

77 Sunny Winter Day . . . . . . . . . . . . . . . . . . . 150

78 TRNSYS Simulation Studio Architecture . . . . . . . . . . . 160 


\section{Nomenclature}

$\mathrm{ACH} \quad$ Air changes per hour, metric of air tightness

AP-30 Apricus evacuated tube solar thermal collector model

CWEC Canadian Weather for Energy Calculation

CWEEDS Canadian Weather Energy and Engineering Data Sets

DHW domestic hot water

DTES diurnal thermal energy store

ESP-r Environmental System Performance - research edition

EUI energy use intensity - DHW and SH energy per square meter

H38 annual DHW draw profile for House 38

HX heat exchanger

GHG green house gasses

GJ gigajoule (one billion joules) - international system's unit of energy

IAM incident angle modifier, relates to efficiency of evacuated tube solar collector

IEA International Energy Agency

IPCC International Panel on Climate Change

$\mathrm{kW} \quad$ kilowatt (one thousand watts), unit of power

NRCan Natural Resources Canada

$\mathrm{Pa} \quad$ unit of pressure, Pascals

xvii 
R-2000 NRCan administered residential construction standard

RE-119 diurnal store tank, Thermo2000 model number

SF

solar fraction

SH space heating

STES seasonal thermal energy store

Thermo2000 diurnal store manufacturer Thermo 2000

TRNSYS transient system simulation tool

Type-T thermocouple wire comprised of copper and constantan

UA heat exchanger overall heat transfer coefficient and fluid contact area

ZCL seasonal store manufacturer ZCL Composites Inc. 


\section{List of Symbols}

$\alpha$

aux

$\beta$

${ }^{\circ} \mathrm{C}$

$\mathrm{CO}_{2}$

$\mathrm{C}_{\mathrm{p}}$

$\Delta$

$\eta_{\text {charge }}$

$\eta_{\text {total }}$

$E^{\text {collectors }}$

$E_{+}^{S T E S}$

$E_{+}^{D T E S}$

$E_{D H W}^{D T E S}$

$E_{D H W}^{A U X}$

$E_{S H}^{S T E S}$

$E_{S H}^{D T E S}$

$E_{S H}^{A U X}$ first iteration of a 'base' case set of parameters

auxiliary supplied energy (subscript)

a refined version of the $\alpha$ case based on parametric analysis results

degrees Celsius

carbon dioxide

specific heat $\left[\frac{\mathrm{kJ}}{\mathrm{kgK}}\right]$

difference between the two associated variables

ratio of energy added to thermal stores to solar thermal energy collected

ratio of energy added to, and heat loss from, stores to solar energy collected

useful energy collected by solar thermal evacuated tube panels

energy added to seasonal thermal store

energy added to diurnal thermal store

energy from diurnal thermal store to domestic hot water

DHW demand supplied using auxiliary energy

energy from seasonal thermal store to space heating

energy from diurnal thermal store to space heating

SH demand supplied using auxiliary energy 
$H X_{D T E S}$ heat exchanger on the diurnal store charging circuit

$H X_{S T E S} \quad$ heat exchanger on the seasonal store charging circuit

L litre

$\mathrm{m}^{3} \quad$ cubic metres

$P_{\text {solar }} \quad$ hydraulic pump on the solar collector circuit

$P_{S H} \quad$ hydraulic pump for either store to meet SH loads

$P_{D T E S} \quad$ hydraulic pump on the diurnal store charging circuit

$P_{S T E S} \quad$ hydraulic pump on the seasonal store charging circuit

$Q_{-}^{D T E S} \quad$ diurnal thermal store heat loss

$Q_{-}^{S T E S} \quad$ seasonal thermal store heat loss

sol solar supplied energy (subscript)

$T_{\text {avg }}^{D T E S} \quad$ average diurnal thermal store temperature

$T_{\text {avg }}^{S T E S} \quad$ average seasonal thermal store temperature

$T_{\text {bottom }}^{D T E S}$ temperature of bottom node of diurnal thermal store

$T_{\text {bottom }}^{S T E S} \quad$ temperature of bottom node of seasonal thermal store

ts simulation time-step

$T_{\text {top }}^{D T E S} \quad$ temperature of top node of diurnal thermal store

$T_{\text {top }}^{S T E S} \quad$ temperature of top node of seasonal thermal store

$T_{\text {outlet }}^{\text {collectors }} \quad$ fluid temperature at outlet of collector array

$T_{\text {cutoff }}^{D T E S} \quad$ diurnal store temperature limit below which the control strategy prevents the diurnal store from providing $\mathrm{SH}$

$T_{+}^{D T E S}$ diurnal store temperature limit below which the control strategy tries to add energy to the diurnal store

$T_{\text {delivery }}^{D H W} \quad$ DHW delivery temperature setpoint 
$T_{+}^{S T E S} \quad$ seasonal store temperature limit below which the control strategy tries to add energy to the seasonal store

$V^{D T E S} \quad$ diurnal solar thermal store volume in litres

$V^{S T E S} \quad$ seasonal solar thermal store volume in cubic meters 


\section{Chapter 1}

\section{Background}

Much of human society today relies on energy resources for daily essentials as well as modern conveniences and comfort. In cold climates, domestic hot water (DHW) and space heating (SH) demands are dominant end-uses. The reliance on fossil fuels for meeting these energy demands has been increasing since the industrial era began. This has been accompanied by an increase in carbon dioxide $\left(\mathrm{CO}_{2}\right)$ emissions. As of 2010 the global $\mathrm{CO}_{2}$ concentrations had increased $39 \%$ over pre-industrial levels (Intergovernmental Panel on Climate Change, 2015, p7)

Atmospheric concentrations of $\mathrm{CO}_{2}$ and other GHGs have reached levels unprecedented for at least the past 800,000 years. The Intergovernmental Panel on Climate Change (IPCC) asserts "it is extremely likely that more than half of the observed increase in global average surface temperature from 1951 to 2010 was caused by the anthropogenic increase in GHG concentrations and other anthropogenic forcings together" (Intergovernmental Panel on Climate Change, 2014, p5). There have been observed changes in sea ice extent, ocean and surface temperature, sea level and precipitation as the IPCC graphics show in Figure 1 (Intergovernmental Panel on 
Climate Change, 2014, p41).

(a) Observed globally averaged combined land and ocean surface temperature anomaly 1850-2012

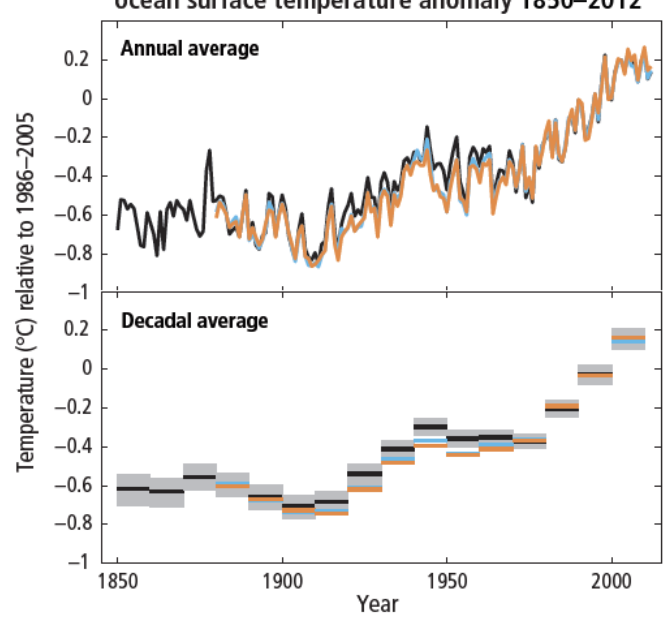

(b)

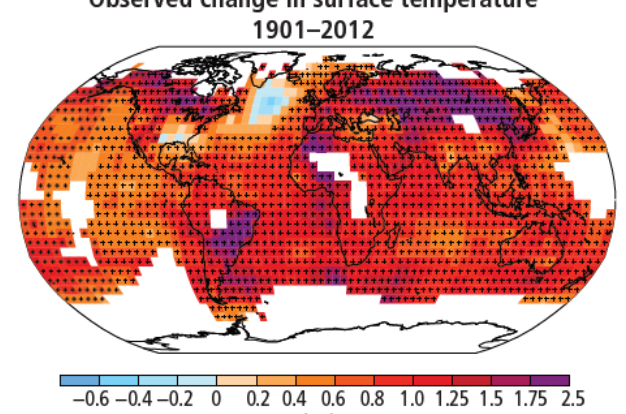

$\left({ }^{\circ} \mathrm{C}\right)$ (c)

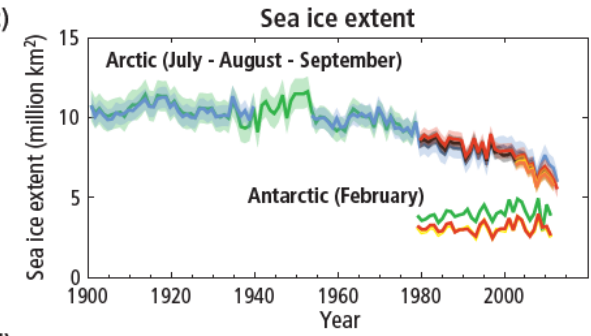

(d) Global mean sea level change 1900-2010

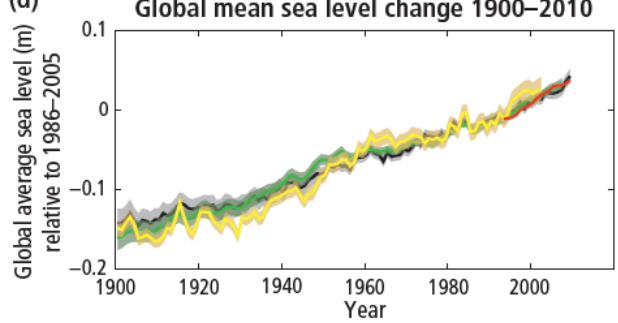

(e)

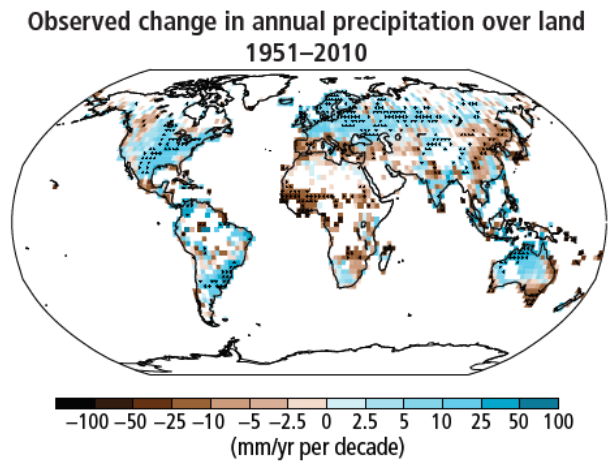

Figure 1.1 | Multiple observed indicators of a changing global climate system. (a) Observed globally averaged combined land and ocean surface temperature anomalies (relative to the mean of 1986 to 2005 period, as annual and decadal averages) with an estimate of decadal mean uncertainty included for one data set (grey shading). (WGI Figure SPM.1, Figure 2.20; a listing of data sets and further technical details are given in the WGI Technical Summary Supplementary Material WGI TS.SM.1.1\} (b) Map of the observed surface temperature change, from 1901 to 2012, derived from temperature trends determined by linear regression from one data set (orange line in Panel a). Trends have been calculated where data availability permitted a robust estimate (i.e., only for grid boxes with greater than $70 \%$ complete records and more than $20 \%$ data availability in the first and last $10 \%$ of the time period), other areas are white. Grid boxes where the trend is significant, at the $10 \%$ level, are indicated by a + sign. (WGI Figure SPM.1, Figure 2.21, Figure TS.2; a listing of data sets and further technical details are given in the WGI Technical Summary Supplementary Material WGI TS.SM.1.2\} (c) Arctic (July to September average) and Antarctic (February) sea ice extent. (WGI Figure SPM.3, Figure 4.3, Figure 4.SM.2; a listing of data sets and further technical details are given in the WGI Technical Summary Supplementary Material WGI TS.SM.3.2]. (d) Global mean sea level relative to the 1986-2005 mean of the longest running data set, and with all data sets aligned to have the same value in 1993, the first vear of satellite altimetry data. All time series (coloured lines indicatina different data sets) show annual values, and where assessed, uncertainties are indicated by coloured

Figure 1: Observed Global Impacts of Climate Change(Intergovernmental Panel on Climate Change, 2014, p41) Image reproduced according to the IPCC Report Graphics terms of use.

The International Energy Agency (IEA) emphasized the importance of the Paris climate change discussions in late 2015 as concerted global effort is required to limit global warming to a $2{ }^{\circ} \mathrm{C}$ temperature rise (International Energy Agency, 2015). The 
Paris Agreement was adopted by 197 parties to the United Nations Framework Convention on Climate Change declaring the target of staying well below the $2^{\circ} \mathrm{C}$ global temperature rise below pre-industrial levels (United Nations Framework Convention on Climate Change, 2016). Reducing cumulative GHG emissions over the next few decades will contribute to reducing the severity of climatic related consequences such as substantial species extinction, food insecurity and extreme weather events (Intergovernmental Panel on Climate Change, 2014, p9).

"Already in Canada, we can see and feel the effects of climate change: we have seen floods in Alberta, wildfires across British Columbia, and Prince Edward Islands coastline is receding. The Arctic is experiencing serious climatic changes with melting permafrost, impacting the lives of Indigenous peoples" (Honourable Catherine McKenna, Minister of Environment and Climate Change, 2015).

The residential sector energy accounted for 17\% of Canada's 2013 total secondary energy end-use. Of this energy, $63 \%$ is used for SH and $19 \%$ for DHW (Office of Energy Efficiency, 2013) as shown in Figure 2.

Natural gas is Canadian's primary energy source for $66 \%$ of SH and $74 \%$ of DHW systems (Office of Energy Efficiency, 2015b,c). Natural gas is also Canada's largest single contributor (29\%) to GHG emissions by energy source (Office of Energy Efficiency, 2015a). 


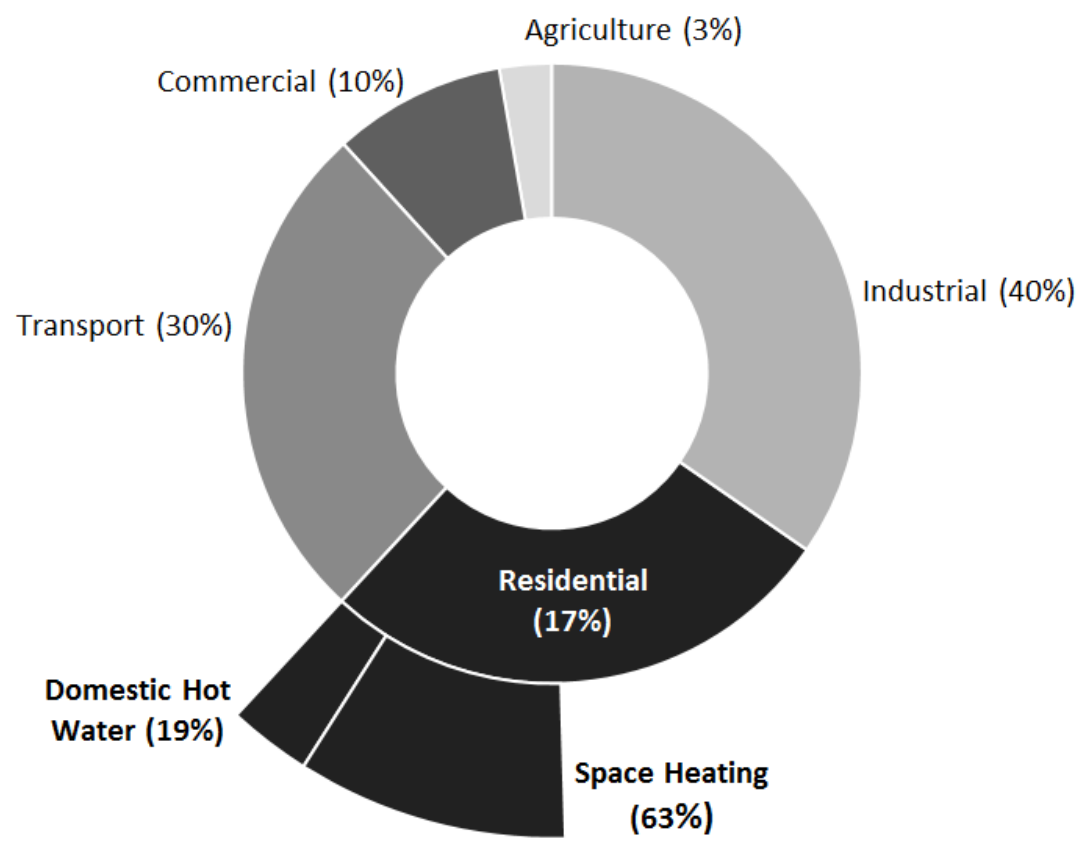

Figure 2: Secondary Energy Use in Canada By Sector, 2013(Office of Energy Efficiency, 2013)

Ontario's Climate Change Action Plan identifies emission reduction from fossilfuel use in buildings as a priority. One of the measures to reduce reliance on fossil fuels for space and water heating is increasing the uptake of technologies such as solar thermal energy systems (Ontario, 2016).

\subsection{Seasonal thermal stores}

The sun is an abundant source of power, many thousand times the energy consumed is transferred to the earth's surface each year (Weiss, 2003). The solar availability for Canada is shown in Figure 3.

However, there is often an offset between availability and energy demands which 


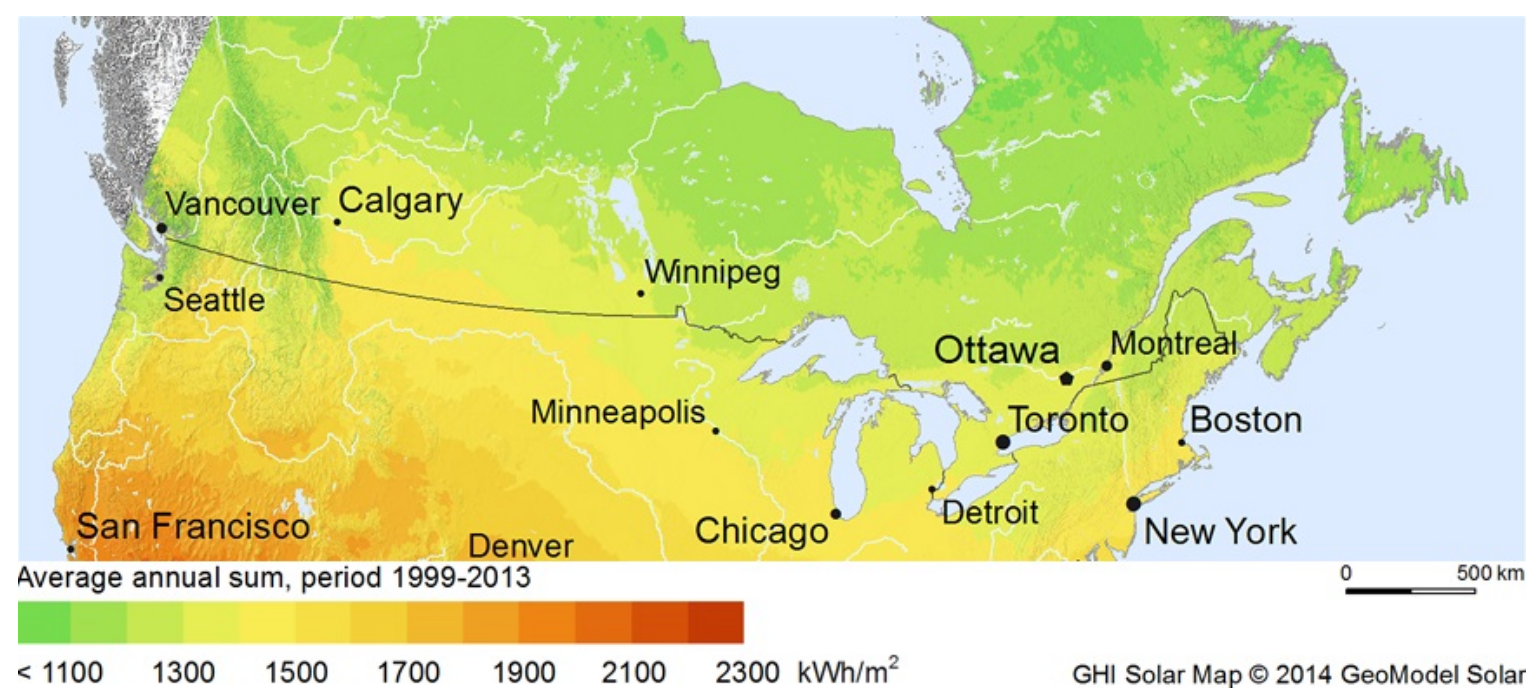

Figure 3: Global Horizontal Irradiation (SolarGIS, 2015) Image reproduced according to the SolarGIS educational maps terms of use.

is shown by plotting the data used in this work (see Figure 4). In the early 1970's the mismatch between solar availability and demand looked to make solar SH an untenable solution for single residential dwellings. So, the IEA began Task 7, a study of large scale seasonal solar thermal storage in 1979.

The Task found in locations between $40^{\circ}$ and $65^{\circ}$ of latitude (such as Canada), larger STES scale applications (i.e., not just for an individual house) are a feasible and non-polluting heating alternative. This is due to a good deal of solar availability and SH being the predominant end-use in the residential sector (International Energy Agency, 1990; Pinel et al., 2011).

A 2009 survey of underground seasonal storage looked at water tank and gravelwater pit methods. The researchers found buried concrete tanks with stainless steel liners for water-tightness were the most common construction method. While 


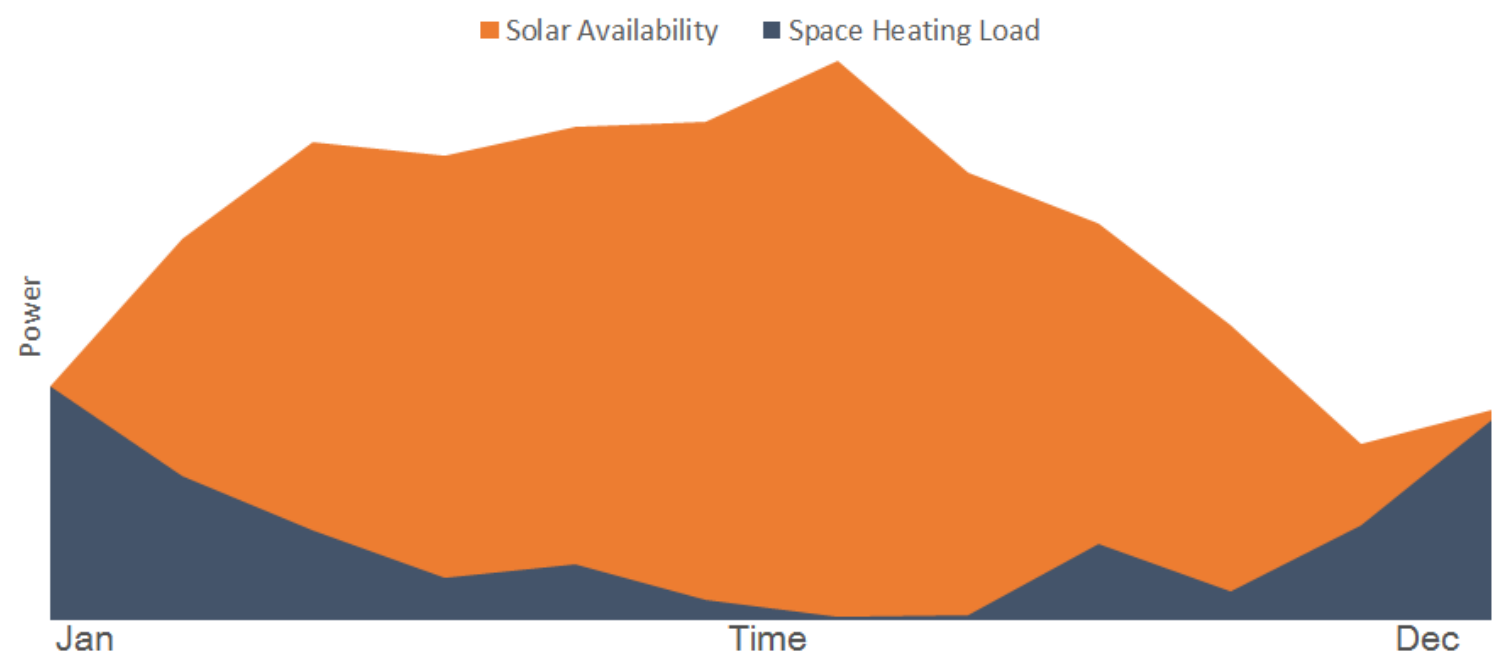

Figure 4: Northern Hemisphere Solar Availability and SH Demand Mismatch

many installations mentioned performed technically as expected, most were not costeffective (Novo et al., 2009). Three installations, a $500 \mathrm{~m}^{3}$ bentonite lined concrete tank, a $3000 \mathrm{~m}^{3}$ ethylene propylene diene monomer lined concrete tank, and a 1000 $\mathrm{m}^{3}$ clay lined store pit encountered leakage problems. A solution was found in a $10000 \mathrm{~m}^{3}$ project in 2003 which reduced cost using high-density polyethylene to line the pit with a steel structure and vapour barrier as a cover (Novo et al., 2009).

Pinel et al. (2011) conducted a thorough review of seasonal thermal store methods suitable for residential applications. The reviewers covered latent and sensible chemical storage and sensible storage using water (tanks and aquifers), soil, gravel, and briefly covered lesser-used mediums such as oil or salt which are typically cost prohibitive.

The Drake Landing Solar Community is comprised of 52 single-detached houses in Okotoks Alberta with a district heating system designed for a solar fraction greater than $90 \%$. Energy collection and seasonal thermal storage is accomplished using 
$2293 \mathrm{~m}^{3}$ of solar collectors and 144 borehole heat exchangers within $34000 \mathrm{~m}^{3}$ of earth (Sibbitt et al., 2012). $240 \mathrm{~m}^{3}$ of short term storage is used with the collectors and seasonal store. Individual houses have their own hot water heating system which meets more than $50 \%$ of the demand. The Drake Landing Five Year report indicates a space-heating solar fraction of $97 \%$ was achieved, exceeding the design targets (Sibbitt et al., 2012).

\subsection{Solar combisystems}

The term 'combisystem' refers to a solar thermal system capable of meeting SH and DHW demands. A combisystem typically includes five key elements, solar thermal collectors, short term thermal store, main controls, auxiliary controls, and a heat distribution method. Depending on the design and configuration of these various components, the percentage of household heating and hot water demands met by the combisystem varies between 10 to 100\% (International Energy Agency, 2014).

The increasing demand for solar based heating systems and the cost-effectiveness of combisystems led the IEA to convene the Solar Heating and Cooling Programme (Task 26) to study the complex interactions between the system components to improve overall performance (International Energy Agency, 2014). Likely one of the largest international efforts to develop the combisystem field, the Task ran from 1998 to 2002 and led to the publication of the Solar Heating Systems for Houses: A Design Handbook for Solar Combisystems (Edwards, 2014; Weiss, 2003). Different system designs were investigated using annual TRNSYS simulations for climate conditions of northern, central, and southern Europe locations (International Energy Agency, 
2003). Research was further developed by including the energy efficiency of the building in the sizing of the short term store and the collector array (Lund, 2005). Advanced storage concepts were evaluated with the goal of achieving $100 \%$ solar fraction for locations at or near $45^{\circ}$ of latitude (Bales et al., 2005).

In response to a follow-up to IEA Task 26 which documented and evaluated 200 installed combisystems throughout Europe (Ellehauge, 2003), combisystem performance with seasonal storage for a single storey detached house in Montreal was evaluated on a thermal energy and financial payback basis using TRNSYS. The study concluded low electricity rates in Québec and high payback periods resulting from high initial capital cost are significant barriers to adoption (Hugo et al., 2010).

Edwards (2014) looked at the performance of single- and double-tank combisystems for Ontario single family residential homes. The combisystems examined used radiators as the SH system, flat plate collector arrays (up to $48 \mathrm{~m}^{2}$ ) and diurnal storage volumes up to 2000 L. Edward's research showed that even with a $2000 \mathrm{~L}$ diurnal storage tank, solar fractions greater than 50\% were not achievable. Edwards concluded that using radiant floors for $\mathrm{SH}$ with lower temperature input requirements may increase the achievable solar fraction and evacuated tube collectors may allow for reduction in the total amount of collector area required.

\subsection{Single-scale residential systems}

While most STES systems tend to be installed for larger scale applications, there are a few examples worldwide of smaller scale installations. In Edmonton Alberta the Riverdale NetZero semi-detached duplex was built. The project was led by 
the Canada Mortgage and Housing Corporation under the national EQuilibrium ${ }^{\mathrm{TM}}$ Sustainable Housing Demonstration Initiative. The Riverdale NetZero solar combisystem is comprised of a $21 \mathrm{~m}^{2}$ array of vertically mounted flat plate collectors, a $17 \mathrm{~m}^{3}$ STES water tank, a $300 \mathrm{~L}$ DTES, and a $7 \mathrm{~kW}$ heat pump. The system was estimated to provide $83 \%$ of DHW and $21 \%$ of SH demands (CMHC, 2009).

In Galway Ireland, an existing $215 \mathrm{~m}^{2}$ Passive House was retrofit with a $22 \mathrm{~m}^{3}$ below-grade water-based STES. The $300 \mathrm{~L}$ DTES is heated first by the $10.8 \mathrm{~m}^{2}$ evacuated tube collector array to $65^{\circ} \mathrm{C}$ before charging the STES. The researchers note that the STES does not achieve any significant thermal stratification. The system achieved DHW and SH SF of $93 \%$ and $56 \%$ respectively. The research concludes that STES assisted combisystems are feasible for energy efficient single-detached homes in Ireland (SM Colclough and PW Griffiths and NJ Hewitt, 2011).

Sweet and Jr (2012) used TRNSYS to model single-family residential houses with soil-based STES in Richmond Virginia. A soil-based STES was selected for its economy of cost compared to other mediums. Six homes were simulated ranging in size from $800-2400 \mathrm{ft}^{2}$ with an air tightness of 1.0 air changes per hour (ACH). The collector areas considered scaled with home square footage ranging from 39-99 $\mathrm{m}^{2}$. A soil STES volume of $15 \mathrm{~m}^{3}$ was determined as optimal for the cases considered (Sweet and Jr, 2012). 


\subsection{Previous Work}

The objective of earlier work by Wills (2013) was the preliminary sizing of a solar collector array and the accompanying seasonal solar thermal storage system. Wills (2013) completed parametric studies of the performance of the seasonal store for volumes and determined a volume with a reasonable compromise between cost, solar fraction, and heat loss effects. Wills considered a $80 \mathrm{~m}^{3}$ seasonal store and $35 \mathrm{~m}^{2}$ of flat plate solar thermal collectors with a radiant floor SH distribution system. With this system, a solar fraction of $89 \%$ was achieved (Wills, 2013). In further unpublished work following his thesis, Wills examined reduced sizes of seasonal stores and evacuated tube solar thermal collectors which informed the seasonal store and collector array systems installed in the Urbandale Centre for Home Energy Research facility.

Further foundational work in the area of solar combisystems and domestic hot water (DHW) draw profiles was conducted by Edwards (2014). DHW draws can vary widely in terms of time-of-use and overall consumption which may affect simulation conclusions. Edwards (2014) showed that the overall magnitude of the draw profile had the greatest impact on overall energy use. The DHW draw profiles collected from measured data were utilised in this work and will be elaborated on in Chapter 2 (Edwards et al., 2015).

In his PhD work, Brideau (2016) examined the radiant floor heat distribution system for the Urbandale Centre for Home Energy Research facility and developed an energy model of the radiant floor. Brideau's design parameters informed the radiant floor system modelled in this research. 


\subsection{Objectives}

The work by Edwards, Brideau, and Wills laid the foundation for the final design choices of the Urbandale Centre for Home Energy Research facility, in particular, the domestic hot water draw profile, modelling the radiant floor system, and sizing the seasonal storage and solar collector array.

Of the three primary systems shown in Figure 5, the solar array and seasonal thermal store having been treated in previous work, the outstanding design work remaining was that of the diurnal storage.

The aim of this work was firstly, to contribute to the successful design and construction of the Urbandale Centre for Home Energy Research facility at Carleton University. To this end, a model of the entire system including building envelope, SH components, solar thermal collector system, both the seasonal thermal energy store (STES) and diurnal thermal energy store (DTES), and all relevant peripheral pumps, heat exchangers, and other equipment was developed.

Developing the whole-system model allowed for conducting analyses, firstly, to evaluate and predict the performance of the as-built facility; secondly, to make a recommendation on diurnal store size; and finally, to determine an appropriate thermal store charging/discharging strategy to achieve a high solar fraction (SF) making use of both the DTES and STES. 


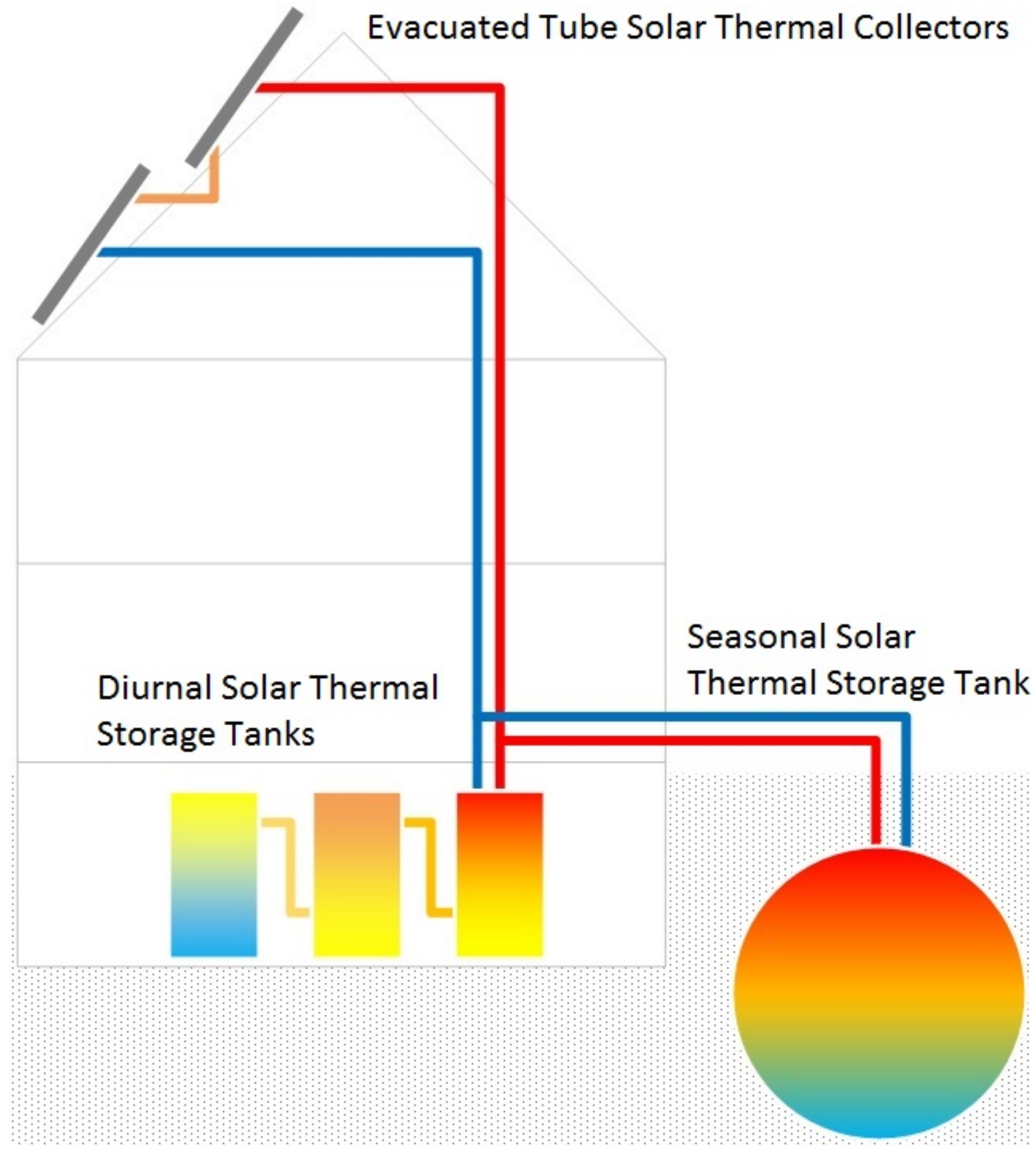

Figure 5: Solar Thermal Charging Loop 
Importantly, going forward this work will provide a platform for future researchers to evaluate new systems and thereby inform the selection of suitable whole-system control strategies. The experimental contributions of this work in conjunction with the simulation-based work will enable model validation against experimentally collected data from the Urbandale Centre for Home Energy Research facility.

The thesis is laid out as follows:

1. Background (thermal storage and solar combisystems) and motivation

2. Simulation methodology (tools, inputs, assumptions, and validation)

3. Experimental contributions and the Urbandale Centre for Home Energy Research facility

4. Results of an initial design ( $\alpha$ case) and subsequent refinement of the design ( $\beta$ case) based on parametric analyses

5. Conclusions and suggestions for continuing work

6. Appendices containing additional results and simulation input files 


\section{Chapter 2}

\section{Simulation Methodology}

This chapter is intended to inform the reader on the simulation tool (Section 2.1) and modelling methodology (Sections 2.2-2.7). However, as the model represents a built-facility, the intention of the model was to represent reality closely. As such, elements of the as-built Urbandale Centre for Home Energy Research will be detailed alongside the simulation models in Sections 2.3 and 2.4. Further in-depth discussion of the experimental facility will occur in subsequent chapters.

\subsection{Simulation Tools}

Developing a well designed house and its energy systems is a complex interdisciplinary undertaking that aims to consider numerous elements such as the thermal properties of the envelope and climate. With the advances in computational analysis tools since the 1980's, building simulation has become a means for building designers to attempt to capture the complexities of real world building physics (Clark, 2001; Hensen and Lamberts, 2011). 
Even with the numerous simulation tools currently available and their ability to model complex heat flow paths or air infiltration, selecting and using the right simulation tool for a given problem remains a difficult task.

The tools used in this research, ESP-r, TRNSYS, and the Co-simulator and their underlying methodology are briefly discussed in sections 2.1.1, 2.1.2, and 2.1.3 respectively. The remainder of this section will discuss the assumptions and inputs of the simulation models including climate and domestic hot water (DHW) data.

\subsubsection{ESP-r}

ESP-r was developed in 1970's at the University of Strathclyde's Energy Systems Research Unit in Glasgow Scotland, and has continued to be developed and applied by government, academia, design professionals and others since then (BeausoleilMorrison, 2000; Energy Systems Research Unit, University of Strathclyde, 2012).

Since 1974, ESP-r has undergone numerous validation studies detailed by Strachan (2000). Some of the core methodologies of ESP-r will be introduced in this section, however, for an in-depth discussion on the underlying methodology used by ESP-r the user is directed to Clark (2001).

Many simulation programs consider only thermal performance, whereas ESP$\mathrm{r}$ is a whole-building simulation system, enabling the capture of many real-world properties and behaviours beyond the thermal domain.

This is accomplished via a multi-zone finite volume analysis based on conservation of energy, mass, and momentum. This approach allows the user to consider heat transfer, air, water, and electrical power flows, moisture transfer, and lighting domains (Beausoleil-Morrison, 2000; Energy Systems Research Unit, University of 
Strathclyde, 2012).

To best capture the inter-related effects of each of these, ESP-r operates with a simultaneous solver that initiates hand shaking between solvers on a time-step basis. ESP-r also pre-calculates solar radiation and shading values based on user inputs and the designated climate file and applies these accordingly at each simulation time-step (Beausoleil-Morrison, 2000).

The zone and nodal discretisation approach of ESP-r is illustrated in a simple form in Figure 6. The longwave radiation and convective heat transfer exchange with the exterior and between nodes in a single zone are treated. Infiltration and air flow from the exterior and between zones are considered.

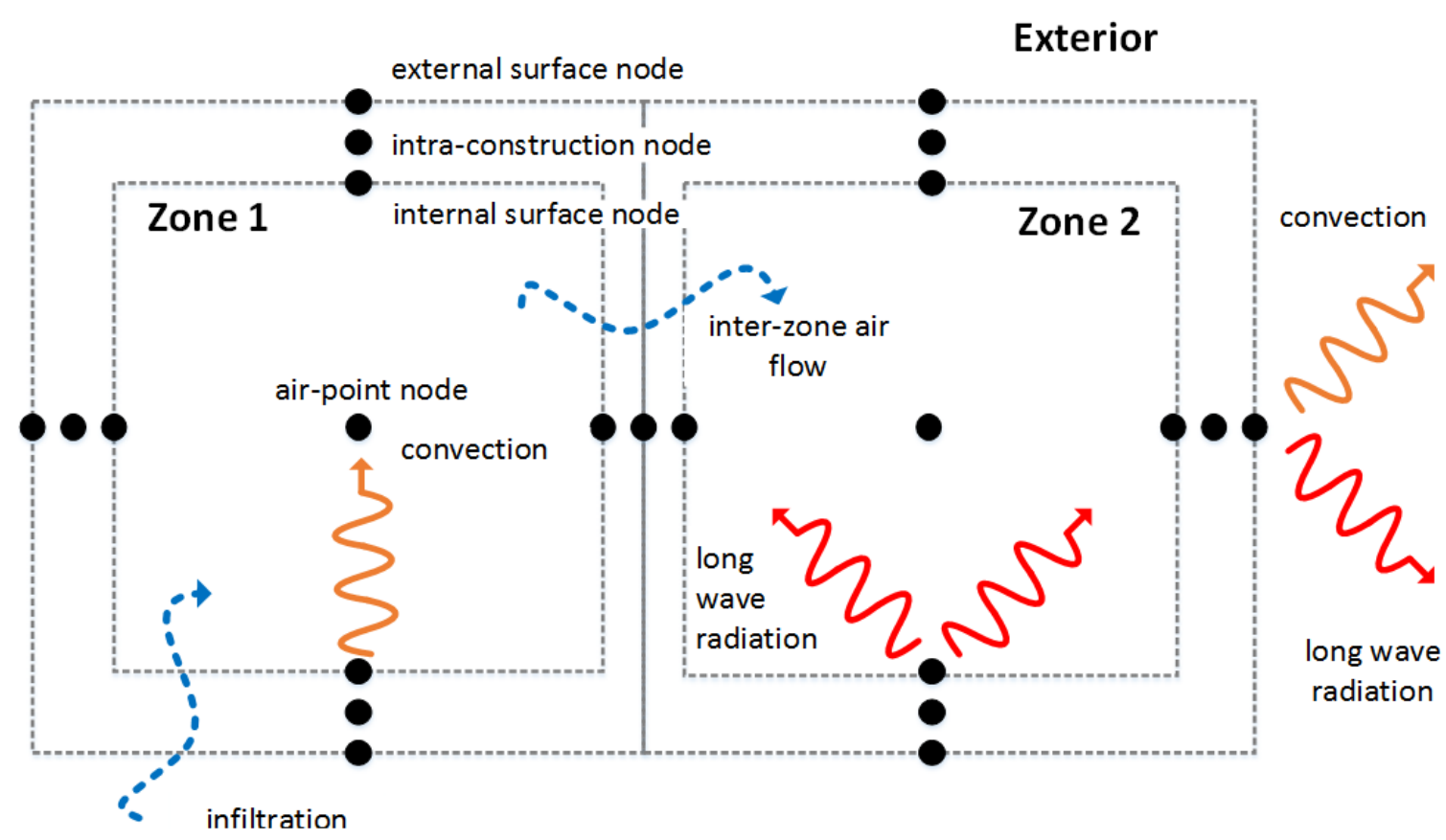

Figure 6: Simplified ESP-r Zone Model Adapted from Beausoleil-Morrison (2000)

Homogeneous materials composing surfaces are discretised into nodes, the number 
of nodes is dependent on the thickness of the material. For the simple case shown in Figure 6, the single material forming each zone wall is discretised into an external surface node, an intra-constructional node, and an internal surface node.

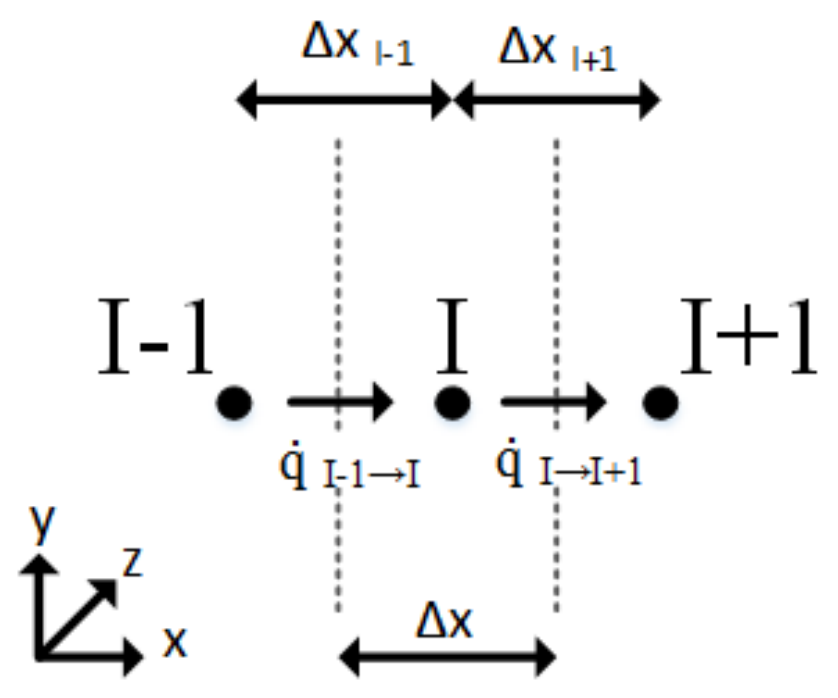

Figure 7: Simplified ESP-r Node Energy Balance Adapted from Beausoleil-Morrison (2000)

The nodal discretisation shown in Figure 6 is simplified to consider only a single intra-constructional zone $(I)$ in Figure 7 within a control volume $\Delta \mathrm{x}$ wide by $\Delta \mathrm{y}$ high and a depth of $\Delta z$. An energy balance is carried out according to Equation 1 between the neighbouring nodes $I-1$ and $I+1$.

$$
\left\{\begin{array}{c}
\text { storage of } \\
\text { heat in } \mathrm{CV}
\end{array}\right\}=\left\{\begin{array}{c}
\text { net conduction } \\
\text { into } \mathrm{CV}
\end{array}\right\}+\left\{\begin{array}{c}
\text { source of heat } \\
\text { within } \mathrm{CV}
\end{array}\right\}
$$

The nodal discretisation method employed in ESP-r is covered more rigorously in the aforementioned references and is only treated conceptually here for the readers information as this will be touched on further in Subsection 2.3.4 in the radiant floor 
model discussion.

\subsubsection{TRNSYS}

TRNSYS primarily focuses on the thermal and electrical domain performance and models the transient behaviour of systems. The primary engine or kernel reads in inputs, handles solving and convergence, and output (Thermal Energy System Specialists, 2015).

The inputs are designed to be used in a modular fashion whereby the user selects plant components from the TRNSYS component library (such as heat exchangers, tanks, etc.), and adds them to a given model. These components can be modified or entirely new components can be written by the user and included in the model.

Unlike ESP-r's simultaneous solver approach for the various domains, TRNSYS solves each component in a given model individually and sequentially. For example, in a simple system where a pump moves flow from a tank to solar collectors and back to the tank, the tank would be solved for the current time step, the outputs of which would be used as inputs for the pump. The pump model would be solved, the outputs of which would be used as inputs for the solar collectors, and so on.

The approach is the separation of one large flexible application problem into many discrete smaller problems (Blair and Keilholz, 2004) which works well for the connection of individual components to model a complex inter-connected system such as the solar energy collectors and storages considered in this work. 


\subsubsection{Co-simulator}

The co-simulation tool was developed to allow each tool to play to its strengths, by coupling the rigorous whole-building capabilities of ESP-r with the flexible component-based system of TRNSYS, and its extensive renewable energy components library. By doing so, the co-simulator allows for treatment of both building physics and energy systems resulting in a more integrated and comprehensive solution (Beausoleil-Morrison et al., 2013).

Without the co-simulator, simulation time could be reduced, however, a method of supplying TRNSYS with a load profile would then be needed. Additionally, the radiant floor model in ESP-r would have different performance characteristics without the feedback from the TRNSYS simulation. The extent of these differences is currently unknown. The amount of manual post-processing work to mesh the subsequent disparate simulations are expected to negate these benefits.

To use the co-simulator, a TRNSYS model and an ESP-r model are created according to the typical procedure for each program. A custom developed TRNSYS Type 130 (see Figure 14) is included in the TRNSYS model and linked to the ESP-r model.

The co-simulator is then used to initiate the simulation and will instruct TRNSYS and ESP-r to proceed for each time-step passing information between the two programs and checking for convergence before proceeding to the next time-step (Beausoleil-Morrison et al., 2013).

The inputs to the co-simulator specifies the ESP-r configuration file and simulation preset to use and the TRNSYS deck file. The co-simulator file for this research is found in Appendix B. For more details regarding the co-simulator, the reader is 
directed to Beausoleil-Morrison et al. (2014).

\subsection{Climate Data}

Canadian Weather for Energy Calculations (CWEC) were developed by the Meteorological Service of Canada and The National Research Council of Canada under the direction of Environment Canada.

The CWEC data are derived from Canadian Weather Energy and Engineering Data Sets (CWEEDS). The climate files were developed by Environment Canada to meet the growing need for long term hourly weather data sets for urban planning, design of solar energy systems, and sustainable buildings (Meteorological Service of Canada (MSC) and The National Research Council of Canada, 2010).

Statistical criteria are applied to CWEEDS files spanning long periods (often 30 years), to create 'typical meteorological months' based on "long-term monthly means

for daily total global radiation, mean, minimum and maximum dry bulb temperature ... and mean and maximum wind speed" (Meteorological Service of Canada (MSC) and The National Research Council of Canada, 2010). From this analysis twelve 'typical' meteorological months are concatenated to form an annual weather file.

For an exhaustive explanation of the CWEC treatment, interested readers are directed to Siurna et. al. (Meteorological Service of Canada (MSC) and The National Research Council of Canada, 2010; Siurna et al., 1984). Both ESP-r and TRNSYS use the same CWEC data file for Ottawa, Canada in the format suitable for each program. 


\section{$2.3 \quad$ ESP-r Model}

The ESP-r model used in this work was built on a pre-construction representation created by Dr. Beausoleil-Morrison. The wire frame of the ESP-r house model is shown in the Project Manager User Interface in Figure 8.

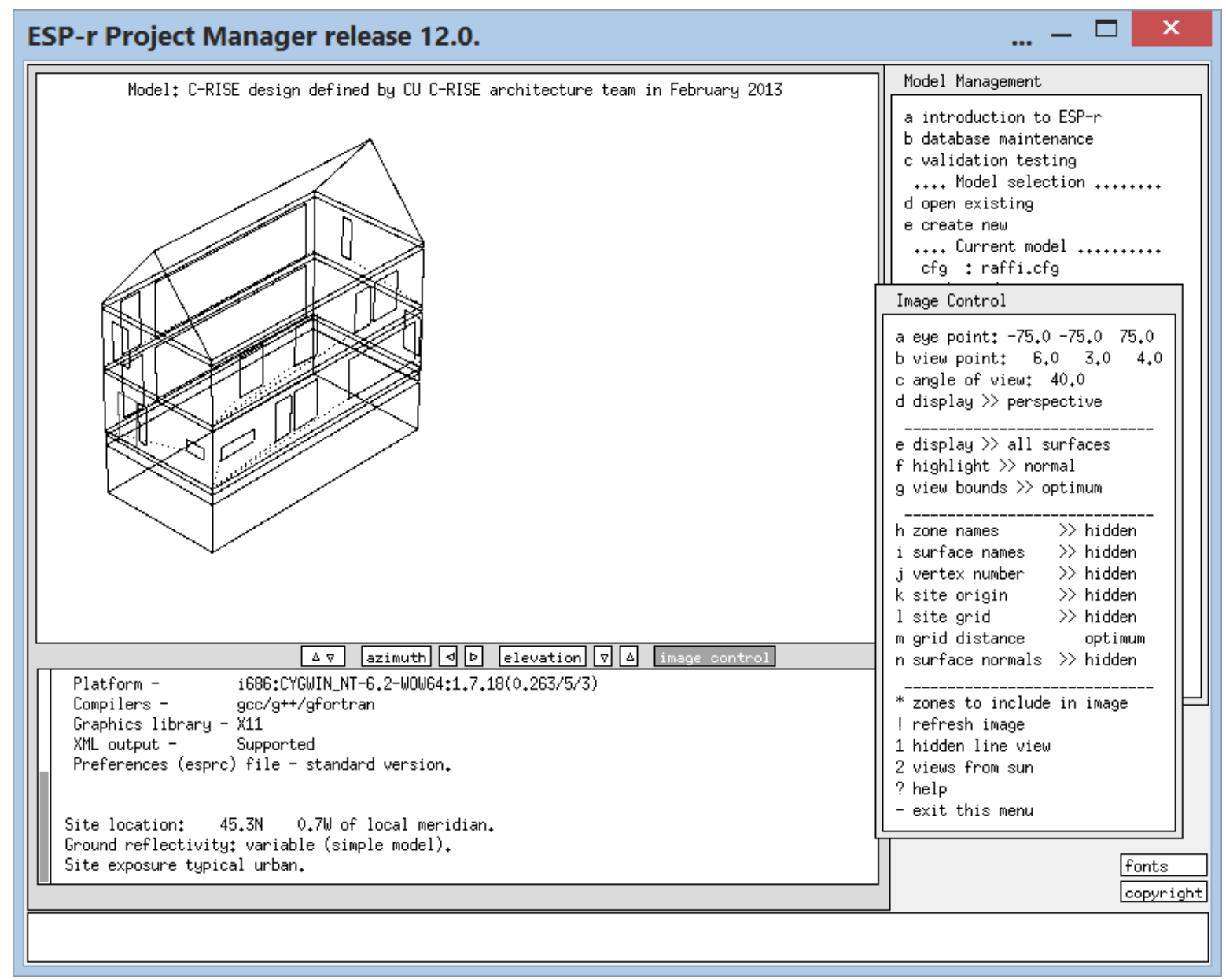

Figure 8: ESP-r Interface and House Model 


\subsubsection{Glazing}

The Urbandale Centre for Home Energy Research has triple-glazed low-e argon filled windows with vinyl frames. Triple-glazed windows were used as they result in lower heat loss than double-glazed windows, while the large glazing area allows for passive solar gains.

The high amount of solar gain through the south-facing glazing will enable research into radiant floor cooling, reduce space heating (SH) loads in the winter, but will require strategic shading to minimize the deleterious effects in summer.

The lack of glazing on the north side is beneficial from a heat loss stand point and it also provides capability to investigate novel insulation approaches such as vacuum insulation as will be discussed further in Subsection 2.3.2.

The distribution of glazing between the east, south, and west faces of the building

are visualised in Figure 9. The projection of the radar plot in each cardinal direction indicates the window-to-wall ratio. For instance the south facing wall has a windowto-wall ratio of $31 \%$ while the north facing wall has a window-to-wall ratio of $0 \%$. 


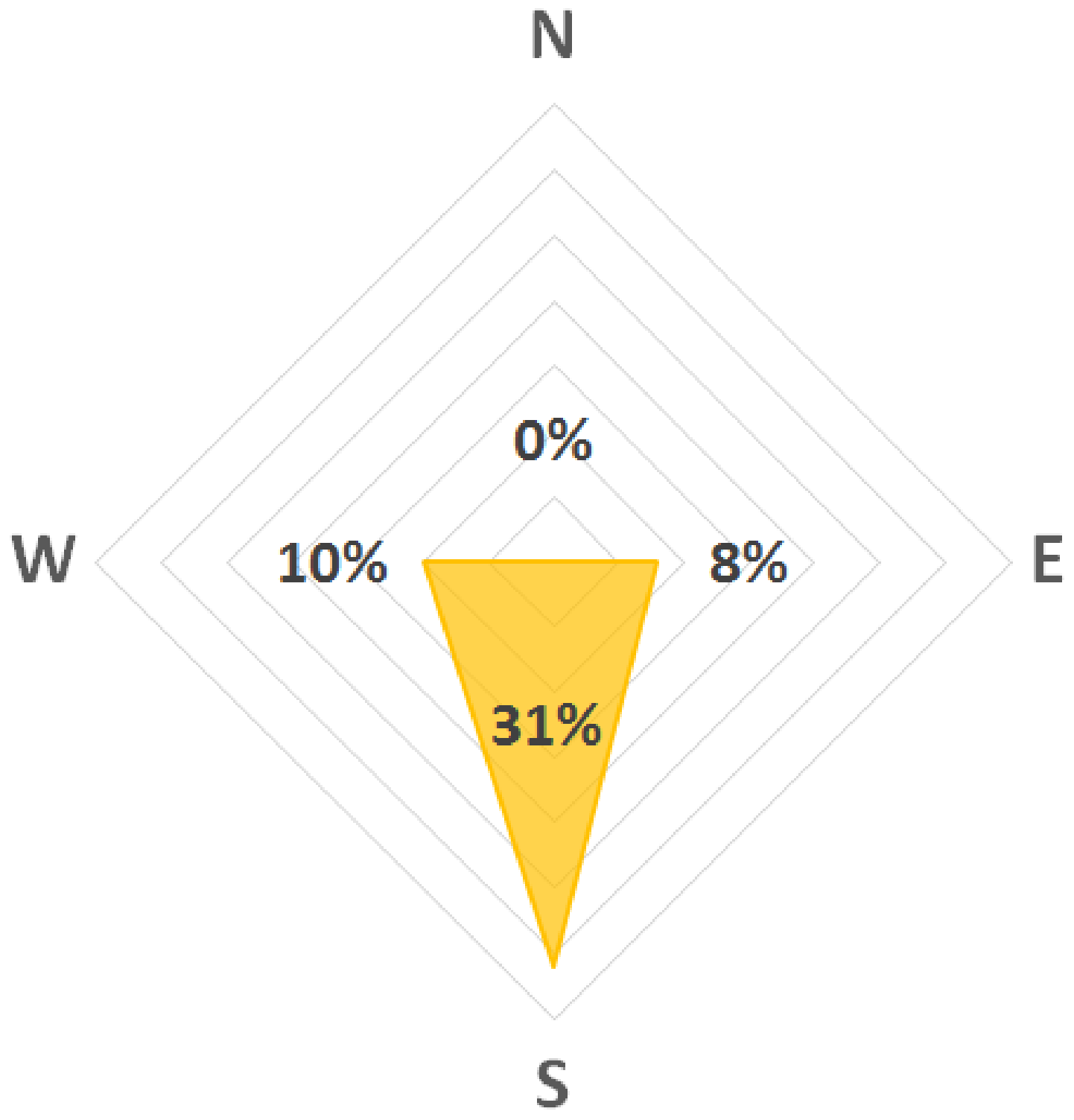

Figure 9: Window-to-Wall Area by Orientation 


\subsubsection{Building Envelope}

The walls are $2 \times 6$ framed walls with batt insulation on the interior of the walls, rigid EPS and OSB sheathing, a 3 inch air gap on the east, south, and west walls, and 5 inch air gap on the north wall between the sheathing and cedar siding.

This construction, as it is modelled in ESP-r, is detailed in Table 3.

Table 3: ESP-r Wall Materials and Construction

\begin{tabular}{lc} 
Outside & Thickness $(\mathrm{mm})$ \\
\hline \hline wood siding & 11.0 \\
gap & 25.0 \\
OSB & 12.7 \\
EPS board & 38.0 \\
fibreglass & 140.0 \\
gypsum board & 12.7 \\
\hline \hline
\end{tabular}

Inside

The rain screen for the wall system was custom designed by the research team to provide flexibility in wall design and insulation approaches. The cedar cladding is backed by red aluminium sheet stock and mounted to the wall using Z-girt aluminium framing and the Cascadia fibreglass clip system.

A Z-girt mounted rain screen panel is shown in Figure 10. Yellow 5 inch Cascadia clips were used for the north wall and orange 3.5 inch clips on the south, east, and west walls. Cascadia clips were secured through the Tyvek air barrier and OSB/EPS sandwich layer and into the wall frame behind with 10 inch screws. The fibreglass clips were selected to minimize thermal bridging relative to metal fasteners. 


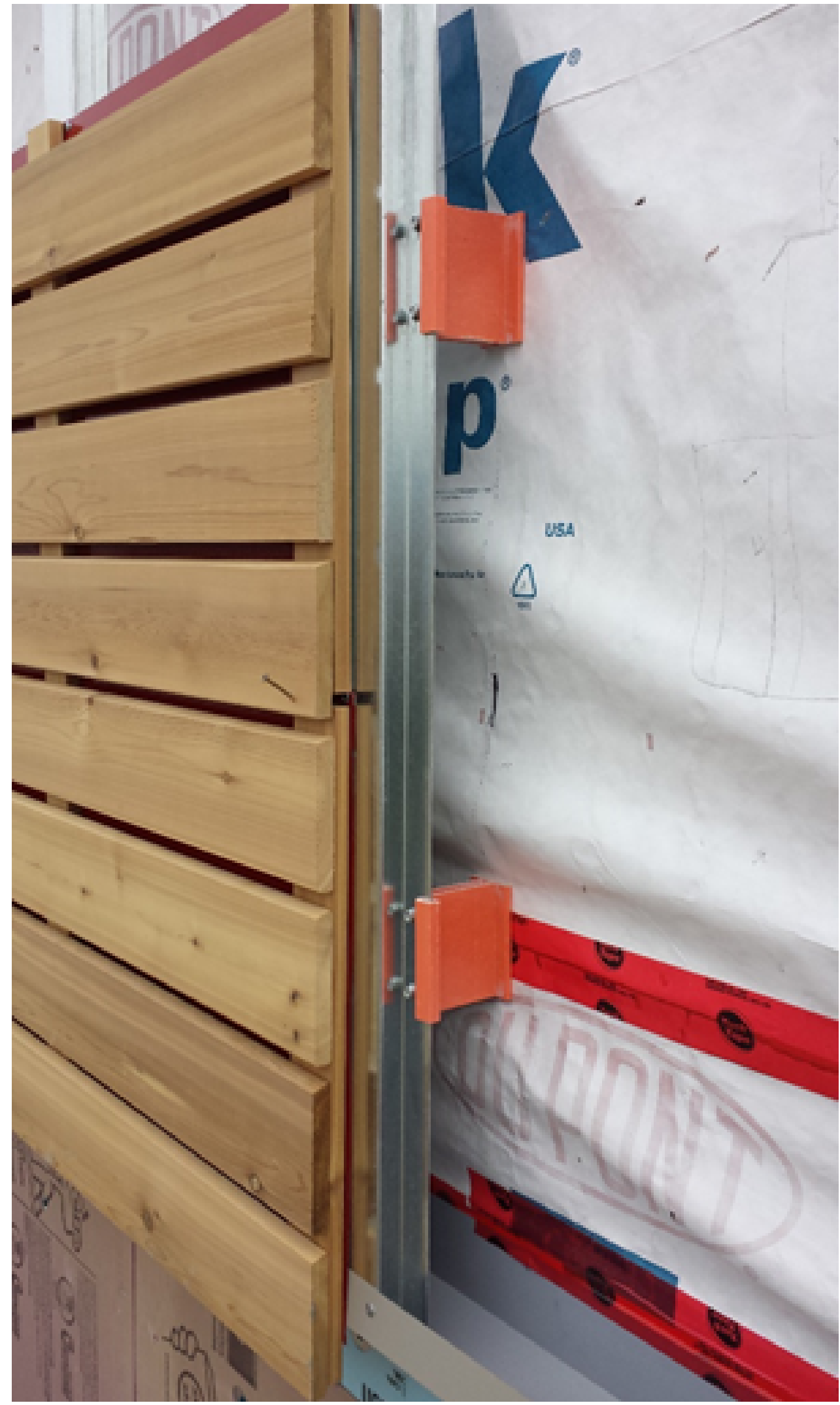

Figure 10: Rain screen System with Cascadia Clips and Z-girts 
The rain screen is shown in Figure 11. The gaps resulting from the different sized Cascadia clips allows varying amounts of exterior insulation to be added on the exterior of the wall either in conjunction with the interior batt insulation or to replace it. This flexibility will enable many insulation design configurations to be investigated including novel technologies such as vacuum insulated panels. These are rigid and delicate panels that must be manufactured to the exact specifications needed for full coverage as they can't be cut or bent on site to accommodate windows, penetrations, or unusual geometry making the window-less north wall a good application site.

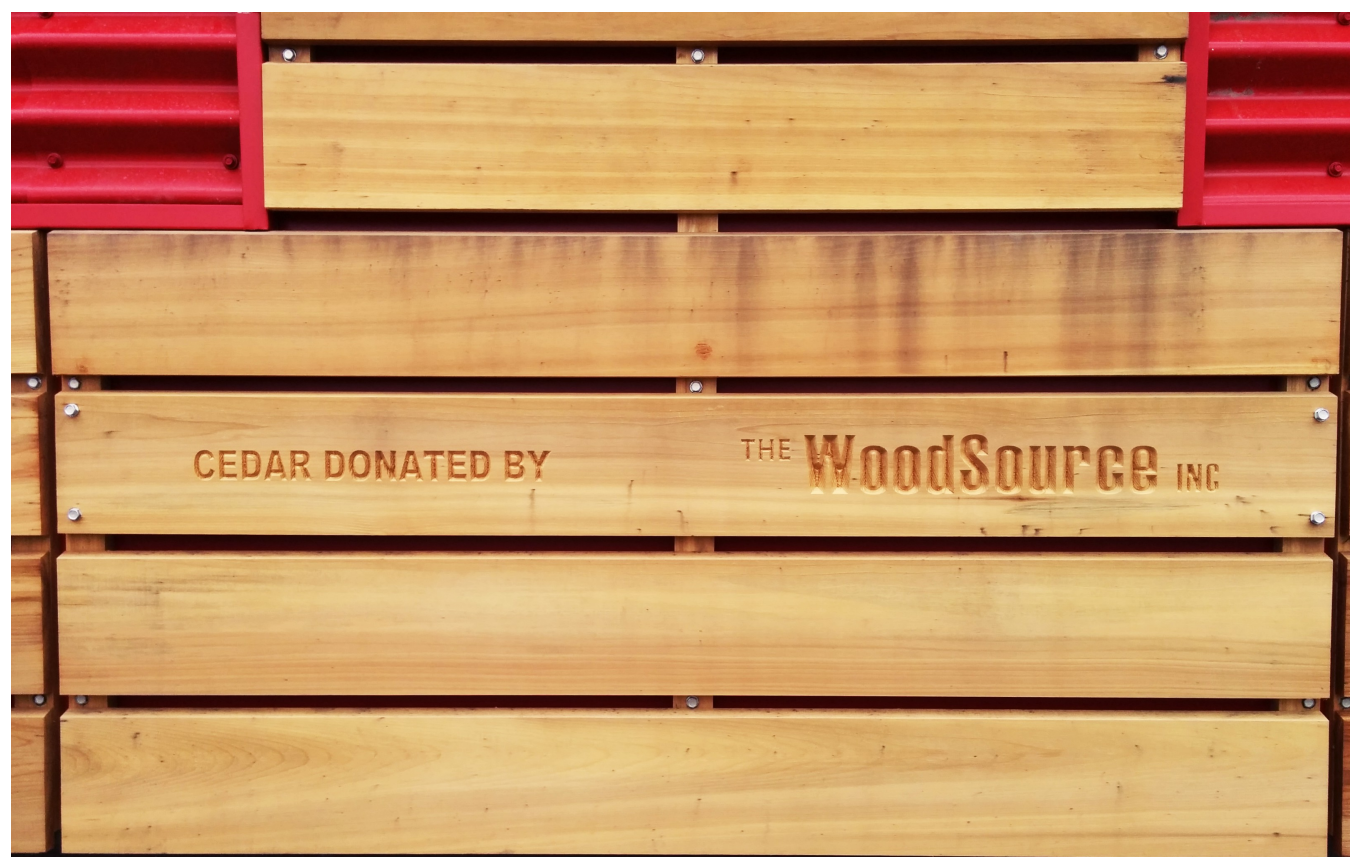

Figure 11: Cedar Rain Screen Panel

Given the experimental nature of the envelope, it is important to ensure adequate access for repair, maintenance, or monitoring. To this end, the panels were built in 2 foot by 4 foot demountable sections for access or re-configuration. 


\subsubsection{Infiltration and Ventilation}

The Alberta Infiltration Model Version 2 (AIM-2) is a single zone model developed by Walker and Wilson (1990). The model considers the stack and wind driven effects on the pressure-flow behaviour of a building to determine the air leakage and infiltration rates (Walker and Wilson, 1990).

Walker and Wilson (1990) conducted their own validation and compared the AIM-2 model's predictions against measured infiltration rates of test houses and to four other simple air flow models. One of the key differences in the AIM-2 model according to the researchers is the separate treatment of the furnace flue as a leakage site. The researchers found that, for a sheltered building, the prediction error of the AIM-2 model is $\sim 16 \%$ (where the error of other models is $40-90 \%$ ). For an unsheltered building with a furnace flue, the AIM-2 model's error decreases to $12 \%$ compared to other models where the error ranges from 20-26\% (Walker and Wilson, 1990).

Wang et al. (2009) conducted an empirical study using measured leakage rates of 16 detached houses and compared the results from a Lawrence Berkeley Laboratory (LBL) model and the AIM-2 model. Wang et al. (2009) concluded the AIM-2 model tended to under-predict leakage rates but resulted in a lower average percentage error (19\%) than the LBL model (25\%) (Wang et al., 2009).

The AIM2 model is used by ESP-r to determine the pressure and wind induced ventilation and leakage rates of the building. The AIM-2 file was created by Dr. Beausoleil-Morrison based on a blower door test. The facility achieved an airtightness of $1.3 \mathrm{ACH}$ at $50 \mathrm{~Pa}$ based. The AIM-2 input file can be found in Appendix C.2. 


\subsubsection{Radiant Floor}

The floor construction as modelled in ESP-r is shown in Figure 12. TRNSYS Type 130 is passed air point zone temperatures from ESP-r, which Type 266, handles and based on the heating setpoint for the zones, determines whether $\mathrm{SH}$ is required. If so, it solves the radiant floor components and ESP-r receives information about the incoming water temperature of the radiant floor system from TRNSYS again via Type 130.

ESP-r's radiant floor plant model is then solved and the determined heat flux injected into the zone requiring SH. More specifically, the heat flux is injected in the floor construction at the intra-constructional node (Node 4) in the porcelain tile (Note: ESP-r's node discretisation was introduced in Subsection 2.1.1).

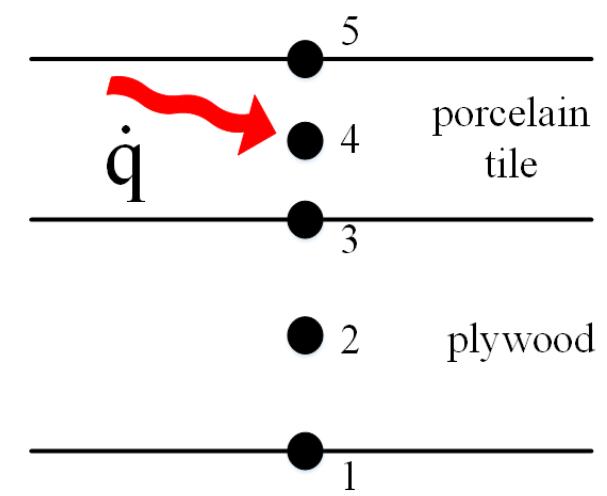

Figure 12: ESP-r's Radiant Floor Heat Injection

The ESP-r model for this work was informed by the work of Sebastian Brideau with input from Adam Wills. The detailed specifications of the radiant floor plant model are contained in Appendix C.4. 


\subsubsection{Shading}

Shading was deemed necessary because of the degree of overheating that occurs throughout the year, particularly in the summer, due to solar gains through the large amount of south facing glazing. (Note: the motivation for the glazing distributions and window technology used were discussed in Subsections 2.3.1 and 2.3.2.)

Although solar gains would be beneficial in the winter to reduce SH loads, it is not possible to have different levels of shading in the model. Thus shading obstructions were created to cover $\sim 50 \%$ of the south facing glazing in the house for the entire simulation period. It's worth mentioning that the zone temperatures are still high in the summer with $50 \%$ shading.

However, the focus of this work is the SH and DHW demands. That being said, much of the infrastructure discussed herewith will lend itself to future work with controllable shading and space cooling with the radiant floor system. A controlled shading system has already been implemented in the experimental facility though not yet operational at the time of this writing. Once operational, varying degrees of shading and control strategies can be explored further. 


\subsubsection{BASESIMP Calculations}

Foundation heat loss can be significant for residential buildings and it is handled in ESP-r differently than above grade envelopes. BASESIMP is a "simple basement model" algorithm developed by Beausoleil-Morrison and Mitalis at Natural Resources Canada and the National Research Council. The algorithm calculates whole-foundation heat loss accounting for thermal bridging with the above grade walls, soil conductivity, insulation configuration, and water table depth (BeausoleilMorrison and Mitalis).

BASESIMP uses algebraic equations to make use of 33000 previously calculated parametric 2-D finite element analyses. Customised coefficients represent the particular basement configuration being modelled to calculate the heat loss from the foundation with minimal computational requirements.

For a full treatment of the algorithms and methodology, the interested reader is directed to Beausoleil-Morrison and Mitalis. The inputs to ESP-r's BASESIMP calculations for this work are found in Appendix C.6 


\subsection{TRNSYS Model}

\subsubsection{Charging and Discharging Systems}

The TRNSYS model was used to simulate all components relating to the solar thermal, diurnal thermal energy store (DTES) and seasonal thermal energy store (STES), and DHW systems. A summary of key TRNSYS types by system component is provided in Table 4.

Table 4: TRNSYS Types Used

\begin{tabular}{lll} 
System & Type & Description \\
\hline \hline DTES & 534 & Vertical Cylindrical Tank \\
STES & & \\
ESP-r Coupling & 130 & Interface with ESP-r \\
Solar Thermal Array & 71 & Evacuated Tube Solar Thermal Collectors \\
Heat Exchangers & $5 \mathrm{~b}$ & Sensible Counter Flow Heat Transfer \\
Custom Controller & 266 & Custom Controller Type \\
DHW Tempering Valve & $11 \mathrm{~b}$ & Mixes Flows to DHW Delivery Temperature \\
Pumps & 3 & Constant Speed Pump \\
Auxiliary Heaters & 6 & In-line Heater with Temperature Setpoint \\
Controlled (3-Way) Valves & $11 \mathrm{~d}$ & Control Signal Operated Valve \\
CWEC Climate Data & $15-5$ & Climate File Reader \\
DHW Draw Profile & $9 \mathrm{e}$ & Data Reader Passes DHW Draw from File
\end{tabular}

A simplified view of the solar and charging circuits for both the diurnal and seasonal stores is provided. Note that the model has been split into two sections at the diurnal and seasonal store connections for simplicity of illustration and ease of 
understanding. The first half represents the charging circuit whereby solar thermal energy is collected by the evacuated tube panels and used to charge either the diurnal or seasonal stores (Figure 13).

The climate file reader passes the Ottawa CWEC file data to the solar collector array. This includes the radiation, ambient temperature, and wind speed. This allows Type 71 to calculate the energy collected by the array and the temperature of the fluid leaving the array. This energy can then be distributed to the thermal stores via the solar hydraulic loop as dictated by the Type 266 controller. The solar collector hydraulic loop consists of the collector array, two heat exchangers to exchange heat with the diurnal thermal energy store (DTES) and seasonal thermal energy store (STES) loops, and a constant speed pump. The heat exchanger model considers sensible counter flow heat transfer with an effectiveness of

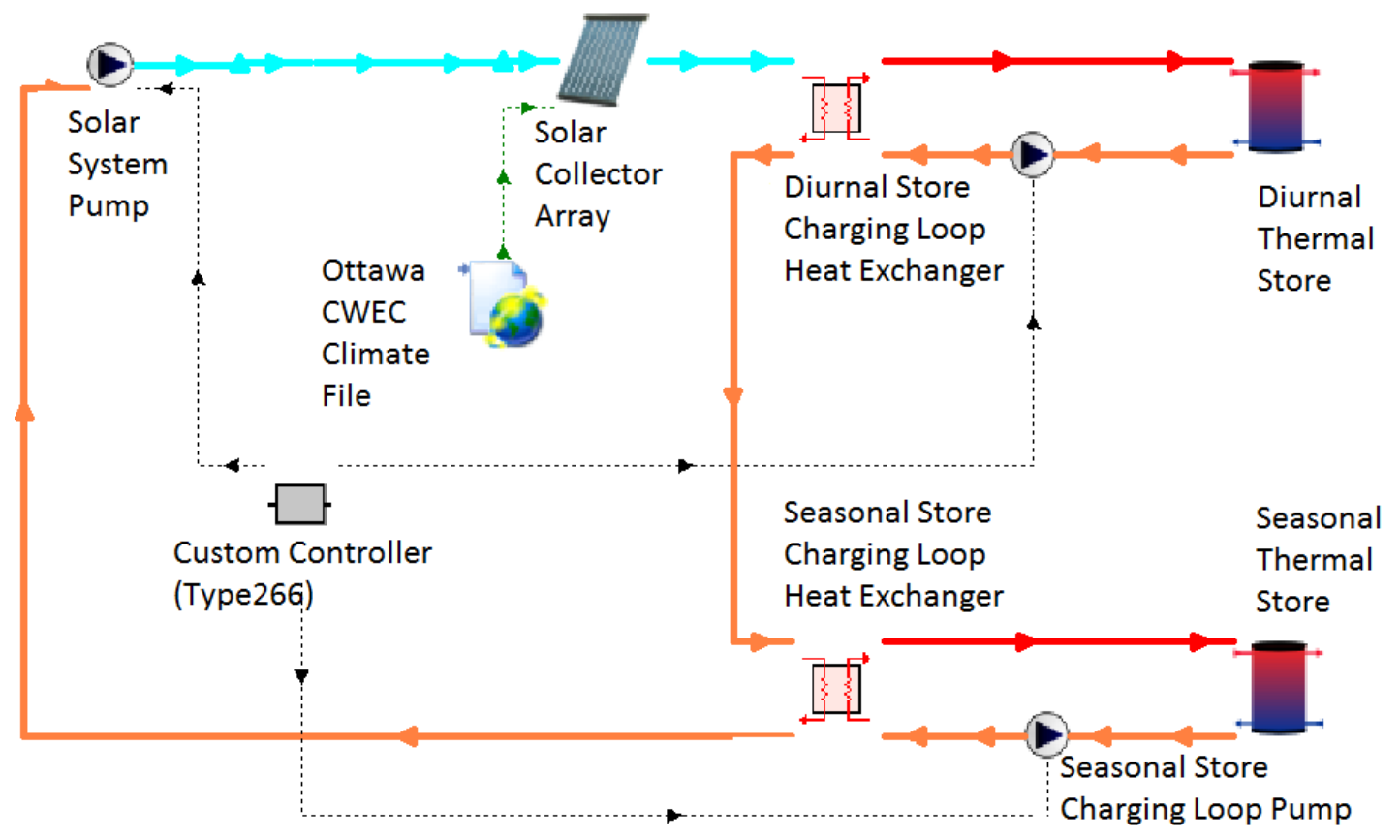

Figure 13: Simplified TRNSYS Solar Thermal Charging Components 
The second half shown in Figure 14 is the discharging circuit. Despite the apparent complexity, there are only 4 primary components, the DTES, the STES, the DHW load, the SH load.

The DTES supplies the DHW draws which are scheduled by the DHW draw profile input file. A tempering valve serves two functions, first it sends mains water to mix with the water coming from the top of the DTES if the flow is above the DHW delivery temperature. It also sends mains water as make up for the water leaving the DTES. This means that high temperature water is drawn from the hottest part of the tank and $10^{\circ} \mathrm{C}$ mains water is added to the bottom and coldest part of the tank. This will be a useful point to keep in mind for the results discussions chapter.

The STES is intended to be the primary store to meet the SH demands. The SH loads are modelled as two circuits, both connecting to the ESP-r interface component (Type 130). There are two circuits because each feeds a radiant floor circuit modelled in ESP-r in the main and second floor zones.

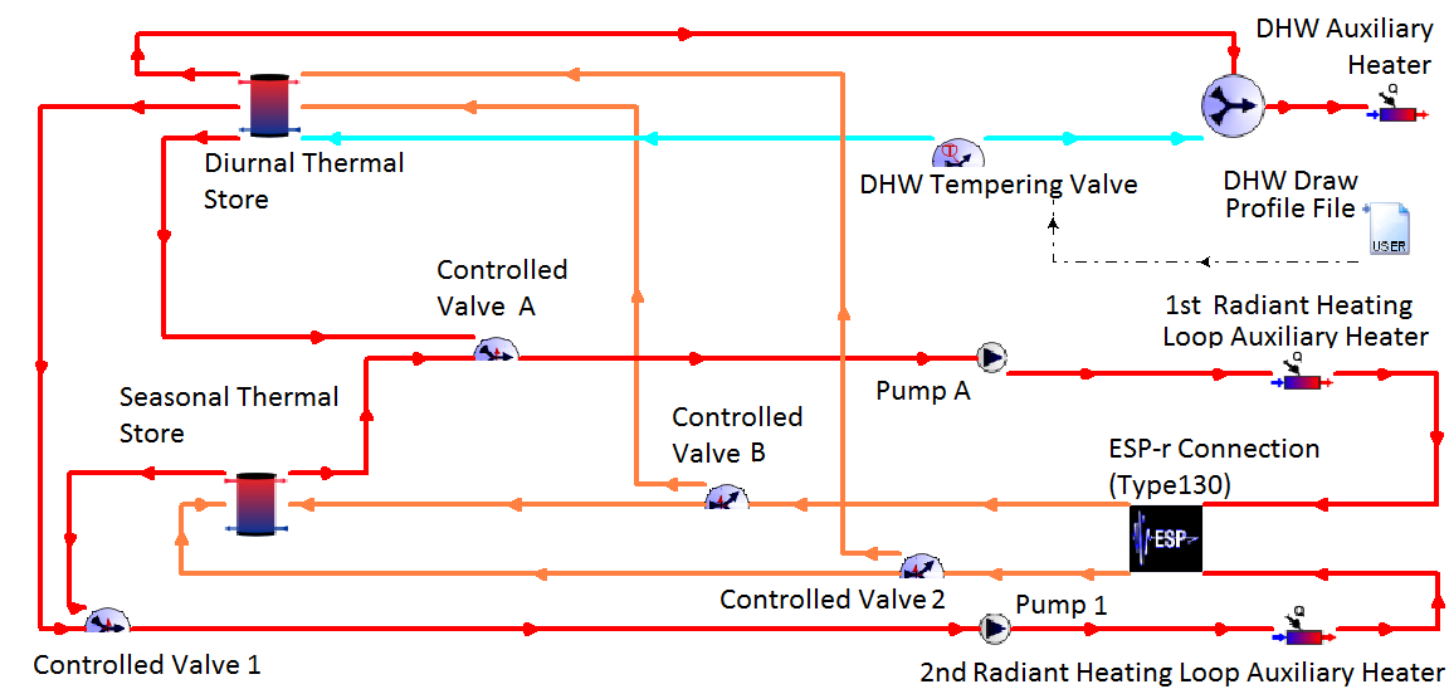

Figure 14: Simplified TRNSYS DHW and SH Components 
All circuits are equipped with an auxiliary heater that will supplement the store energy as needed to ensure the system setpoints are always satisfied.

In addition, the DTES can also supply SH if certain conditions, determined by the Type 266 controller, are met. This neccessitates additional valves and hydraulic lines that can switch between the two thermal stores when SH is called for.

\subsubsection{Custom Type 266 Controller}

The operation of all the components just discussed required writing a bespoke controller type to handle the unique requirements of this system. To discuss the Type 266 controller logic, a number of symbols are introduced for brevity. These symbols will be elaborated on here, and used throughout remaining chapters.

The diurnal thermal energy store's (DTES) charging setpoint temperature $\left(T_{+}^{D T E S}\right)$ is the metric by which the diurnal tank is deemed 'charged' or 'not charged' from a control strategy perspective. Similarly the seasonal thermal energy store's (STES) charging setpoint temperature $\left(T_{+}^{S T E S}\right)$ is used to determine whether the store is 'charged' or whether any available solar energy should be supplied.

The diurnal cutoff temperature $\left(T_{\text {cutoff }}^{D T E S}\right)$, is the metric used in the control algorithm to determine when the DTES is sufficiently charged that it is able to meet some of the SH demand. If the DTES temperature is below $T_{\text {cutoff }}^{D T E S}$, the STES will meet any SH demand. Otherwise, the DTES will take precedence over the STES for meeting the loads.

The DHW delivery temperature $\left(T_{\text {delivery }}^{D H W}\right)$ refers to the temperature the simulation is to deliver to the end-user at the rate and quantity specified by the domestic hot water draw profiles discussed earlier in Subsection 2.4.7. 
The temperature of the fluid leaving the collector array is defined as the collector outlet temperature ( $\left.T_{\text {outlet }}^{\text {collers }}\right)$.

\section{Type 266 Logic}

The logic for Type 266 was designed to be as simple as possible to reduce convergence errors which can be a concern with a complex model such as this and effectively three simulation programs running.

On the charging side, if there is no solar radiation, the solar loop is inactive. Type 266 instructs the solar collector pump $\left(P_{\text {solar }}\right)$ to activate when there is solar energy available according to the climate file.

This is is a simplification of the real system in two main ways. Firstly, if the built system is cold (i.e, the Bio-Green heat transfer fluid temperature is $<30^{\circ} \mathrm{C}$ ) it activates a bypass loop that short-circuits the rest of the system until it is warmed sufficiently. Secondly on hot days when the stores are charged and there is a high amount of solar radiation, the collectors would normally stagnate, meaning $T_{\text {outlet }}^{\text {collects }}$ will climb as high as $\sim 170^{\circ} \mathrm{C}$. In the installed system, radiator panels on the north side of the roof allow for the solar loop to dissipate some of the excess heat and limit the temperature rise of the Bio-Green. The Bio-Green fluid is capable of withstanding stagnation but if it occurs frequently, the performance of the fluid will degrade over time and need to be replaced. Other components in the system would likely be damaged by fluid at these temperatures however, so the solar circuit would dissipate heat until the temperature dropped sufficiently.

In the model, stagnation will only occur during periods of high solar availability (typically in the summer) when the thermal stores are charged. Even in the real 
system, the solar collector systems continue to operate up to $120^{\circ} \mathrm{C}$ or higher, just as the simulation does. When the collector outlet temperature climbs well above $120^{\circ} \mathrm{C}$, the higher temperature fluid will have a negligible impact on system performance as the thermal stores must be fully charged for the collectors to stagnate. Since there is no risk of damage to the virtual components of the model, the added complexity of control systems and additional components is unwarranted.

Neither a heat dump or bypass loop are modelled here as these factors have more direct bearing on the real components rather than the system performance of interest here. Rather, the solar collector loop is treated as an ON/OFF system effectively. An overview of the store charging logic is provided as a flow diagram in Figure 15.

The thermal stores are connected indirectly via DTES and STES charging circuit heat exchangers ( $H X_{D T E S}$ and $H X_{S T E S}$ respectively) to the solar collector circuit meaning they can charge individually or in-series. The DTES being the smaller store needs to be charged as much as possible to meet the daily and more immediate demands of the system. As such the DTES is given charging priority.

If the solar collector is collecting energy and the DTES is not charged, Type 266 compares the $T_{\text {outlet }}^{\text {collectors }}$ to the average temperature $\left(T_{\text {avg }}^{D T E S}\right)$ of the DTES. If $T_{\text {avg }}^{D T E S}$ is $<T_{\text {outlet }}^{\text {collers }}$, the diurnal charging loop pump $\left(P_{D T E S}\right)$ will be activated.

If the STES is not charged and $T_{\text {avg }}^{S T E S}<$ the temperature of the fluid leaving the $H X_{D T E S}$, the $P_{D T E S}$ will be activated. This decision is not dependent on whether the DTES is also charging or not. 


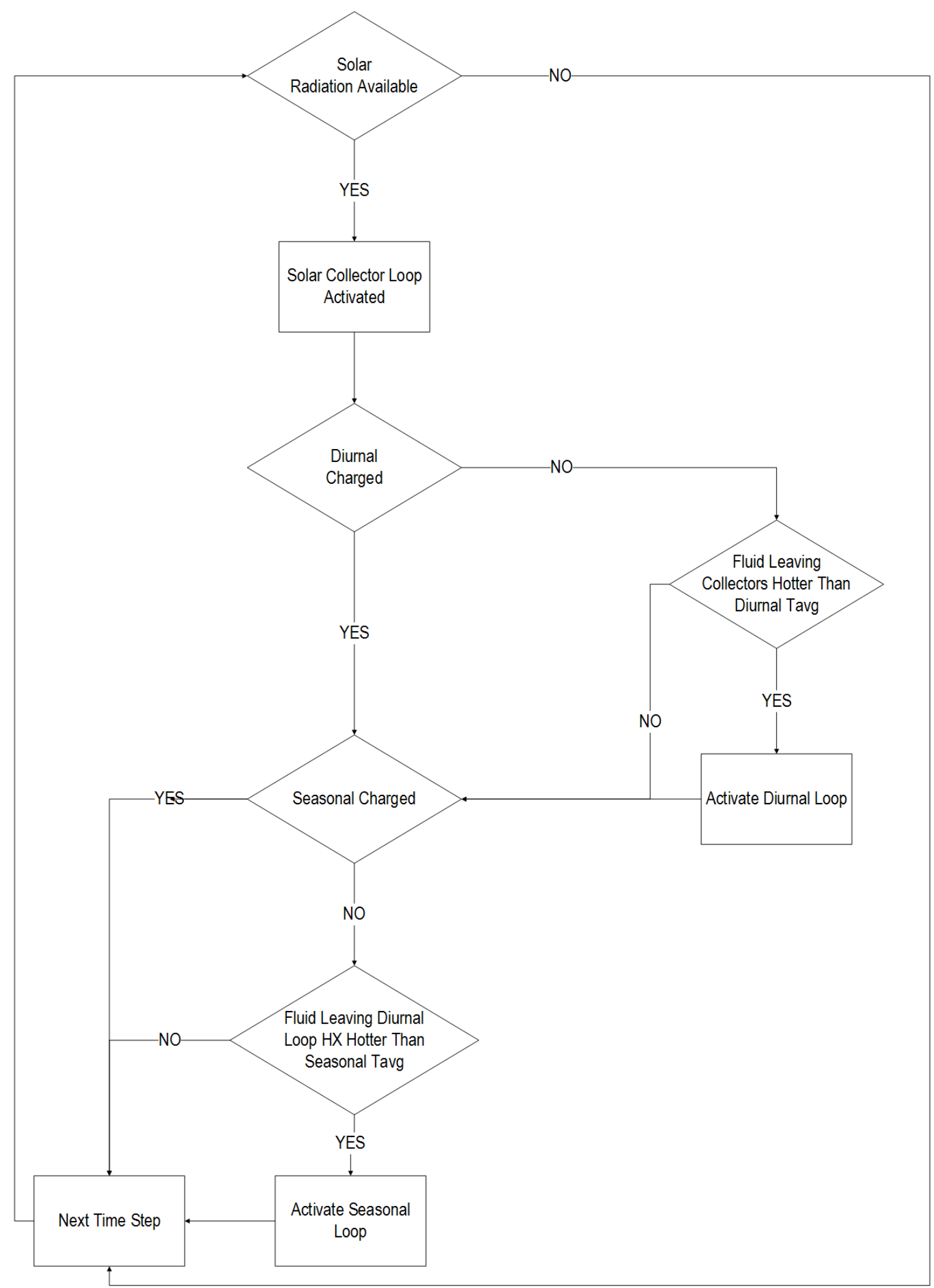

Figure 15: Custom TRNSYS Type - Thermal Store Charging Logic 
On the discharging side of the system, the STES and the DTES must be used in conjunction to meet the DHW and SH demands. A flow chart of this store discharging logic of Type 266 is provided in Figure 16. The DHW demands can only be supplied by the DTES. So when DHW demand exists, then the tempering valve and mixing tee act like a pump by sending flow rates dictated by the DHW draw profile. Regardless of whether the DTES is hot enough to meet the $T_{\text {delivery }}^{D H W}$, it will activate as it is a closed system design and so fluid must be sent from somewhere. The auxiliary heater will bring the flow up to the appropriate temperature as needed.

On the SH side, Type 130 will tell the Type 266 controller whether there is a demand for SH or not. The zone setpoint temperature for both the main and second floor zones in the building is $20^{\circ} \mathrm{C}$. Setback temperatures would be a challenge for the systems examined here as they are not designed for rapid recovery after a setback period. Thus, setback temperatures are not considered here as optimising this control strategy warrants its own dedicated analyses. Interested readers are referred to Brideau (2016) where setback strategies with radiant floor heating are considered.

The STES always has the fall-back responsiblity for meeting the loads typically. Even if the STES is at a very low temperature, the closed system design requires on of the systems to activate in order for the auxiliary heaters to raise the fluid temperature to meet the demand. If the DTES temperature is greater than $T_{\text {cutoff }}^{D T E S}$ and there are no current DHW demands, it will be used to supply the SH. The idea is to reduce standing losses, and it is more easily replenished quickly because of its small thermal mass. 


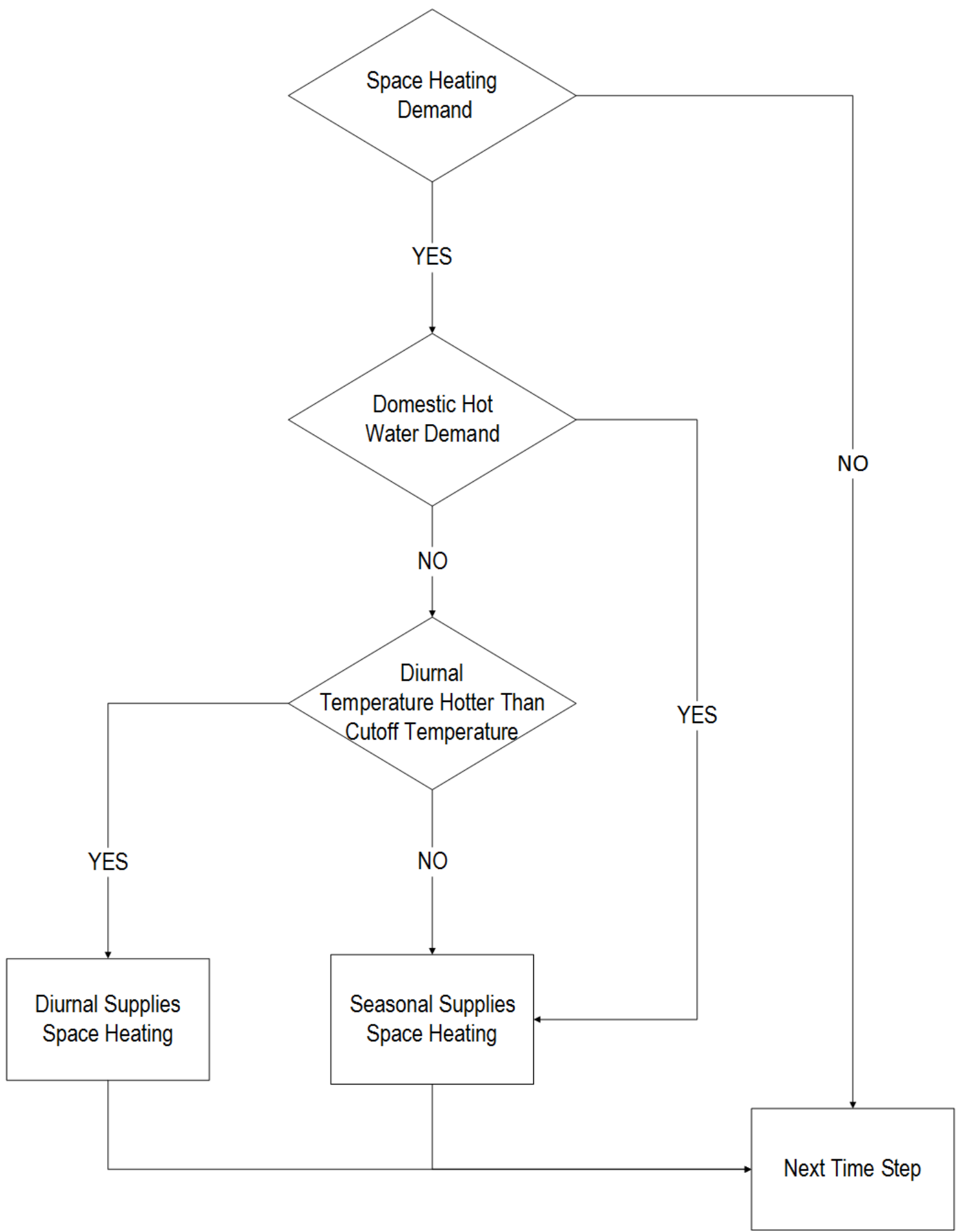

Figure 16: Custom TRNSYS Type - Radiant Floor Heating Logic 


\subsubsection{Diurnal and Seasonal Storage Tanks - Type 534}

Type 534 models a vertical cylindrical storage tank with fixed isothermal temperature nodes to allow for stratification. The degree of temperature stratification in the tank is dependent on the users selection of number of nodes (Thermal Energy System Specialists, 2012b).

Modelling nodes in the water tanks allows TRNSYS to account for thermal stratification effects and to have different temperatures between inlet and outlet ports between the tanks and the solar collector charging loop and the loads. Thus the amount of loads impacts the stratification and can impact the overall performance of the system. The real stratification that will be measured experimentally will likely vary relative to the simulated profile but until this comparison is done, the extent of this variation is unknown.

The number of nodes selected for each tank was based on the recommended values from sensitivity study done by Wills (2013). A 300 L diurnal tank and STES of 300 $m^{3}$ were considered (Wills, 2013, p78,97). The store height over which the number of nodes is distributed in Wills (2013) was $1.7 \mathrm{~m}$ and the $450 \mathrm{~L}$ DTES in this work has similar height of $1.9 \mathrm{~m}$ (Wills, 2013, p78). Likewise, although the STES volumes were much larger, the vertical height of the store Wills $(2013)$ examined $(3.5 \mathrm{~m})$ is similar in scale to the $3 \mathrm{~m}$ tank height in this work (Wills, 2013, p97).

Wills (2013) conducted a parametric study varying the number of nodes in the DTES from 1 to 50 and found increasing from 1 to 10 in the DTES had the greatest impact to the auxiliary DHW energy use and increasing beyond 10 had much less significant impact (Wills, 2013, p98-99). For this work, a 10-node discretization was selected based on Wills (2013) parametric results for similar tank heights. Using 
too many nodes could over-estimate the performance of the system by artificially increasing the stratification in the tank. In a real system, flow in and out of the tank can lead to the tank being mixed which is not captured by this model.

If there was a known number of thermocouples in the diurnal tank to measure the temperature profile, this would have been taken into consideration for comparison and calibration. At the time of this writing, there is not yet an instrumented thermocouple rack in the DTES to inform this decision.

For the seasonal store, a parametric study of nodes ranging from 1 to 20 was also conducted and 20 was shown to result in the greatest decrease in auxiliary SH requirements (Wills, 2013, p100-101). In this work, the as-built seasonal storage volume has a height of $3 \mathrm{~m}$ and is instrumented with 25 thermocouples over its height. Therefore, in order to provide stratification profile results that are similar to the experimental data, 25 nodes were used to represent seasonal store stratification.

The real STES tank more closely resembles a horizontal cylinder with rounded ends. Although TRNSYS does have a horizontal cylinder tank model, it caused the simulation to crash and was unreliable. The more reliable vertical tank model was used as a necessary work around to represent the STES tank. As the ground temperature is a fixed model input, the heat loss differences between the two shapes should be minimal. The more important consideration is the impact on thermal stratification. By keeping the same vertical height for the modelled tank, the thermal stratification is expected to be representative of the horizontal storage tank. The impact on the heat loss and stratification of this assumption will be quantified when experimental data becomes available.

Type 534 tank model is capable of modelling internal heat exchangers but none 
were modelled for this analysis and thus this functionality will not be treated here. The interested reader may refer to Thermal Energy System Specialists (2012b) for details on this topic.

Type 534 allows the user to select how to select from a number of inlet and outlet location options; fixed inlet and outlet locations (Mode 1); fractional inlets and outlets (Mode 2); temperature seeking inlets with fixed outlets (Mode 3).

Both diurnal stores were modelled as Mode 1 components where the flow rates for one inlet and outlet pair are equal as shown in Figure 17. The number of inlet and outlet pairs is user specified and the location of inlets and outlets with respect to the tank nodes is also an input.

For this work, the solar charging loop brings hot water to the top node of the tank at a flow rate $\dot{m}_{1}$ and returns cooler water at the same rate. The loads are supplied from the hottest node at the top of the tank at a flow rate of $\dot{m}_{2}$ and the return flow at the same rate is sent to the bottom of the tank to be re-heated.

Heat transfer is considered vertically between nodes as well as heat loss from the side, bottom, and top of the tank. The rate of heat loss is dependent on the insulation value and fluid properties the user specifies, and the ambient temperature. The ambient temperature is the ground temperature in the case of the seasonal store and the zone setpoint temperature in the case of the diurnal store. 


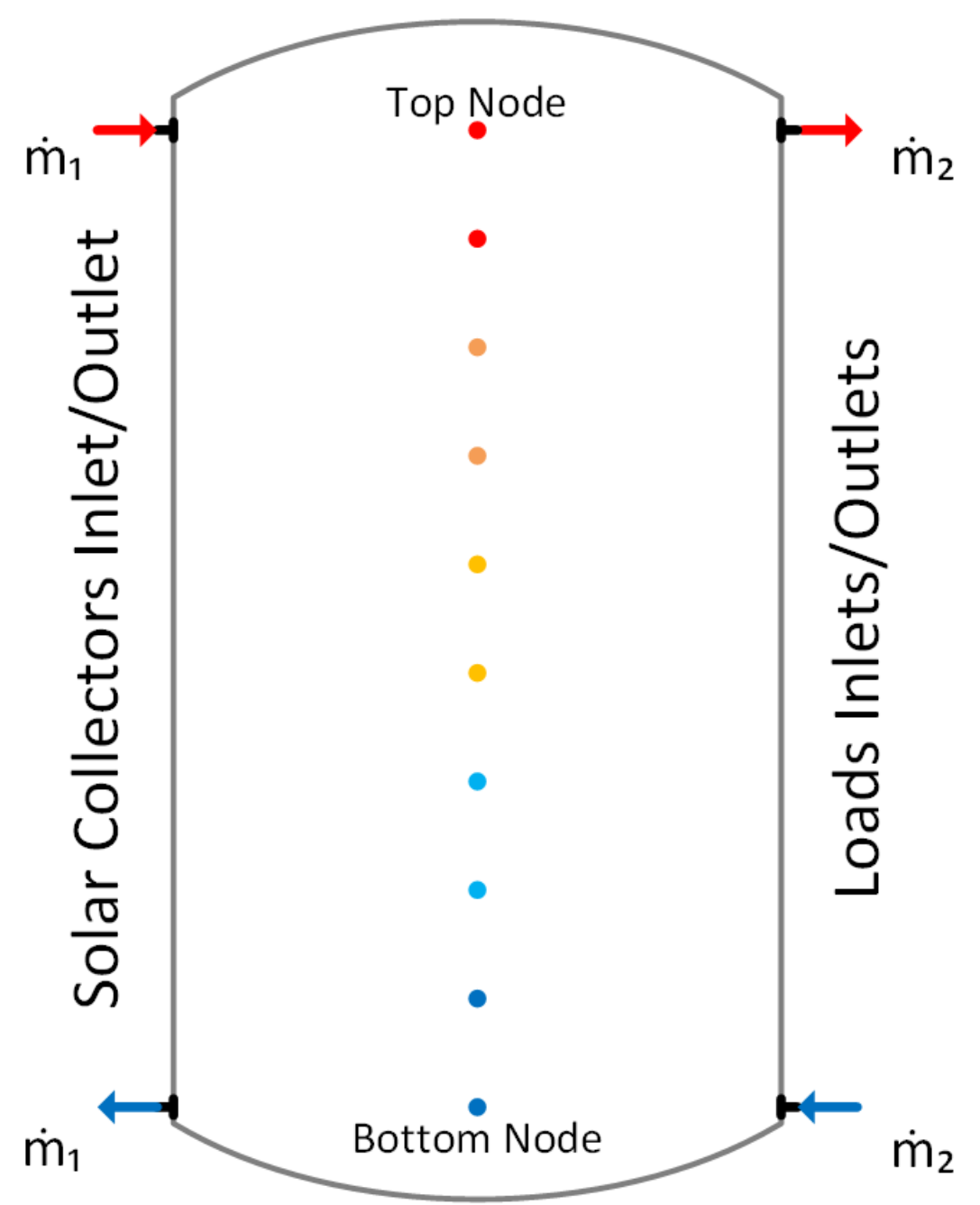

Figure 17: Type 534 Flow Mode 1 and Diurnal Store Node Layout 
Key inputs values for both diurnal and seasonal store are provided in Table 5 and 6 respectively.

Table 5: Diurnal Store Inputs

\begin{tabular}{lll} 
Input & Unit & Value \\
\hline \hline Volume & $\mathrm{L}$ & 450 \\
Height & $\mathrm{m}$ & 1.9 \\
Insulation & $\frac{K m^{2}}{W}\left(\frac{{ }^{\circ} F f t^{2}}{B T U}\right)$ & 1.4 RSI (R8)
\end{tabular}

Table 6: Seasonal Store Inputs

\begin{tabular}{lll} 
Input & Unit & Value \\
\hline \hline Volume & $m^{3}$ & 35 \\
Height & $\mathrm{m}$ & 3 \\
Insulation & $\frac{K m^{2}}{W}\left(\frac{\circ F f t^{2}}{B T U}\right)$ & 13.2 RSI (R75) \\
Ground Temperature & ${ }^{\circ} \mathrm{C}$ & 10
\end{tabular}

\subsubsection{Evacuated Tube Solar Thermal Collector - Type 71}

Type 71 allows the user to input data for a particular solar collector. Performance characteristics from the Solar Rating and Certification Commission (SRCC) test of the Apricus AP-30 collectors (installed in the Urbandale Centre for Home Energy Research) were used (Solar Rating and Certifcation Commission, 2009). The installation is shown in Figure 19.

The SRCC administers certification, standards, testing, and rating programs for 
solar collectors and solar water heating systems (Solar Rating \& Certification Corporation, 2015). TRNSYS's solar thermal collector models allows for the use of SRCC performance data as inputs (Thermal Energy System Specialists, 2012a, p. 74). The SRCC efficiency calculation method for evacuated tube and flat plate solar thermal collectors is the same. The difference between the two panels is in the treatment of the incident angle modifiers (IAMs) (Thermal Energy System Specialists, 2012a, p. $74)$.

The incident angle modifier accounts for the angle between the radiation beam and the collector normal. There are two possible incident angle directions, transversal and longitudinal. In flat plat collectors, the differentiation between the two is not required but for evacuated tube collectors, both angles are accounted for (Solar Rating \& Certification Corporation, 2012, p. 17-18).

\subsubsection{Heat Exchangers}

Flat plate brazed heat exchangers (AIC LB31-50) are used between the solar thermal collector loop and each of the DTES and STES hydraulic circuits. The manufacturer supplied heat exchanger UA value is used in the TRNSYS model along with the flow rates specified in Table 7 .

\begin{tabular}{llc} 
Input & Value & Unit \\
\hline \hline UA & 1873 & $\frac{\mathrm{W}}{K}$ \\
Water flowrates & 900 & $\frac{\mathrm{kg}}{\mathrm{h}}$ \\
Bio-Green flowrates & 1888 & $\frac{\mathrm{kg}}{\mathrm{h}}$
\end{tabular}

Table 7: Simulation Heat Exchangers Inputs 


\subsubsection{Working Fluids}

Bio-Green is a non-toxic heat transfer fluid developed with a corn sugar base (versus petroleum-based) consisting of a 1,3 propanediol blend (The Greenway Group, 2013). It is used as the working fluid for the solar thermal collector circuit for heat transfer characteristics and resistance to freezing. This is the fluid being used in the Urbandale Centre for Home Energy Research's solar thermal system.

Water is used in all other circuits in the facility as they are designed to avoid the risk of freezing. The specific heat $\left(\mathrm{C}_{\mathrm{p}}\right)$ value for the fluids is provided in Table 8 . In reality, the specific heat is temperature dependent but it is treated as a constant value because TRNSYS is limited to a single value for fluid properties. The variation in specific heat capacities ranges from $3.39 \mathrm{~kJ} / \mathrm{kg} \mathrm{K}$ at $25^{\circ} \mathrm{C}$ to $3.98 \mathrm{~kJ} / \mathrm{kg} \mathrm{K}$ at $120^{\circ} \mathrm{C}\left(\right.$ SUSTERRA ${ }^{\circledR}, 2017$, p.24).

\begin{tabular}{lcc} 
Input & Unit & $\mathrm{C}_{\mathrm{p}}$ \\
\hline \hline Bio-Green & $\frac{k J}{k g K}$ & 3.5 \\
Water & $\frac{k J}{k g K}$ & 4.2
\end{tabular}

Table 8: Working Fluids (The Greenway Group, 2013)

\subsubsection{Domestic Hot Water Data}

To model combisystems, reliable DHW draw profiles are necessary. To address this, Edwards et al. (2015) used measured data for seventy three homes collected by Hydro Québec. During autumn, winter, and spring for 2006-2007, hot water consumption was measured continuously for these homes. 
"Both the magnitude and temporal distribution of the measured data was significant" (Edwards, 2014, p44). For example, consumption ranged from 70-438 L/day. (Edwards, 2014, p39). Four consumption levels and three temporal patterns were identified to create 12 annual draw profiles.

The draw profile for three occupants with an 'average' consumption pattern was used for this research (referred to as 'H38'). The annually averaged daily consumption for H38 is $176 \mathrm{~L} /$ day with the greatest usage in the mornings. Further details regarding the annual DHW profiles are contained in Edwards et al. (2015).

The data provided by Edwards et al. (2015) work is provided at 5-minute resolution. In order to make use of the data for the 6-minute time steps of the energy simulations, the data was converted. This was done on an hourly basis by summing the total draw in litres for the hour and spreading it equally over the 6-minute time steps as shown in the simplified example for one time step in Equation 2.

$$
t s_{i}^{6 m i n}=\frac{5}{60} * t s_{i}^{5 \min }+\frac{1}{60} * t s_{i+1}^{5 \min }
$$

The total consumption remains unchanged on an annual and hourly basis, however on a sub-hourly basis this approach would lead to altered draw patterns but the total consumption on an hourly basis was deemed sufficient for this research.

\subsection{Ground Temperature Sensitivity Study}

To ascertain the significance of ground temperatures on tank heat loss and overall system performance, a number of cases were run for over a range as defined in Tables 9 and 10. 
The greatest impact on performance between a ground temperature of $5^{\circ} \mathrm{C}$ and a ground temperature of $25^{\circ} \mathrm{C}$ is observed in the amount of heat loss from the seasonal store. This makes sense as the larger temperature difference between the ground and the storage volume would result in greater heat transfer. Interestingly, there is a negligible impact on the overall solar fraction.

The energy collected (Table 9) is greater than the total the energy added to both the STES and DTES. There are times when there is available solar energy but more enery can't be added to the stores for one reason or another. While there is no explicitly defined heat dissipation system in the model, energy is lost to the environment as it would be in the real system.

Table 9: Auxiliary Energy Use and Store Charging

\begin{tabular}{ccccccc} 
& SF & $E_{\text {aux }}^{S H}$ & $E_{\text {aux }}^{D H W}$ & $E^{\text {collectors }}$ & $E_{+}^{\text {STES }}$ & $E_{+}^{\text {DTES }}$ \\
Case & - & GJ & GJ & GJ & GJ & GJ \\
\hline \hline $5^{\circ} \mathrm{C}$ & 0.91 & 0.3 & 2.4 & 69.8 & 28.5 & 17.4 \\
$\alpha$ & 0.91 & 0.2 & 2.4 & 69.8 & 28.1 & 17.4 \\
$25^{\circ} \mathrm{C}$ & 0.91 & 0.2 & 2.3 & 67.9 & 26.2 & 17.4
\end{tabular}

In reality the ground is not at a constant temperature, it warms in summer and cools in winter. However, TRNSYS requires a constant ground temperature and a value of $10^{\circ} \mathrm{C}$ is used for the annual simulations. This is deemed a reasonable assumption given it falls within the range of temperatures for which there is minimal impact on overall system performance. Being closer to the lower end of the range $10^{\circ} \mathrm{C}$ is a more conservative annual value. 
Table 10: Annual Heat Loss and Averaged Store Temperatures

\begin{tabular}{ccccccc} 
& $\begin{array}{c}T_{\text {top }}^{\text {DTES }} \\
\text { Case }\end{array}$ & $\begin{array}{c}T_{\text {bottom }}^{\text {DTES }} \\
{ }^{\circ} \mathrm{C}\end{array}$ & $\begin{array}{c}T_{\text {top }}^{S T E S} \\
{ }^{\circ} \mathrm{C}\end{array}$ & $\begin{array}{c}T_{\text {bottom }}^{\text {STES }} \\
{ }^{\circ} \mathrm{C}\end{array}$ & $\begin{array}{c}Q_{-}^{D T E S} \\
\text { GJ }\end{array}$ & $\begin{array}{c}Q_{-}^{S T E S} \\
\text { GJ }\end{array}$ \\
\hline \hline $5^{\circ} \mathrm{C}$ & 48.6 & 25.3 & 78.6 & 64.4 & 1.6 & 9.7 \\
$\alpha$ & 48.6 & 25.3 & 78.9 & 64.6 & 1.6 & 9.0 \\
$25^{\circ} \mathrm{C}$ & 48.6 & 25.5 & 79.5 & 65.3 & 1.6 & 6.9
\end{tabular}

\subsection{Simulation period and time step}

All simulations were run for a 5 -year period beginning January $1^{\text {st }}$. Only the data from the fifth year of simulation is presented here. A seasonal thermal storage typically takes 1-2 years to be able to provide useful energy. In real applications, there are interactions with the surrounding ground but in the model, these are not modelled. The thermal mass of the STES is the reason a multi-year charging period is necessary. This is due to the large volume and low initial temperature (assumed to be $\left.20^{\circ} \mathrm{C}\right)$.

The first four simulations years provide time for the system to become fully charged and begin the fifth year with more realistic initial conditions, and operate at a relative steady state over the annual period being analysed. It was observed that it took 4-5 simulation years for a cyclical trend to be seen in the STES temperatures from year to year. Hence the 5th year was considered representative of steady-state performance.

A time step $(t s)$ of 6 -minutes is used to attain greater resolution of thermal and plant variables than an hourly simulation would provide. 


\subsection{Model Verification}

The simulation tools employed in this research require extensive input from the user, many of which require a detailed underestanding of the underlying methodologies and assumptions. All of the simulation tools have been externally validated in numerous ways but the most common source of error in modelling is user error.

As such the behaviour of the model was checked throughout the simulation development period to verify that the control algorithm of the custom TRNSYS type behaves as intended.

The convergence of the simulations was also checked for each case. The simulation uses the default Co-simulator convergence criteria of $0.01^{\circ} \mathrm{C}$ for temperatures (Francesca Macdonald and Romain Jost and Ian Beausoleil-Morrison and Mich ael Kummert and Timothy McDowell, 2012, p24).

Additionally, simple hand calculations were done to verify the programs were making calculations as expected such as the heat loss from the thermal stores and other energy values to verify the results are reasonable and trends are sensible. These trends will be further explored in the diurnal and annual results in subsequent sections. 


\section{Chapter 3}

\section{Experimental Work}

\subsection{Urbandale Centre for Home Energy Research}

The Urbandale Centre for Home Energy Research (shown in Figure 18), in Ottawa Canada, is an unoccupied two-storey residential house commissioned in 2015 at Carleton University. The building is intended to exceed current efficiency standards and represent Canadian residential construction 5-10 years in the future. To calculate the EUI for the building, the total DHW and SH energy required over the year (31.8 GJ) is normalised by the total floor area (each level is $74.3 \mathrm{~m}^{2}$ ) of the main and second storeys of the building using the exterior dimensions. The energy use intensity (EUI) for the building is $0.21 \mathrm{GJ} / \mathrm{m}^{2}$. The EUI can be used for general comparison of the performance of buildings only if it is calculated with the same methodology and assumptions.

The building was constructed using standard residential practises and exceeds the 2012 R-2000 standard although it has not been independently certified. The R-2000 standard is a technical performance criteria endorsed by industry and administered 


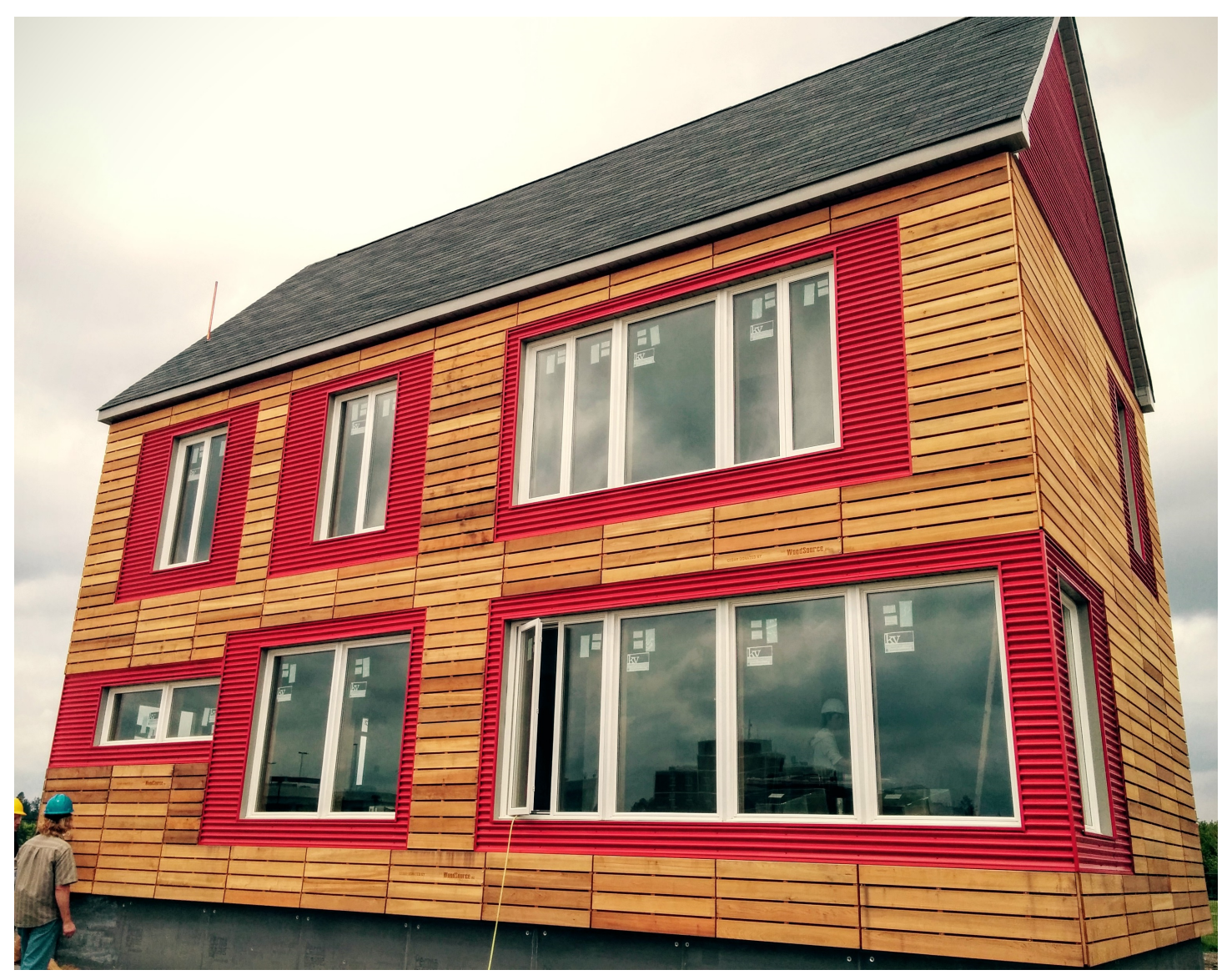

Figure 18: Urbandale Centre for Home Energy Research

by Natural Resources Canada. It describes requirements for energy efficiency, air tightness, and environmental responsibility. Houses satisfying the standard typically exceed the current Canadian building codes (Natural Resources Canada, 2014).

The south face of the roof faces due south with a pitch of $50^{\circ}$ to accommodate $40 \mathrm{~m}^{2}$ of Apricus AP-30 evacuated tube solar thermal collectors mounted at a tilt of $60^{\circ}$ to horizontal to charge the thermal stores (refer to Figure 19). Evacuated tube collectors were chosen based on earlier recommendations by Edwards (2014) and research by Wills (2013). The higher collector temperatures achieved with evacuated 
tubes were also desired for potential future experimental work with an absorption chiller for solar-assisted cooling research. The lithium-bromide absorption chiller would require high generator inlet temperatures that could not be supplied by flat plate collectors.

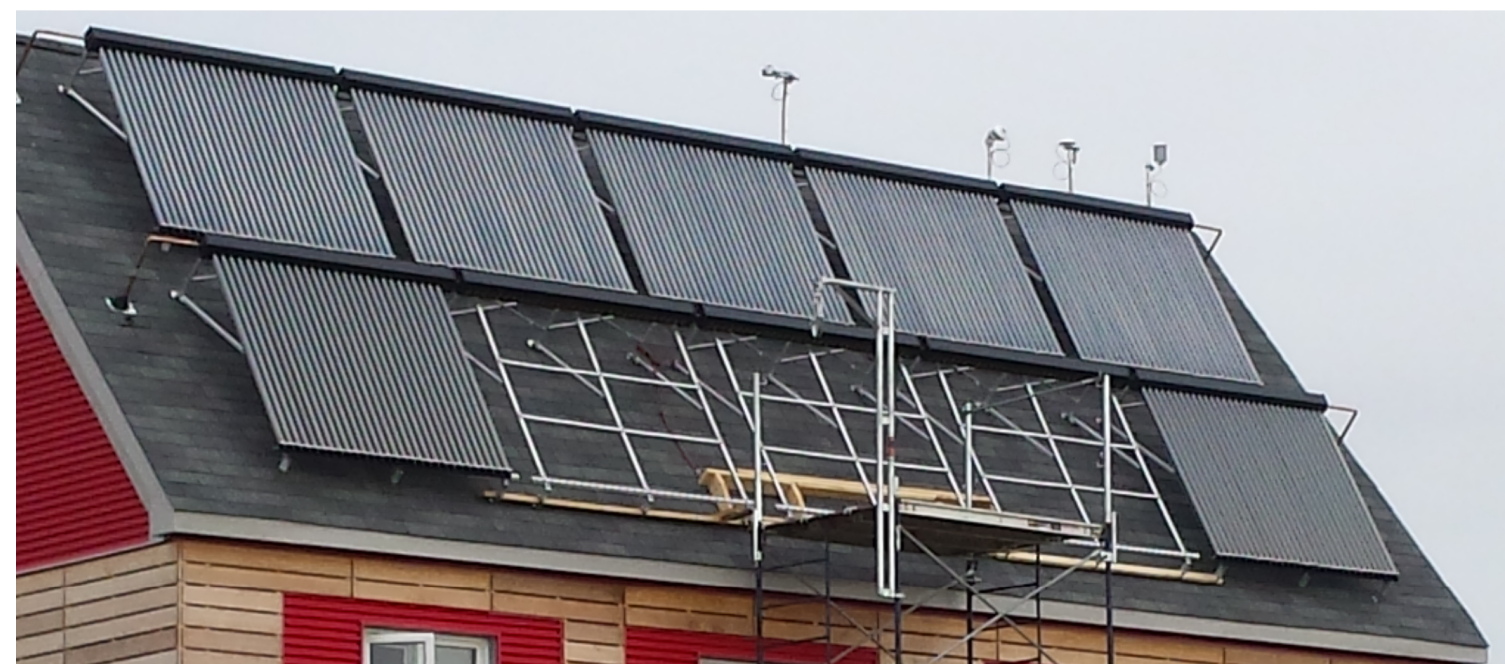

Figure 19: Solar Collectors - Urbandale Centre for Home Energy Research

The solar thermal system is designed to use a large seasonal and a smaller diurnal water-based stores to meet domestic hot water demands and meet long- and shortterm space heating demands via the Roth radiant floor panel system that covers the main and second storeys.

The south-facing triple-paned low-e argon filled windows unshaded by eaves enables the collection of large amounts of passive solar gain over the year to reduce space heating demands.

The house and all experimental apparatus is heavily instrumented with thermocouples, thermopiles, flow meters, heat flux meters, and a dedicated weather station for measuring on-site direct and global horizontal solar radiation, temperature, wind 
speed and direction, and atmospheric pressure. Research is ongoing on technologies and innovations to improve performance of Canadian residential buildings through efficiency and renewable energy system use.

\subsubsection{Seasonal Thermal Store}

The seasonal thermal store (shown in Figure 20) holds $35 \mathrm{~m}^{3}$ of water at sustained temperature of $93^{\circ} \mathrm{C}$. The tank was custom manufactured in Brockville by ZCL using a high-temperature resin in the reinforced double fibreglass walls.

To minimise heat loss, R-75 Proline Plus 200 spray foam insulation was applied between the double walled shell of the tank. The double wall protects the tank insulation from ground moisture and long-term burial, has minimal thermal bridging, and mitigated risk of short-term or long-term leaks which other seasonal storage installations have experienced.

The tank charging and discharging inlets and outlets use diffusers to encourage stratification as illustrated in Figure 21. The tank is instrumented with three vertical thermocouple racks, each with 25 Type-T thermocouples at intervals of approximately 5 inches. This will enable the measurement of the temperature profile over the height of the tank to ascertain the extent of thermal stratification effects. 


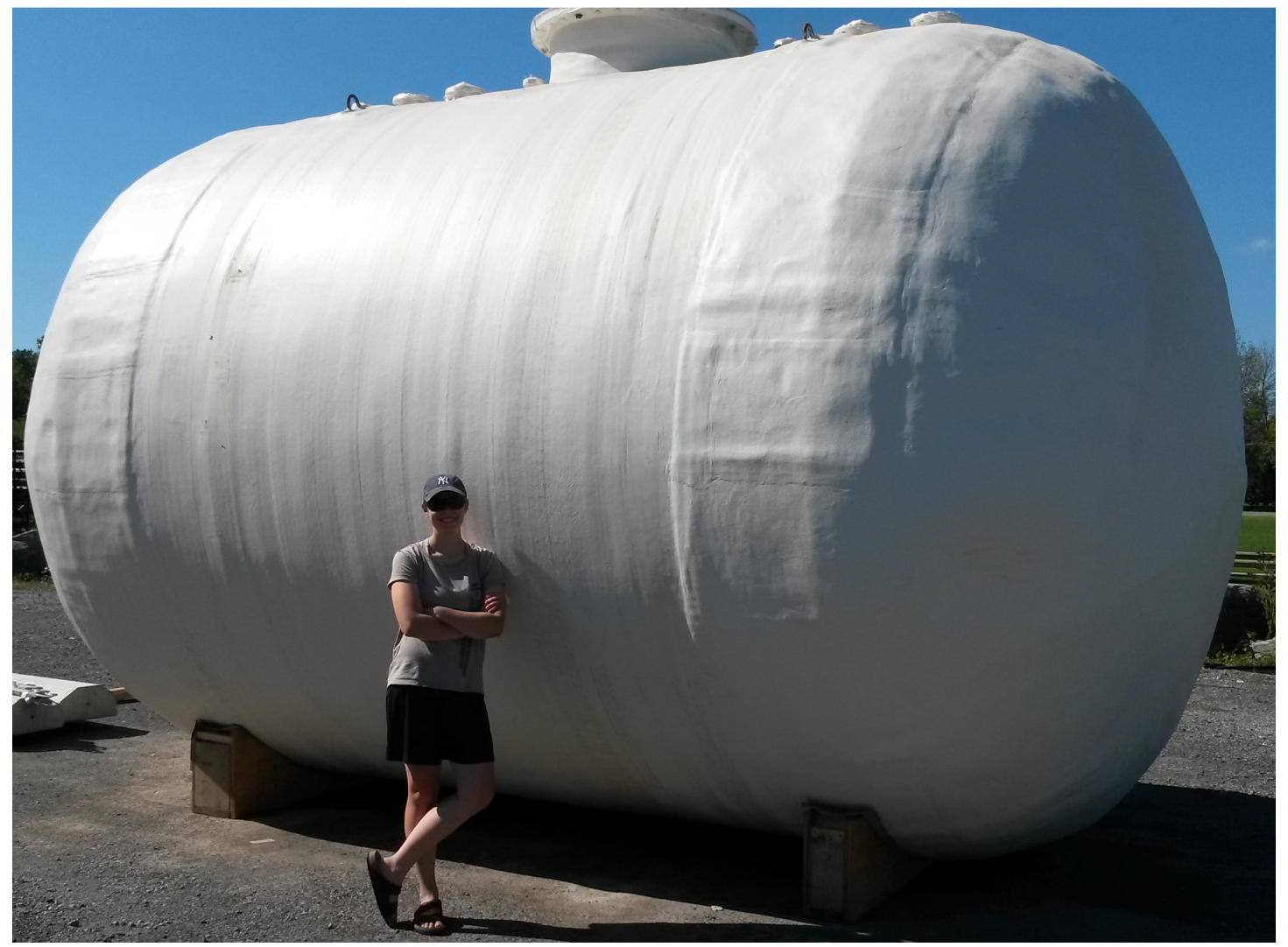

Figure 20: $35 \mathrm{~m}^{3}$ Below-grade Seasonal Thermal Storage Tank

The tank has two ports for the charging loop and two ports for the loads supply loop. Each port is connected to a diffuser to help maintain thermal stratification. As shown in Figure 21 fluid stream inlet diagram. 


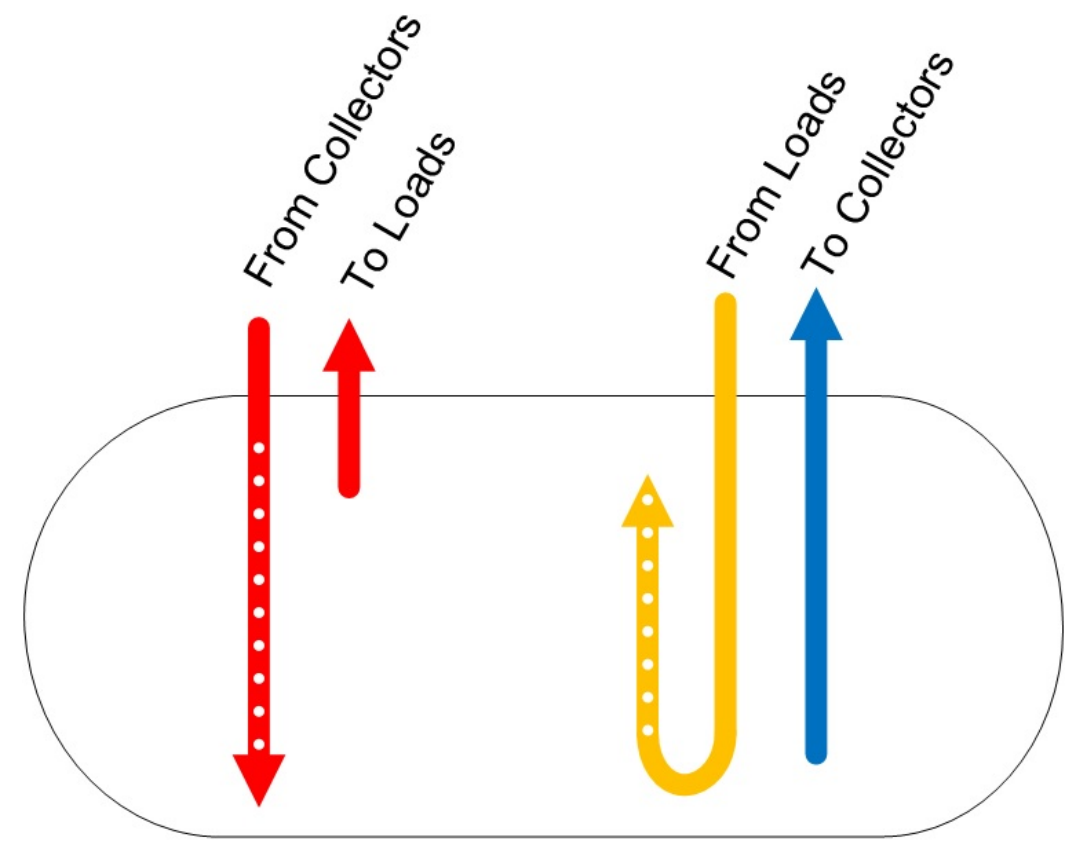

Figure 21: Seasonal Store Diffuser Design

'From Collectors' has a long perforated diffuser, the intent of this is that the fluid can then exit the diffuser at a thermally equivalent level with higher temperature fluid leaving at the top and lower temperature fluid at the bottom. 'To Collectors' has a long un-perforated diffuser enabling the solar collector return fluid stream to be taken from the lowest (and therefore coldest) part of the tank.

'To Loads' takes the fluid from the top (where the temperature should be the greatest) and sends it to meet SH and DHW demands. Returning 'From Loads', the fluid temperature will be lower and the u-shaped perforated tube allows the fluid to find a roughly thermal equivalent layer to exit the diffuser. 


\subsubsection{Diurnal Thermal Store}

The diurnal thermal storage (Figure 22) consists of three factory-insulated Thermo2000 RE-119 storage tanks each with a volume of 450 L. The tanks can be utilised individually or in series to provide 450, 900 or $1350 \mathrm{~L}$ of storage volume.

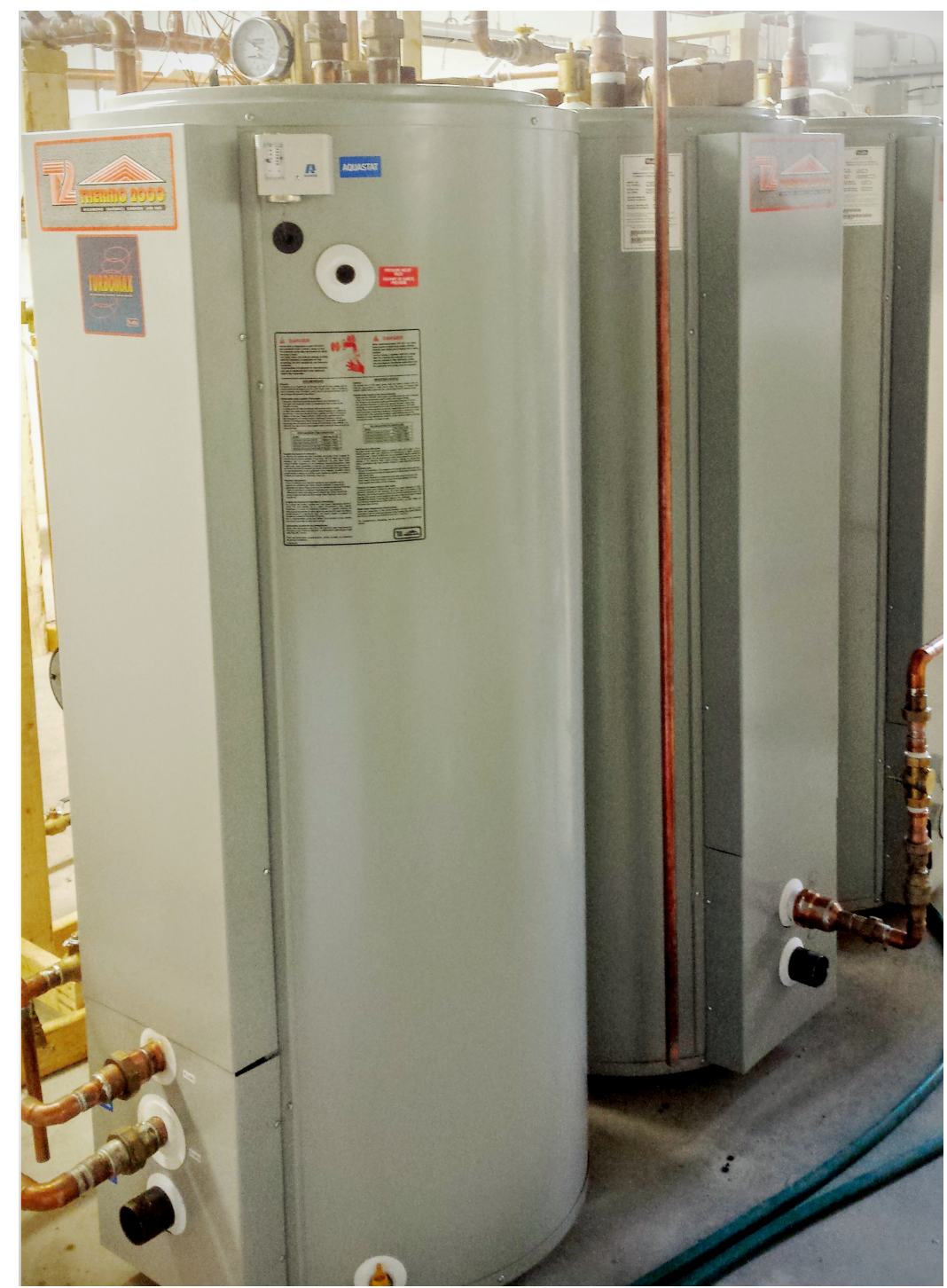

Figure 22: Three 450 L Diurnal Store Tanks 


\subsubsection{Roth Radiant Floor Heating System}

The installed floor construction consisted of the Roth radiant floor panel system of high density polystyrene and bonded 24 gauge aluminium with channels for PEX tubing as seen in Figure 23 (Roth, 2016). The floor was overlaid with cement board and grout to provide a more rigid support for the tile floor on top.

The floor design was contributed by Roth Industries to zone each room and the main and second floor for individual heating or cooling control using thermostatic valves on the manifolds.

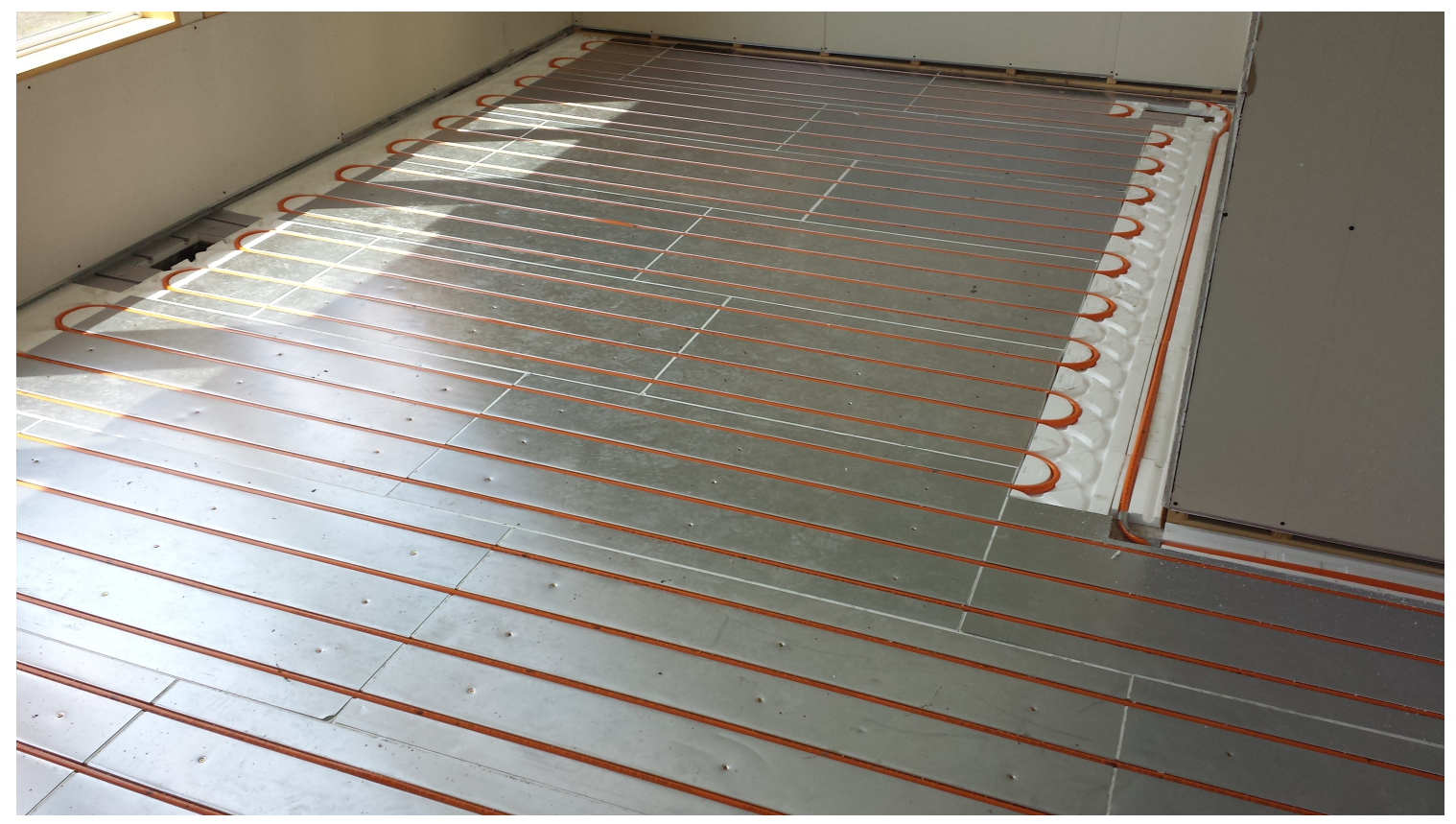

Figure 23: 2nd Floor Radiant Floor Layout 


\subsubsection{Personal Contributions}

\section{Facility Design and Management}

From the outset of the project, I have been directly involved in design, selection, and installation of the research and supporting equipment in the facility.

For instance, I worked with the solar system designer to design a suitable control structure and system layout to mimic hot water draws, charge the seasonal or diurnal stores, and dissipate heat to mimic house loads. I created the layout for basement and below-grade equipment and directed the electricians and the builder to ensure there would be adequate electricity infrastructure and in the correct locations.

I also worked with the research team to design and draw the house plans and design a custom rain screen solution to enable research into novel insulation solutions.

\section{Solar Thermal Energy Stores}

Although Wills (2013) laid the groundwork for the sizing of the seasonal store and solar collector array, once the facility was fully designed, these decisions were revisited based on availability, cost, solar thermal collection potential, and house loads. The $35 \mathrm{~m}^{3}$ volume was chosen based on these considerations and parametric simulation results for a range of volumes and collector array sizes.

After considerable effort and contacting companies across North America and Europe, I sourced a company willing and able to manufacture a below-grade seasonal store to the project's specifications. I worked with the manufacturer to design and manufacture customised tank to meet the specifications of the project. I worked with the contractor and the manufacturer to ensure correct installation for the functional, 
environmental, and structural limits of the tank.

\section{Instrumentation and Data Acquisition}

Instrumenting the seasonal storage tank also provided a challenge but was necessary for capturing the thermal profile in the large tank. The 1 inch diameter sealed sleeves included in the design provided enough room to fit 25 thermocouples. It was necessary to ensure the delicate wires were not damaged during installation and that they maintained contact with the tube surface for greater accuracy. I designed a rack with an elastic diameter that made it easier to install and helped hold the thermocouples against the sleeve surface once installed. I supervised the construction of the racks to my design specifications and Dr. Beausoleil-Morrison and I installed them in the tank (see Figure 24).

I contributed to the selection of the data acquisition system components and hardware architecture to record the data from hundreds of thermocouples, moisture meters, climate instruments, thermopiles, and actuate pumps, valves, and other components.

\section{Outcomes}

The goal of this experimental work was to enable adequate monitoring to validate and evaluate the performance of individual systems, and the facility as a whole. All of the goals for doing this were achieved and future researchers are well positioned to follow through on future work. 


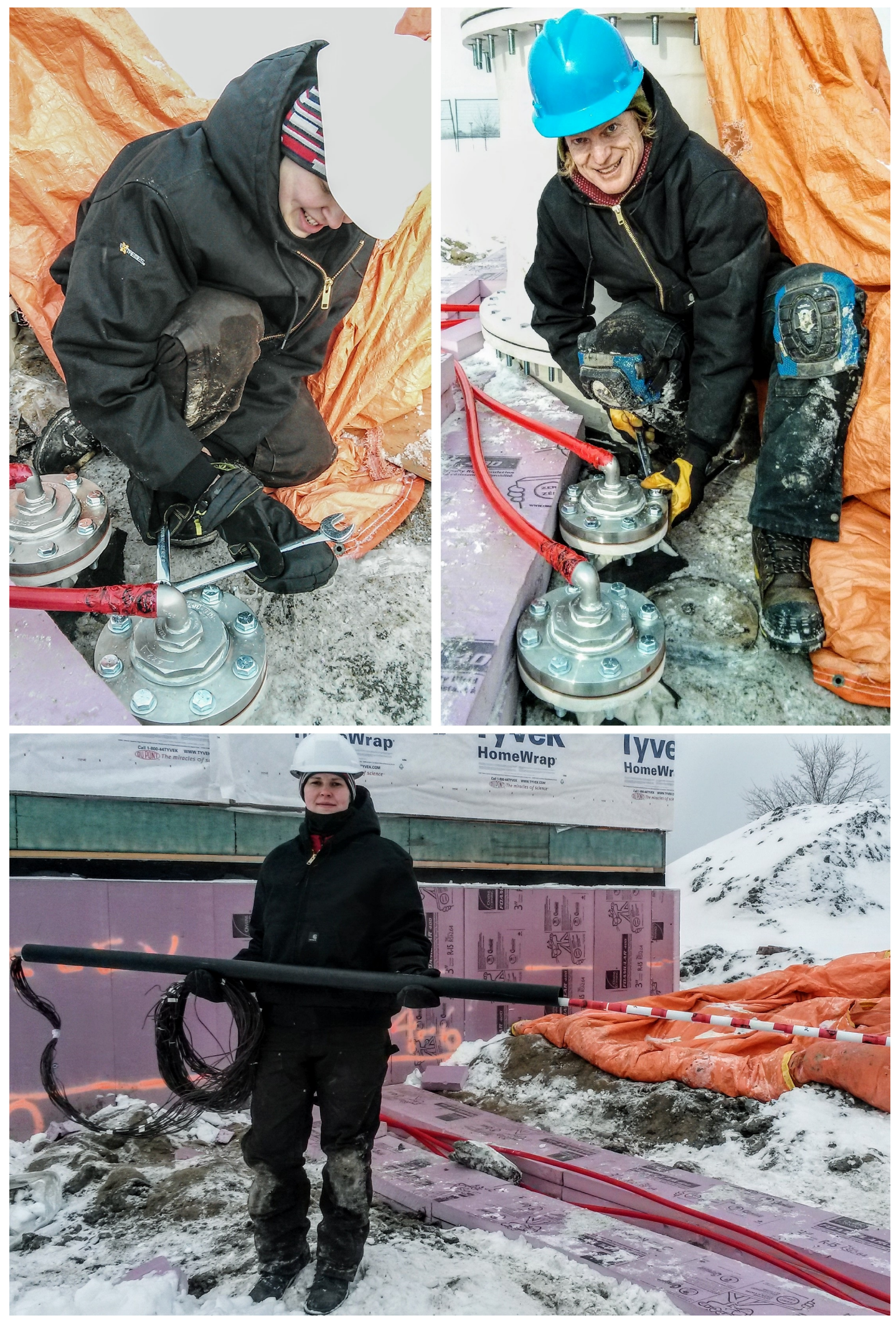

Figure 24: ZCL Thermocouple Rack Installation 


\section{Chapter 4}

\section{Simulation Results}

Having developed a model with which to represent the experimental Urbandale Centre for Home Energy Research facility, some means of measurement by which to assess system performance was needed.

To this end, a set of reasonable values for key inputs to the system was established. This base case is referred to as the ' $\alpha$ case' and it provided the means to establish a performance benchmark from which to improve control strategies and system design. To determine which parameter values and control strategies provided the most benefit

to the overall system performance, a parametric study was carried out. Based on the outcomes of the parametric analyses, a second set of system input values was established referred to as the ' $\beta$ case'

This chapter will begin by introducing some of the relevant terminology and concepts for the readers understanding in Section 4.1. The remainder of this chapter will then present, the results of the $\alpha$ case (preliminary system design) in Section 4.2. This is done on both an annual and a daily basis by season for sunny and cloudy days. Next, the outcomes of parametric analyses for a range of input parameters will 
be covered in Section 4.3. Finally, in Section 4.4, the definition and performance of the $\beta$ case (recommended design) are presented.

\subsection{Concepts and Terminology}

Components of solar radiation, specifically direct normal and diffuse horizontal radiation, will be presented to aid understanding of the daily results. When radiation from the Sun hits the Earth's atmosphere, it can be reflected back into space, be absorbed by the atmosphere, or pass through the atmosphere.

The radiation that arrives at the Earth's surface and lands on a surface perpendicular to the Sun's beam is the direct normal portion. The radiation that is scattered by the atmosphere and lands on a horizontal surface is the diffuse portion (Australian Government, 2012).

Solar fraction $(\mathrm{SF})$ is the primary metric of evaluation and comparison for the results as the objective of this research is to develop a control strategy and system configuration such that the highest possible SF is achieved. The system SF is defined in Equation 3 and will be used more extensively later in this chapter. In this work, the SF represents how much of the space heating (SH) and domestic hot water (DHW) demands for the house were met with solar (sol) versus auxiliary (aux) energy.

$$
S F=\frac{S H_{\text {sol }}+D H W_{\text {sol }}}{S H_{\text {aux }+ \text { sol }}+D H W_{\text {aux }+ \text { sol }}}
$$

Parametric results or cases will be referred to frequently. This refers to varying the values of the $\alpha$ case inputs (or parameters) over a range for both the seasonal and diurnal inputs, one at a time whilst holding all other inputs constant, to produce 
a set of so-called parametric results.

The charging efficiency ( $\left.\eta_{\text {charge }}\right)$ is written out in Equation 4. It quantifies the amount of collected solar energy added to either the STES or DTES.

$$
\eta_{\text {charge }}=\frac{E_{+}^{D T E S}+E_{+}^{S T E S}}{E^{\text {collectors }}}
$$

The second efficiency used, $\eta_{\text {total }}$ is calculated according to Equation 5 and accounts for the heat loss from both stores.

$$
\eta_{\text {total }}=\frac{\left(E_{+}^{D T E S}+E_{+}^{S T E S}\right)-\left(Q_{-}^{D T E S}+Q_{-}^{S T E S}\right)}{E^{\text {collectors }}}
$$

\section{2 $\alpha$ Case Results}

The initial system design or $\alpha$ case was established by selecting desirable or typical values for key inputs. For example, a DTES volume $\left(V^{D T E S}\right)$ of $450 \mathrm{~L}$ (the smallest diurnal volume possible in the Urbandale Centre for Home Energy Research) would be the ideal solution both from a capital cost and space perspective in a home so this was used as the $\alpha$ case $V^{D T E S}$.

A diurnal storage temperature of $54^{\circ} \mathrm{C}$ is the lowest temperature recommended by the Canada Safety Council (2016) from a health and safety perspective to reduce the risk of bacterial growth. The risk for both Legionnaires disease or pneumonia may increase for temperatures under $50^{\circ} \mathrm{C}$. Thus a diurnal charging temperature setpoint $\left(T_{+}^{D T E S}\right)$ of $55^{\circ} \mathrm{C}$ is used. 
As the experimental STES is below-grade and already installed, a STES volume $\left(V^{S T E S}\right)$ of $35 \mathrm{~m}^{3}$ is used. A specialised material was used in the seasonal storage tank construction to enable a maximum sustained temperature $93^{\circ} \mathrm{C}$. This allows for the higher storage temperatures possible with an evacuated tube solar thermal collectors. Therefore with some reasonable margin, a seasonal charging temperature setpoint $\left(T_{+}^{S T E S}\right)$ of $90^{\circ} \mathrm{C}$ is selected for the $\alpha$ case.

The diurnal cutoff temperature, $T_{\text {cutoff }}^{D T E S}$, was set to $42^{\circ} \mathrm{C}$. The DHW draw profiles created by Edwards (2014) were based on a $T_{\text {delivery }}^{D H W}$ of $55^{\circ} \mathrm{C}$.

The selected $\alpha$ case inputs are summarised in Table 11 below. The performance of the $\alpha$ case will be discussed on an annual basis next (Subsection 4.2.1) and on a daily basis in Subsection 4.2.2.

Table 11: $\alpha$ Case

\begin{tabular}{llll} 
Store & Parameter & Value & Unit \\
\hline \hline Diurnal & $V^{\text {DTES }}$ & 450 & $\mathrm{~L}$ \\
& $T_{+}^{\text {DTES }}$ & 55 & ${ }^{\circ} \mathrm{C}$ \\
& $T_{\text {cutoff }}^{\text {DTES }}$ & 42 & ${ }^{\circ} \mathrm{C}$ \\
& $T_{\text {delivery }}^{\text {DHW }}$ & 55 & ${ }^{\circ} \mathrm{C}$ \\
Seasonal & $V^{\text {STES }}$ & 35 & $\mathrm{~m}^{3}$ \\
& $T_{+}^{\text {STES }}$ & 90 & ${ }^{\circ} \mathrm{C}$
\end{tabular}




\subsubsection{Annual Performance}

The solar and auxiliary energy use by end-use is shown in Figure 25 and the amount of energy collected relative to the amount of energy added to each of the stores over the year is seen in Figure 26. The $\alpha$ case has the smallest $V^{D T E S}$ considered $(450 \mathrm{~L})$ and also a very low $T_{\text {cutoff }}^{D T E S}\left(42^{\circ} \mathrm{C}\right)$ and so the STES meets the SH loads predominantly.

The mismatch of solar availability and SH and DHW draws is evident in Figures 25 and 26. Although the greatest SH demands are in December and January, Figure 26 shows these months see the 2nd and 3rd least amount of solar energy collected. Figure 27 of the STES temperatures over the year indicates that in April-May, the seasonal tank reaches a charged state which is largely maintained until late autumn. This same time period has the lowest $\eta_{\text {charge }}$ because there is a great amount of solar energy being collected but the stores are nearly or fully charged most of the time. Whereas when the store temperatures are at their lowest point in January, the $\eta_{\text {charge }}$ is greatest and much of the energy is put into the stores, particularly the seasonal as it has the greatest of the two storage volumes.

Although the top DTES temperature reaches temperatures high enough to preventl bacterial growth, the entire tank does not. If this system were to be used, it would be important to institute a control strategy such that at least once a day, the entire tank would be heated to a sufficient temperature to kill bacterial growth.

Auxiliary SH energy is required in January and February but at no other time of the year. Some amount of auxiliary energy is required throughout the year to meet the DHW demands (refer to Figure 25). 


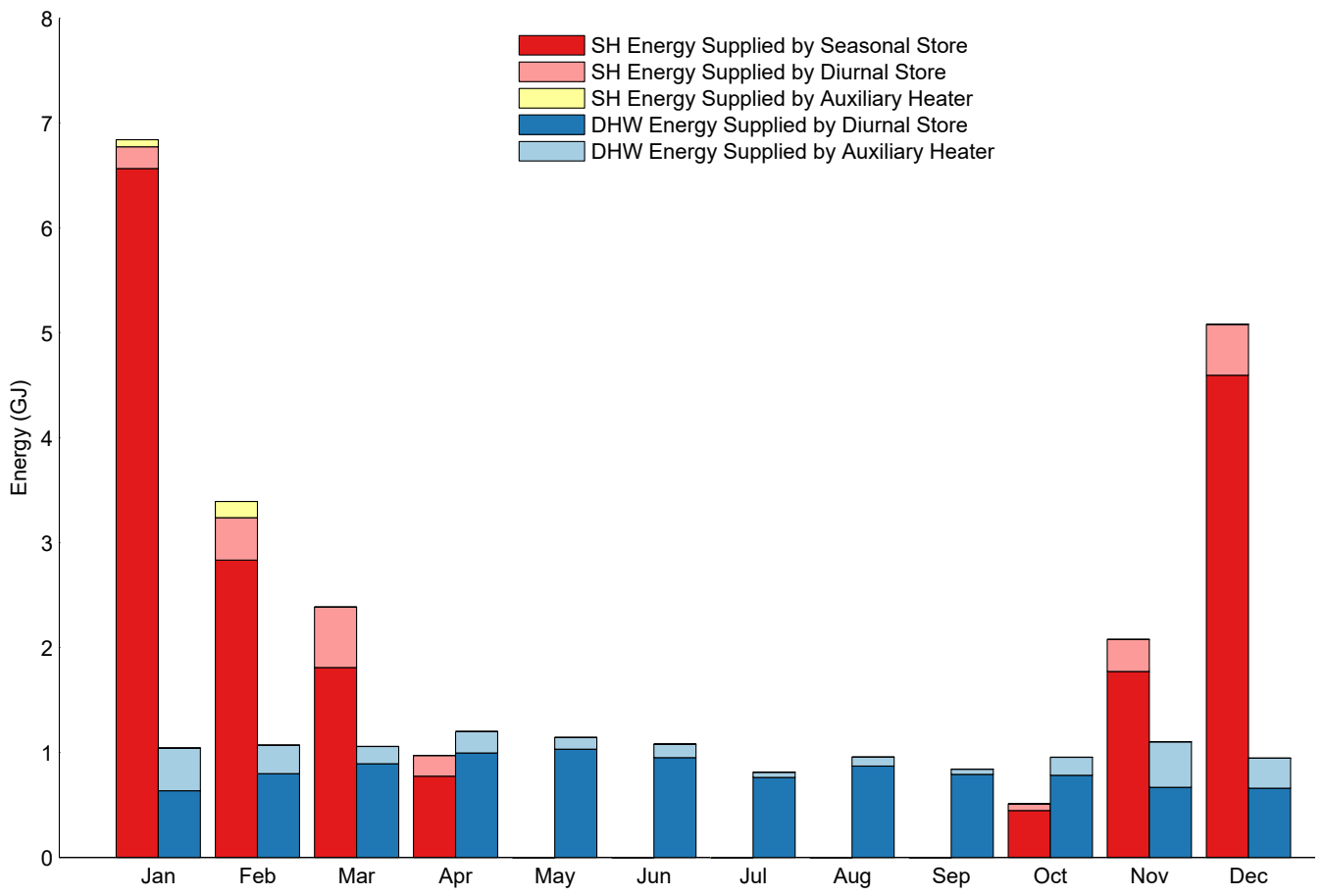

Figure 25: Energy Supplied by End-Use ( $\alpha$ Case)

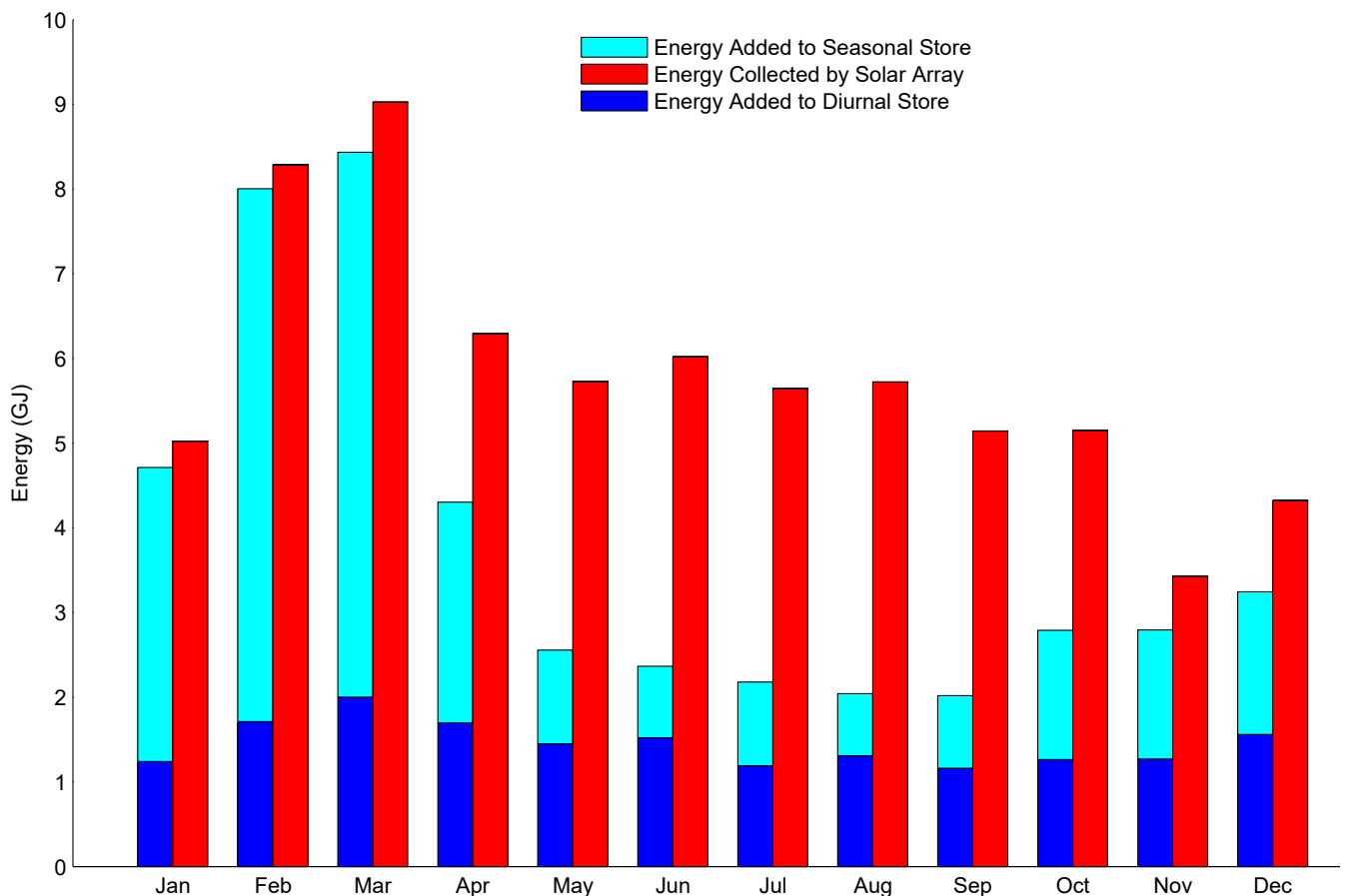

Figure 26: Energy Collected and Added to Thermal Stores ( $\alpha$ Case) 


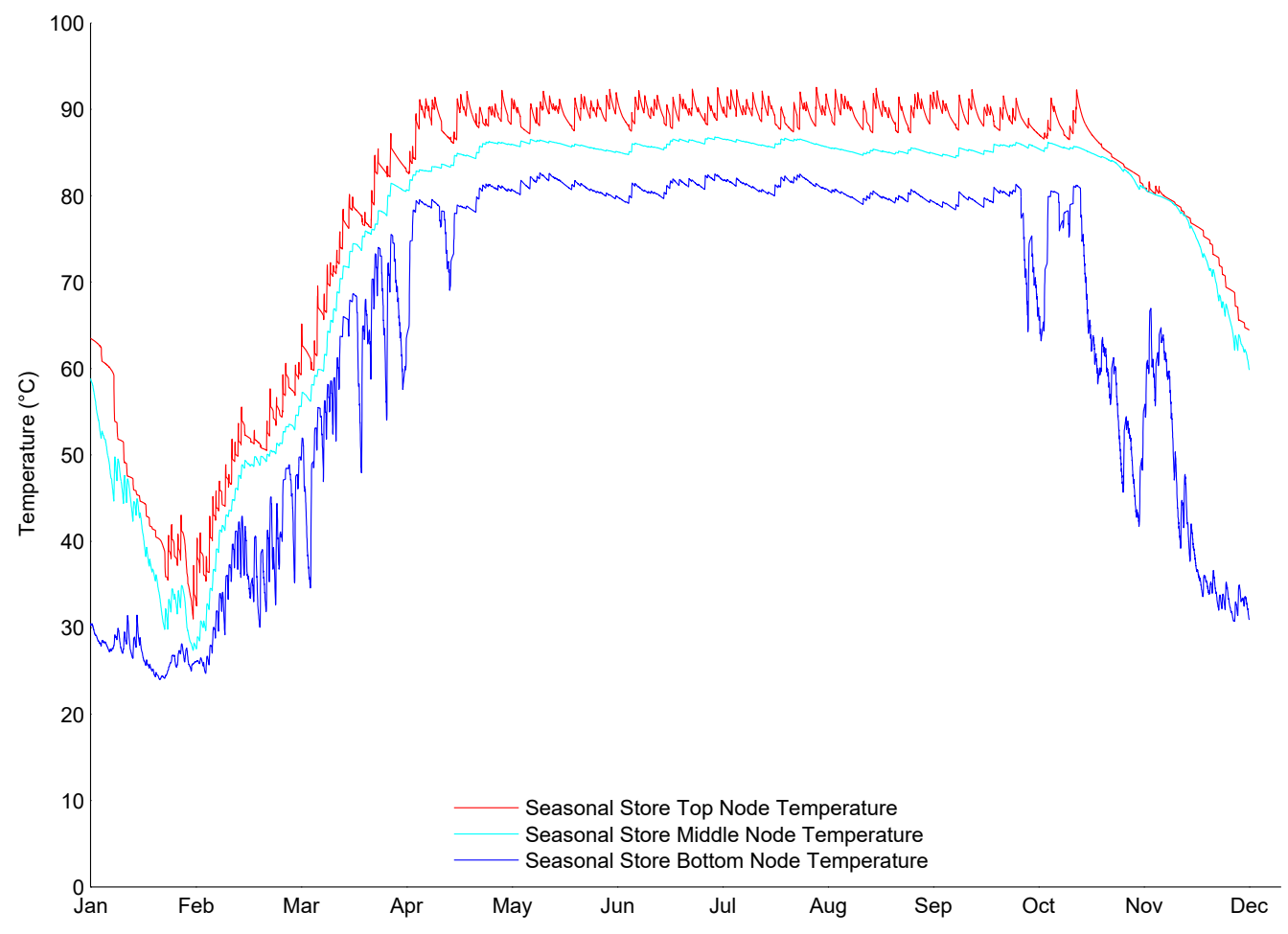

Figure 27: Seasonal Store Temperature Profile ( $\alpha$ Case)

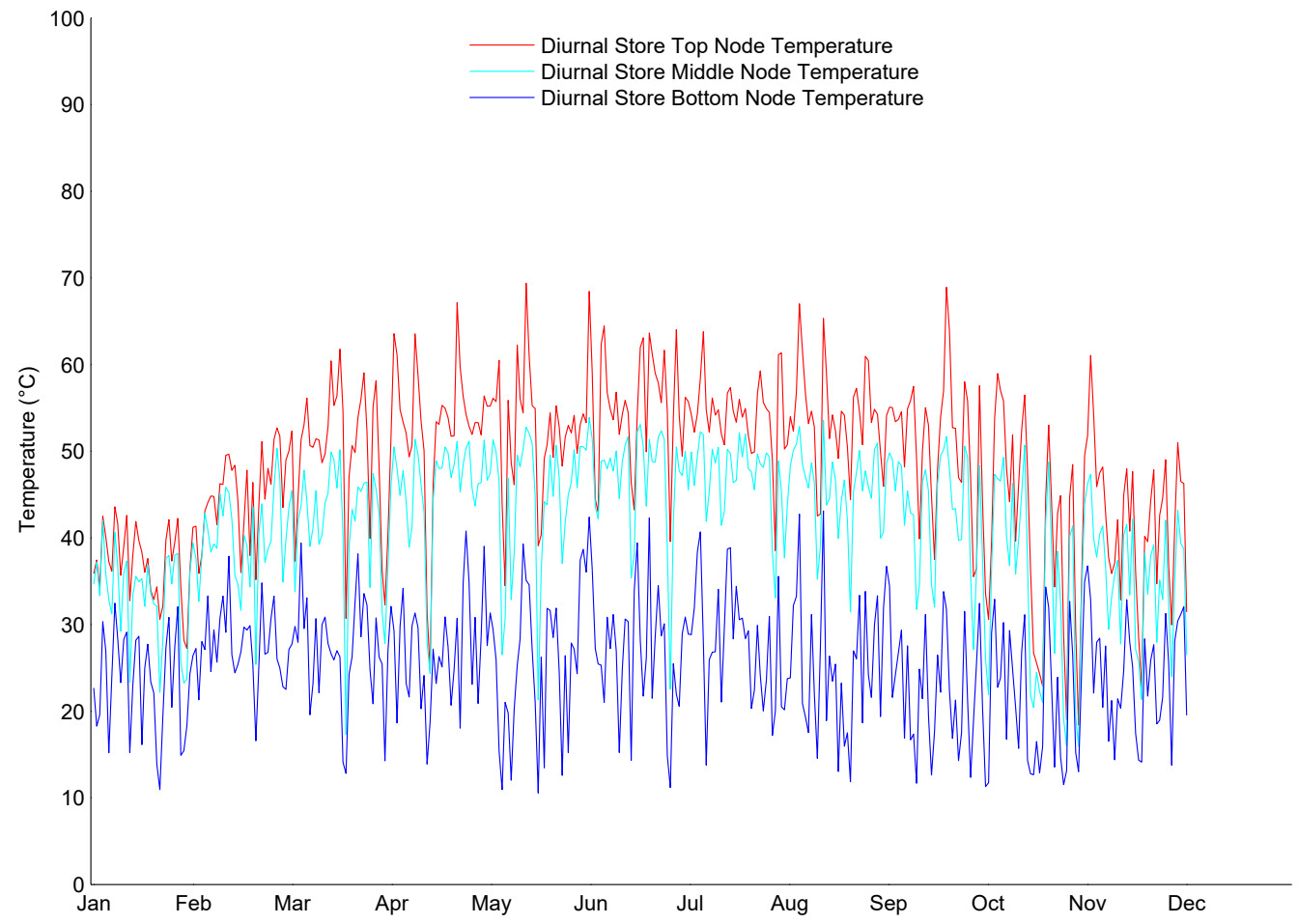

Figure 28: Diurnal Store Temperature Profile ( $\alpha$ Case) 


\subsection{2 $\alpha$ Case Performance on Specific Days}

Analysing the system on a daily basis will provide more insight into how the system performs on different days and which parameters might improve the design overall. Of particular interest will be the $V^{D T E S}$ as sizing the store is one of the major objectives of this work.

The daily results discussions are divided into cloudy and sunny days by season. Plotted results sets include data for ambient conditions, SH loads and store charging behaviour, DHW loads, and store heat loss.

The plot set is presented for a cloudy summer day and the other cloudy day results discussed here are found in Appendix A. On a cloudy summer day, the system should be resilient enough to still meet loads without auxiliary energy as there would be no SH demands and the diural store should be nearly always charged and able to handle the DHW draws.

Similarly the plot set for a sunny winter day is presented here and the remainder of the sunny day results are discussed here and the plots included in Appendix A. When SH demands are high and there are DHW draws, such as on a sunny winter day, the system design should perform well with high solar availability. 


\section{Cloudy Summer Day - 8 August}

August 8th as seen in Figure 29 has predominantly diffuse horizontal and less than $500 \mathrm{~W} / \mathrm{m}^{2}$ with low direct normal radiation (less than $250 \mathrm{~W} / \mathrm{m}^{2}$ ). The ambient outdoor temperature stays below $25^{\circ} \mathrm{C}$ for the day as well. As a consequence, the temperature of the fluid leaving the solar thermal collectors does not climb higher than $50^{\circ} \mathrm{C}$.

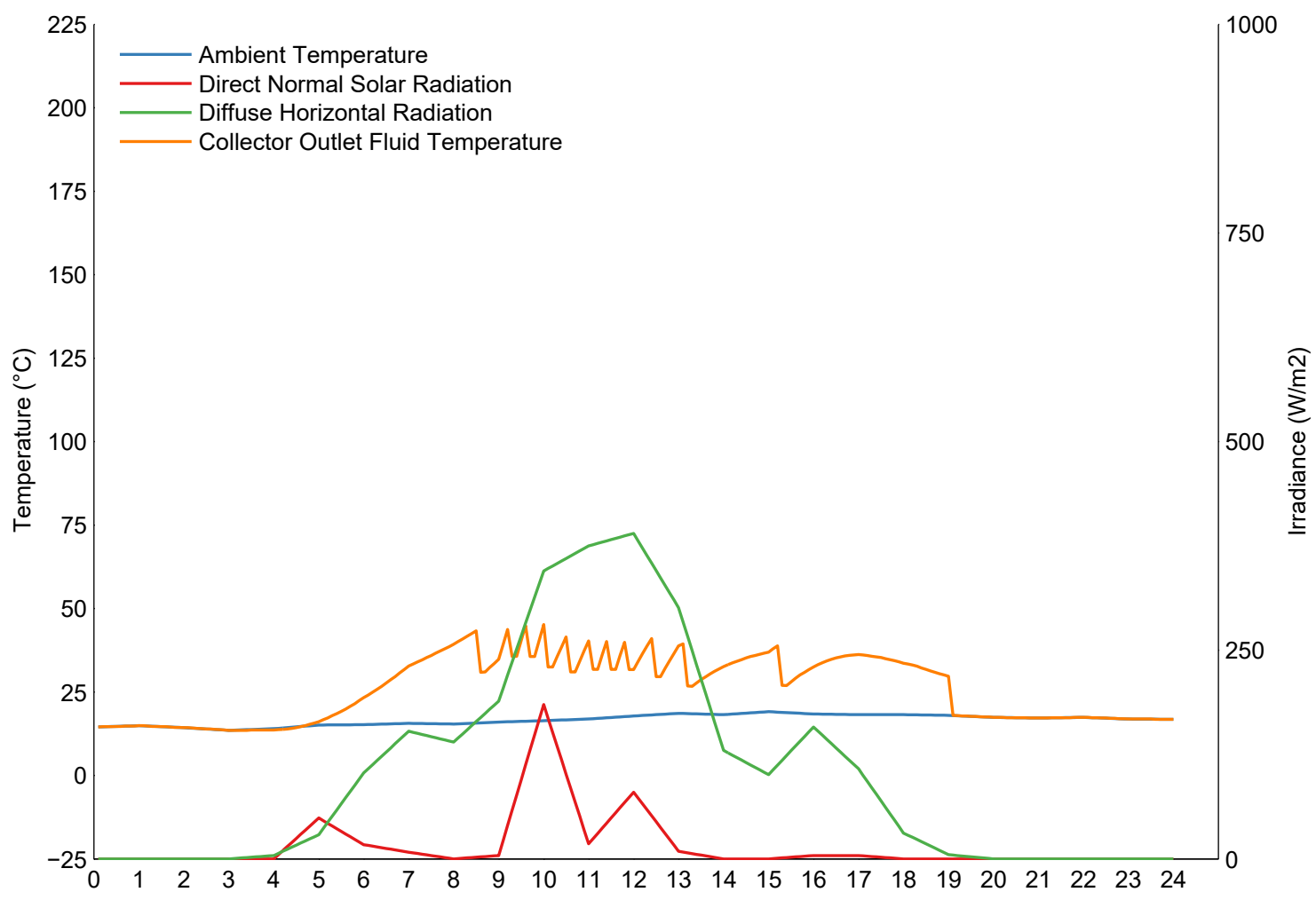

Figure 29: Cloudy Summer Day - Ambient Temperature and Irradiance 
The low solar availability means that no energy is added to either the DTES (Figure 30a) or the STES (Figure 30b). By the middle of summer the STES is nearly always fully charged and on this day stays remains at nearly $90^{\circ} \mathrm{C}$ while the DTES remains around $50^{\circ} \mathrm{C}$.

It's worth noting that the overheating expected as a result of the high south facing glazing ratios can be clearly seen as the main zone air temperature floats between $30^{\circ} \mathrm{C}$ and $40^{\circ} \mathrm{C}$ despite $50 \%$ shading even on an overcast day. Of course, there are no heating loads on this day either which means the control system is behaving expected for an overcast summer day so far.

One improvement that could be considered for the system is a variable speed pump on the solar collector loop. To compensate for low solar availability the system could decrease the solar loop flow rate and increasing the $\Delta \mathrm{T}$ across the collectors. This will not be examined in this work due to time constraints and the convergence errors that arose early on in this work as a result of a complex simulation control strategy. It will be left as a recommendation for future work. 
(a) Diurnal

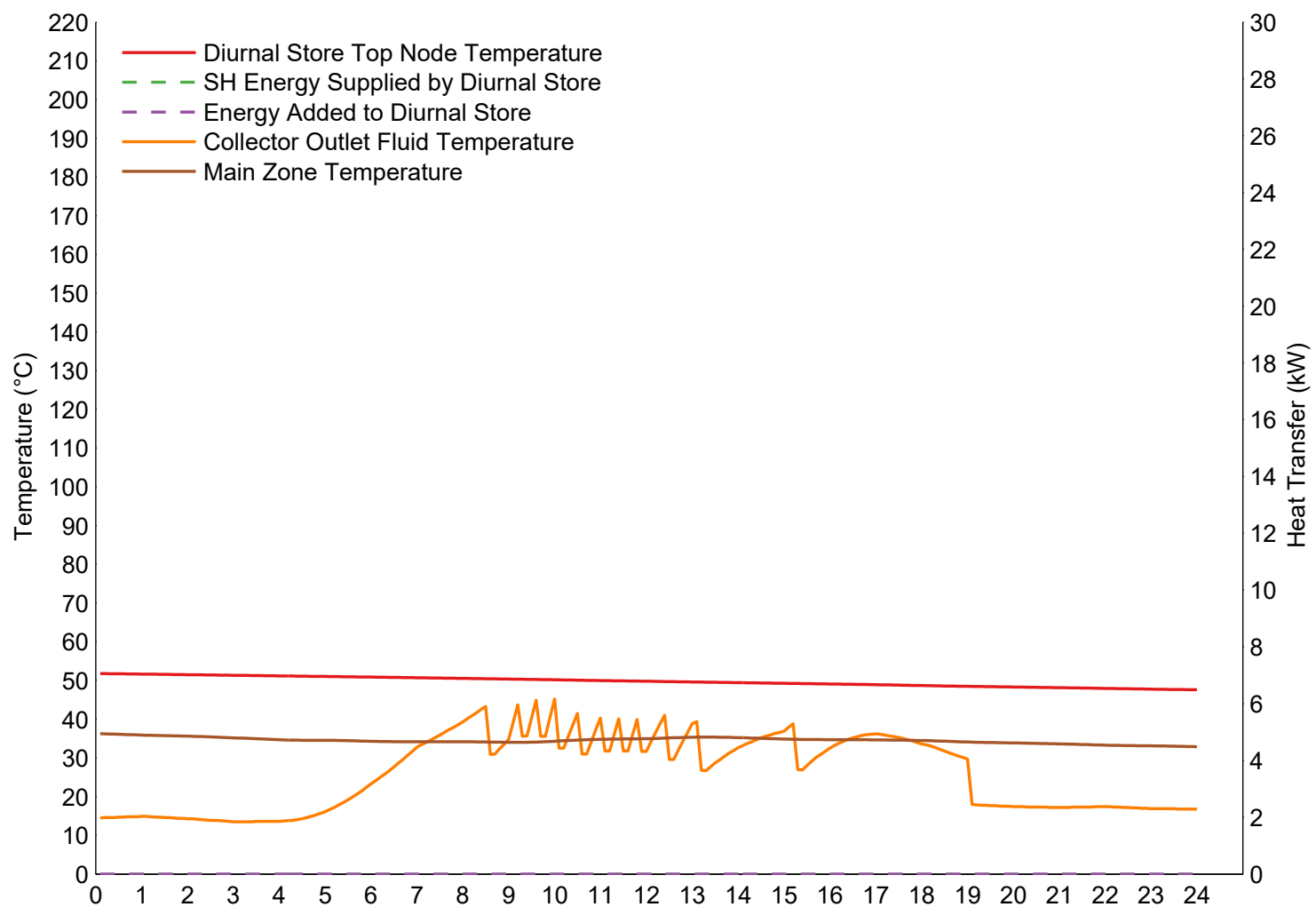

(b) Seasonal

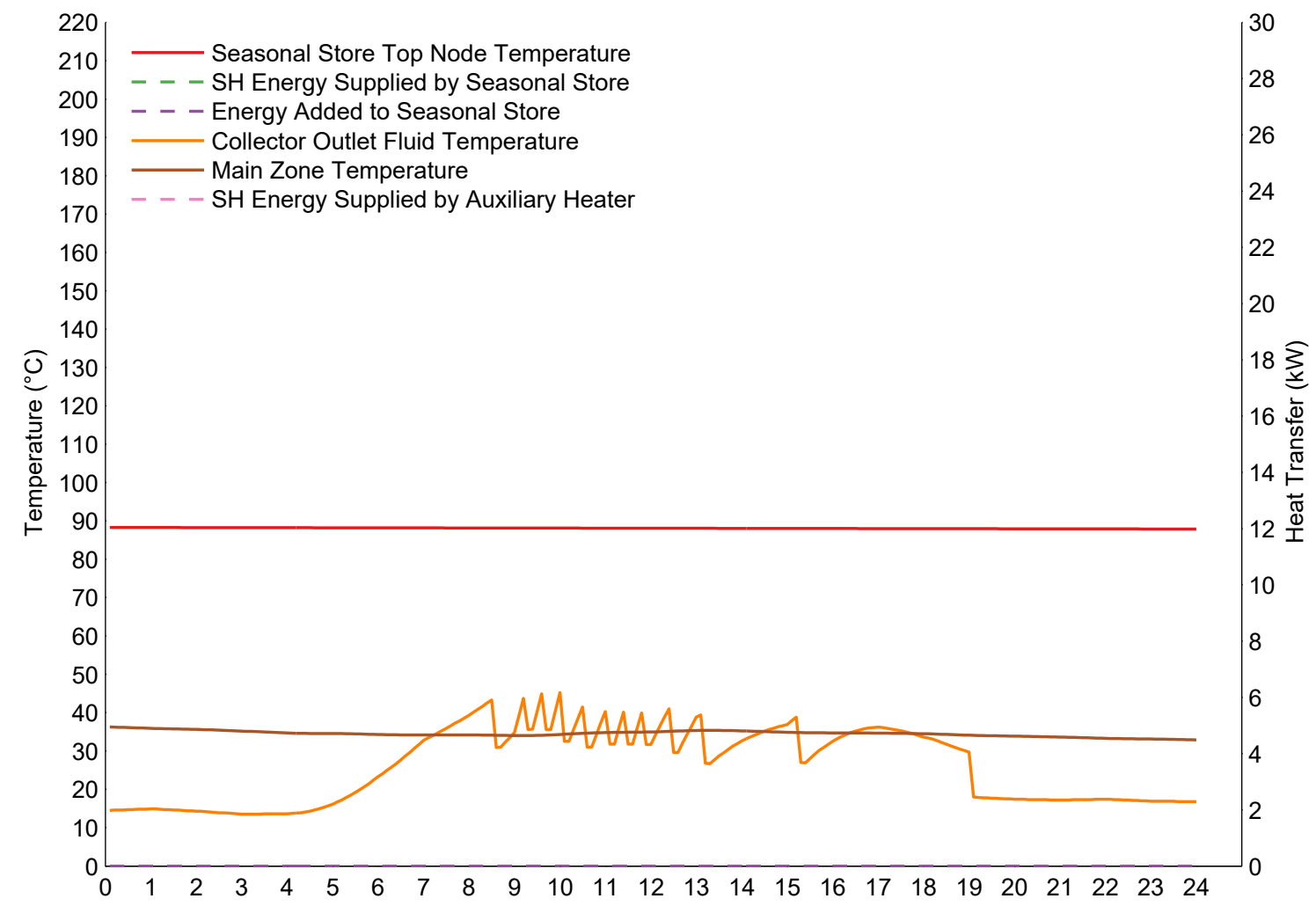

Figure 30: Cloudy Summer Day - Store Behaviour 
Figure 31 shows the DHW loads and there are five periods of DHW draws which are largely supplied by the DTES. Some auxiliary energy that is required is used to bring the DHW supply up to the $T_{\text {delivery }}^{D H W}$ of $55^{\circ} \mathrm{C}$.

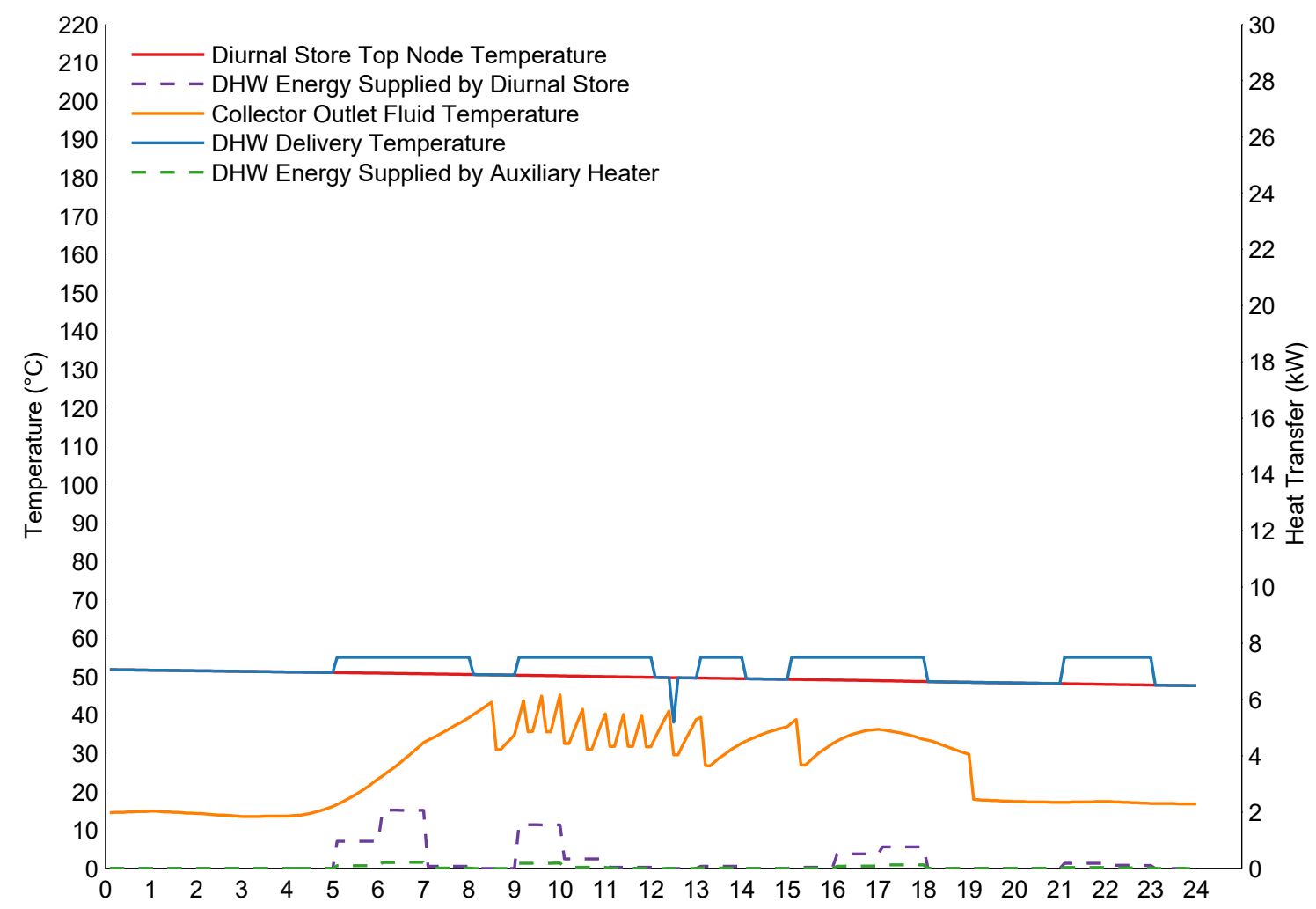

Figure 31: Cloudy Summer Day - DHW Loads

If the $\alpha$ case can't supply DHW loads on a summer day (even an overcast one) this is a good indication that increasing $V^{D T E S}$ would improve SF of the system by reducing or eliminating auxiliary energy requirements on days where the stores are nearly fully charged. Similarly, it is also likely that setting the $T_{+}^{D T E S}$ no higher than the $T_{\text {delivery }}^{D H W}$ input increases the chances that auxiliary energy is required. 
Figure 32 shows the trend of heat loss from the STES and DTES over the day. The STES maintains a level temperature state over the day and the heat loss trend shows the same behaviour.

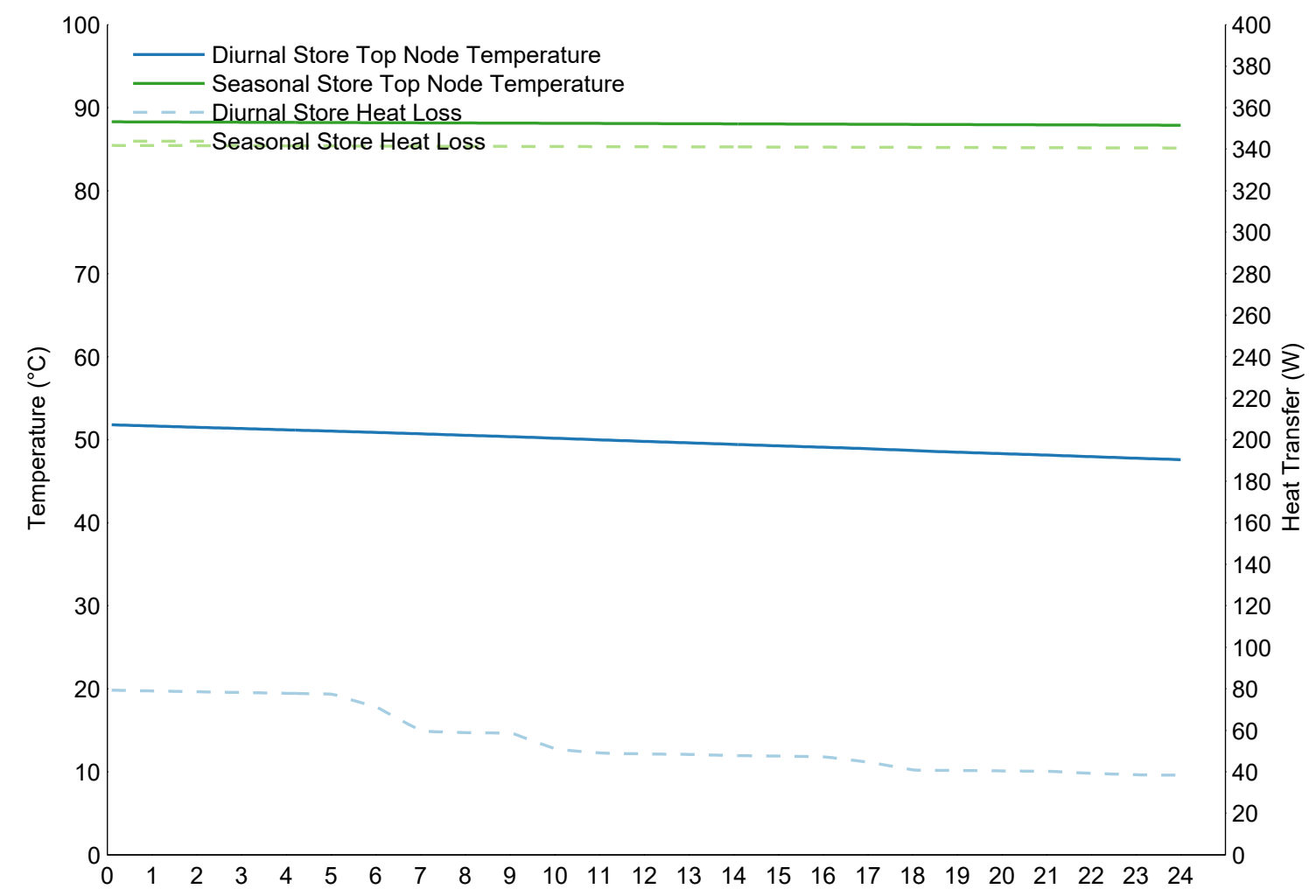

Figure 32: Cloudy Summer Day - Store Heat Loss

The DTES on the other hand tracks well with temperature until around 06h00 at which time it decreases in periods roughly correlated with the DHW draws seen in Figure 31. The cause of the varying relationship between temperature and heat loss makes more sense when the daily stratification for the DTES is considered (Figure $33 a)$. 
The thermal stratification in the DTES shown in Figure 33a is significant because the DHW draws are sent from the DTES top node and returned to the bottom node of the DTES at $10^{\circ} \mathrm{C}$ (the constant assumed temperature of the mains water supply). Whether this degree of stratification will be achieved in reality remains a question for the future planned experimental validation.

The thermally stratified behaviour shown explains the heat loss trends seen in 32. Although the top temperature of the DTES shows a steady decrease, the rest of the tank nodes show much more significant temperature decreases over the day and thus the rate of heat loss on the whole decreases more rapidly in periods roughly corresponding to the DHW draws.

The STES thermal stratification shown in Figure 33b is much more evenly distributed between the 25 nodes. The temperature profile remains steady over the day and with a $\Delta \mathrm{T}$ of $10^{\circ} \mathrm{C}$. 
(a) Diurnal

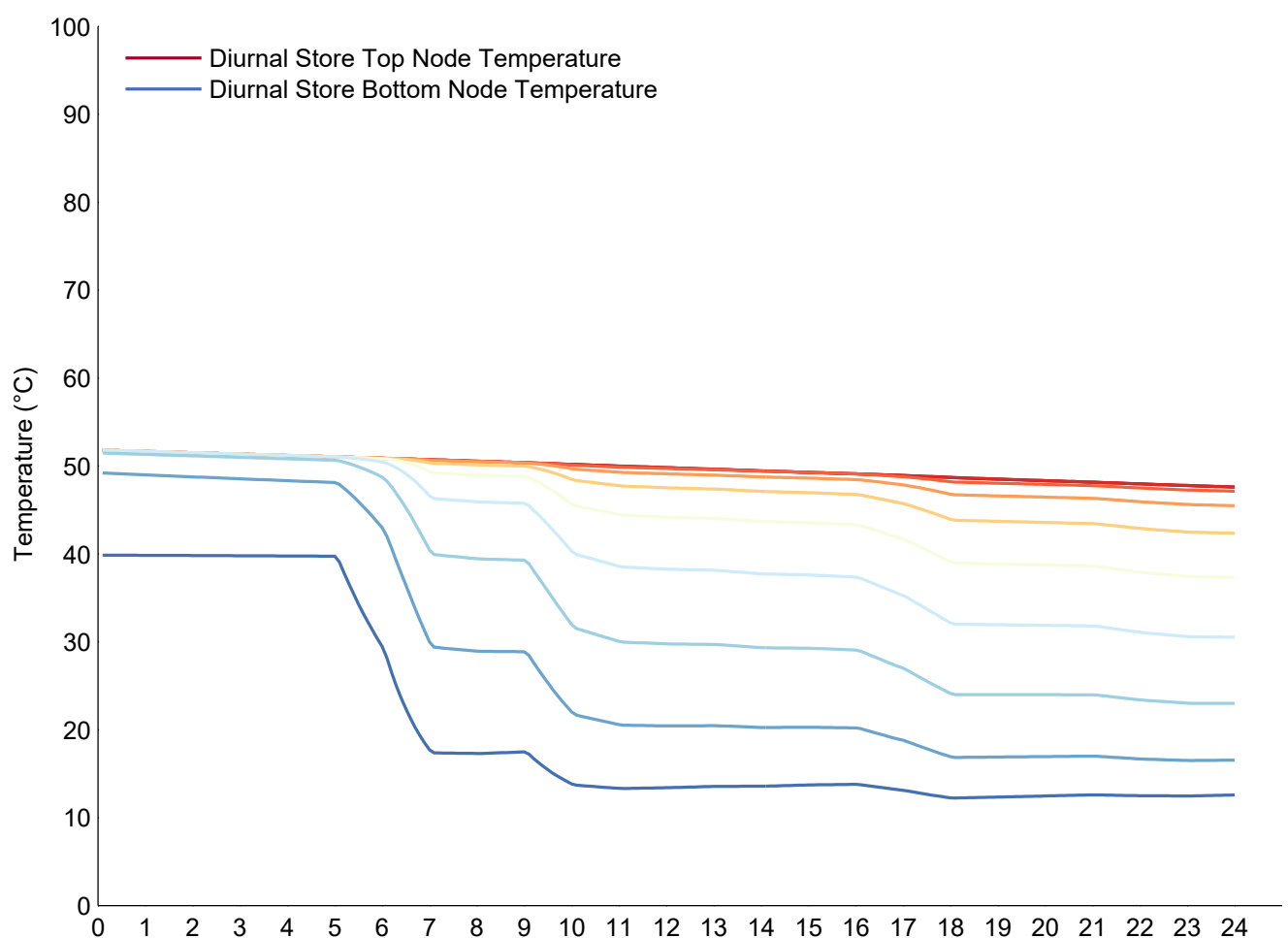

(b) Seasonal

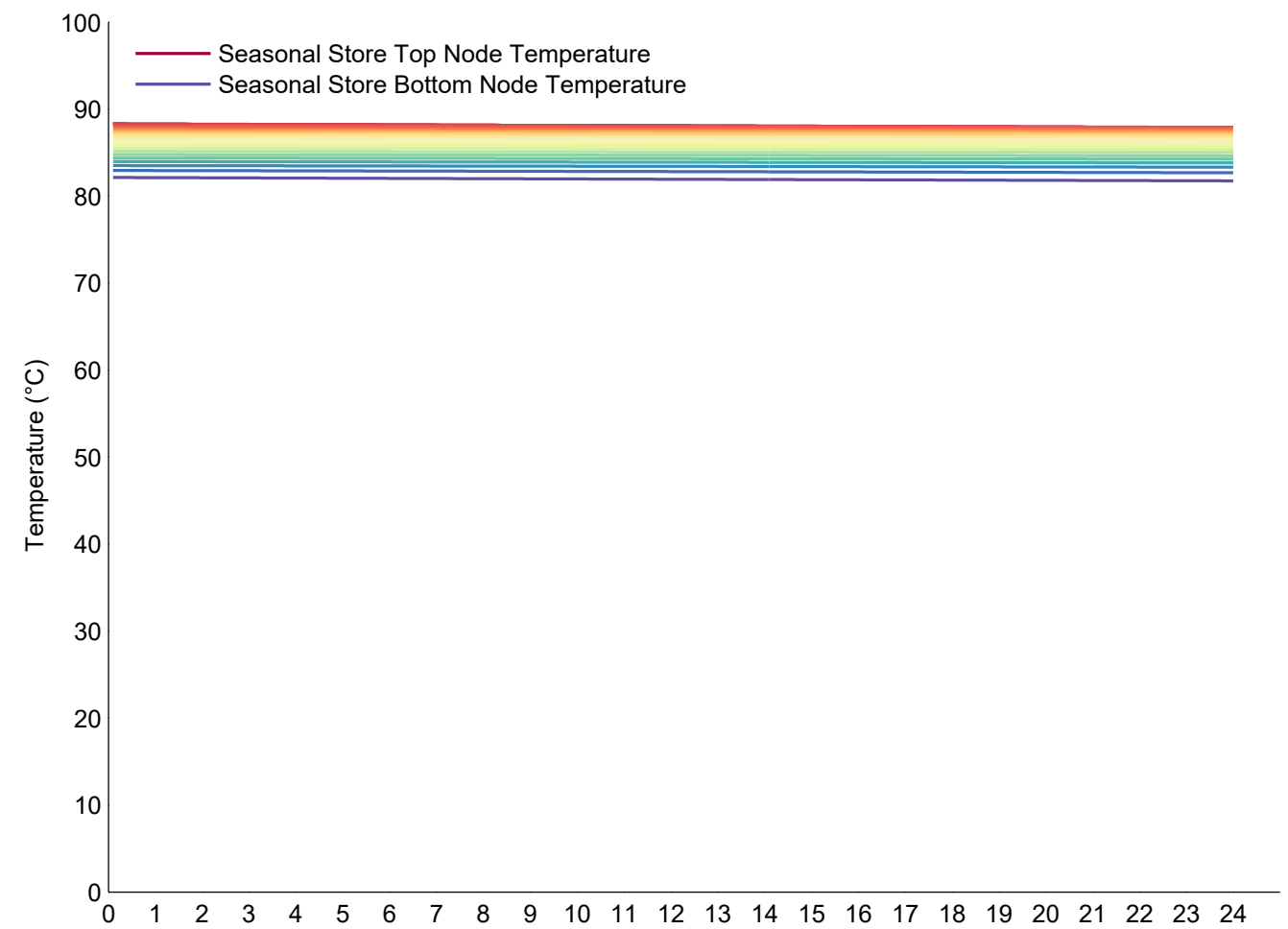

Figure 33: Cloudy Summer Day - Store Stratification 


\section{Cloudy Spring Day - 12 May}

The $12^{\text {th }}$ of May was a cloudy day with moderate temperatures around $15^{\circ} \mathrm{C}$ during the bulk of the day. The plot sets for this overcast spring day are included in Appendix A Figures $47-51 \mathrm{~b}$.

The solar radiation consisted predominantly of low-moderate levels of diffuse horizontal with only a short period of direct normal radiation between $16 \mathrm{~h} 00$ and 17h00. The $T_{\text {outlet }}^{\text {collers }}$ climbs to $90^{\circ} \mathrm{C}$.

Both stores remain charged or nearly charged throughout the day and the DTES meets nearly all DHW loads without the need for auxiliary energy as a result. The $V^{D T E S}$ is able to carry over some of the benefits of a high solar gains day but not enough to eliminate the auxiliary energy. This should improve with an increased $V^{D T E S}$.

\section{Cloudy Autumn Day - 3 October}

An overcast autumn day of the $3^{\text {rd }}$ of October has similar ambient conditions to the cloudy spring day just discussed. However, as the preceeding day did not leave the DTES charged, and with a $T_{\text {outlet }}^{\text {collectors }}$ less than $50^{\circ} \mathrm{C}$, the solar loop provides all the energy it can to the DTES between $07 \mathrm{~h} 00$ and $16 \mathrm{~h} 00$ only managing to bring the DTES up to $\sim 45^{\circ} \mathrm{C}$. This means that auxiliary energy supplemented the DTES to meet the DHW loads.

Interesetingly the STES is still fully charged at this time and if it could be used instead of the auxiliary energy during the shoulder seasons, it may not have a significant impact on the STES ability to meet the more significant SH demands in the winter. 


\section{Cloudy Winter Day - 13 January}

January $13^{\text {th }}$ has the lowest ambient temperatures $\left(-20^{\circ} \mathrm{C}\right)$ and lowest solar availability of any of the days yet discussed. Consequently, the $T_{\text {outlect }}^{\text {collers }}$ does not even reach $25^{\circ} \mathrm{C}$.

With the DTES dropping below $40^{\circ} \mathrm{C}$ it relies heavily on auxiliary energy to meet the DHW demands. STES is also at a relatively low temperature by this time of the year with the top of the store below $50^{\circ} \mathrm{C}$ and a $\Delta T$ of $20^{\circ} \mathrm{C}$ with the bottom of the store. Yet, the STES still manages to provide all the SH energy indicating that the $V^{S T E S}$ is at least adequately sized.

\section{Sunny Winter Day - 12 January}

January 12 th is a sunny winter day. Figure 34 show consistent direct normal solar radiation over the day with a maximum of near $900 \mathrm{~W} / \mathrm{m}^{2}$ along with low amounts of diffuse horizontal solar radiation.

The temperature of the solar collector fluid at the outlet of the collector array in Figure 34 stays around $50^{\circ} \mathrm{C}$ despite the high solar gains. Perhaps the very low ambient temperatures throughout the day of around $-20^{\circ} \mathrm{C}$ contribute to this but it is primarily the store charging behaviour that explains the temperature profile seen here. These results are discussed next. 


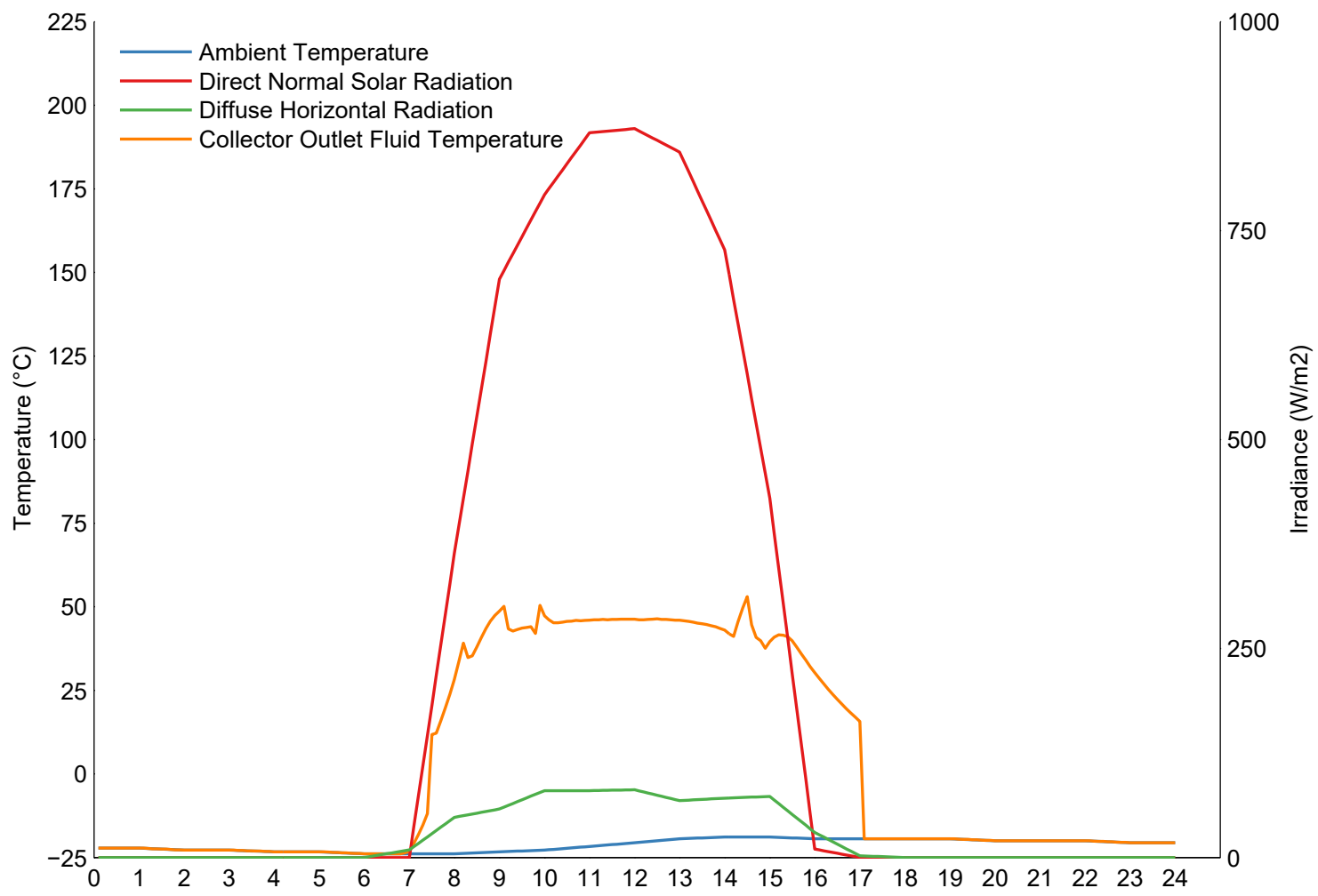

Figure 34: Sunny Winter Day - Ambient Temperature and Irradiance

The DTES is very active on a winter day with a low ambient temperature and good solar availability as seen in Figure 35a. It begins charging as solar availability increases around 08h00 and continues charging until the DTES top node temperature reaches $T_{\text {outlet }}^{\text {collectors. }}$.

Similarly in Figure 35b, the STES starts charging around 09h00 and continues to receive $\sim 16 \mathrm{~kW}$ of energy throughout a good part of the available solar period.

The energy added to the DTES and STES together help to explain the limited rise in $T_{\text {outlet }}^{\text {collectors }}$, although again, it may be that with the use of a variable speed solar loop pump, higher temperatures could be achieved. 
The STES provides all the SH in the morning but the DTES contributes to some of the $\mathrm{SH}$ in the afternoon and the zone temperature setpoint of $20^{\circ} \mathrm{C}$ is maintained.

Given that the DTES has charging priority in the control algorithm being used, it may seem odd that the STES has far more energy delivered to it despite having very similar top node temperatures. The different thermal stratification profiles of the two stores is behind this result as is seen in Figures 36a and 36b.

The relatively small $V^{D T E S}$ means the entire tank can be raised to $T_{+}^{D T E S}$ with adequate solar availability even on a cold winter day with SH and DHW loads to meet (Figure 36a). As a result, once the average DTES temperature reaches $T_{\text {outlet }}^{\text {collectors }}$, the control logic allows the STES to start charging.

It continues sending energy throughout the day because the relatively large $V^{S T E S}$ takes much longer to respond and the average store temperature never reaches $T_{\text {outlet }}^{\text {collectors }}$ as Figure $36 \mathrm{~b}$ shows.

The DTES thermal stratification (Figure 36a) becomes pronounced after it stops being charged in the early evening and continues to meet DHW and SH loads. This is further indication that a large $V^{D T E S}$ would be beneficial as greater thermal mass would result in more steady DTES behaviour rather than rapid response. A slower responding system would take longer to charge but would help the DTES meet loads occurring when there is no solar availability. 
(a) Diurnal

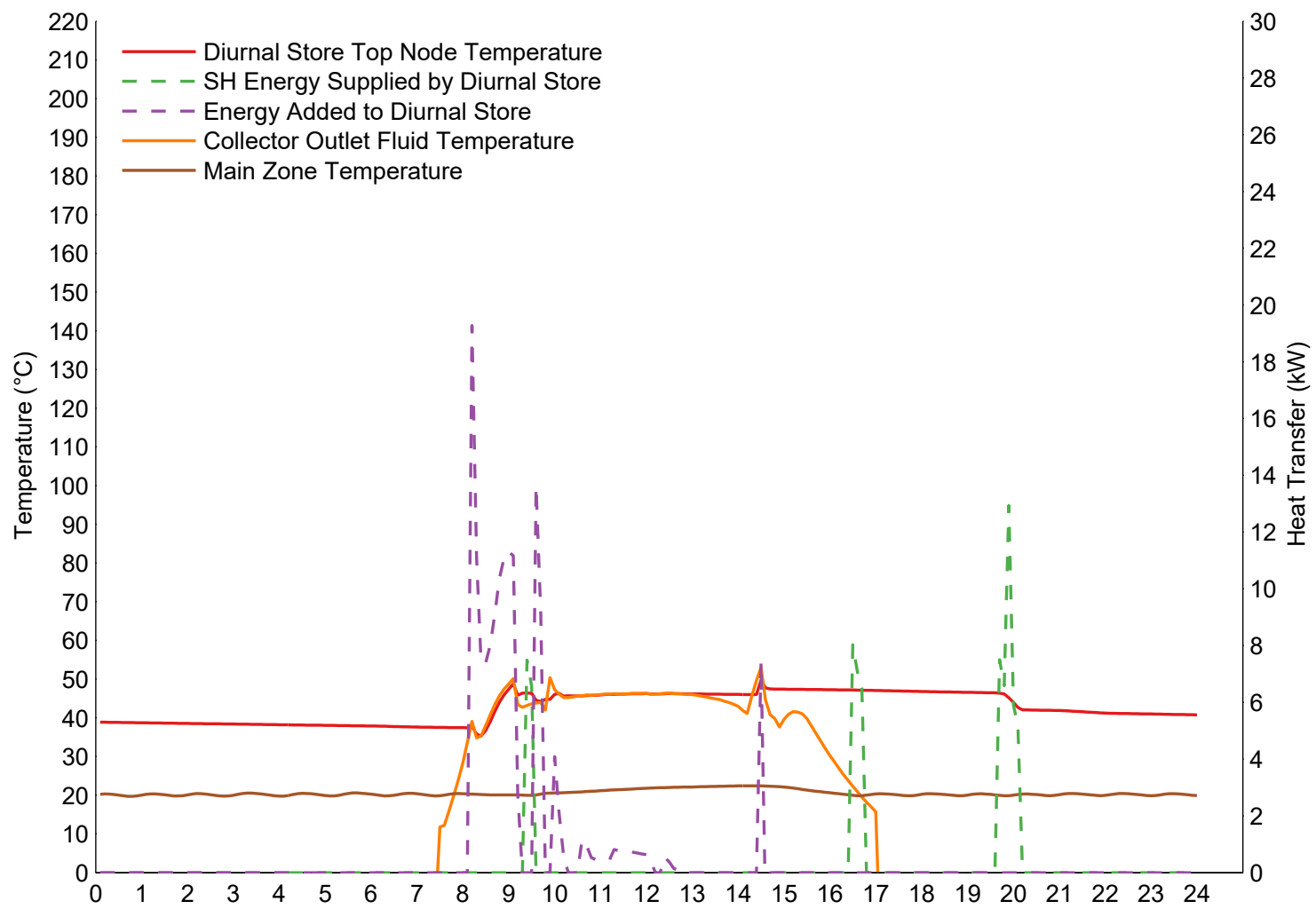

(b) Seasonal

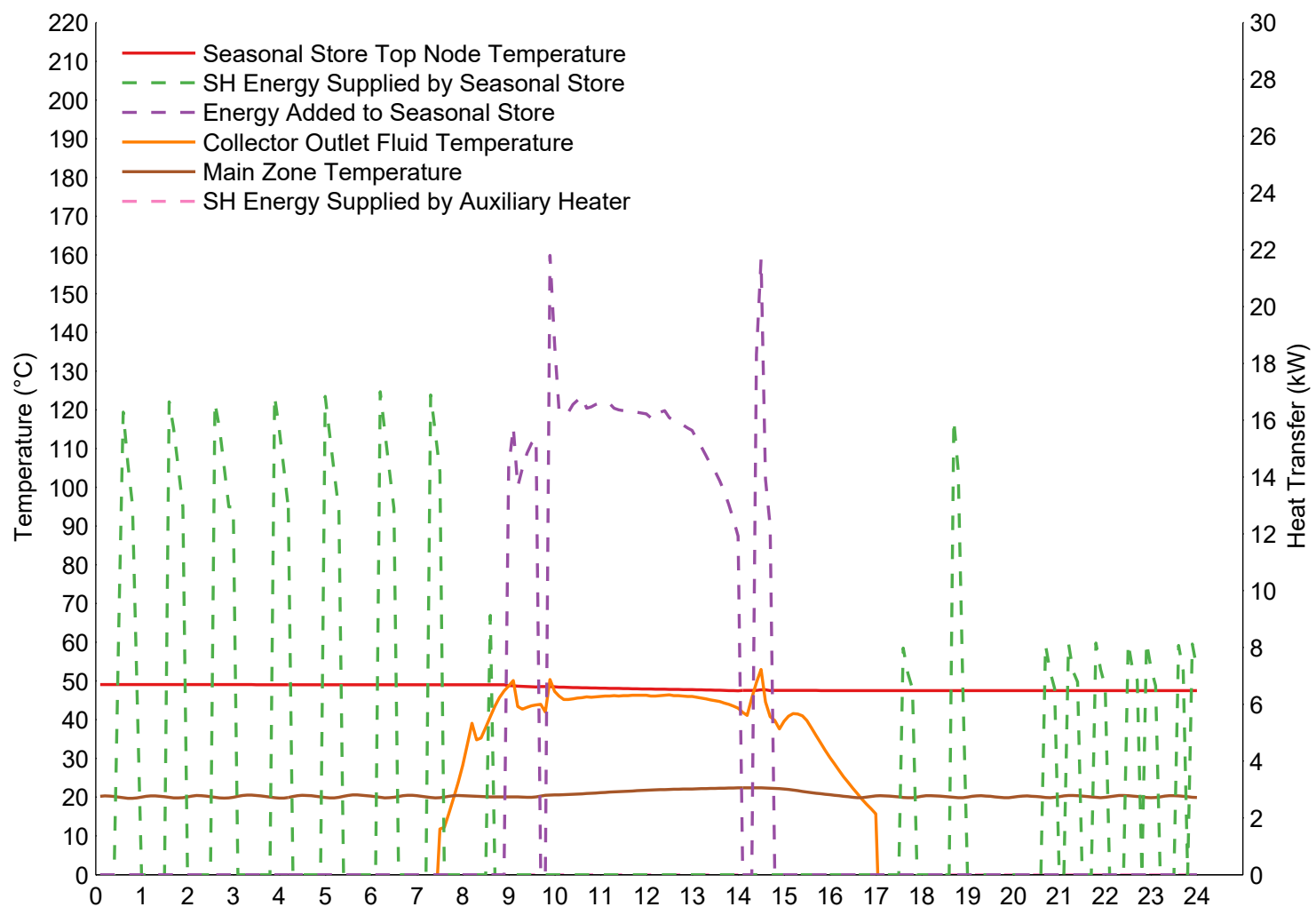

Figure 35: Sunny Winter Day - Store Behaviour 
(a) Diurnal

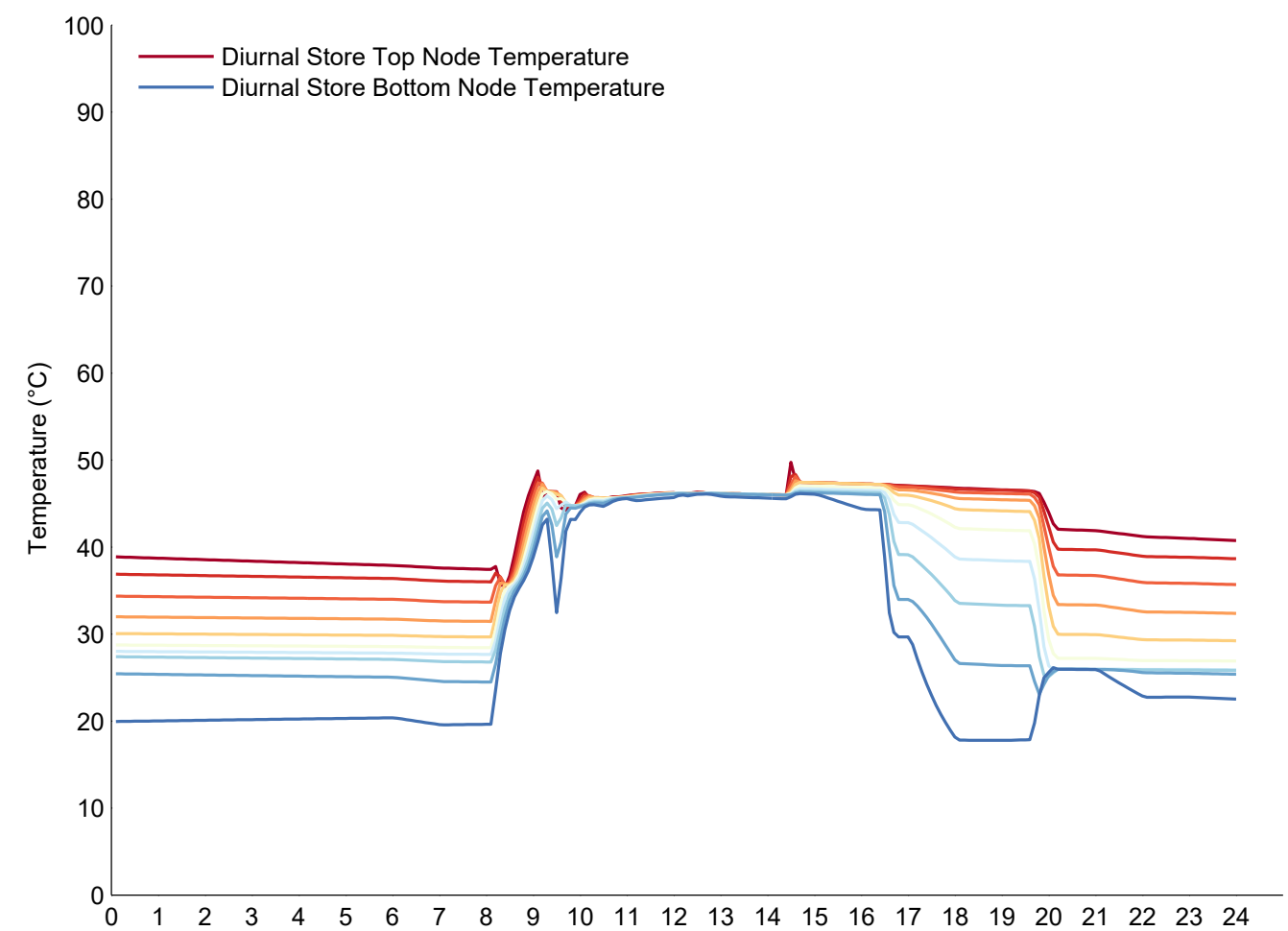

(b) Seasonal

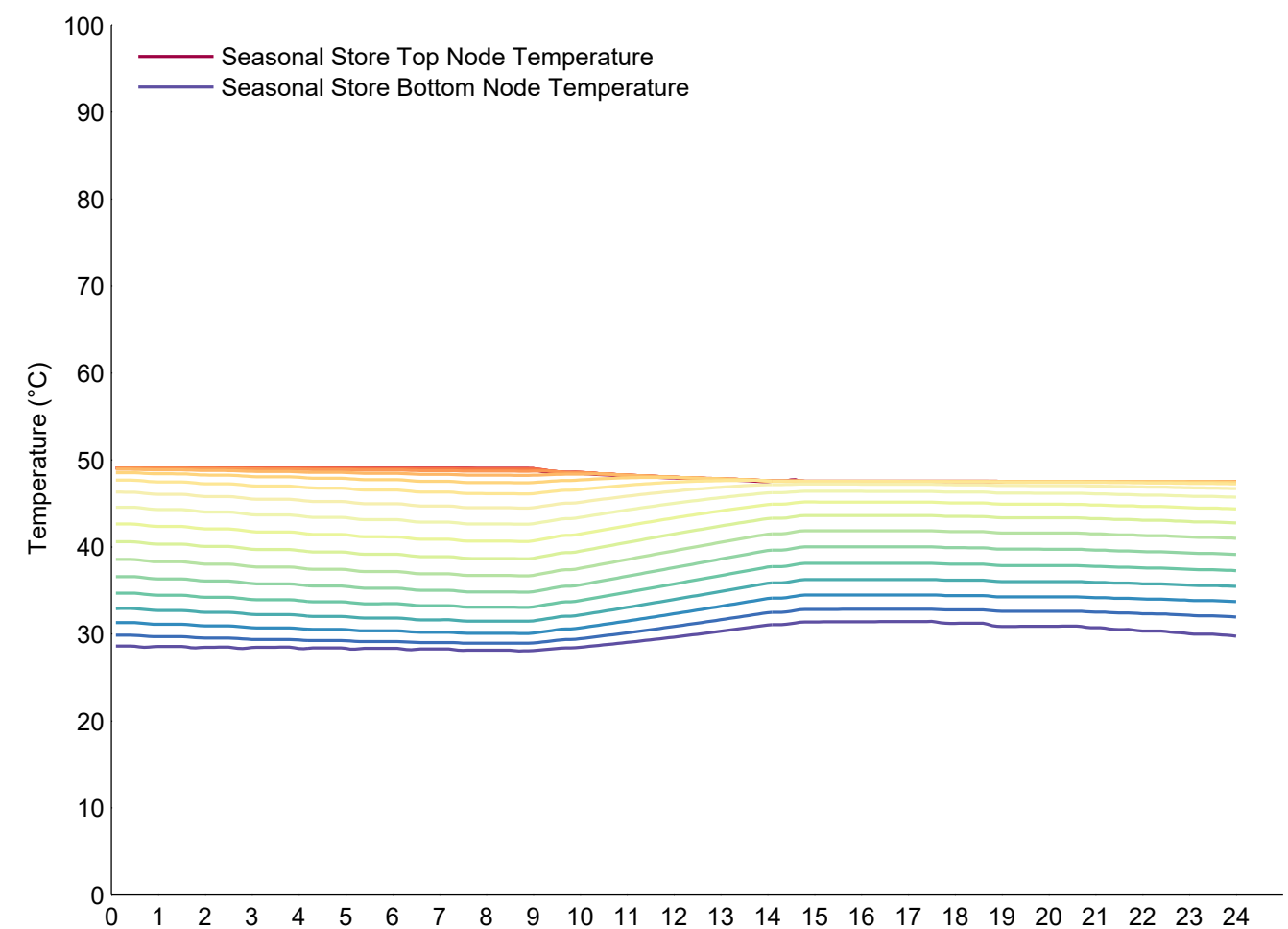

Figure 36: Sunny Winter Day - Store Stratification 
There are numerous DHW draws over the day, all of which require some auxiliary energy use to meet the $T_{\text {delivery }}^{D H W}$ requirement. The magnitude of the draws is fairly low throughout the day with the exception of $17-18 \mathrm{~h} 00$.

If anything, this further reinforces the need for increasing $V^{D T E S}$ as a larger thermal mass may have allowed the tank to start the day at a temperature closer to $T_{\text {delivery }}^{D H W}$ if there was more solar availability the previous day. This would also be more likely if the $T_{+}^{D T E S}$ was $10-20^{\circ} \mathrm{C}$ higher than $T_{\text {delivery }}^{D H W}$ as well.

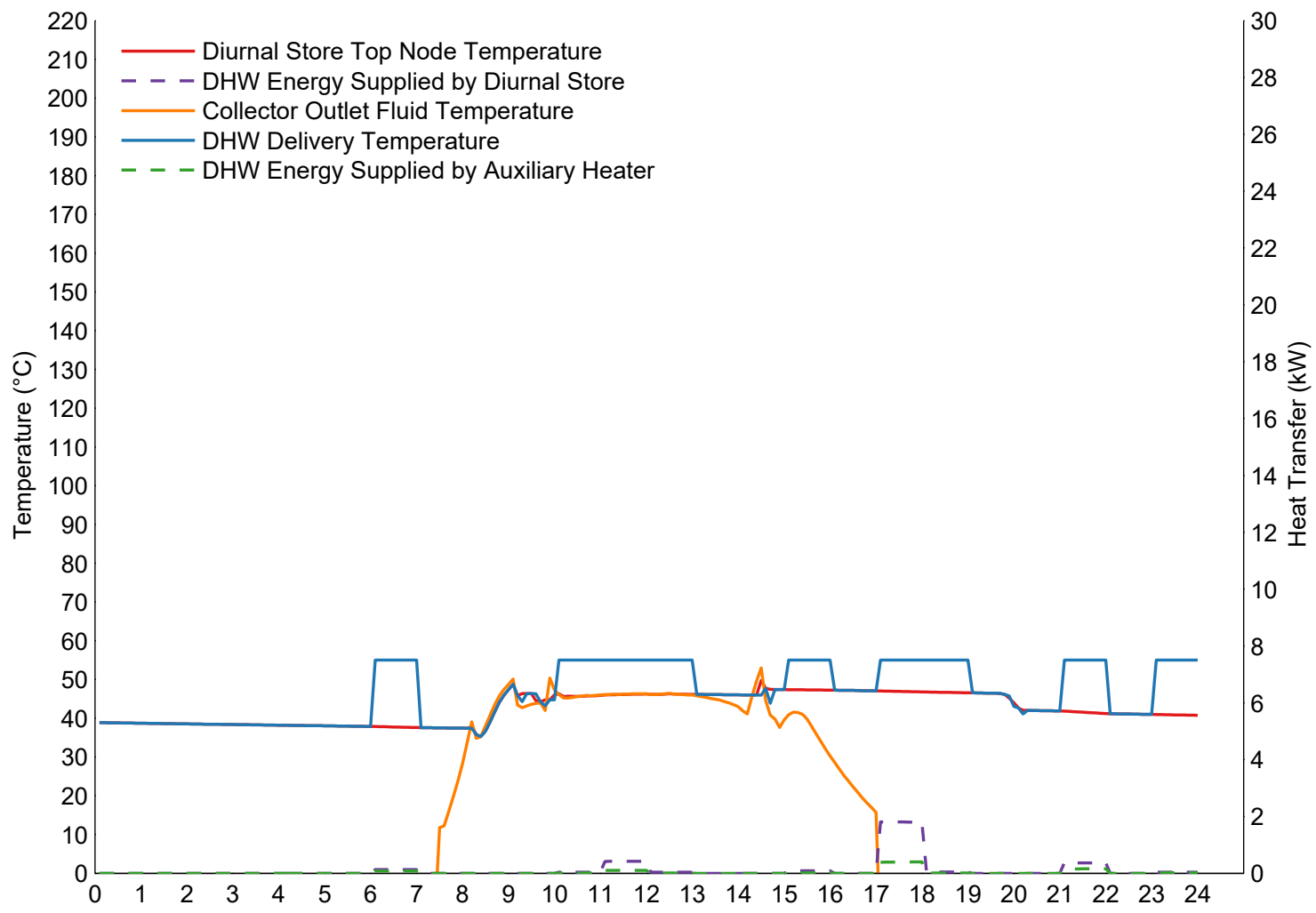

Figure 37: Sunny Winter Day - DHW Loads 
The DTES heat loss trend relates closely to the top node temperature and the behaviour is otherwise unremarkable.

The STES on the other hand shows increasing heat loss later in the day despite a drop in top node temperature. This is the result of consistent charging over the day which brings the average tank temperature up despite the top node seeing a decrease.

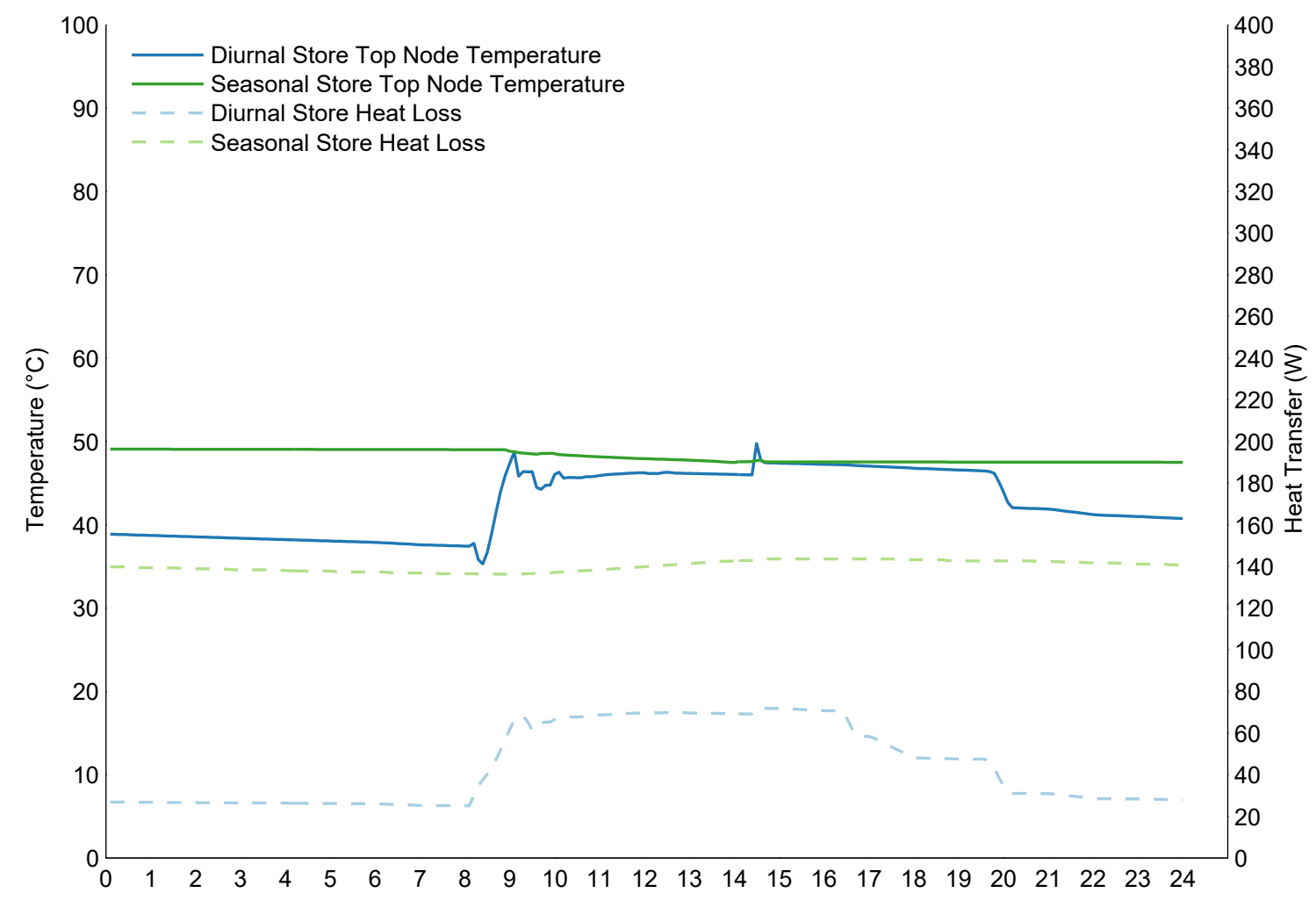

Figure 38: Thermal Store Heat Loss 


\section{Sunny Spring Day - 6 May}

May 6th had sunny spring conditions with nearly $1000 \mathrm{~W} / \mathrm{m}^{2}$ of direct normal radiation and a top $T_{\text {outlet }}^{\text {collects }}$ of $\sim 170^{\circ} \mathrm{C}$. (The plot set for this day is contained in Appendix A.4 Figures 62-66b.)

These high collector temperatures are allowed in the simulation because no antistagnation system is modelled for the collectors. The model assumes that the solar collector loop is activated whenever there is useable solar radiation to collect whether the stores are charging or not as this does not impact the stores or loads of interest for this work.

In reality, the system would normally dissipate heat if fluid temperatures became too hot and risked damaging components such as pumps. The Urbandale Centre for Home Energy Research does have a heat rejection system for hot sunny days when the Bio-Green heat transfer fluid would otherwise boil. In fact, the fluid can handle stagnation although it will eventually degrade the fluid's performance characteristics.

These conditions allow the DTES and STES to be charged in tandem over the day. The high $T_{\text {outlet }}^{\text {collers }}$ drops suddenly over the day as between 10-20 kW of heat are sent to either the DTES or the STES. As both stores remain essentially charged

during the day with the DTES temperature dropping below $T_{\text {delivery }}^{D H W}$ only a couple times and requires a small auxiliary input.

The store temperature profiles show that the DTES is subject to overcharging when the solar array is providing such sudden and significant heat additions with the top of the store reaching around $60^{\circ} \mathrm{C}$. With high solar availability, the system should be able to charge the DTES such that no auxiliary energy is required to supply $\mathrm{SH}$. However, as the DTES is only being charged up to the same $55^{\circ} \mathrm{C}$ temperature 
the DHW must be delivered at, the DTES requires auxiliary heat whenever it is not actively being charged.

\section{Sunny Summer Day - 13 August}

A hot day like August $13^{\text {th }}$ is not vastly different than the spring day just discussed. There was high direct normal radiation (more than $750 \mathrm{~W} / \mathrm{m}^{2}$ most of the day) and $T_{\text {outlet }}^{\text {collects }}$ climbed above $150^{\circ} \mathrm{C}$ with a moderately warm ambient temperature of $\sim 20^{\circ} \mathrm{C}$. The zone temperature climbed towards $30^{\circ} \mathrm{C}$ which again, is not a surprise given the large amount of south glazing.

Both thermal stores receive charging energy over the day and the DHW demand is met nearly entirely by the DTES. The DTES continues to have a much more pronounced thermal stratification than the STES and this is especially so when the store is charged. As the solar collector loop heat is transferred to the top node of the DTES whilst the energy to supply the DHW load is pulled from the bottom of the tank and returned to the bottom of the tank at mains temperatures. This causes a $\Delta T$ of $40^{\circ} \mathrm{C}$ which is likely larger than will actually be achieved but the extent to which mixing occurs will be part of the experimental calibration of this model. If multiple tanks are used to achieve a larger $V^{D T E S}$ however, mixing could be significantly reduced perhaps.

\section{Sunny Autumn Day - 14 October}

On the sunny autumn day of October $4^{\text {th }}$, there is very good solar availability, primarily direct normal radiation of $900 \mathrm{~W} / \mathrm{m}^{2}$ or more resulting in $T_{\text {outlet }}^{\text {collects }}$ of $125^{\circ} \mathrm{C}$. Significant amounts of energy are added to both stores as a result of the thermal 
stratification reducing the average tank temperatures. The DTES has a $\Delta T$ of $40^{\circ} \mathrm{C}$ at the beginning of the day, the tank becomes more mixed during charging periods with the whole DTES reaching a temperature closer to $50^{\circ} \mathrm{C}$.

The $T_{\text {outlet }}^{\text {collects }}$ dropping below the top temperature of the DTES which then requires auxiliary heat around $12 \mathrm{~h} 00$. This is likely remedied with a higher $T_{+}^{D T E S}$.

\subsection{3 $\alpha$ Case Summary}

The performance of the $\alpha$ case on an annual and daily basis indicate that a larger $V^{D T E S}$ and a higher $T_{+}^{D T E S}$ are likely to improve system performance. The higher thermal mass will allow the system to better meet loads that occur when there is no solar availability. Additionally, charging the DTES to a higher temperature will prevent the inevitable cool down from heat loss or DHW draws from neccessitating auxiliary energy almost immediately.

Although the SF performance of the $\alpha$ case is not optimal, the system did meet the DHW and SH demands successfully. The $\alpha$ case achieved an overall annual SF of 0.91 .

Additional model features that can be left as recommendations for future work include a variable speed solar loop pump. This would help increase $T_{\text {outlet }}^{\text {collers }}$ on cloudy days and decrease it on sunny days when the stores are charged.

It remains to be determined which parameters have the greatest impact on system performance. This is the focus of the next section which will discuss the results of a parametric analysis to refine the $\alpha$ case parameters. 


\subsection{Parametric Results}

To investigate the impact of each parameter selected for the $\alpha$ case, the inputs in Table 12 were simulated parametrically. That is, one parameter was varied at a time over a range, whilst all other inputs remained constant to observe the resulting impacts on system performance. A colour key is used to more easily identify the parameter being varied.

Table 12: Parametric Simulation Cases

\begin{tabular}{lccl}
\multicolumn{2}{l}{ ParameterUnit } & $\alpha$ Case & Values \\
\hline \hline$V^{S T E S}$ & $\mathrm{~m}^{3}$ & 35 & $20,25,30,40,45$ \\
$T_{+}^{S T E S}$ & ${ }^{\circ} \mathrm{C}$ & 90 & 70,80 \\
$V^{D T E S}$ & $\mathrm{~L}$ & 450 & 900,1350 \\
$T_{+}^{\text {DTES }}$ & ${ }^{\circ} \mathrm{C}$ & 55 & $65,75,85,95$ \\
$T_{\text {cutoff }}^{\text {DTES }}$ & ${ }^{\circ} \mathrm{C}$ & 42 & $40,45,50,55$
\end{tabular}

Each set of parametric cases is assigned a letter for ease of reference, lowercase for diurnal parameter variations and uppercase for seasonal parameter variations. The $\alpha$ system inputs are the a benchmark for the performance of each parametric change. The inputs for each case are summarised in Table 13.

The performance of the system resulting from each input change is most useful when viewed relative to the performance of the other parametric cases and the $\alpha$ case. To enable comparison of all of these cases together, the performance of each system is presented in Figure 39 as a dot plot. 
Table 13: Parametric Cases Inputs

\begin{tabular}{cccccc} 
Case & $V^{S T E S}$ & $V^{D T E S}$ & $T_{+}^{S T E S}$ & $T_{+}^{\text {DTES }}$ & $\begin{array}{c}T_{\text {cutoff }}^{\text {DTES }} \\
{ }^{\circ} \mathrm{C}\end{array}$ \\
\hline \hline $\mathrm{A}$ & $\mathrm{m}^{3}$ & $\mathrm{~L}$ & ${ }^{\circ} \mathrm{C}$ & ${ }^{\circ} \mathrm{C}$ & 42 \\
$\mathrm{~B}$ & 20 & 450 & 90 & 55 & 42 \\
$\mathrm{C}$ & 30 & 450 & 90 & 55 & 42 \\
$\mathrm{D}$ & 35 & 450 & 70 & 55 & 42 \\
$\mathrm{E}$ & 35 & 450 & 80 & 55 & 42 \\
$\mathrm{G}$ & 40 & 450 & 90 & 55 & 42 \\
$\mathrm{H}$ & 45 & 450 & 90 & 55 & 42 \\
$\alpha$ & 35 & 450 & 90 & 55 & 42 \\
$\mathrm{a}$ & 35 & 1350 & 90 & 55 & 42 \\
$\mathrm{~b}$ & 35 & 900 & 90 & 55 & 42 \\
$\mathrm{~d}$ & 35 & 450 & 90 & 65 & 42 \\
$\mathrm{e}$ & 35 & 450 & 90 & 75 & 42 \\
$\mathrm{f}$ & 35 & 450 & 90 & 85 & 42 \\
$\mathrm{~g}$ & 35 & 450 & 90 & 95 & 42 \\
$\mathrm{~h}$ & 35 & 450 & 90 & 55 & 40 \\
$\mathrm{i}$ & 35 & 450 & 90 & 55 & 45 \\
$\mathrm{j}$ & 35 & 450 & 90 & 55 & 50 \\
$\mathrm{k}$ & 35 & 450 & 90 & 55 & 55 \\
& & & & &
\end{tabular}

The dot plot shows the SF along the $\mathrm{x}$-axis for each lettered parametric case simulated on the y-axis. Each dot is colour coded according to the colour key. The plot allows for observation of patterns in overall performance differences between values of a certain parameter, and comparisons between different parameters and with the $\alpha$ case. 


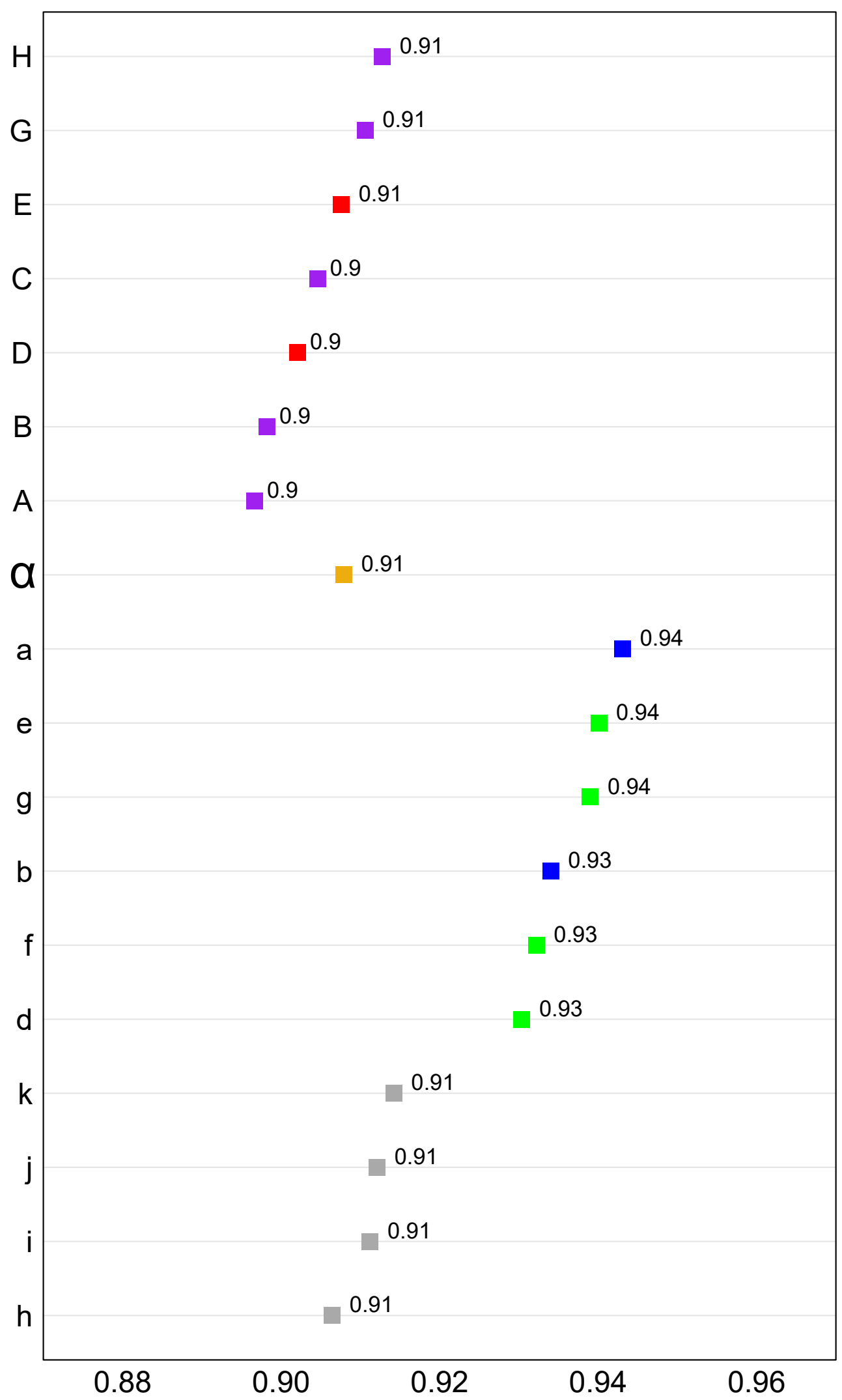

Figure 39: Annual Average Solar Fraction for Seasonal \& Diurnal Cases 
For both the diurnal and the seasonal stores, increasing the storage volume not only improves the SF, it provides more improvement to SF than any other varied parameter considered here.

The largest seasonal store volume (case H) has a SF of 0.91 compared to 0.90 for the smallest volume (case A, $20 \mathrm{~m}^{3}$ ) considered, and 0.91 for the $\alpha$ case.

Increasing $V^{D T E S}$ from the $\alpha$ case $(450 \mathrm{~L})$ to the largest volume considered (case a, $1350 \mathrm{~L})$ results in an increase of SF of 0.91 to 0.94 .

In the case of the seasonal storage, there is a single percentage point difference between the $\mathrm{SF}$ for a $70^{\circ} \mathrm{C}$ charging setpoint (case D) vs the $\alpha$ case $90^{\circ} \mathrm{C}$. The $\mathrm{SF}$ of the $80^{\circ} \mathrm{C}$ setpoint (case E) however shows no benefit when increased to $90^{\circ} \mathrm{C}$. Likely the $90^{\circ} \mathrm{C}$ setpoint has more standing losses and the lower temperature setpoint can provide sufficient $\Delta T$ to satisfy the DHW and SH delivery temperatures.

The diurnal setpoint results in a more significant SF difference between the $\alpha$ case of $55^{\circ} \mathrm{C}(0.91)$ and $75^{\circ} \mathrm{C}$ (case e, 0.94). Notably, the performance of a $75^{\circ} \mathrm{C}$ diurnal setpoint temperature is essentially equivalent to a $95^{\circ} \mathrm{C}$ setpoint.

A $40^{\circ} \mathrm{C} T_{\text {cutoff }}^{D T E S}$ (case $\mathrm{h}$ ) has a SF of 0.91 but this can be increased slightly by setting the $T_{\text {cutoff }}^{D T E S}$ to $55^{\circ} \mathrm{C}$ (case $\mathrm{k}$ ). For the purposes of this parametric analysis, the $T_{\text {cutoff }}^{D T E S}$ range is limited by the $\alpha$ case $T_{+}^{D T E S}$.

These observations will be considered to design the $\beta$ case. At a minimum the $\beta$ should improve on the $\alpha$ case. However, comparison with these parametric results as well will better inform the ultimate recommendations of this work. The inputs and results of the $\beta$ case will be investigated in the next section. 


\section{4 $\beta$ Case Results}

Based on the results from the parametric study and the $\alpha$ case, the following $\beta$ case should provide a whole system improvement to system SF performance. The results of the $\beta$ case are presented in this section. Then all case metrics considered will be compared and summarised in more detail including additional performance beyond $\mathrm{SF}$ and an overall performance ranking.

From the $\alpha$ and parametric results, it seemed a larger $V^{D T E S}$ would improve system performance by making the system more resiliant on days of low solar availability. Further, with an unchanged $T_{\text {delivery }}^{D H W}$, the amount of auxiliary energy inputs is expected to decrease as $T_{+}^{D T E S}$ increases. It will provide a temperature band in which the DTES can still meet DHW demands even when it is not fully charged.

The STES is a fixed quantity in reality and adequately sized, so $V^{S T E S}$ will be left unchanged. The best performing $T_{+}^{D T E S}$ and $T_{+}^{S T E S}$ from the parametric analyses will be used here. A summary of the $\beta$ case inputs is in Table 14 .

Table 14: $\beta$ Case

\begin{tabular}{lccc} 
Parameter & $\alpha$ Case & $\beta$ Case & Unit \\
\hline \hline$V^{D T E S}$ & 450 & 1350 & $\mathrm{~L}$ \\
$T_{\text {cutoff }}^{\text {DTES }}$ & 42 & 55 & ${ }^{\circ} \mathrm{C}$ \\
$T_{+}^{D T E S}$ & 55 & 75 & ${ }^{\circ} \mathrm{C}$ \\
$T_{\text {delivery }}^{\text {DHW }}$ & 55 & 55 & ${ }^{\circ} \mathrm{C}$ \\
$V^{\text {STES }}$ & 35 & 35 & $\mathrm{~m}^{3}$ \\
$T_{+}^{S T E S}$ & 90 & 80 & ${ }^{\circ} \mathrm{C}$
\end{tabular}




\subsubsection{Annual Performance}

The solar and auxiliary energy end-use for the $\alpha$ case and $\beta$ case are provided in Figures 40a and 40b for easy comparison. These plots show that the total amount of supplied SH, particularly in January, differs between $\alpha$ and $\beta$ cases. The $\beta$ case with higher DTES temperatures maintains the zone temperatures more consistently. This and the constant speed pump results in a different on-off cycling pattern for SH delivery. An example of this is seen in Appendix A.7 containing a side-byside comparison of the STES behaviour for each case on a sunny winter day. It is important that future work involve fine tuning the system performance for the selected system.

$E_{S H}^{D T E S}$ becomes negligible in January for the $\beta$ case. This is primarily due to the increase in the $T_{\text {cutoff }}^{D T E S}$. The DTES temperatures are lowest in January and February and therefore can't meet the $T_{\text {cutoff }}^{D T E S}$ requirement to provide SH. $E_{S H}^{D T E S}$ increases noticeably in March for the $\beta$ case owing to the higher $T_{+}^{D T E S}$ and larger $V^{D T E S}$.

The $T_{+}^{S T E S}$ reduction to $80^{\circ} \mathrm{C}$ in the $\beta$ case has resulted in a $-\Delta T$ of $\sim 10-15^{\circ} \mathrm{C}$ for the top, middle, and bottom nodes throughout the year as well (see Figures 41a and 41b).

As expected, the DTES top node temperature is greater as the $T_{+}^{D T E S}$ was increased, but the $\beta$ case middle and bottom nodes are on average greater than the $\alpha$ case as well (see Figures $42 \mathrm{a}$ and $42 \mathrm{~b}$ ). Whilst auxiliary requirements are not eliminated, the $E_{D H W}^{A U X}$ use has decreased. In January, where the highest SH demands are seen, the $E_{S H}^{A U X}$ demands are greater relative to the $\alpha$ case. 
(a) $\alpha$ Case

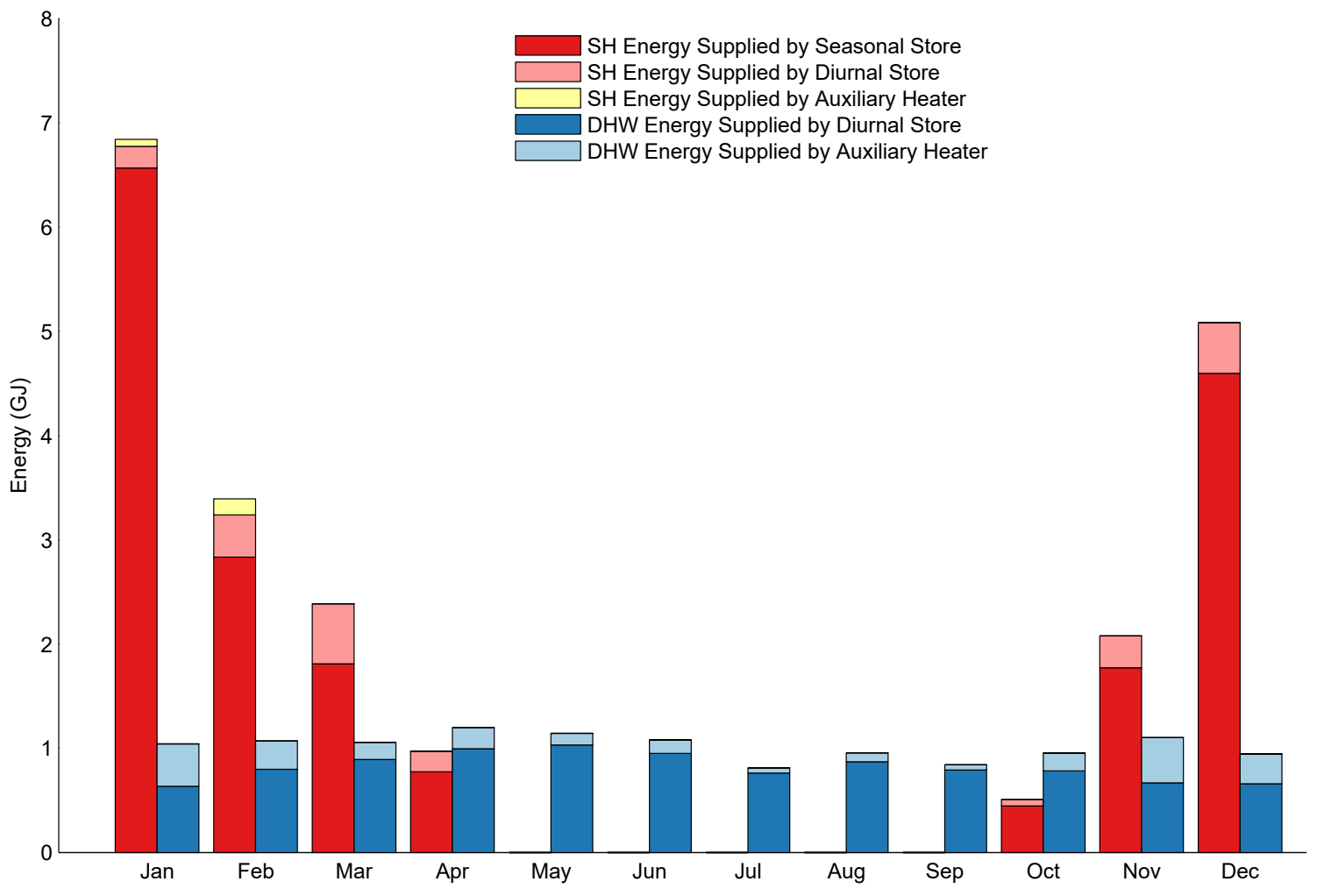

(b) $\beta$ Case

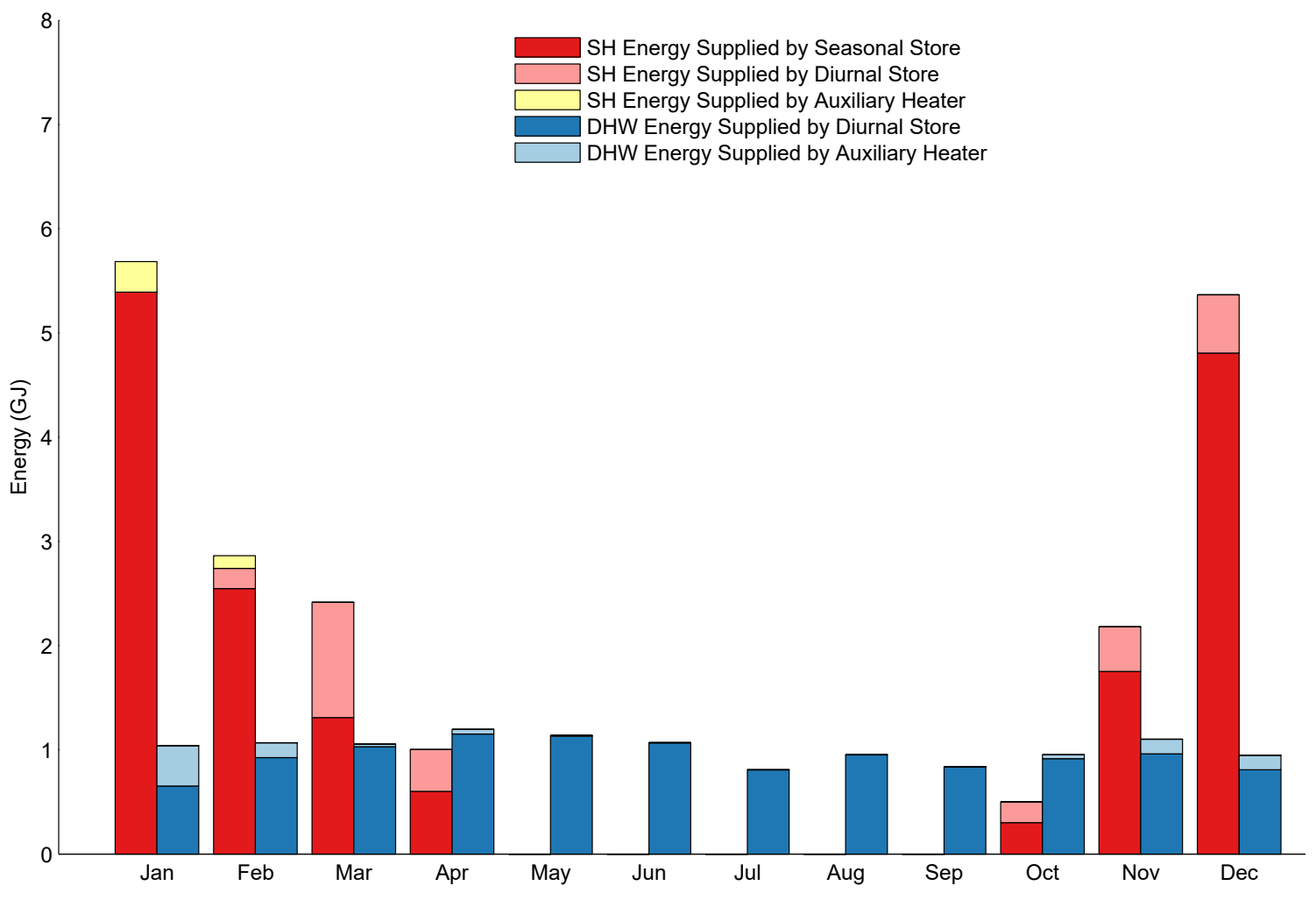

Figure 40: Energy Supplied by End-Use 
(a) $\alpha$ Case

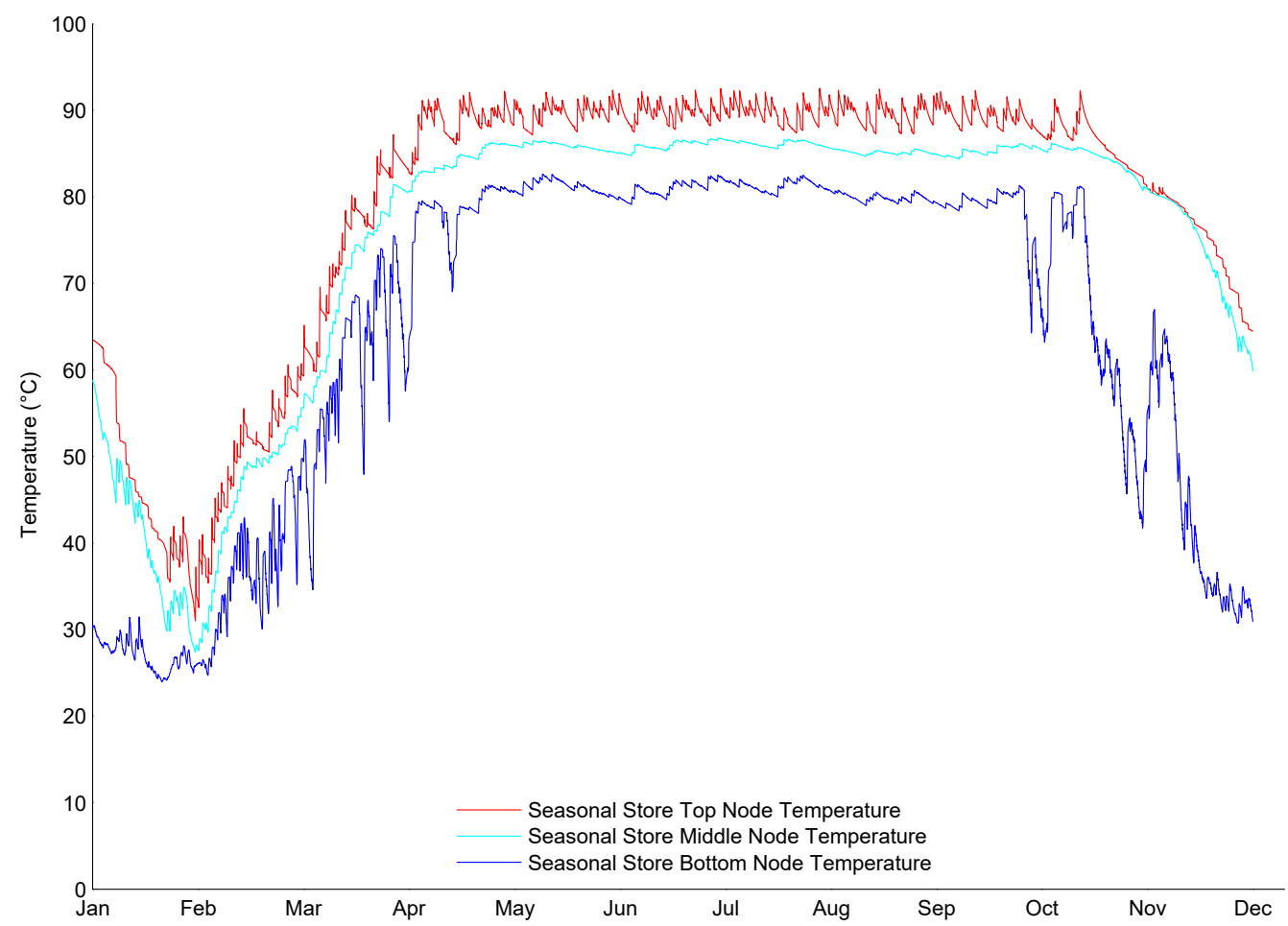

(b) $\beta$ Case

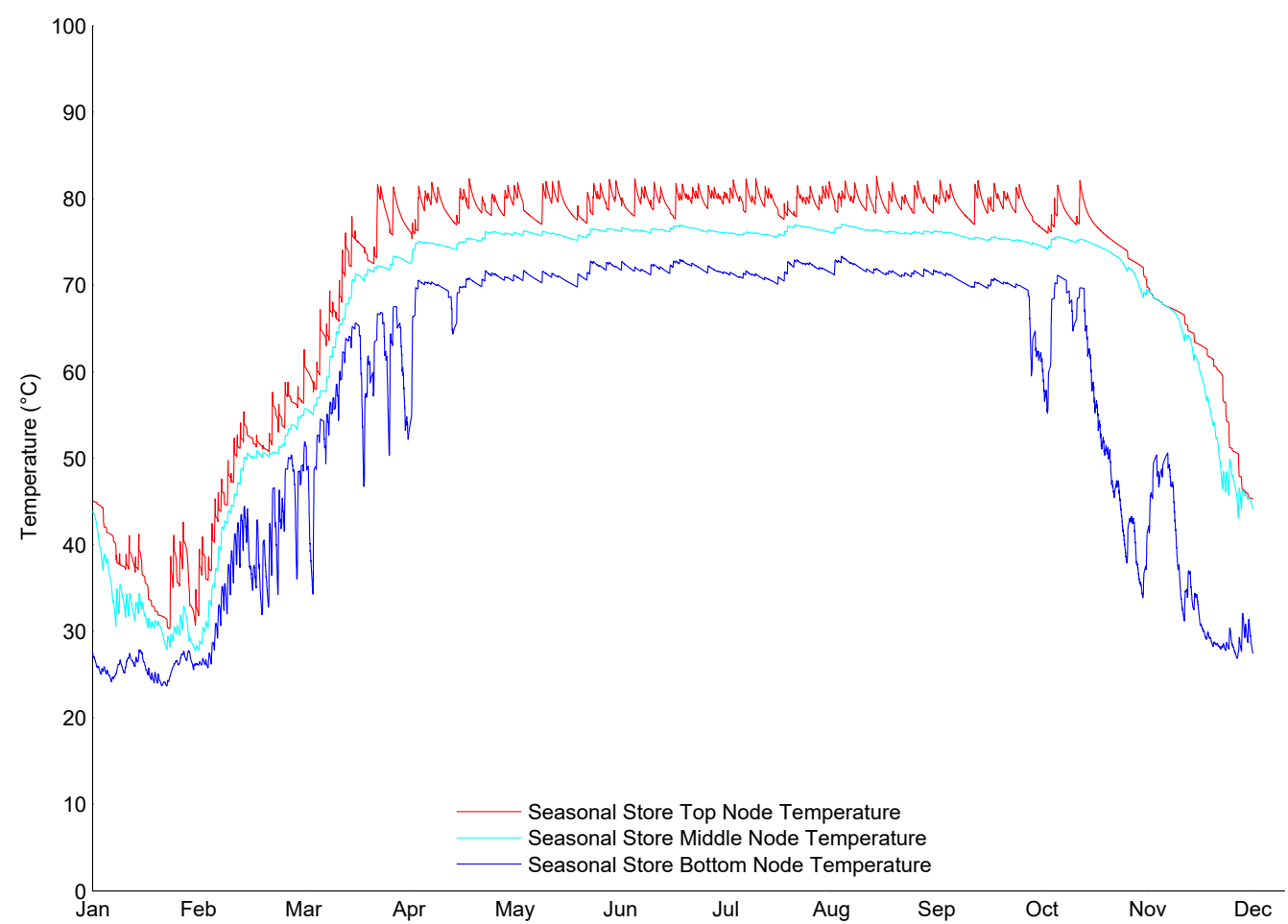

Figure 41: Seasonal Store Temperatures 
(a) $\alpha$ Case

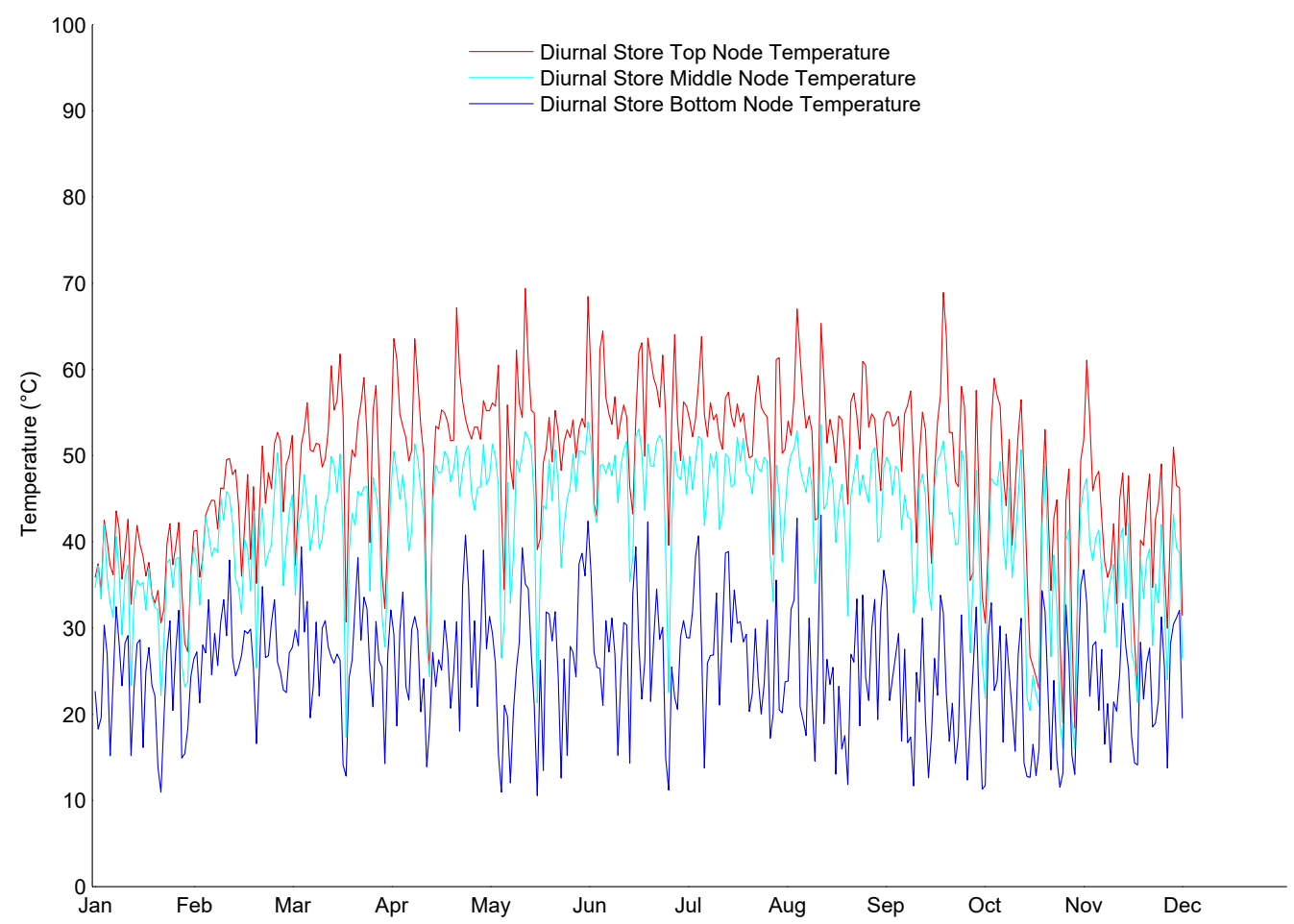

(b) $\beta$ Case

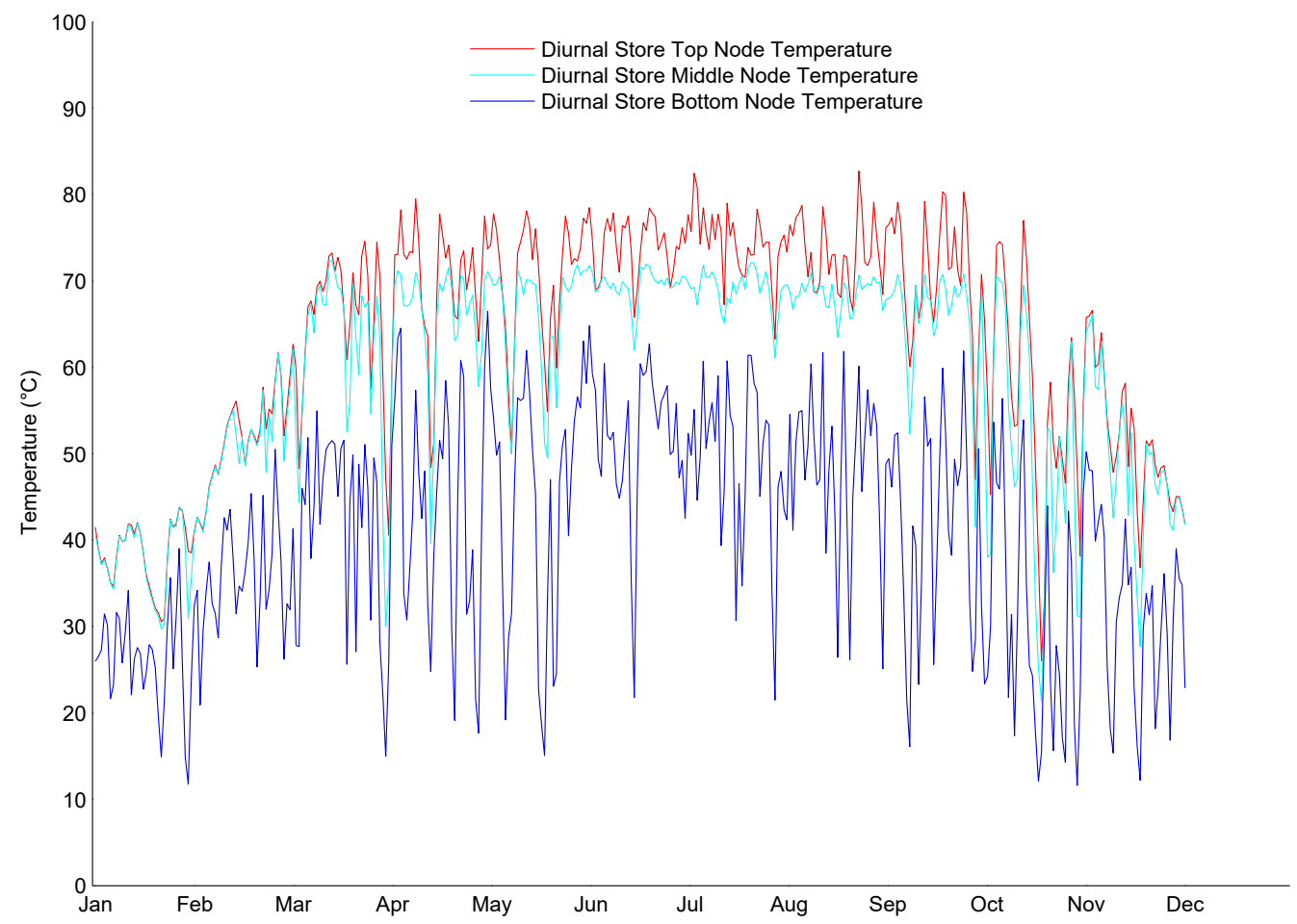

Figure 42: Diurnal Store Temperatures 
Perhaps the most pronounced difference between the $\alpha$ case and $\beta$ case is seen in Figures $43 \mathrm{a}$ and $43 \mathrm{~b}$ showing the $\mathrm{SF}$ variation over the year. The $\beta$ case $\mathrm{SF}$ is significantly less variable year round and has stretches of complete solar reliance in the summer.

The different allocation of collected energy between the two thermal stores is shown in Figures 44a and 44b. The DTES requires more charging energy generally, and the STES, less. The amount of collected energy utilised also improves.

Figures $45 \mathrm{a}$ and $45 \mathrm{~b}$ show the zone temperature over the year illustrating further the necessity of more shading and possibly heat extraction via the radiant floor in the future nearly year round to prevent over-heating. Importantly, it also confirms that the zone temperature of $20^{\circ} \mathrm{C}$ is maintained year round.

Likewise, Figures 46a and 46b show the DHW delivery temperature. Note that times between DHW demands are artificially set to $55^{\circ} \mathrm{C}$ for ease of understanding. The delivery temperature does not drop below $55^{\circ} \mathrm{C}$ during $\mathrm{DHW}$ draws. However, the large overshooting of the $T_{\text {delivery }}^{D H W}$ means the flow rates used in the mixing valve need to be optimised. If the mixing valve is well designed, it will reduce the amount of hot water needed from the DTES which is directly related to the temperature of the water being sent from the DTES.

The SF for each case does not provide all the information necessary to decide which is the 'best' option per se. The next sections will look deeper into the energy use; efficiency metrics; and store temperatures and heat loss for the parametric cases. 
(a) $\alpha$ Case

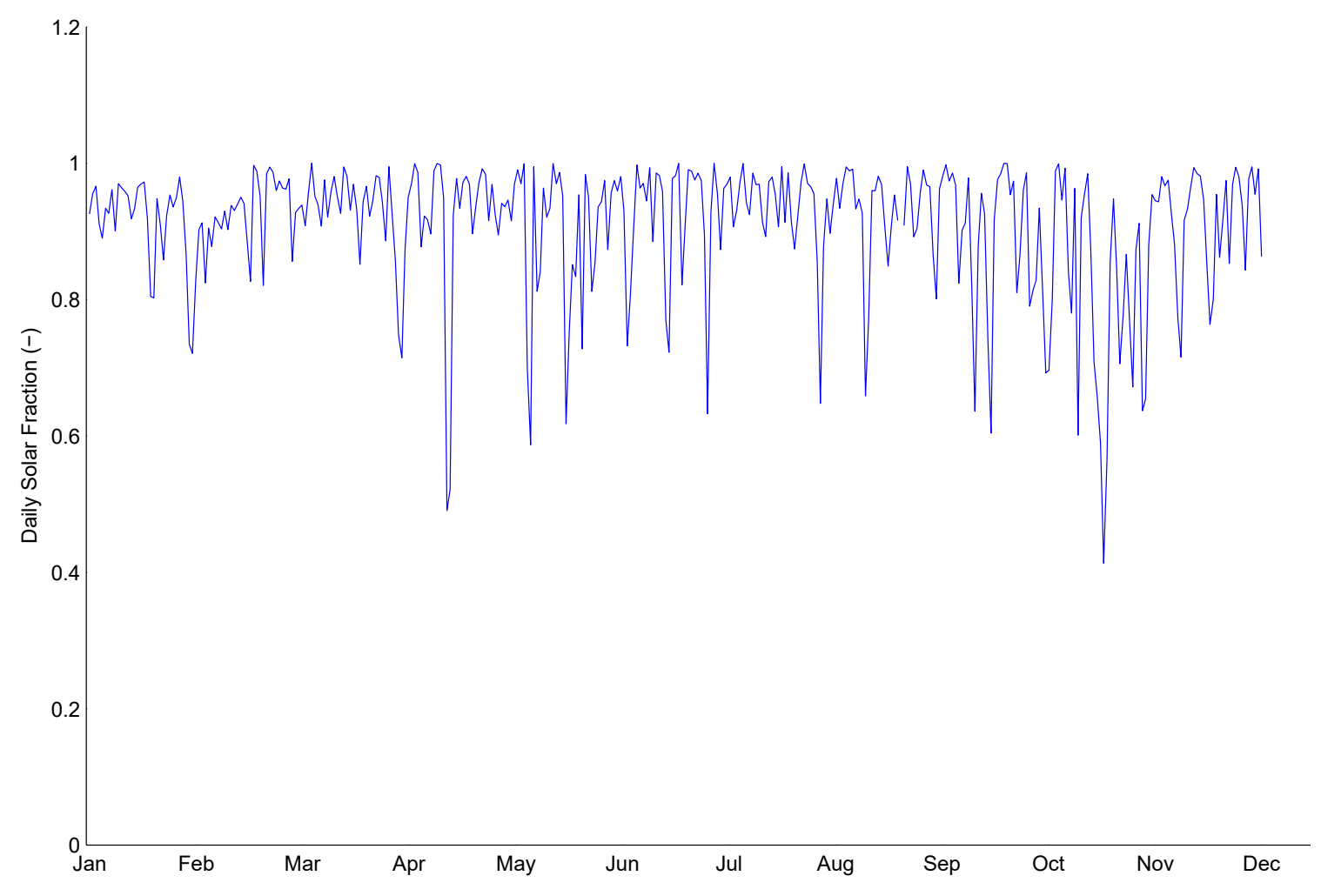

(b) $\beta$ Case

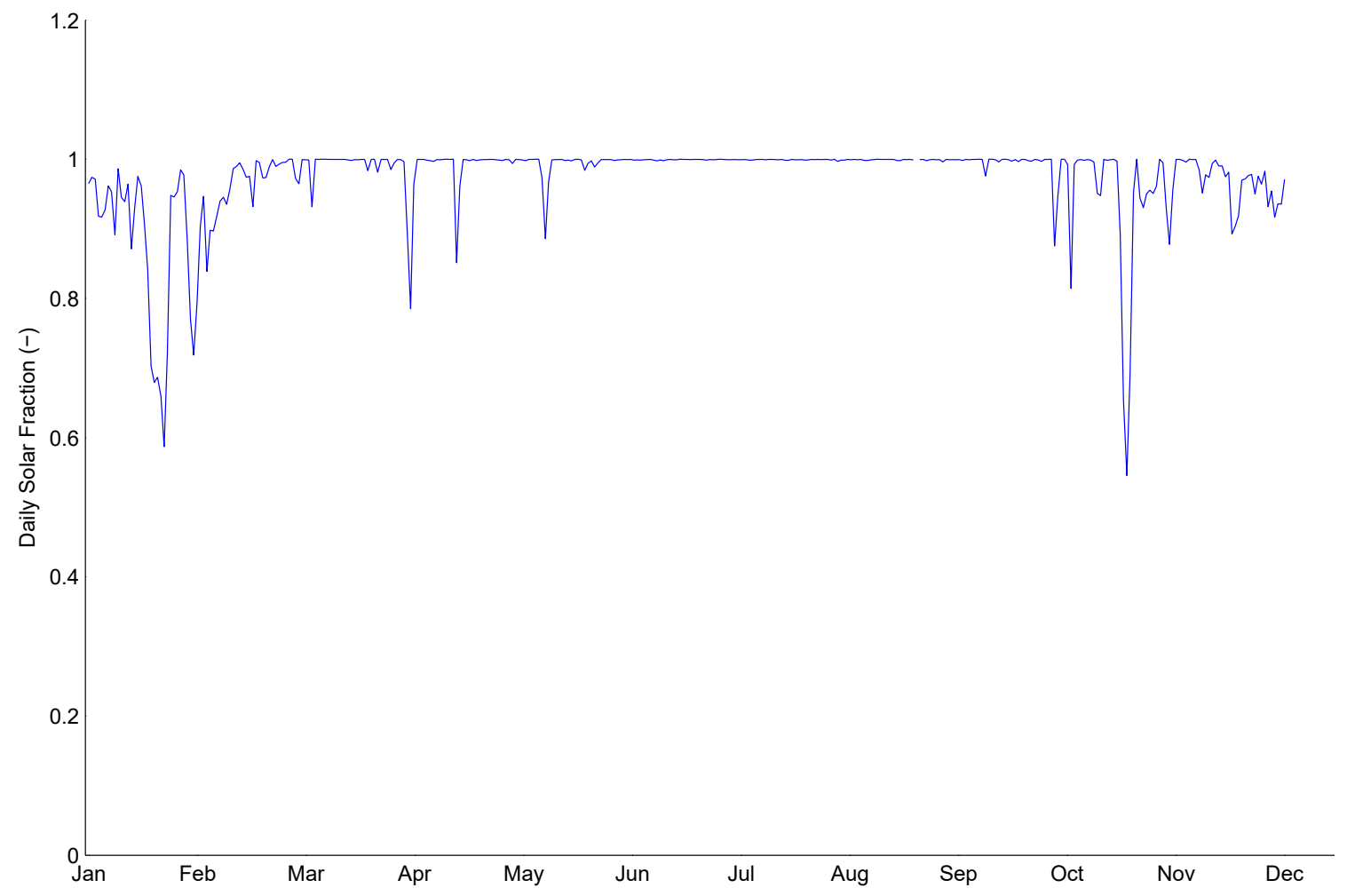

Figure 43: Solar Fraction 
(a) $\alpha$ Case

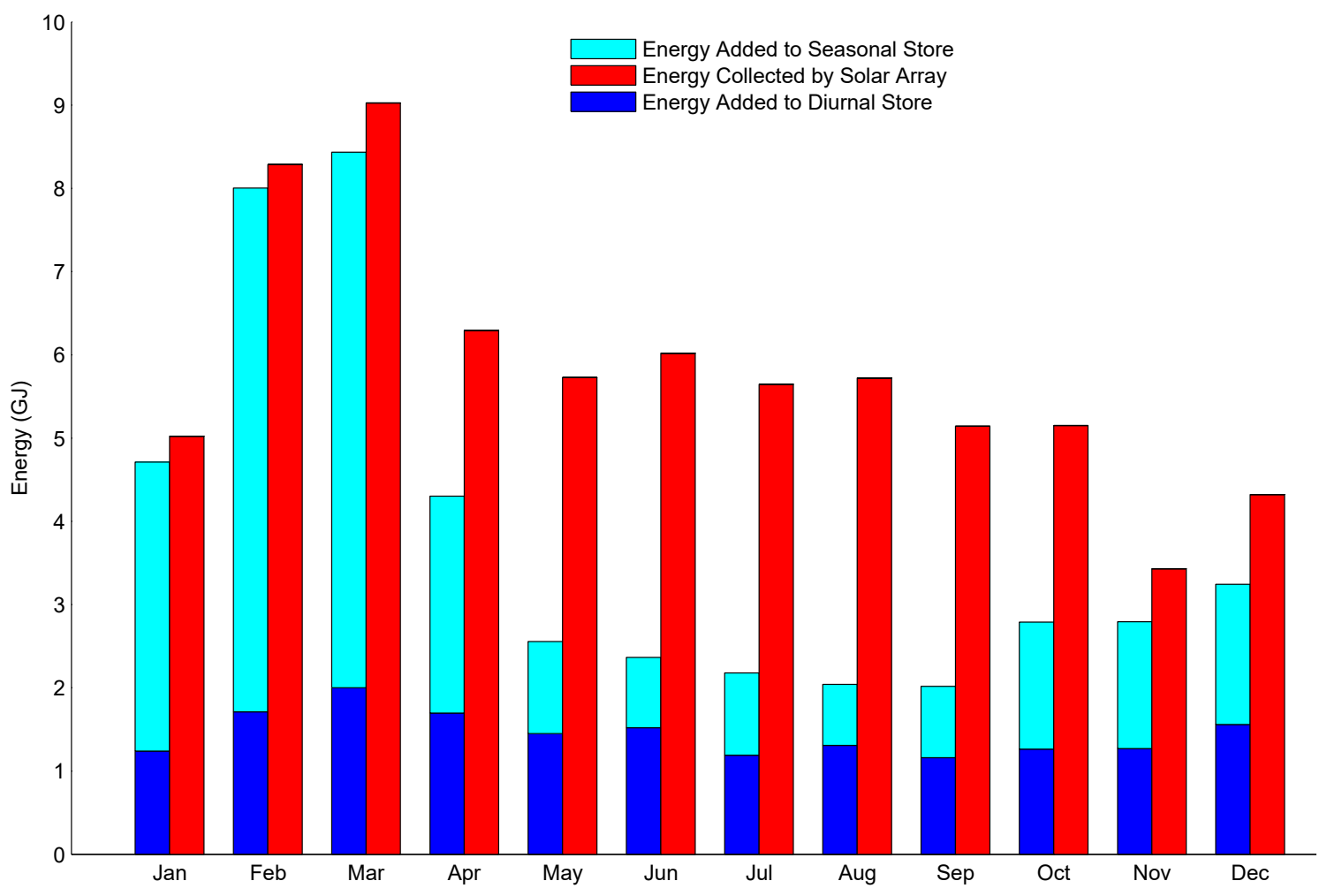

(b) $\beta$ Case

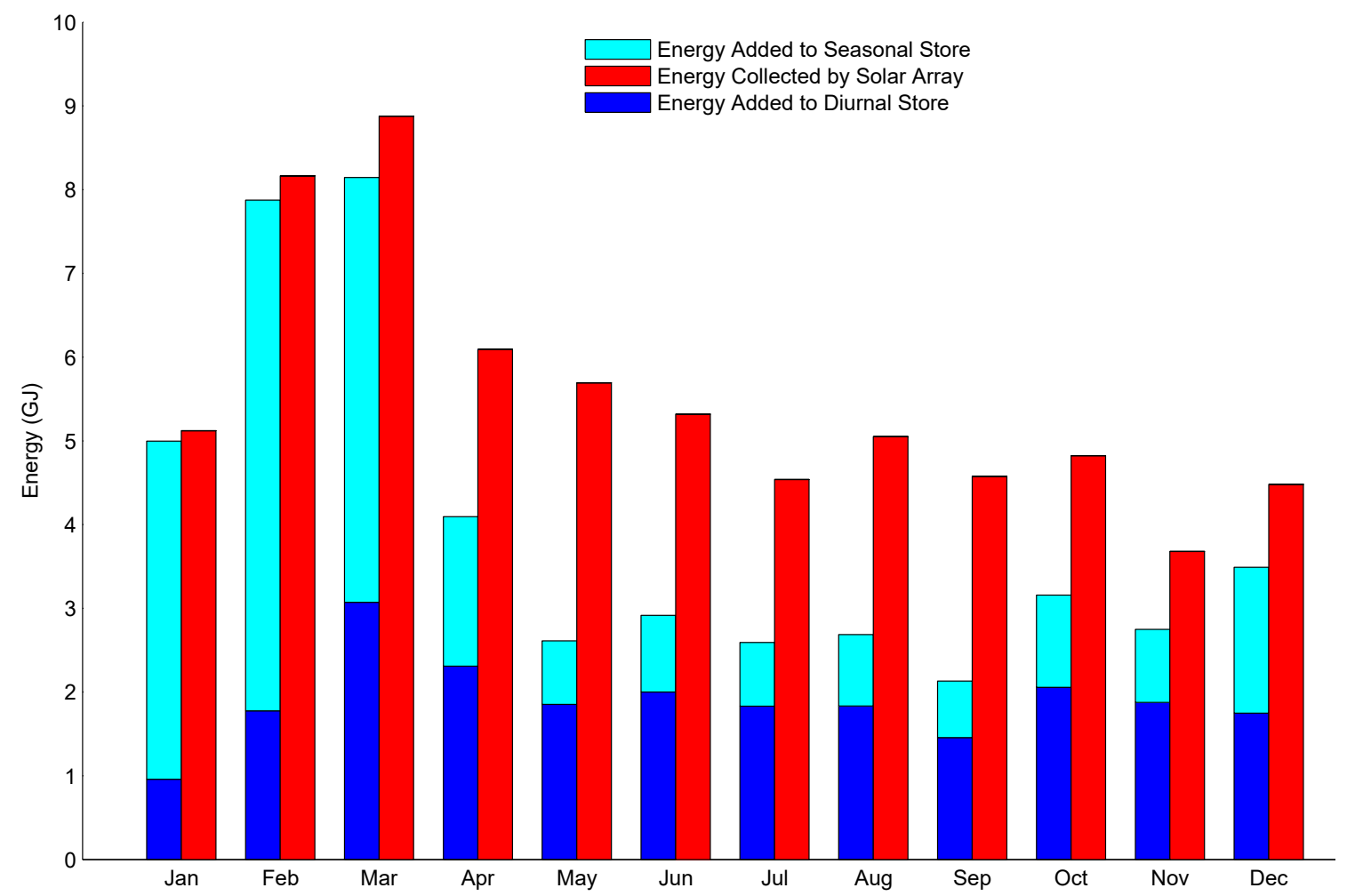

Figure 44: Energy Collected and Added to Thermal Stores 
(a) $\alpha$ Case

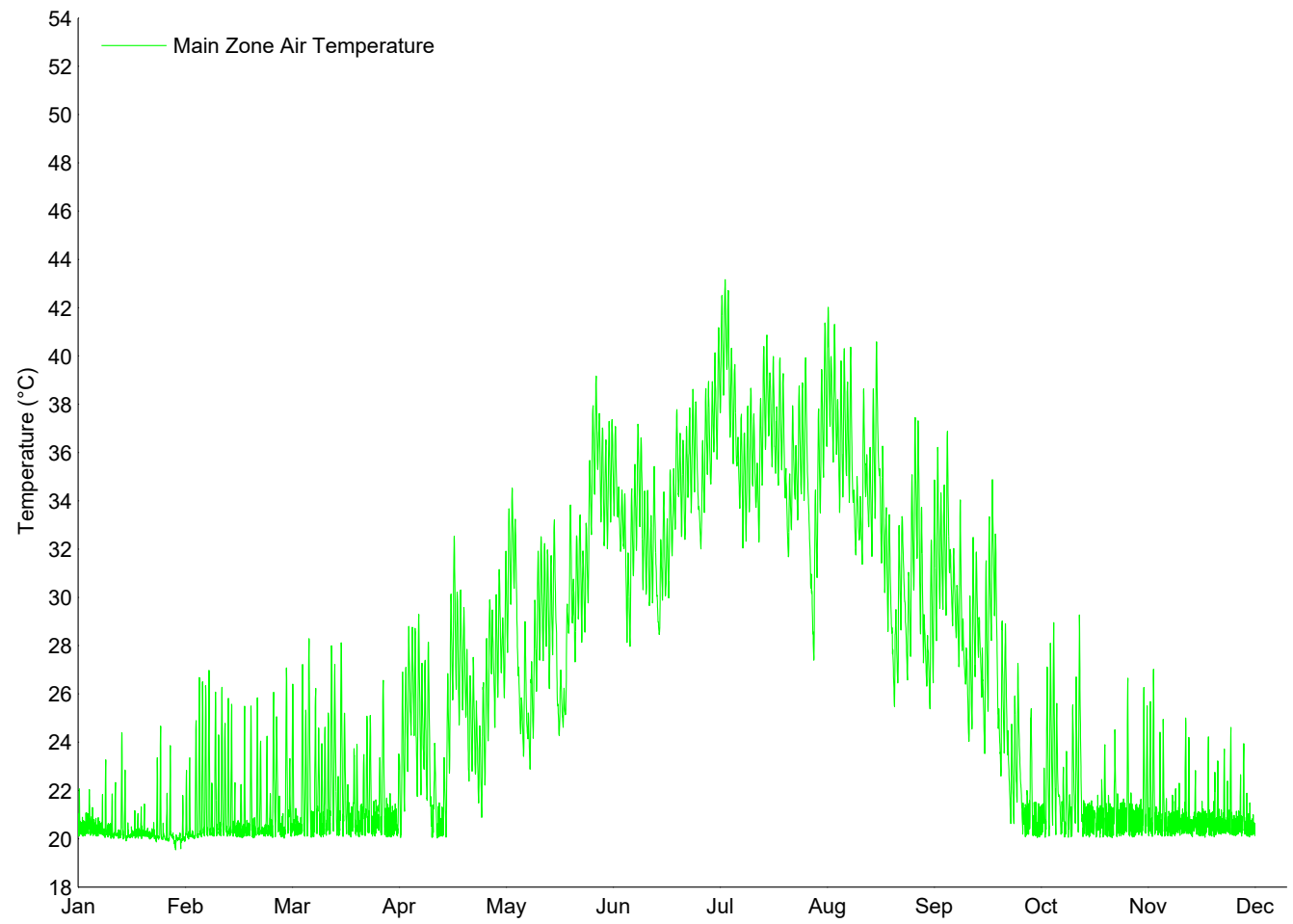

(b) $\beta$ Case

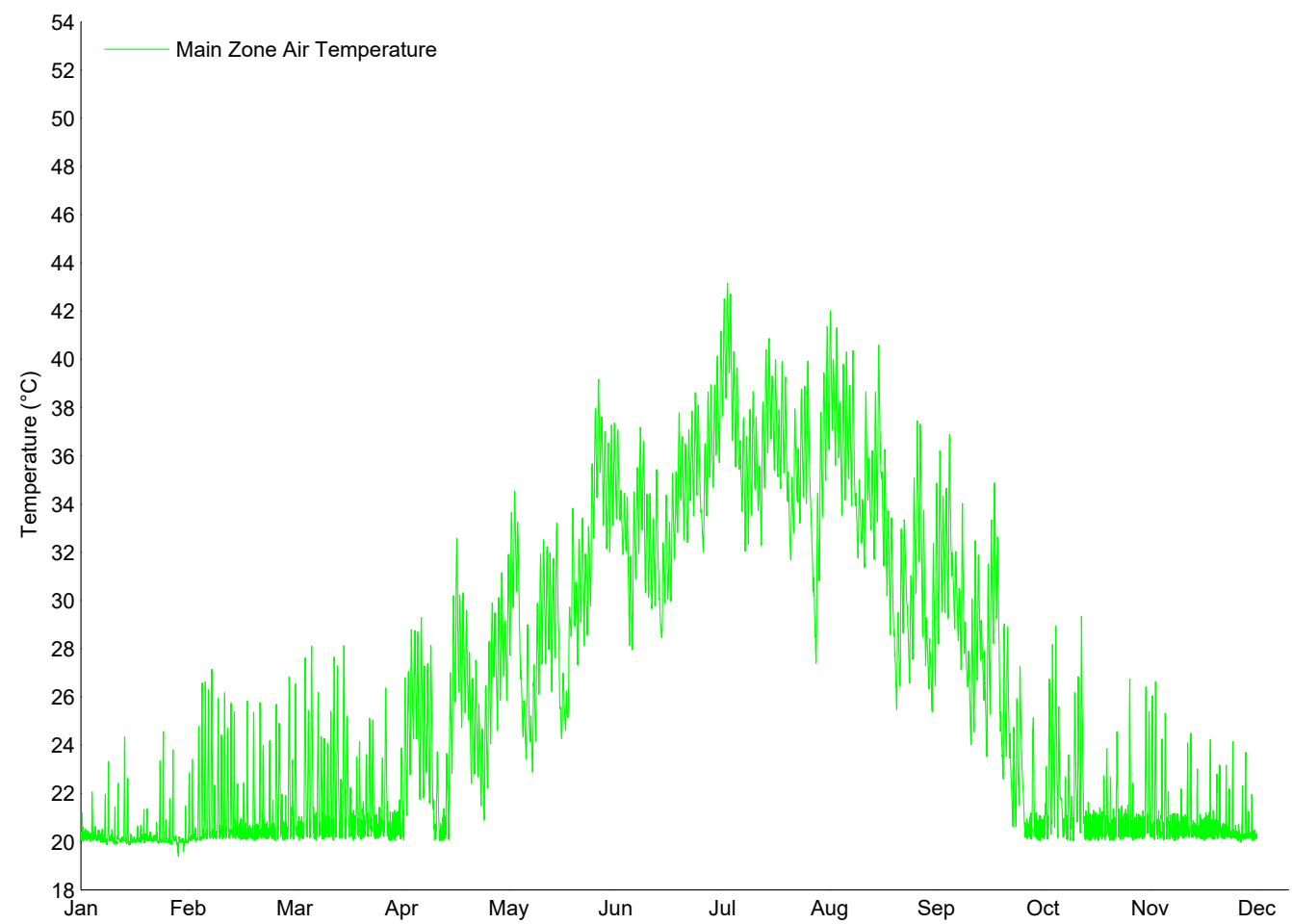

Figure 45: Zone Temperature 
(a) $\alpha$ Case

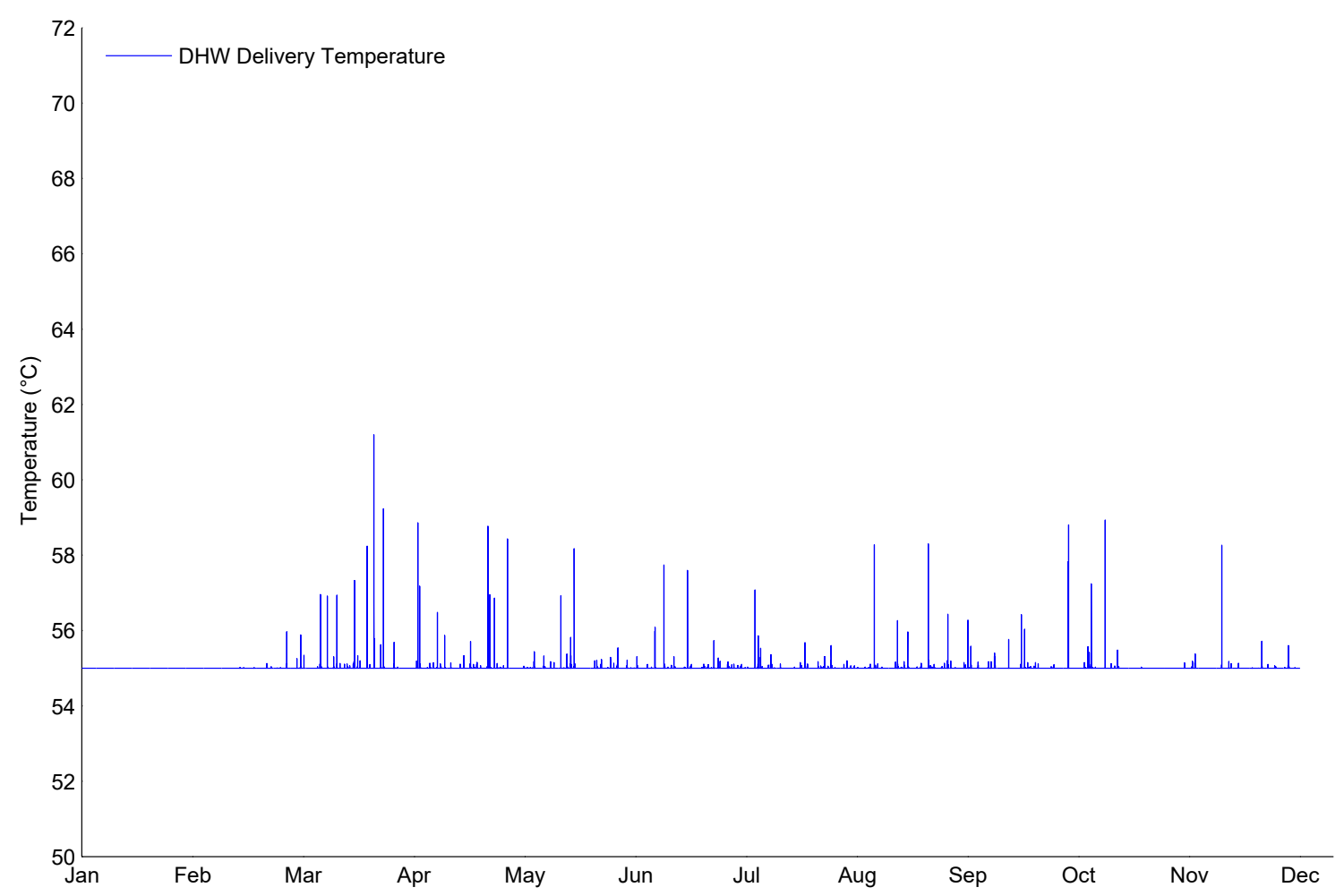

(b) $\beta$ Case

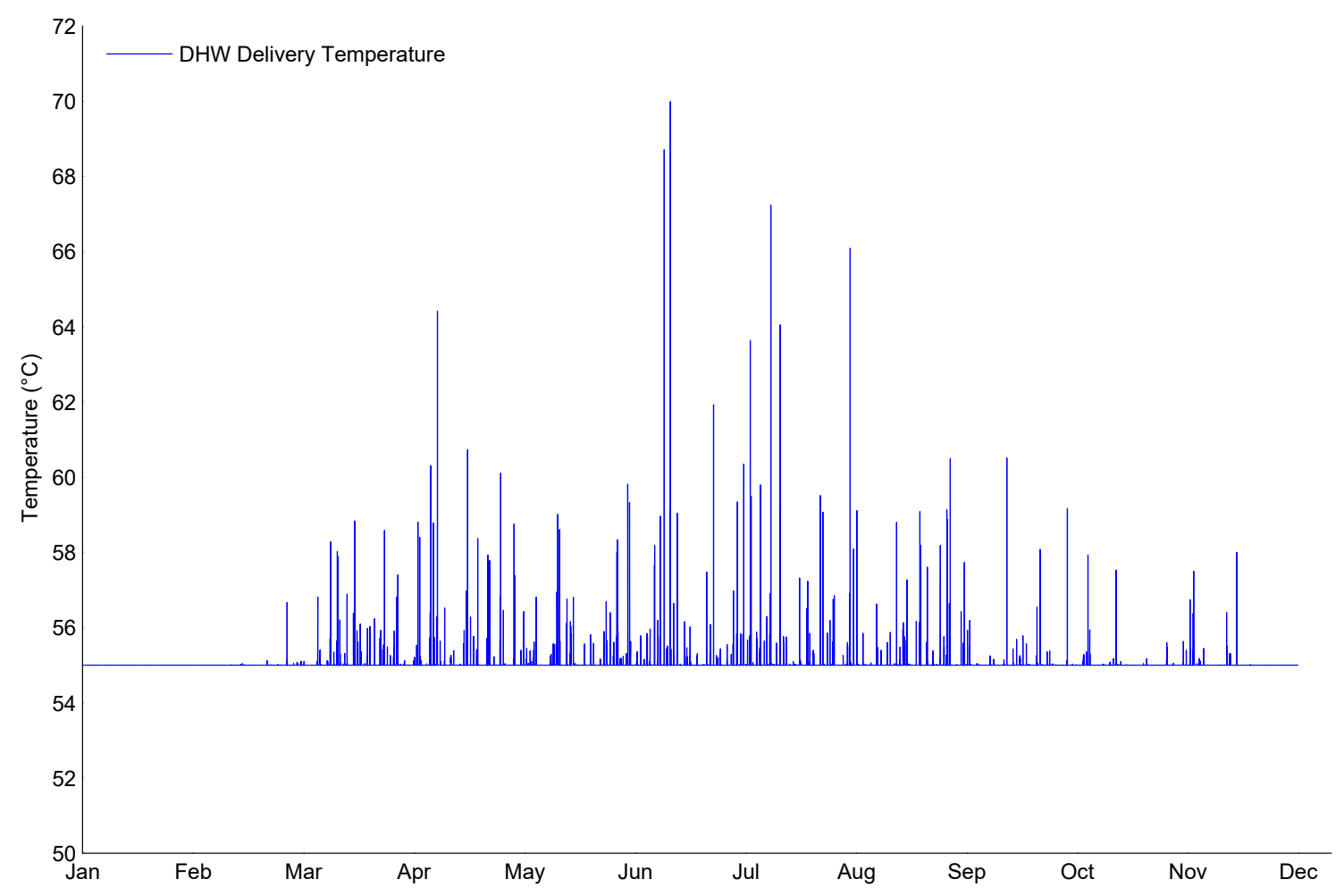

Figure 46: DHW Delivery Temperature 


\subsubsection{Seasonal Cases}

The values for energy end-uses, efficiency, store temperatures and heat loss results will be presented here for the $\beta$ case along with the STES parametric cases for comparison.

Referring to Table 15 , the $\beta$ case increased SH supplied by the DTES by $55 \%$ over the $\alpha$ case and saw an 14\% decrease in STES supplied SH, the lowest of the STES parametric cases. The amount of $E_{S H}^{A U X}$ is unchanged between the $\alpha$ case and $\beta$ case; however there is a $67 \%$ drop in $E_{D H W}^{A U X}$ relative to the $\alpha$ case. This is important because the $E_{D H W}^{A U X}$ is more significant on a GJ basis than the $E_{S H}^{A U X}$.

Table 15: Energy Use

\begin{tabular}{cccccc} 
& $\begin{array}{c}E_{S H}^{D T E S} \\
\text { Case }\end{array}$ & $\begin{array}{c}E_{S H}^{S T E S} \\
\text { GJ }\end{array}$ & $\begin{array}{c}E_{S H}^{A U X} \\
\text { GJ }\end{array}$ & $\begin{array}{c}E_{D H W}^{D T E S} \\
\text { GJ }\end{array}$ & $\begin{array}{c}E_{D H W}^{A U X} \\
\text { GJ }\end{array}$ \\
\hline \hline $\mathrm{A}$ & 2.1 & 16.8 & 1.4 & 9.8 & 2.4 \\
$\mathrm{~B}$ & 2.1 & 17.5 & 0.9 & 9.7 & 2.4 \\
$\mathrm{C}$ & 2.1 & 18.3 & 0.5 & 9.8 & 2.4 \\
$\mathrm{D}$ & 2.0 & 17.7 & 0.8 & 9.7 & 2.5 \\
$\mathrm{E}$ & 2.1 & 18.3 & 0.5 & 9.8 & 2.4 \\
$\beta$ & 3.4 & 16.1 & 0.2 & 11.4 & 0.8 \\
$\alpha$ & 2.2 & 18.8 & 0.2 & 9.8 & 2.4 \\
$\mathrm{G}$ & 2.2 & 19.2 & 0.1 & 9.9 & 2.3 \\
$\mathrm{H}$ & 2.4 & 19.3 & 0.0 & 9.9 & 2.3
\end{tabular}


Table 16 shows the $\beta$ case sees less energy collection total than the $\alpha$ case, but the $\eta_{\text {charge }}$ is higher. Due to the increased $V^{D T E S}$ and $T_{+}^{D T E S}, 17 \%$ more of the $E^{\text {collectors }}$ can be added to the stores overall.

The impact of the DTES changes has a greater impact than increasing the $V^{S T E S}$ to $45 \mathrm{~m}^{3}$ (case $\left.\mathrm{H}\right)$ on the $\eta_{\text {charge }}$ which only saw a $3 \%$ increase.

The shift of charging requirements between the DTES and the STES are evident also with the $\beta$ case DTES receiving 6.4 GJ more than the $\alpha$ case.

Table 16: Energy Efficiency

\begin{tabular}{ccccc} 
Case & $\begin{array}{c}E^{\text {collectors }} \\
\text { GJ }\end{array}$ & $\begin{array}{c}E_{+}^{S T E S} \\
\text { GJ }\end{array}$ & $\begin{array}{c}E_{+}^{\text {DTES }} \\
\text { GJ }\end{array}$ & $\begin{array}{c}\eta_{\text {charge }} \\
-\end{array}$ \\
\hline \hline $\mathrm{A}$ & 66.7 & 23.2 & 17.1 & 0.60 \\
$\mathrm{~B}$ & 66.8 & 24.9 & 17.2 & 0.63 \\
$\mathrm{C}$ & 68.0 & 26.5 & 17.1 & 0.64 \\
$\mathrm{D}$ & 68.5 & 24.7 & 17.0 & 0.61 \\
$\mathrm{E}$ & 68.3 & 26.3 & 17.1 & 0.64 \\
$\beta$ & 58.3 & 24.1 & 23.8 & 0.82 \\
$\alpha$ & 69.8 & 28.1 & 17.4 & 0.65 \\
$\mathrm{G}$ & 70.6 & 29.4 & 17.3 & 0.66 \\
$\mathrm{H}$ & 70.6 & 30.2 & 17.5 & 0.67
\end{tabular}


Overall the cases perform relatively similarly as the change in $T_{+}^{S T E S}$ is not dramatic and the change in $V^{S T E S}$ has the greatest impact on the store heat loss. The lower STES temperatures do serve to reduce the amount of heat loss from the tank by $12 \%$ as compared to the $\alpha$ case.

Case $\mathrm{H}$ with the $45 \mathrm{~m}^{3} V^{S T E S}$ saw the greatest amount of heat loss and case A with a $25^{3} V^{S T E S}$ had the least heat loss. However, the $\beta$ case total efficiency $\left(\eta_{\text {total }}\right)$ remains higher than all other cases

Table 17: Store Temperatures and Heat Loss By Seasonal Parametric Case

\begin{tabular}{cccccccc} 
Case & $\begin{array}{c}T_{\text {top }}^{D T E S} \\
{ }^{\circ} \mathrm{C}\end{array}$ & $\begin{array}{c}T_{\text {botom }}^{D T E S} \\
{ }^{\circ} \mathrm{C}\end{array}$ & $\begin{array}{c}Q_{-}^{D T E S} \\
\text { GJ }\end{array}$ & $\begin{array}{c}T_{\text {top }}^{S T E S} \\
{ }^{\circ} \mathrm{C}\end{array}$ & $\begin{array}{c}T_{\text {bottom }}^{\text {STES }} \\
{ }^{\circ} \mathrm{C}\end{array}$ & $\begin{array}{c}Q_{-}^{S T E S} \\
\text { GJ }\end{array}$ & $\begin{array}{c}\eta \text { total } \\
-\end{array}$ \\
\hline \hline $\mathrm{A}$ & 48.5 & 25.4 & 1.6 & 78.8 & 64.4 & 6.1 & 0.49 \\
$\mathrm{~B}$ & 48.4 & 25.3 & 1.6 & 79.0 & 64.7 & 7.2 & 0.50 \\
$\mathrm{C}$ & 48.4 & 25.1 & 1.6 & 78.9 & 64.7 & 8.1 & 0.50 \\
$\mathrm{D}$ & 47.9 & 25.2 & 1.6 & 63.2 & 51.3 & 6.9 & 0.48 \\
$\mathrm{E}$ & 48.4 & 25.2 & 1.6 & 71.1 & 57.9 & 7.9 & 0.50 \\
$\beta$ & 65.0 & 42.3 & 5.9 & 70.2 & 58.6 & 7.9 & 0.59 \\
$\alpha$ & 48.6 & 25.3 & 1.6 & 78.9 & 64.6 & 9.0 & 0.50 \\
$\mathrm{G}$ & 48.9 & 25.1 & 1.6 & 78.8 & 64.6 & 9.9 & 0.50 \\
$\mathrm{H}$ & 49.3 & 25.3 & 1.6 & 79.2 & 64.9 & 10.8 & 0.50
\end{tabular}

The next section will provide a better basis for comparison for the DTES cases with the $\beta$ case. 


\subsubsection{Diurnal Cases}

The values for energy end-uses, efficiency, store temperatures, and heat loss results will be presented here for the $\beta$ case along with the DTES parametric cases for comparison.

Table 18 shows the $\beta$ case remains the best performer in the amount of $E_{D H W}^{A U X}$ used and the $\alpha$ case, the worst performer. The least amount of $E_{S H}^{A U X}$ was achieved by case 'a' with the largest $V^{S T E S}$ and the lowest $T_{\text {cutoff }}^{D T E S}$.

Table 18: Energy-use

\begin{tabular}{|c|c|c|c|c|c|}
\hline Case & $\begin{array}{c}E_{S H}^{D T E S} \\
\text { GJ }\end{array}$ & $\begin{array}{c}E_{S H}^{S T E S} \\
\text { G.J }\end{array}$ & $\begin{array}{c}E_{S H}^{A U X} \\
\text { G.J }\end{array}$ & $\begin{array}{c}E_{D H W}^{D T E S} \\
\text { G.J }\end{array}$ & $\begin{array}{c}E_{D H W}^{A U X} \\
\text { GJ }\end{array}$ \\
\hline$\beta$ & 3.4 & 16.1 & 0.2 & 11.4 & 0.8 \\
\hline $\mathrm{a}$ & 5.0 & 15.8 & 0.1 & 10.6 & 1.5 \\
\hline $\mathrm{b}$ & 4.0 & 16.8 & 0.2 & 10.4 & 1.8 \\
\hline$\alpha$ & 2.2 & 18.8 & 0.2 & 9.8 & 2.4 \\
\hline d & 2.9 & 18.0 & 0.3 & 10.2 & 2.0 \\
\hline e & 3.0 & 17.7 & 0.4 & 10.4 & 1.8 \\
\hline $\mathrm{f}$ & 3.0 & 17.7 & 0.4 & 10.3 & 1.9 \\
\hline $\mathrm{g}$ & 3.1 & 17.4 & 0.4 & 10.4 & 1.8 \\
\hline $\mathrm{h}$ & 2.4 & 18.6 & 0.2 & 9.8 & 2.4 \\
\hline $\mathrm{i}$ & 1.8 & 19.1 & 0.2 & 9.9 & 2.3 \\
\hline $\mathrm{j}$ & 1.1 & 19.9 & 0.3 & 10.0 & 2.2 \\
\hline $\mathrm{k}$ & 0.2 & 20.6 & 0.5 & 10.1 & 2.1 \\
\hline
\end{tabular}


The amount of energy collected is far more dependent on the $V^{D T E S}$ than the $V^{S T E S}$ as indicated by the greater range of values in Table 19 than seen in the STES cases (refer to Table 16). Case ' $\mathrm{g}$ ' shows a 17\% higher amount of energy collected over the year than the $\alpha$ case. The $95^{\circ} \mathrm{C} T_{+}^{D T E S}$ takes more energy from the solar loop reducing the temperature of the fluid returning to the collectors allowing more energy to be collected.

The $\beta$ case energy collection is $16 \%$ lower than the $\alpha$ case but it has a $17 \%$ higher $\eta_{\text {charge }}$ than the $\alpha$ case. It shows that the best $\eta_{\text {charge }}$ is achieved by increasing the $V^{D T E S}$. Case ' $\mathrm{k}$ ' sees the lowest $E_{+}^{D T E S}$ as a result of the result of the low $T_{+}^{D T E S}$ and the high $T_{\text {cutoff }}^{D T E S}$.

Table 19: Charging Efficiency By Diurnal Parametric Case

\begin{tabular}{ccccc} 
Case & $\begin{array}{c}E^{\text {collectors }} \\
\text { GJ }\end{array}$ & $\begin{array}{c}T_{+}^{S T E S} \\
\text { GJ }\end{array}$ & $\begin{array}{c}T_{+}^{\text {DTES }} \\
\text { GJ }\end{array}$ & $\begin{array}{c}\eta_{\text {charge }} \\
\end{array}$ \\
\hline \hline$\beta$ & 58.3 & 24.1 & 23.8 & 0.82 \\
\hline $\mathrm{a}$ & 65.5 & 24.9 & 21.7 & 0.71 \\
$\mathrm{~b}$ & 65.9 & 25.9 & 20.2 & 0.70 \\
$\alpha$ & 69.8 & 28.1 & 17.4 & 0.65 \\
$\mathrm{~d}$ & 74.2 & 27.1 & 19.0 & 0.62 \\
$\mathrm{e}$ & 79.0 & 26.9 & 19.8 & 0.59 \\
$\mathrm{f}$ & 80.1 & 26.4 & 20.1 & 0.58 \\
$\mathrm{~g}$ & 81.5 & 26.4 & 20.5 & 0.58 \\
$\mathrm{~h}$ & 69.2 & 27.8 & 17.5 & 0.66 \\
$\mathrm{i}$ & 69.7 & 28.3 & 17.0 & 0.65 \\
$\mathrm{j}$ & 69.5 & 29.1 & 16.3 & 0.65 \\
$\mathrm{k}$ & 70.1 & 29.8 & 15.3 & 0.64
\end{tabular}


Table 20 shows the diurnal temperatures and heat loss for the $\beta$ case are significantly higher than the other STES cases due to having three times the $V^{S T E S}$ and a $20^{\circ} \mathrm{C}$ higher $T_{+}^{D T E S}$.

Case 'a' ties for the best $\eta_{\text {total }}$ despite having $125 \%$ more heat loss than the $\alpha$ case owing to the $1350 \mathrm{~L} V^{D T E S}$. Likewise, case 'g' shows a $69 \%$ higher heat loss than the $\alpha$ case results from the higher $95^{\circ} \mathrm{C} T_{+}^{D T E S}$. Having both the largest $V^{D T E S}$ and the highest $T_{+}^{D T E S}$, the $\beta$ case has the highest $Q_{-}^{D T E S}$ of the diurnal cases, more than 2 times greater than the $\alpha$ case.

Yet the $\eta_{\text {total }}$ for the $\beta$ case remains better than all other cases considered.

Table 20: Store Temperatures and Heat Loss By Diurnal Parametric Case

\begin{tabular}{cccccccc} 
Case & $\begin{array}{c}T_{\text {top }}^{\text {DTES }} \\
{ }^{\circ} \mathrm{C}\end{array}$ & $\begin{array}{c}T_{\text {botom }}^{\text {DTES }} \\
{ }^{\circ} \mathrm{C}\end{array}$ & $\begin{array}{c}Q_{-}^{\text {DTES }} \\
\text { GJ }\end{array}$ & $\begin{array}{c}T_{\text {top }}^{\text {STES }} \\
{ }^{\circ} \mathrm{C}\end{array}$ & $\begin{array}{c}T_{\text {bottom }}^{\text {STES }} \\
{ }^{\circ} \mathrm{C}\end{array}$ & $\begin{array}{c}Q_{-}^{S T E S} \\
\text { GJ }\end{array}$ & $\begin{array}{c}\eta \text { total } \\
-\end{array}$ \\
\hline \hline$\beta$ & 65.0 & 42.3 & 5.9 & 70.2 & 58.6 & 7.9 & 0.59 \\
$\mathrm{a}$ & 50.7 & 30.4 & 3.6 & 79.0 & 65.0 & 9.0 & 0.52 \\
$\mathrm{~b}$ & 50.1 & 28.7 & 2.7 & 79.1 & 65.1 & 9.0 & 0.52 \\
$\alpha$ & 48.6 & 25.3 & 1.6 & 78.9 & 64.6 & 9.0 & 0.50 \\
$\mathrm{~d}$ & 53.9 & 27.1 & 1.9 & 78.3 & 64.3 & 8.9 & 0.47 \\
$\mathrm{e}$ & 58.3 & 29.4 & 2.3 & 77.5 & 63.9 & 8.8 & 0.45 \\
$\mathrm{f}$ & 60.5 & 31.0 & 2.4 & 76.7 & 63.1 & 8.7 & 0.44 \\
$\mathrm{~g}$ & 63.3 & 32.4 & 2.7 & 76.2 & 63.9 & 8.7 & 0.44 \\
$\mathrm{~h}$ & 48.5 & 25.5 & 1.6 & 79.0 & 64.5 & 9.0 & 0.50 \\
$\mathrm{i}$ & 49.1 & 25.2 & 1.6 & 78.9 & 64.5 & 9.0 & 0.50 \\
$\mathrm{j}$ & 49.5 & 25.0 & 1.7 & 78.2 & 64.1 & 8.9 & 0.50 \\
$\mathrm{k}$ & 50.0 & 24.4 & 1.7 & 77.6 & 63.5 & 8.8 & 0.49
\end{tabular}




\subsection{Overall Ranking of Considered Cases}

Having seen the diurnal behaviour of the $\alpha$ case and the annual performance of the parametric and $\beta$ case, Table 21 gives a summary of all of the cases ranked by their performance. Five metrics are used; SF; auxiliary SH energy; auxiliary DHW energy; store heat loss; charging efficiency; and $\eta_{\text {total }}$.

Additional simulation outputs could be taken into consideration for evaluation. However some metrics, such as average tank temperature, are not informative on the set as a whole. This is due to the varying of the $T_{+}^{D T E S}$ and $T_{+}^{S T E S}$ in both the STES and DTES parametrics.

The $\beta$ case was ranked $1^{\text {st }}$ overall. Although it performed well, the $\eta_{\text {total }}$ is reduced because the $Q_{-}^{D T E S}$ from a larger $V^{D T E S}$ stored at a higher temperature makes it less

efficient than a smaller $V^{D T E S}$ at a lower storage temperature. The $\beta$ case has the highest SF, the least required total and auxiliary energy, and it is using the collected energy more efficiently. 
Table 21: $\beta$ Case Rank Compared to Parametric Cases

\begin{tabular}{ccccccccc} 
& Rank & SF & $E_{S H}^{A U X}$ & $E_{D H W}^{A U X}$ & $Q_{-}^{D T E S}$ & $Q_{-}^{S T E S}$ & $\eta_{\text {charge }}$ & $\eta_{\text {total }}$ \\
\hline$\beta$ & 1 & 0.98 & 0.2 & 0.8 & 5.9 & 7.9 & 0.82 & 0.59 \\
$\mathrm{a}$ & 2 & 0.94 & 0.1 & 1.5 & 3.6 & 9.0 & 0.71 & 0.52 \\
$\mathrm{~b}$ & 3 & 0.93 & 0.2 & 1.8 & 2.7 & 9.0 & 0.70 & 0.52 \\
$\mathrm{H}$ & 4 & 0.91 & 0.0 & 2.3 & 1.6 & 10.8 & 0.67 & 0.50 \\
$\mathrm{j}$ & 5 & 0.91 & 0.3 & 2.2 & 1.7 & 8.9 & 0.65 & 0.50 \\
$\mathrm{G}$ & 5 & 0.91 & 0.1 & 2.3 & 1.6 & 9.9 & 0.66 & 0.50 \\
$\mathrm{i}$ & 7 & 0.91 & 0.2 & 2.3 & 1.6 & 9.0 & 0.65 & 0.50 \\
\hline$\alpha$ & 8 & 0.91 & 0.2 & 2.4 & 1.6 & 9.0 & 0.65 & 0.50 \\
$\mathrm{~h}$ & 9 & 0.91 & 0.2 & 2.4 & 1.6 & 9.0 & 0.66 & 0.50 \\
$\mathrm{k}$ & 10 & 0.91 & 0.5 & 2.1 & 1.7 & 8.8 & 0.64 & 0.49 \\
$\mathrm{e}$ & 11 & 0.94 & 0.4 & 1.8 & 2.3 & 8.8 & 0.59 & 0.45 \\
$\mathrm{C}$ & 11 & 0.90 & 0.5 & 2.4 & 1.6 & 8.1 & 0.64 & 0.50 \\
$\mathrm{~d}$ & 13 & 0.93 & 0.3 & 2.0 & 1.9 & 8.9 & 0.62 & 0.47 \\
$\mathrm{E}$ & 13 & 0.91 & 0.5 & 2.4 & 1.6 & 7.9 & 0.64 & 0.50 \\
$\mathrm{f}$ & 15 & 0.93 & 0.4 & 1.9 & 2.4 & 8.7 & 0.58 & 0.44 \\
$\mathrm{~g}$ & 16 & 0.94 & 0.4 & 1.8 & 2.7 & 8.7 & 0.58 & 0.44 \\
$\mathrm{~B}$ & 17 & 0.90 & 0.9 & 2.4 & 1.6 & 7.2 & 0.63 & 0.50 \\
$\mathrm{D}$ & 17 & 0.90 & 0.8 & 2.5 & 1.6 & 6.9 & 0.61 & 0.48 \\
$\mathrm{~A}$ & 19 & 0.90 & 1.4 & 2.4 & 1.6 & 6.1 & 0.60 & 0.49
\end{tabular}




\section{Chapter 5}

\section{Conclusions and Recommendations}

The purpose of this research was firstly, to contribute to the successful design and construction of the Urbandale Centre for Home Energy Research facility at Carleton University including sizing of the diurnal store; secondly, to develop a simulation model to evaluate and predict the performance of the as-built facility; and finally, using this simulation tool, determine an appropriate charging/discharging strategy to achieve a high solar fraction using the diurnal and seasonal solar thermal stores.

The simulation tools used for this work and the simulation methodology were outlined. The author's personal contributions to the design, selection, construction, and commissioning of the facility and research capabilities were discussed. This experimental work laid the groundwork for researchers to expand, validate, and improve this work.

A simulation model was developed using TRNSYS, ESP-r, and a co-simulation tool based on a set of initial conditions referred to as the ' $\alpha$ case'. The performance of this $\alpha$ case was presented on an annual basis in terms of solar fraction primarily, but also; store top, middle, and bottom temperature profiles; energy use by end-use; 
charging efficiency; and behaviour on typical sunny and winter days in each season.

To compare and evaluate the parameters selected for the $\alpha$ case, a range of inputs was investigated. The charging setpoints and volumes for the thermal stores were varied, as was the diurnal cutoff temperature. Based on the findings of the parametric study, a new set of $\beta$ case parameters were selected and the performance compared with the rest of the cases considered.

The findings from these analyses will be summarised in the remainder of this chapter and recommendations made for the control and operation of the facility for improved results. Finally recommendations will be made for validation or improvements of this work and suggestions for future work.

\subsection{Conclusions}

First it is worth stating that with the backup auxiliary energy all of the simulation cases achieved the zone and $T_{\text {delivery }}^{D H W}$ requirements established. Additionally, with a solar combisystem with STES and DTES, supplying $90 \%$ or more of the SH and DHW loads for an energy efficient single family dwelling is possible.

Some $E_{S H}^{A U X}$ was used in January and February for all cases considered (although the $45 \mathrm{~m}^{3} V^{S T E S}$ requirements was the lowest, 0.02 GJ for the year). To a greater extent, $E_{D H W}^{A U X}$ was also required for all cases considered, again this was reduced by increasing the $V^{D T E S}$ and the $\beta$ case outperformed all other cases.

The temperature profiles showed the same trends from case-to-case for DTES and STES. During the high solar availability period of spring and summer, the store 
temperatures steadily increased. From October through February, the store temperatures steadily decrease as ambient temperatures decrease and SH demands increase. By January and February the stores are nearly depleted and can't be fully charged. Hence the use of auxiliary energy in January and February.

For the $\alpha$ case the $T_{+}^{D T E S}$ of $55^{\circ} \mathrm{C}$ is the same as the $T_{\text {delivery }}^{D H W}$. As a result, the DTES will require $E_{D H W}^{A U X}$ unless it is fully charged. The $\alpha$ case was the third worst performer in terms of $E_{S H}^{D H W}$ use of all the cases considered.

In contrast, the $\beta$ case had an increased $V^{D T E S}(1350 \mathrm{~L})$ and a $T_{+}^{D T E S}$ of $75^{\circ} \mathrm{C}$ and performed $47 \%$ better on an annual $E_{D H W}^{A U X}$ basis than the runner up (case 'a') with $1350 \mathrm{~L} V^{D T E S}$ and $\left.55^{\circ} \mathrm{C} T_{+}^{D T E S}\right)$.

The $\beta$ case also performed $56 \%$ better on an annual basis than the $75^{\circ} \mathrm{C} T_{+}^{D T E S}$ (case 'e') parametric case which ranked fourth in $E_{D H W}^{A U X}$. Increasing the thermal mass and the charging setpoint reduced the $E_{D H W}^{A U X}$ requirements as shown by the $\beta$ case results.

Increasing the seasonal thermal store volume would have the same effect of reducing the $E_{S H}^{A U X}$ requirements. The capital cost and sheer size of the seasonal store even at $35 \mathrm{~m}^{3}$ is already cost prohibitive for a residential install. This is because of the custom fabrication necessary to achieve: the high insulation levels necessary to enable long-term heat loss; the double-walled construction method to protect the insulation over long-term burial; the material requirements for a tank storing water at temperatures up to $93^{\circ} \mathrm{C}$; and the structural considerations for installation belowgrade. Furthermore, the seasonal storage has already been selected and installed at the facility. For these reasons, other measures to decrease the $E_{S H}^{A U X}$ are desired and the $\beta$ case shows better overall performance than simply increasing the $V^{S T E S}$. 
The $\beta$ case parameters demonstrated performance improvements on the basis of SF; overall energy use; total auxiliary energy required; $\eta_{\text {charge }}$; and $\eta_{\text {total }}$. This was accomplished by increasing the thermal mass of the diurnal store, increasing the

$T_{+}^{D T E S}$ above the $T_{\text {delivery }}^{D H W}$, increasing the $T_{\text {cutoff }}^{D T E S}$ requirement for providing $\mathrm{SH}$, and reducing the $T_{+}^{S T E S}$.

The scope of this work did not include addressing the demands for space cooling for the facility which experiences over heating in large part due to the high glazingto-wall ratio on the south face. This will be a recommendation for future work. However, all of the considered cases were able to meet SH and DHW demand with a SF of 0.9 or better, a significant achievement in any case.

Operating the Urbandale Centre for Home Energy Research based on the defined parameters for the $\beta$ case will result in improved overall system performance relative to the original $\alpha$ case.

\subsection{Future Work}

While simulation tools are advanced and this author took care to model a system deemed representational of the as-built facilities, the instrumentation and experimental capabilities provide the unique opportunity to validate the simulation results presented herein, an opportunity often lacking in simulation applications.

It is recommended that future researchers use measured data to validate and improve the model based on:

- overall solar fraction of the system

- amount of energy provided by the solar thermal collector system over year 
- the charging profiles of both thermal stores over the year

- the amount of energy added to each thermal store over the year

- the degree of stratification in each thermal store on an hourly and daily

- the amount of auxiliary energy required for SH and DHW loads

- heat losses from DTES and STES 
It is further recommended that intelligent shading techniques be implemented to:

- mitigate overheating in the facility, particularly during the summer

- reduce the amount of SH energy required in the winter by allowing passive solar gains when beneficial

Based on the experimental results and model calibration, there may be additional efficiencies to be found in the overall system design. There were indications that a variable speed pump on the solar loop, and possibly the DHW system, could improve performance on overcast days. By reducing the collector flow rates, a higher $T_{\text {outlet }}^{\text {collectors }}$ could be achieved increasing the opportunities to charge the stores. Higher store temperatures are likely to reduce the required auxiliary energy use. A variable speed pump on the DHW system could potentially reduce DHW temperature overshoot as well.

To achieve a scalable design, maximising the $\eta_{\text {total }}$ may allow the size of the seasonal store and/or solar thermal collector array to be reduced. As these two system components represent the largest capital investments for the facilities, there may be acceptable trade-off between SF, cost, and auxiliary energy use. 


\section{Bibliography}

Australian Government. Solar Radiation Definitions. Technical report, Bureau of Meteorology, 2012. Accessible online at http://www.bom.gov.au/climate/austmaps/ solar-radiation-glossary.shtml.

Chris Bales, Harald Drück, Chemin Devin, and Wolfgang Streicher. Advanced Storage Concepts for Solar Houses and Low Energy Buildings - IEA-SHC Task 32. Technical report, 2005. Accessible online at http://www.bfe.admin.ch/ dokumentation/publikationen/index.html?lang $=\mathrm{en}$.

I. Beausoleil-Morrison, F. MacDonald, and M. Kummert. Co-Simulation Between ESP-r and TRNSYS: More Highly Resolved Modelling of Integrated Building and Energy Systems. In 13th Conference of International Building Performance Simulation Association, pages 3458-3465, Chambéry, France, August 2013. IBPSA.

Ian Beausoleil-Morrison. The adaptive coupling of heat and air flow modelling within dynamic whole-building simulation. PhD thesis, University of Strathclyde, Glasgow, Scotland, 2000.

Ian Beausoleil-Morrison and Gintas Mitalis. BASESIMP: A Residential-Foundation 
Heat-Loss Algorithm for Incorporating into Whole-Building Energy-Analysis Programs. Technical report, Natural Resources Canada, Ottawa. Accessible online at http://www.esru.strath.ac.uk/Documents/BASESIMP_theory.pdf.

Ian Beausoleil-Morrison, Francesca Macdonald, Michaél Kummert, Timothy McDowell, and Romain Jost. Co-simulation between ESP-r and TRNSYS. Building Performance Simulation, 7(2):133-151, 2014. doi: 10.1080/19401493.2013.794864. Accessible online at http://dx.doi.org/10.1080/19401493.2013.794864.

N Blair and W. Keilholz. Introduction to TRNSYS. Technical report, CSTB, 2004. Accessible online at http://www.cmu.edu/iwess/workshops/TRNSYS_2004.pdf.

Sébastien Athanase Brideau. Collection and Storage of Solar Gains Incident on a Radiant Floor in Highly Glazed Houses. PhD thesis, Carleton University, Ottawa, Canada, 2016.

Canada Safety Council. Heated Debate about Hot Water. Technical report, Canada Safety Council, 2016. Accessible online at https://canadasafetycouncil. org/home-safety/heated-debate-about-hot-water.

JA Clark. Energy Simulation in Building Design. Butterworth Heinemann, Oxford, 2001.

CMHC. Riverdale NetZero Active Solar Thermal System. Technical report, Canada Mortgage and Housing Corporation, 2009. Accessible online at https://www. cmhc-schl.gc.ca/odpub/pdf/66741.pdf?fr $=1337021684560$. 
Skai Edwards. Sensitivity Analysis of Two Solar Combisystems Using Newly Developed Hot Water Draw Profiles. Master's thesis, Carleton University, Ottawa, Canada, 2014.

Skai Edwards, Ian Beausoleil-Morrison, and André Laperrière. Representative hot water draw profiles at high temporal resolution for simulating the performance of solar thermal systems. Solar Energy, 111:43 - 52, 2015. ISSN 0038-092X. doi: http://dx.doi.org/10.1016/j.solener.2014.10.026.

K. Ellehauge. Solar combisystems. Technical report, 2003. Accessible online at http://www.elle-kilde.dk/altener-combi/.

Energy Systems Research Unit, University of Strathclyde. ESP-r. Technical report, 2012. Accessible online at http://www.esru.strath.ac.uk/Programs/ESP-r.htm.

Francesca Macdonald and Romain Jost and Ian Beausoleil-Morrison and Mich ael Kummert and Timothy McDowell. Getting Started with the ESP-r-TRNSYS CoSimulator. Technical report, Carleton University, 2012.

Jan LM Hensen and Roberto Lamberts, editors. Building Performance Simulation for Design and Operation. Spon Press, London, 2011.

Honourable Catherine McKenna, Minister of Environment and Climate Change. Canada plays instrumental role in reaching historic climate agreement. Technical report, Government of Canada, 2015. Accessible online at http://news.gc.ca/ web/article-en.do?nid=1024639.

Alexandre Hugo, Radu Zmeureanu, and Hugues Rivard. Solar combisystem with seasonal thermal storage. Journal of Building Performance Simulation, 3(4):255-268, 
December 2010. ISSN 1940-1493. doi: 10.1080/19401491003653603. Accessible online at http://www.tandfonline.com/doi/abs/10.1080/19401491003653603.

Intergovernmental Panel on Climate Change. Climate change 2014 synthesis report. Technical report, IPCC, 2014. Accessible online at http://www.ipcc.ch/pdf/ assessment-report/ar5/syr/AR5_SYR_FINAL_All_Topics.pdf.

Intergovernmental Panel on Climate Change. Summary for Policymakers. In: IPCC Special Report on Renewable Energy Sources and Climate Change Mitigation. Technical report, Cambridge University Press, Cambridge, United Kingdom and New York, NY, USA., 2015. Accessible online at http://www.ipcc.ch/pdf/ special-reports/srren/Summary\%20for\%20Policymakers.pdf.

International Energy Agency. Task 7 - Central Solar Heating Plants with Seasonal Storage - Status Report. Technical report, IEA, 1990.

International Energy Agency. Report on Solar Combisystems Modelled in Task 26 (System Description, Modelling, Sensitivity, Optimisation). Technical report, IEA, 2003. Accessible online at http://task26.iea-shc.org/data/sites/1/publications/ task26-c-combisystems modelled.pdf.

International Energy Agency. Solar Combisystems. Technical report, IEA, 2014. Accessible online at http://task26.iea-shc.org/.

International Energy Agency. World Energy Outlook 2015 Special Report on Energy and Climate Change. Technical report, IEA, 2015. Accessible online at https://www.iea.org/publications/freepublications/publication/ WEO2015SpecialReportonEnergyandClimateChange.pdf. 
P.D. Lund. Sizing and applicability considerations of solar combisystems. Solar Energy, 78(1):59-71, January 2005. ISSN 0038092X. doi: 10.1016/j.solener. 2004.07.008. Accessible online at http://linkinghub.elsevier.com/retrieve/pii/ S0038092X04001975.

Meteorological Service of Canada (MSC) and The National Research Council of Canada. CANADIAN WEATHER FOR ENERGY CALCULATIONS (CWEC FILES). Technical report, Atmospheric Environment Service (AES) of Environment Canada, Downsview, 2010. Accessible online at ftp://ftp.tor.ec.gc.ca/Pub/Engineering_Climate_Dataset/Canadian_ Weather_year_for_Energy_Calculation_CWEC/ENGLISH/CWEEDS\% 20documentation_Revised\%2020100602.txt.

Natural Resources Canada. What is R-2000? Technical report, NRCan, 2014. Accessible online at http://www.nrcan.gc.ca/energy/efficiency/housing/new-homes/ 5051.

Amaya V Novo, Joseba R Bayon, Daniel Castro-Fresno, and Jorge RodriguezHernandez. Review of seasonal heat storage in large basins: Water tanks and gravel-water pits. Applied Energy, 87(2):390-397, February 2009. ISSN 03062619. doi: 10.1016/j.apenergy.2009.06.033. URL http://www.sciencedirect.com/science/ article/B6V1T-4WXRDS5-1/2/87bd784f61678d8e2b2cf7a7b14193ff.

Office of Energy Efficiency. Canada's Secondary Energy Use by Sector, EndUse and Sub-Sector. Technical report, OEE, Ottawa, 2013. Accessible online at http://oee.nrcan.gc.ca/corporate/statistics/neud/dpa/menus/trends/ handbook/handbook_aaa_ca.cfm. 
Office of Energy Efficiency. Canada's secondary energy use and ghg emissions by energy source. Technical report, OEE, Ottawa, 2015a. Accessible online at http: //oee.nrcan.gc.ca/corporate/statistics/neud/dpa/showTable.cfm.

Office of Energy Efficiency. 2011 Survey of Household Energy Use (SHEU) 6.1 Main Heating System. Technical report, OEE, Ottawa, 2015b. Accessible online at http://oee.nrcan.gc.ca/corporate/statistics/neud/dpa/showTable. cfm?type $=$ SH\&sector $=$ aaa\&juris $=$ ca\&rn $=20 \&$ page $=1$.

Office of Energy Efficiency. 2011 Survey of Household Energy Use (SHEU) - 9.1 Hot Water. Technical report, OEE, Ottawa, 2015c. Accessible online at http://oee.nrcan.gc.ca/corporate/statistics/neud/dpa/showTable.cfm? type $=$ SH\&sector $=$ aaa $\&$ juris $=$ ca\&rn $=30 \&$ page $=1$.

Ontario. Climate change action plan. Technical report, Ministry of the Environment and Climate Change, Ottawa, 2016. Accessible online at https://www.ontario.ca/ page/climate-change-action-plan.

Patrice Pinel, Cynthia Cruickshank, Ian Beausoleil-Morrison, and Adam Wills. A review of available methods for seasonal storage of solar thermal energy in residential applications. Renewable and Sustainable Energy Reviews, 15(7):3341-3359, September 2011. ISSN 13640321. doi: 10.1016/j.rser.2011.04.013. Accessible online at http://linkinghub.elsevier.com/retrieve/pii/S136403211100150X.

Roth. Panel System for Radiant Heating Systems. Technical report, Roth, 2016. Accessible online at http://www.roth-usa.com/products_radiant_panelsystem.cfm. 
Bruce Sibbitt, Doug McClenahan, Reda Djebbar, Jeff Thornton, Bill Wong, Jarrett Carriere, and John Kokko. The Performance of a High Solar Fraction Seasonal Storage District Heating System - Five Years of Operation. Energy Procedia, 30: 856-865, January 2012. ISSN 18766102. doi: 10.1016/j.egypro.2012.11.097. Accessible online at http://linkinghub.elsevier.com/retrieve/pii/S187661021201613X.

DL Siurna, LJ D'Andrea, and KGT Hollands. A Canadian Representative Meteorological Year for Solar System Simulation. In Proceedings of the 10th annual conference of the Solar Energy Society of Canada, Calgary, Alberta, Canada, Aug 1984. SESCI.

SM Colclough and PW Griffiths and NJ Hewitt. A year in the life of a Passive House with Solar Energy Store. Technical report, University of Ulster, 2011. Accessible online at http://www.energyexpertise.net/attachments/File/A_Year_ in_the_Life/A_year_in_the_ife.pdf.

Solar Rating \& Certification Corporation. Quality Assurance in solar thermal heating and cooling technology - keeping track with recent and upcoming developments. A Guide to Standard EN 12975. Technical report, SRCC, 2012. Accessible online at http://www.solar-rating.org/about/purpose.html.

Solar Rating \& Certification Corporation. About Us - Purpose. Technical report, SRCC, 2015. Accessible online at http://www.solar-rating.org/about/purpose. html.

Solar Rating and Certifcation Commission. Solar Collector Certification and Rating - Apricus AP-30. Technical report, SRCC, Branford, CT, 2009. 
SolarGIS. Maps of Global horizontal irradiation (GHI). Technical report, GeoModel Solar, Bratislava, 2015. Accessible online at http://solargis.info/doc/ free-solar-radiation-maps-GHI\#C.

Paul Strachan. ESP-r: Summary of Validation Studies. Technical report, 2000. Accessible online at http://www.esru.strath.ac.uk/Documents/validation.pdf.

SUSTERRA ${ }^{\circledR}$. INTERCOOL ${ }^{\circledR}$ BIO-GREEN. Technical report, 2017. Accessible online at http://www.2hsc.com/biogreen/pdf/INTERCOOL\%20BIOGREEN\% 20TECHNICAL\%20DATA.pdf.

Marshall L Sweet and James T McLeskey Jr. Numerical simulation of underground seasonal solar thermal energy storage (sstes) for a single family dwelling using trnsys. Solar Energy, 86:289-300, 2012. ISSN 0038-092X/\$. doi: 10.1016/j.solener. 2011.10.002.

The Greenway Group. Intercool ${ }^{\circledR}$ Bio-Green Heat Transfer Fluid. Technical report, The Greenway Group, Burlington ON, 2013.

Thermal Energy System Specialists. Component Library Overview. Technical report, TESS, 2012a. Accessible online at http://www.trnsys.com/.

Thermal Energy System Specialists. TESS Storage Tank Library Mathematical Reference. Technical report, TESS, 2012b. Accessible online at http://www.trnsys. $\operatorname{com} /$.

Thermal Energy System Specialists. TRNSYS. Technical report, TESS, 2015. Accessible online at http://www.trnsys.com/. 
United Nations Framework Convention on Climate Change. Paris agreement. Technical report, UNFCCC, 2016. Accessible online at http://unfccc.int/paris _ agreement/items/9444.php.

IS Walker and DJ Wilson. The Alberta Air Infiltration Model. Technical report, University of Alberta, Edmonton, 1990. Accessible online at http://www.aivc.org/ sites/default/files/airbase_3705.pdf.

Weimin Wang, Ian Beausoleil-Morrison, and James Reardon. Evaluation of the Alberta air infiltration model using measurements and inter-model comparisons. Building and Environment, 44:309-318, 2009.

Werner Weiss, editor. Solar Heating Systems for Houses A Design Handbook for Solar Combisystems. The Cromwell Press, London, 2003.

Adam Wills. Design and co-simulation of a seasonal solar thermal system for a Canadian single - family detached house. Master's thesis, Carleton University, Ottawa, Canada, 2013. 


\section{Appendix A}

\section{Additional Results Plots}

\section{A.1 Cloudy Spring Day - 12 May}

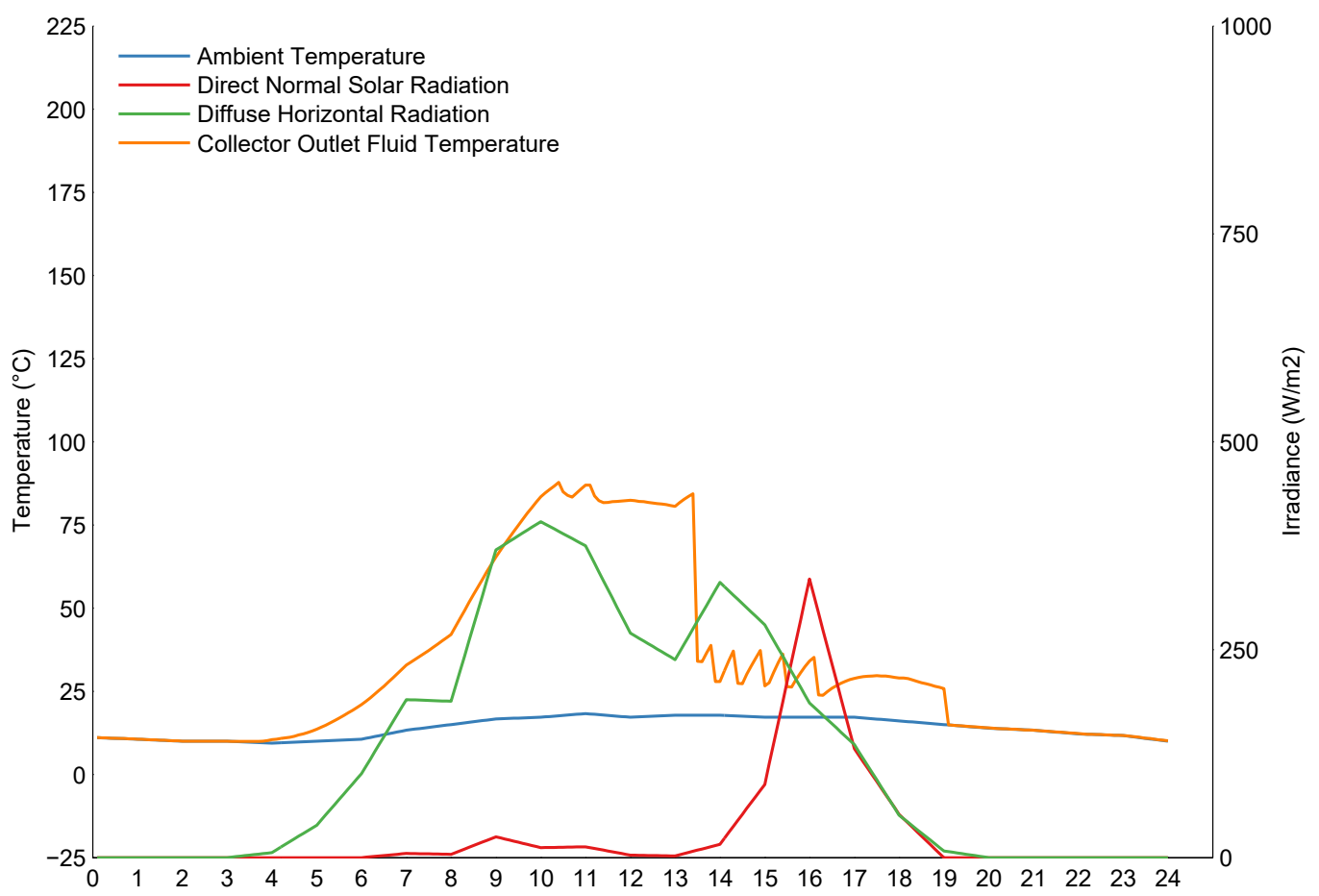

Figure 47: Cloudy Spring Day - Ambient Temperature and Irradiance 
(a) Diurnal

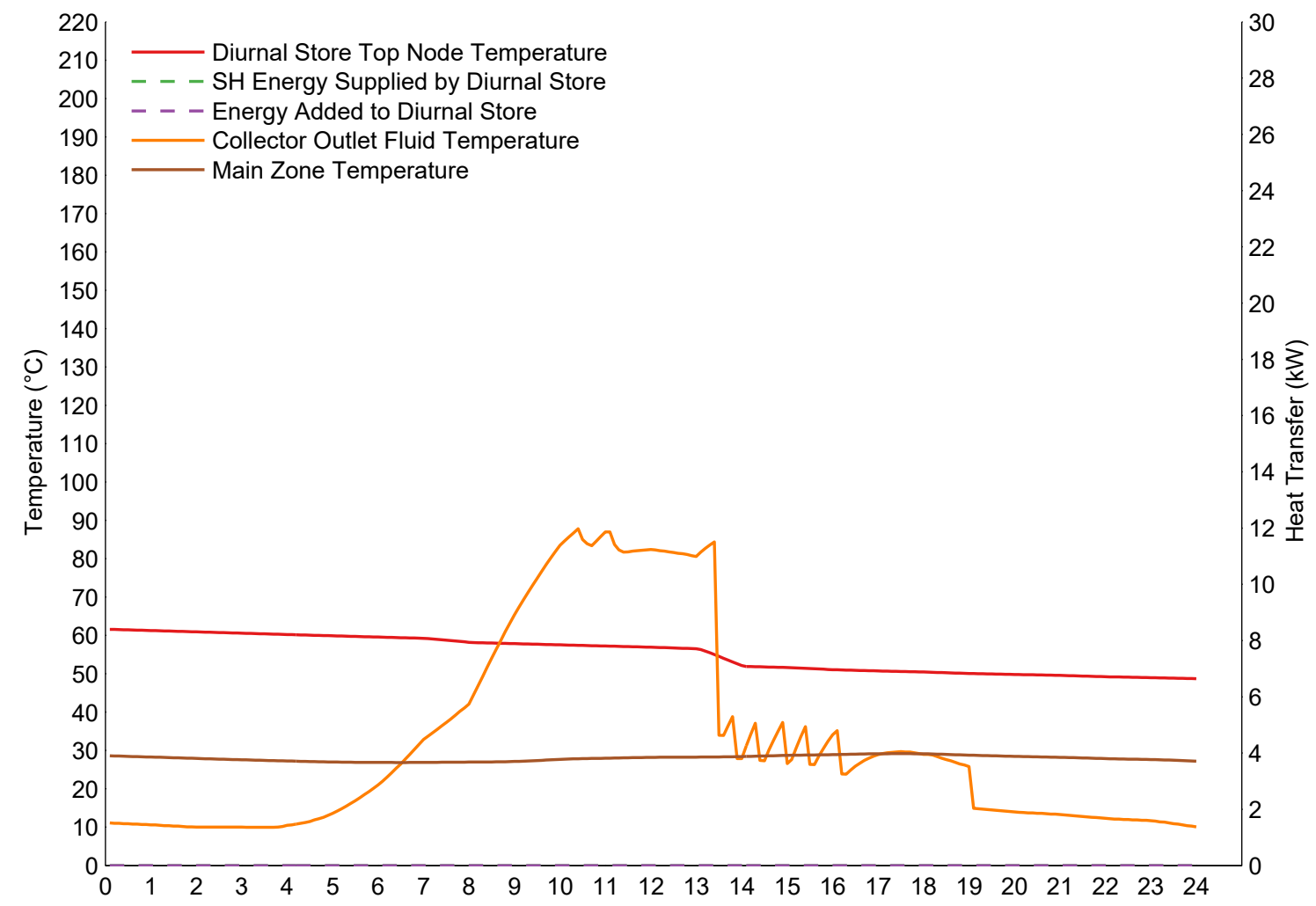

(b) Seasonal

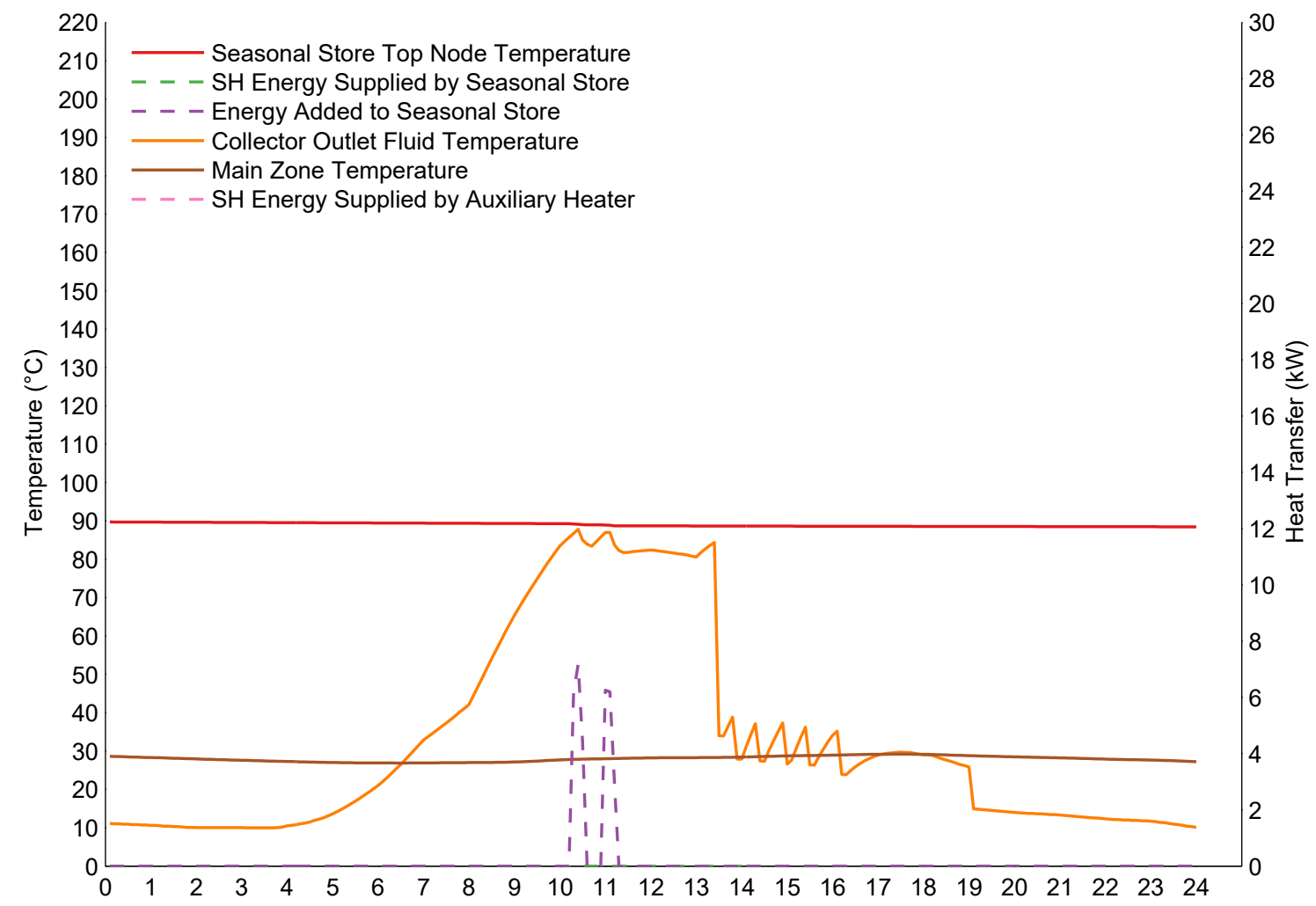

Figure 48: Cloudy Spring Day - Store Behaviour 


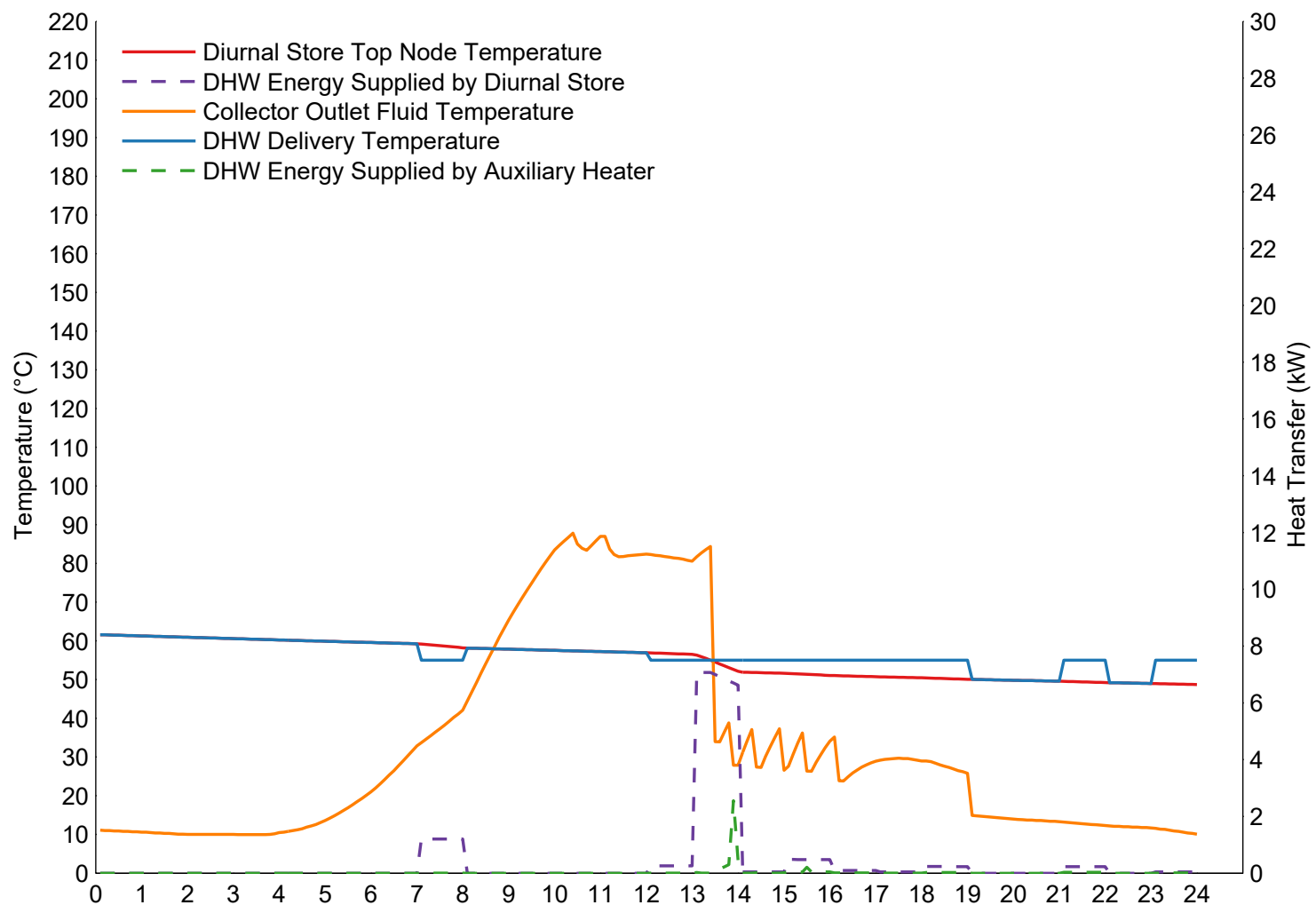

Figure 49: Cloudy Spring Day - DHW Loads

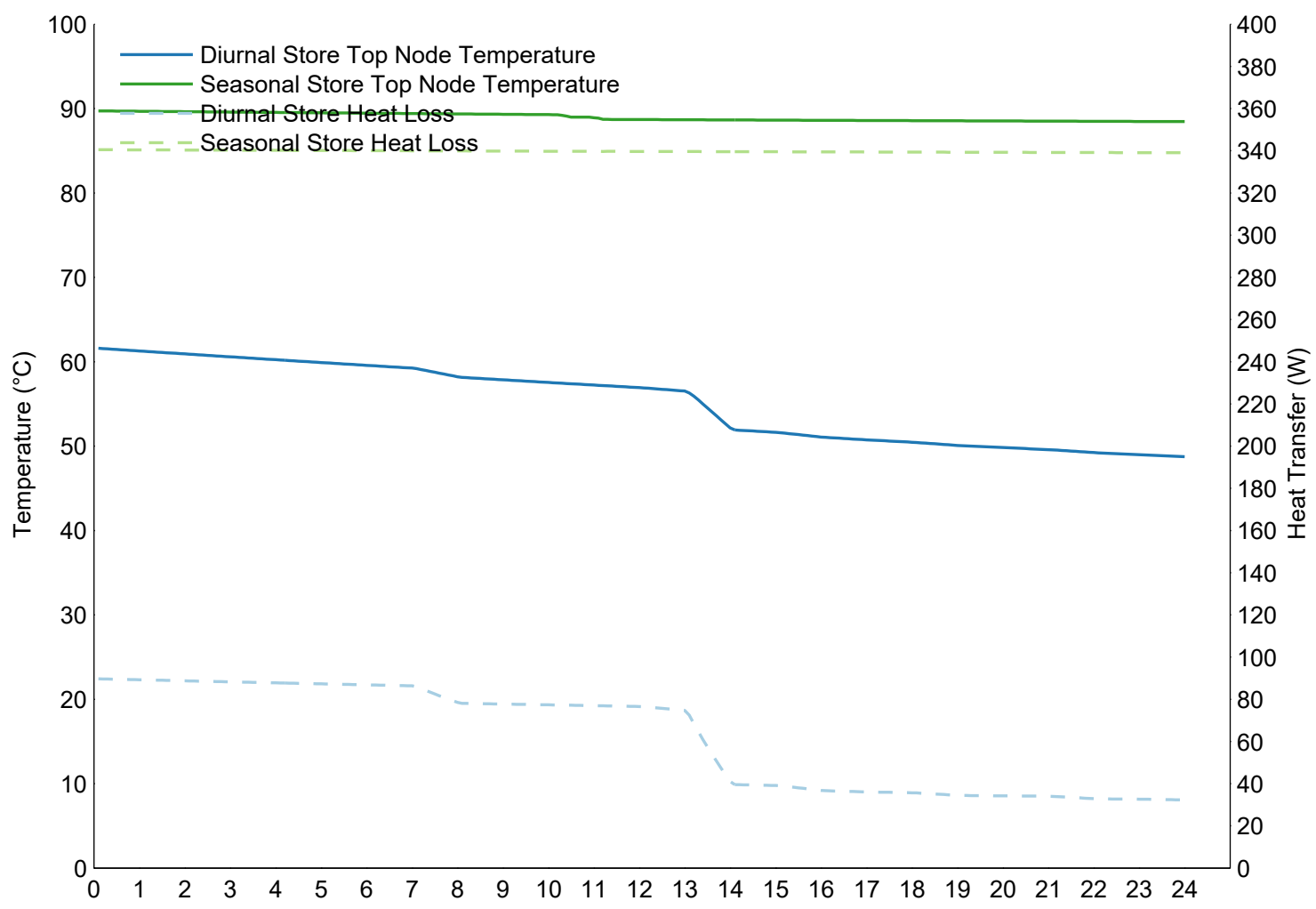

Figure 50: Cloudy Spring Day - Heat Loss 
(a) Diurnal

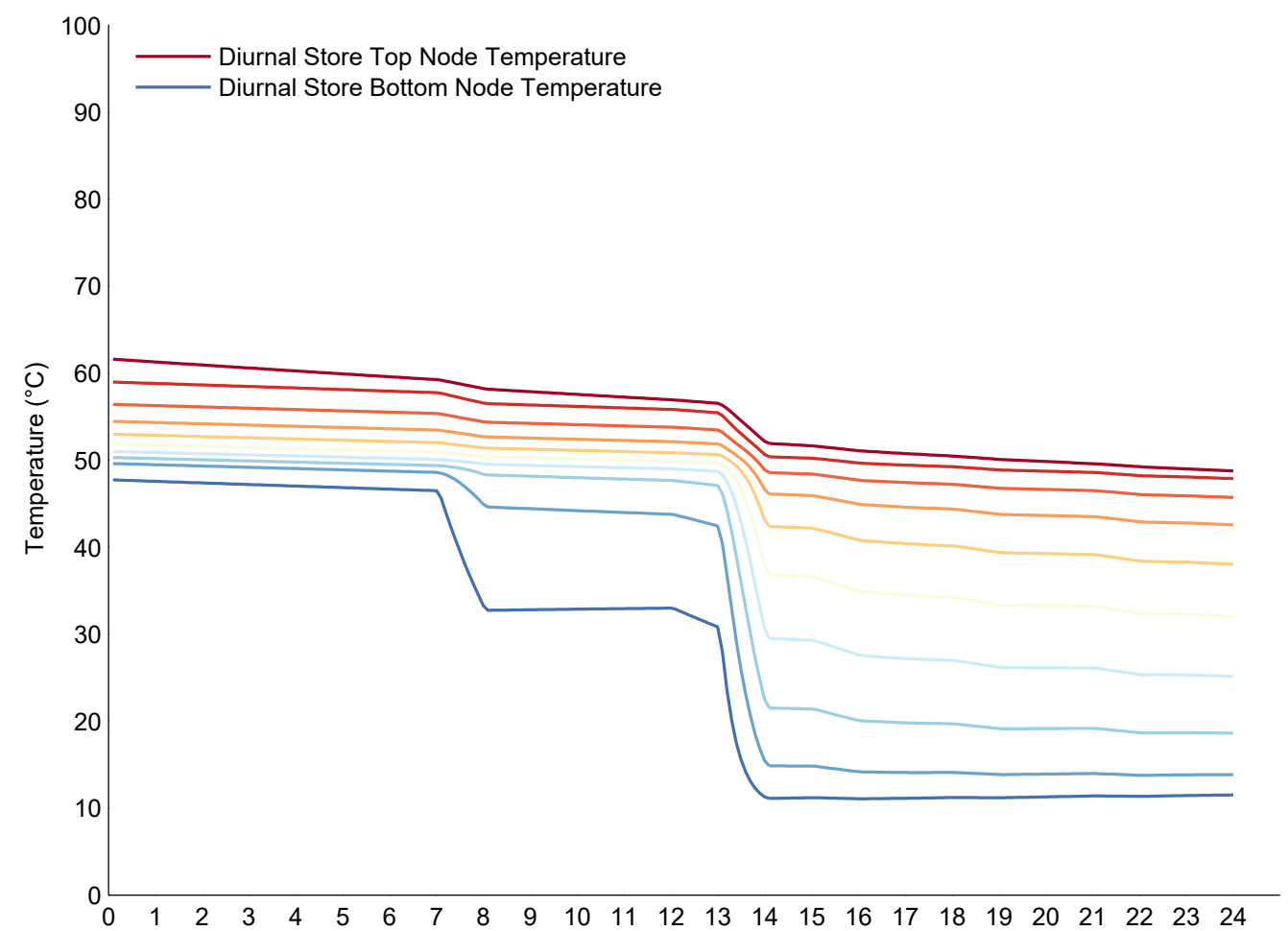

(b) Seasonal

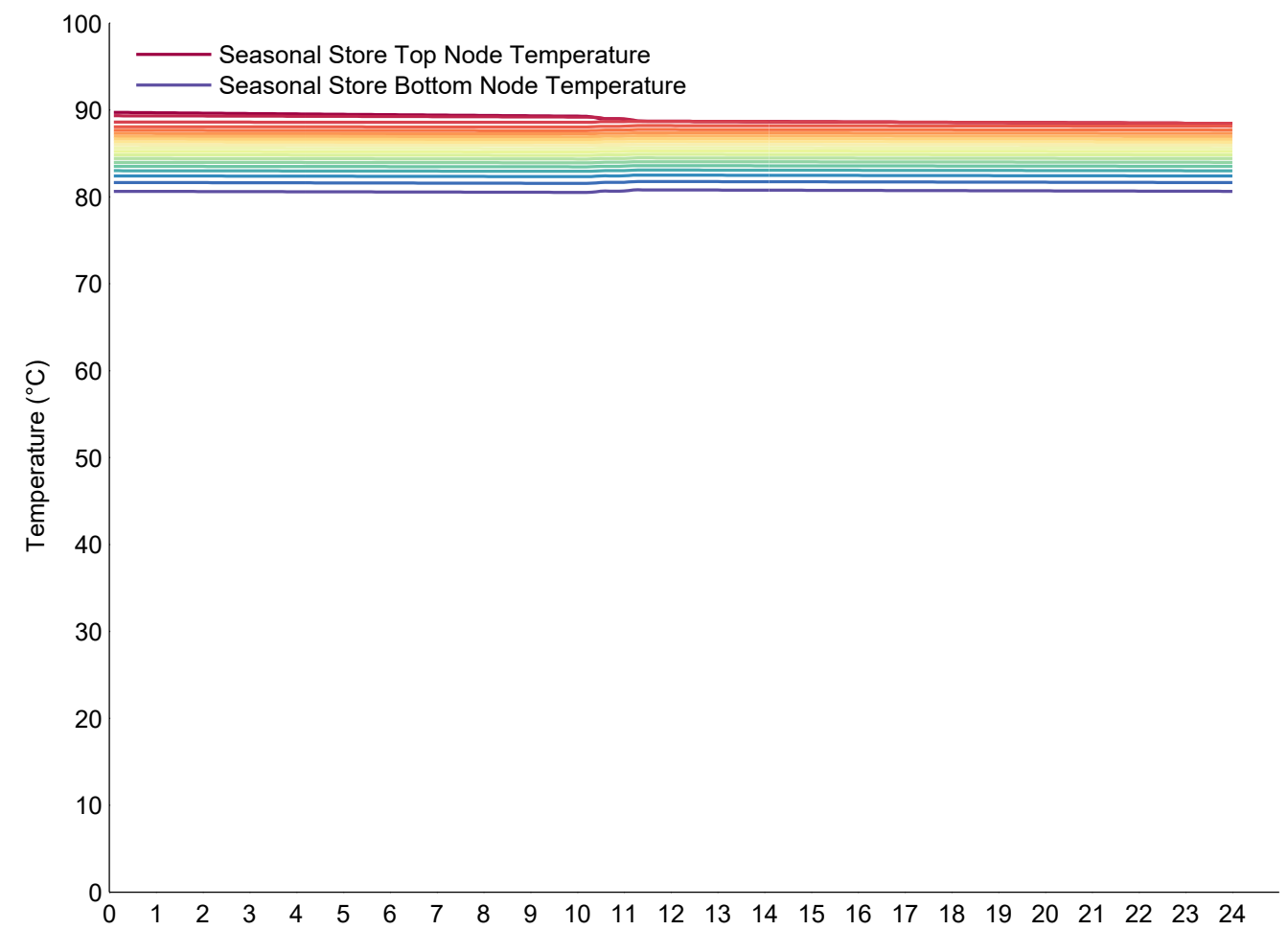

Figure 51: Cloudy Spring Day - Store Stratification 


\section{A.2 Cloudy Autumn Day - 3 October}

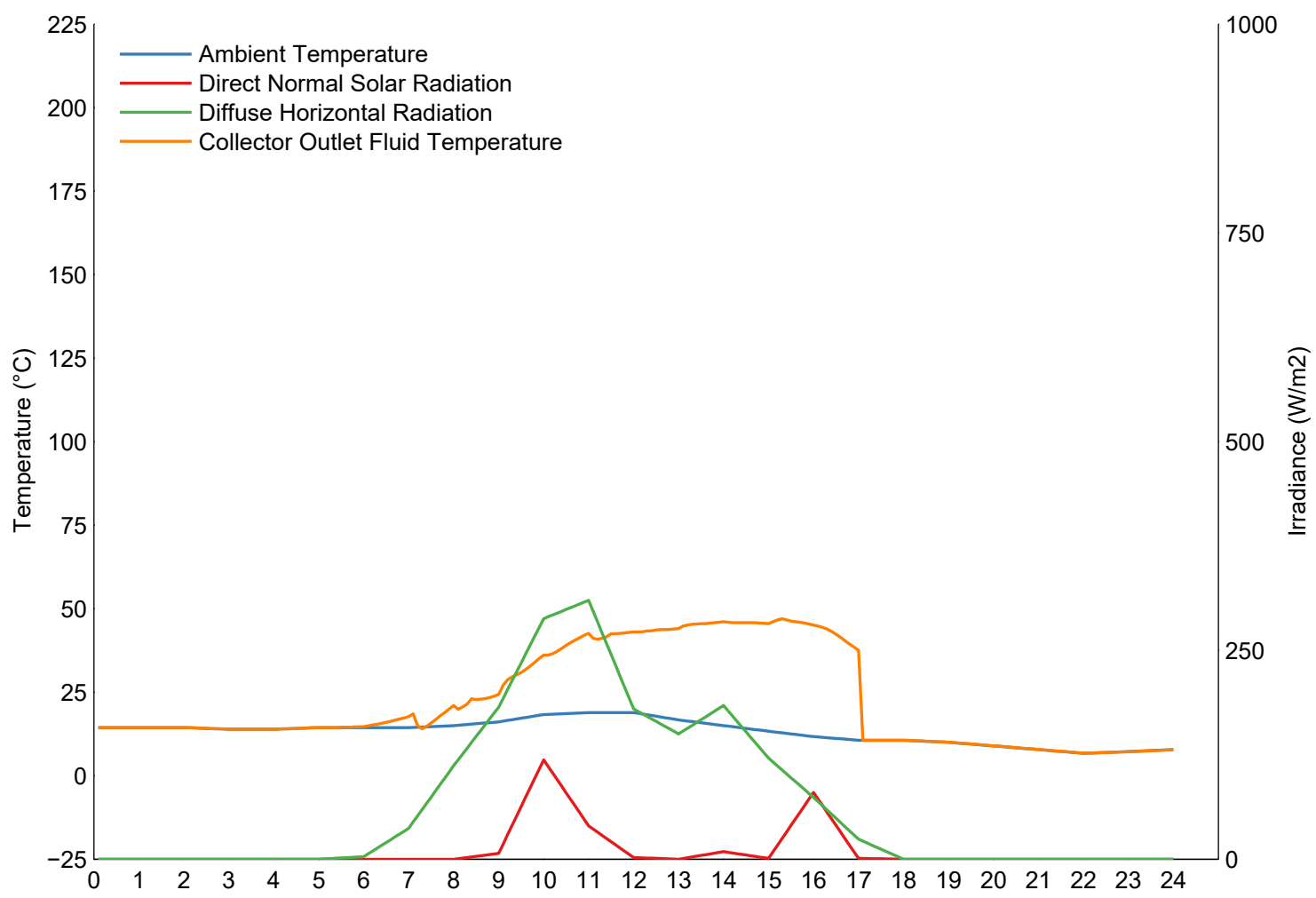

Figure 52: Cloudy Autumn Day - Ambient Temperature and Irradiance 
(a) Diurnal

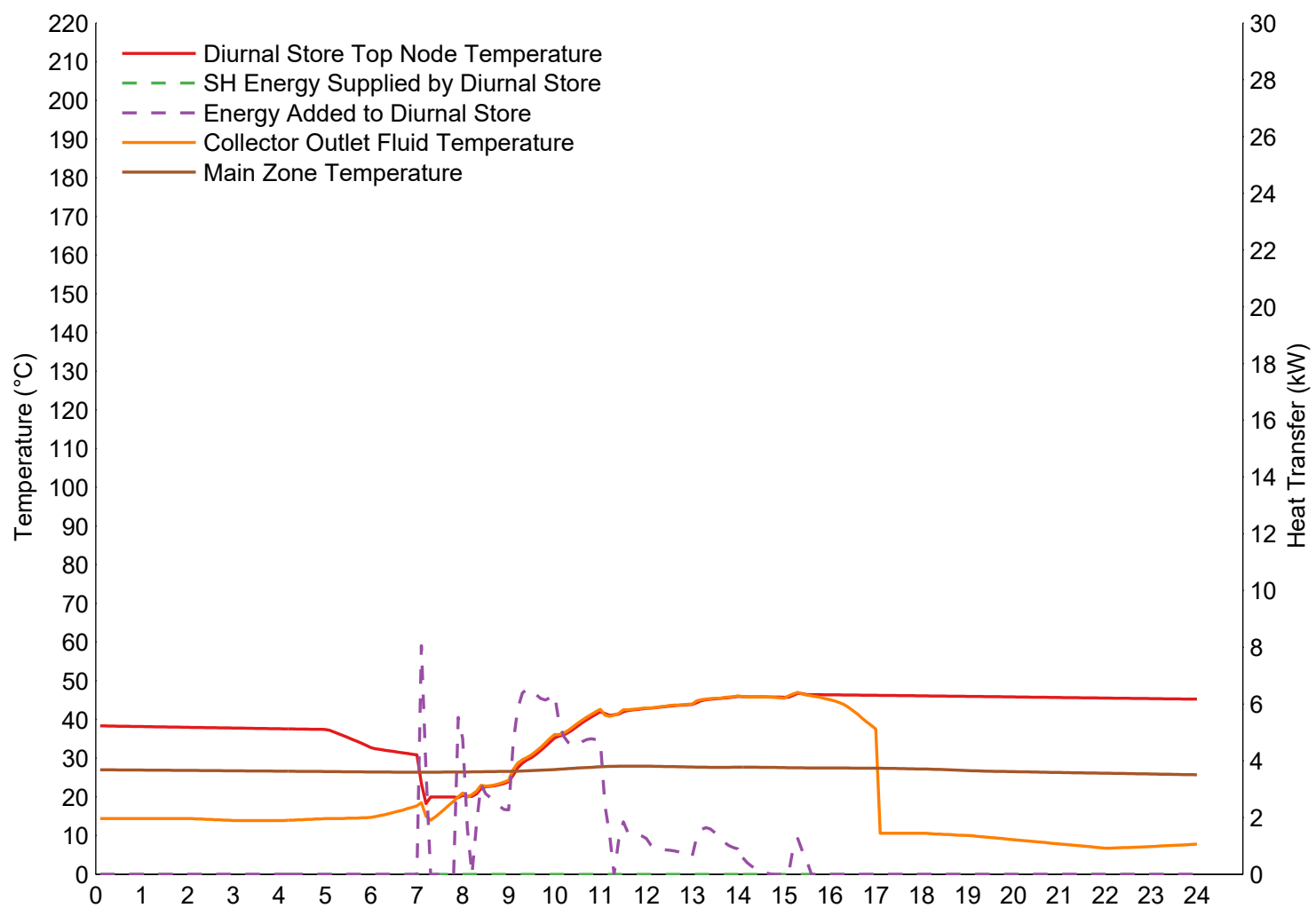

(b) Seasonal

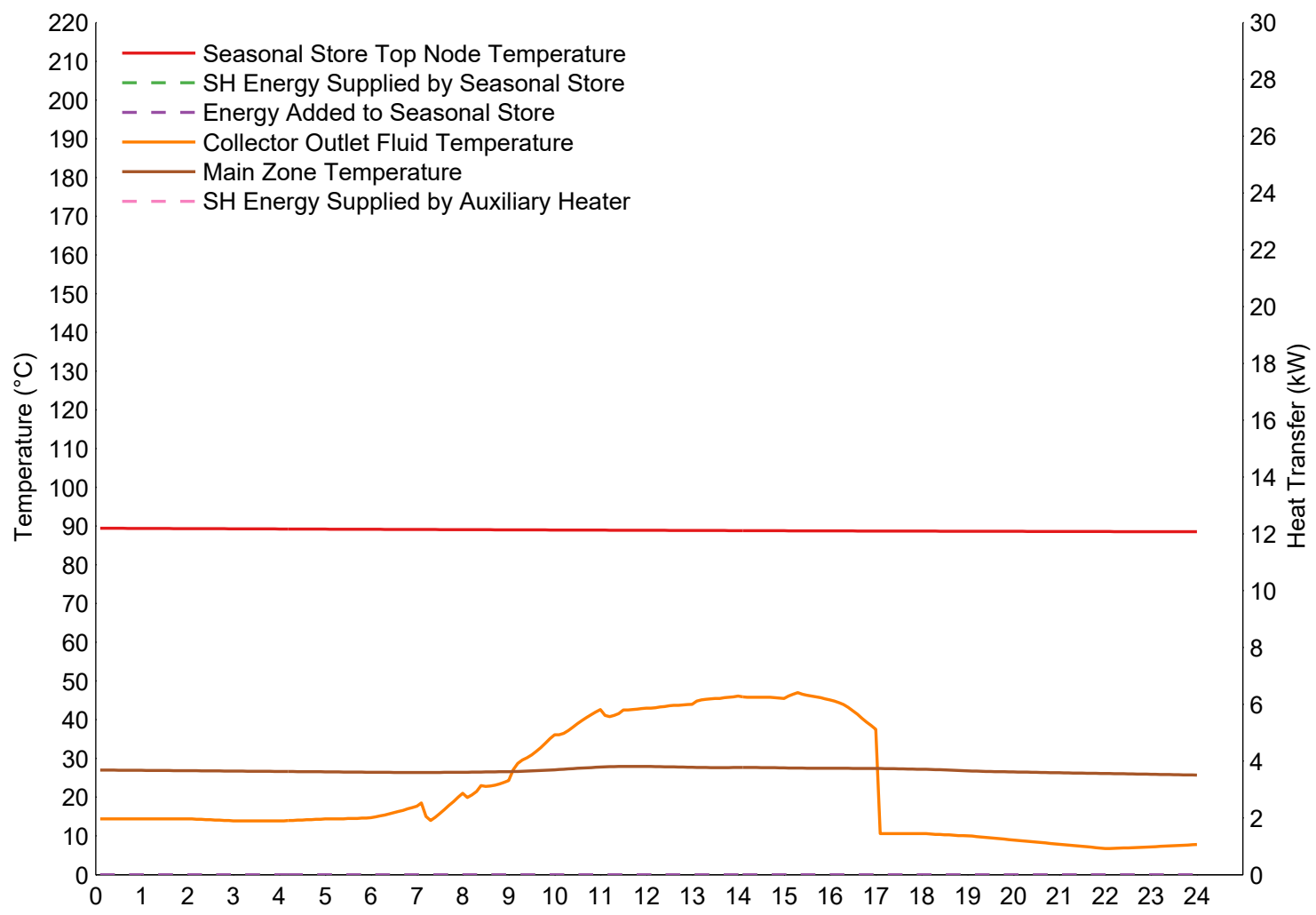

Figure 53: Cloudy Autumn Day - Store Behaviour 


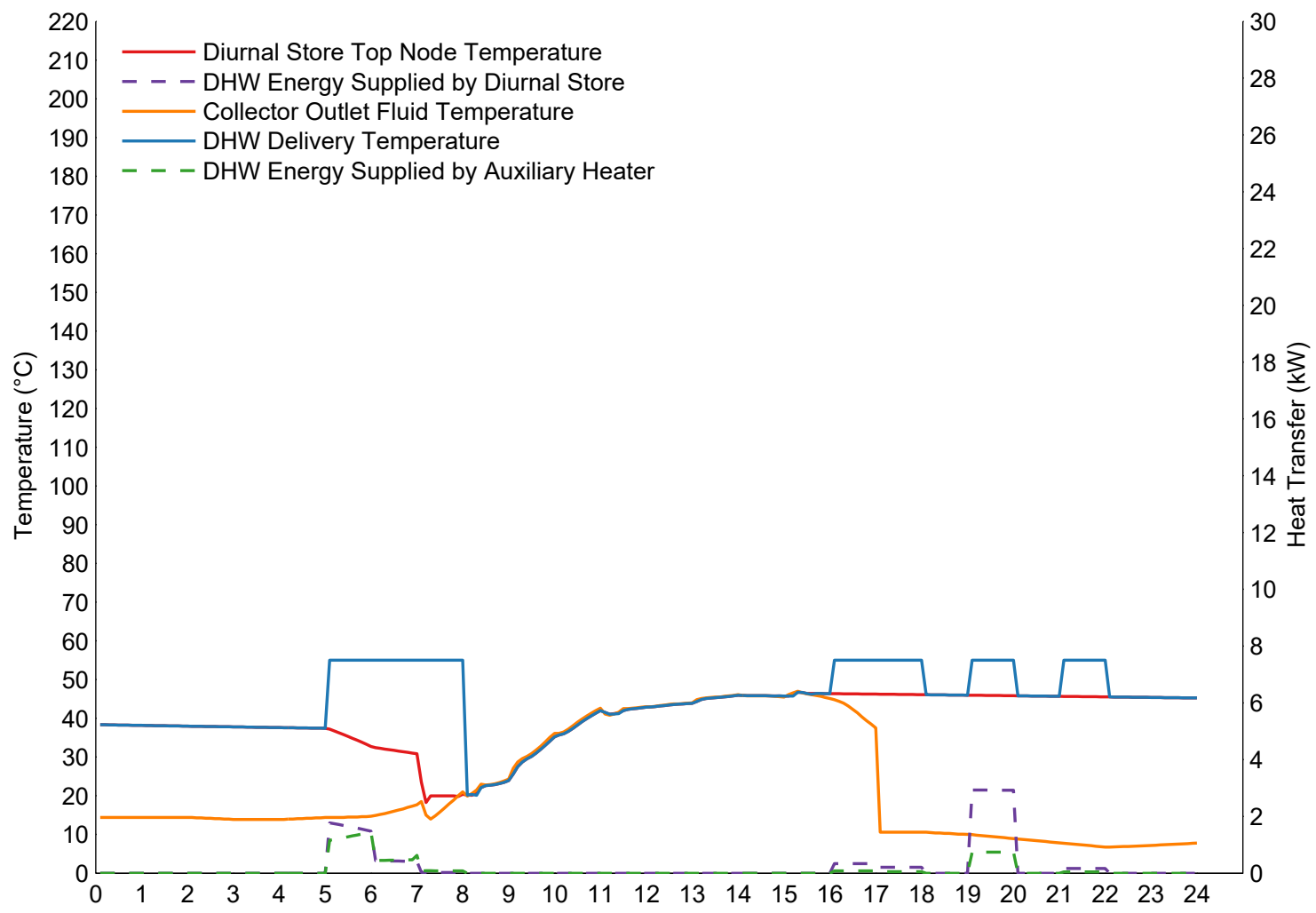

Figure 54: Cloudy Autumn Day - DHW Loads

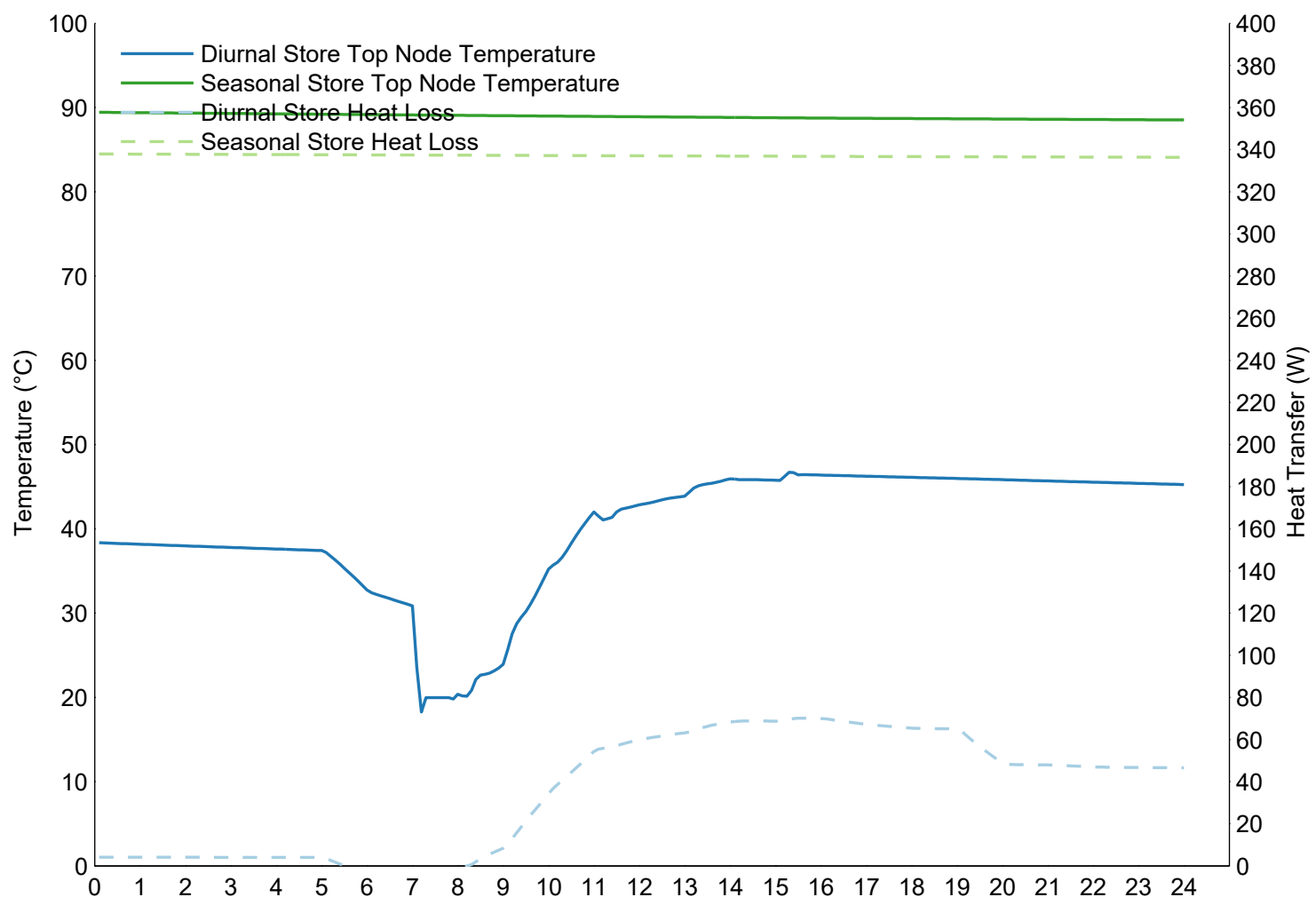

Figure 55: Cloudy Autumn Day - Heat Loss 
(a) Diurnal

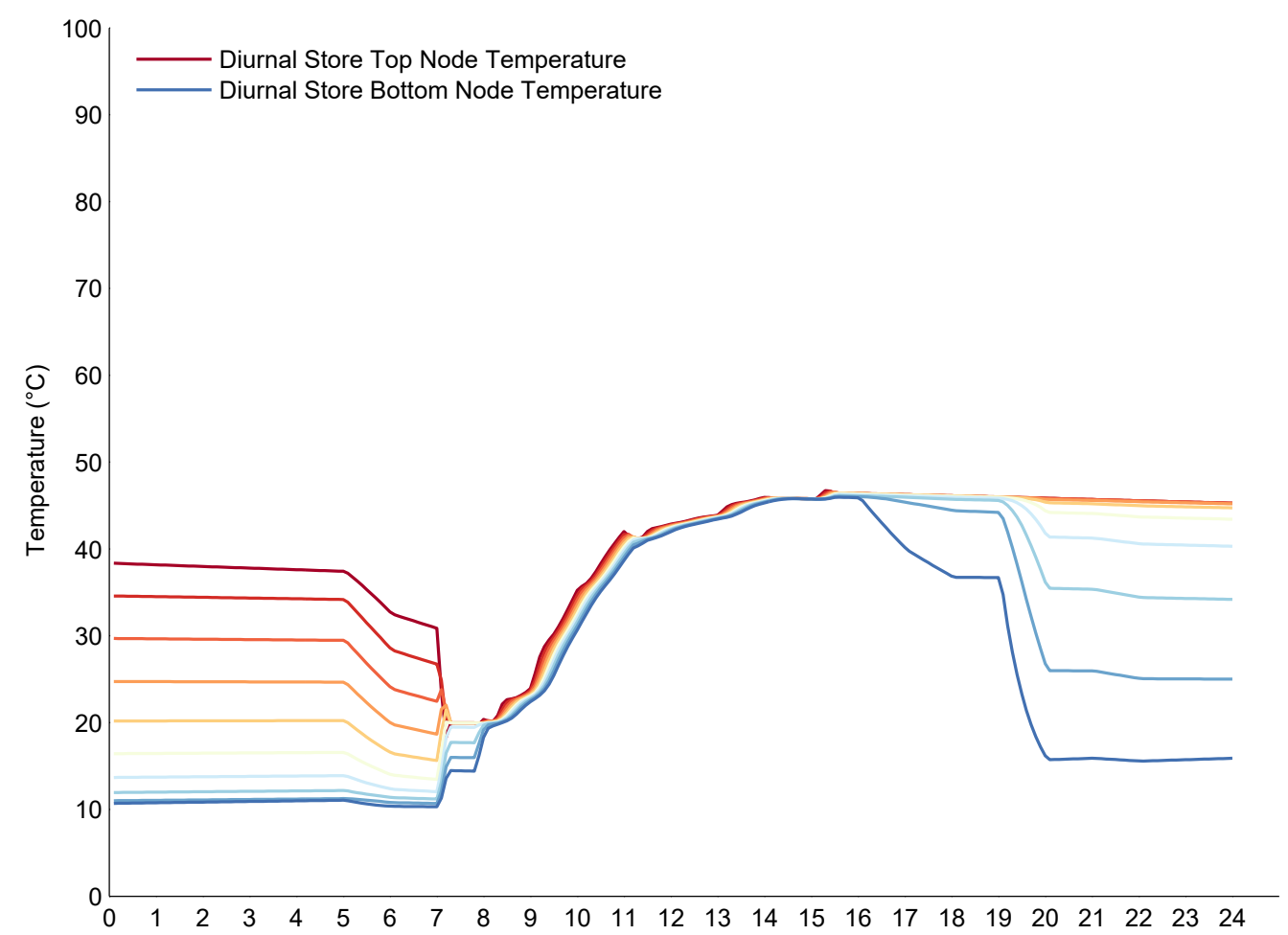

(b) Seasonal

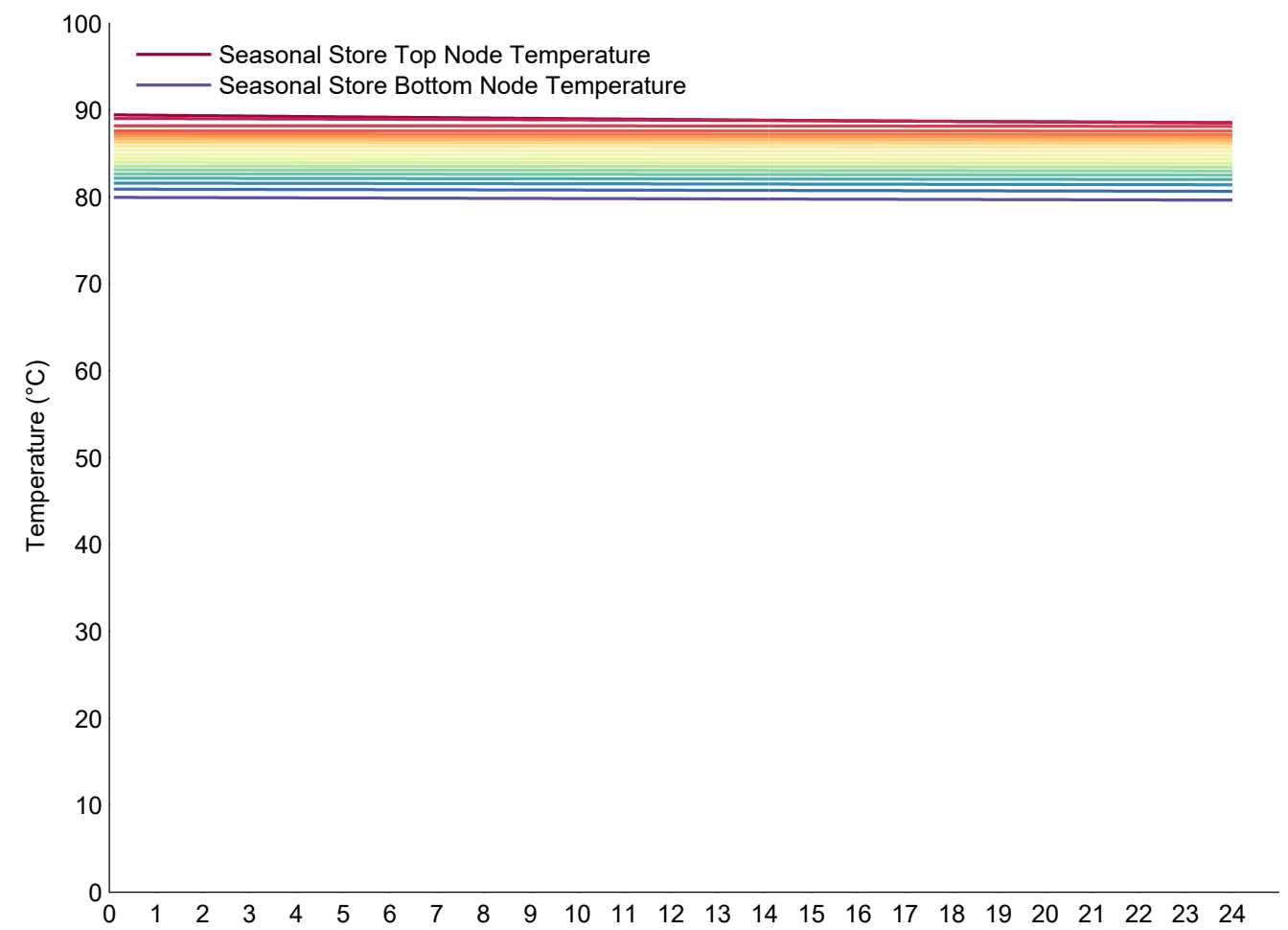

Figure 56: Cloudy Autumn Day - Store Stratification 


\section{A.3 Cloudy Winter Day - 13 January}

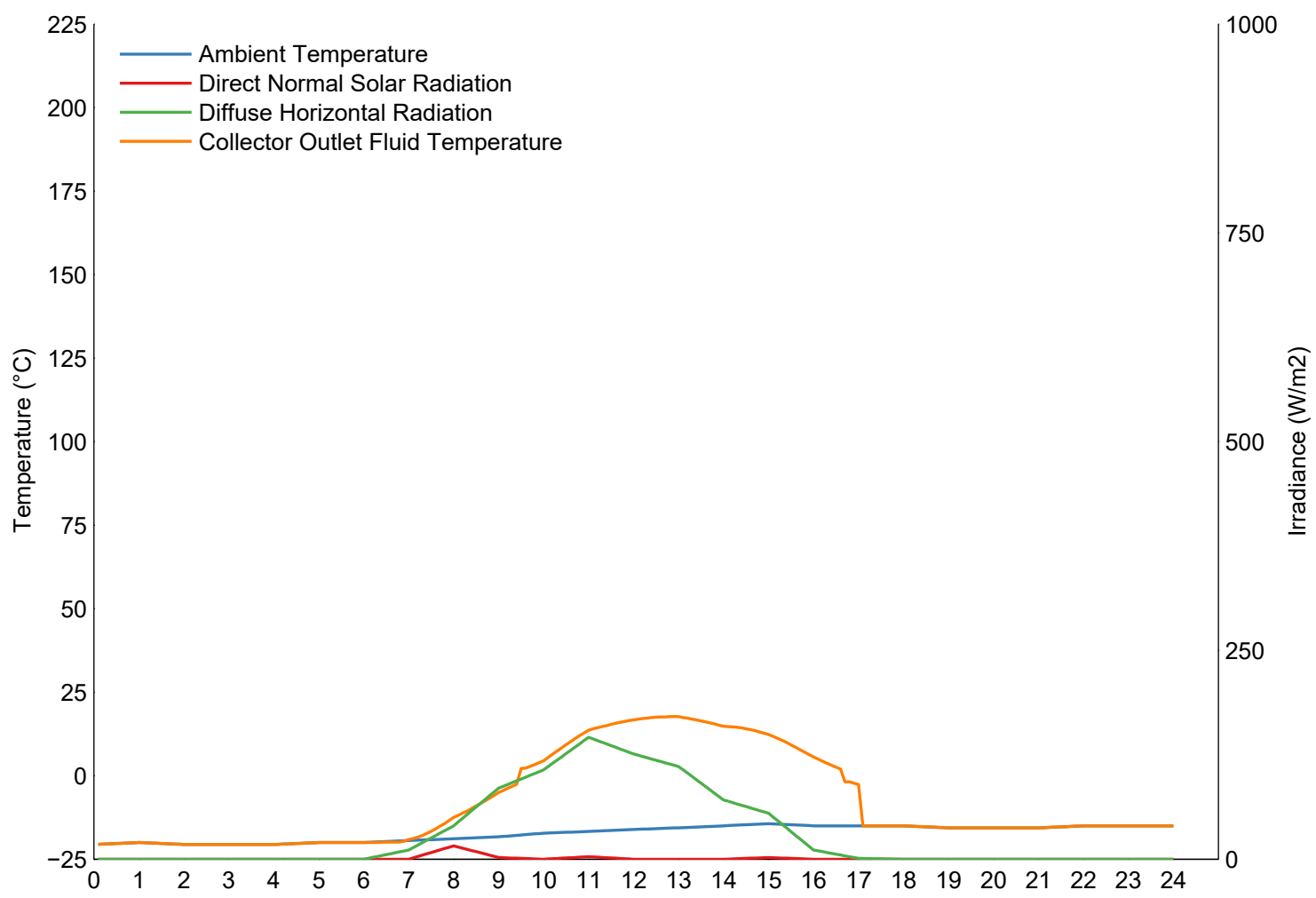

Figure 57: Cloudy Winter Day - Ambient Temperature and Irradiance 
(a) Diurnal

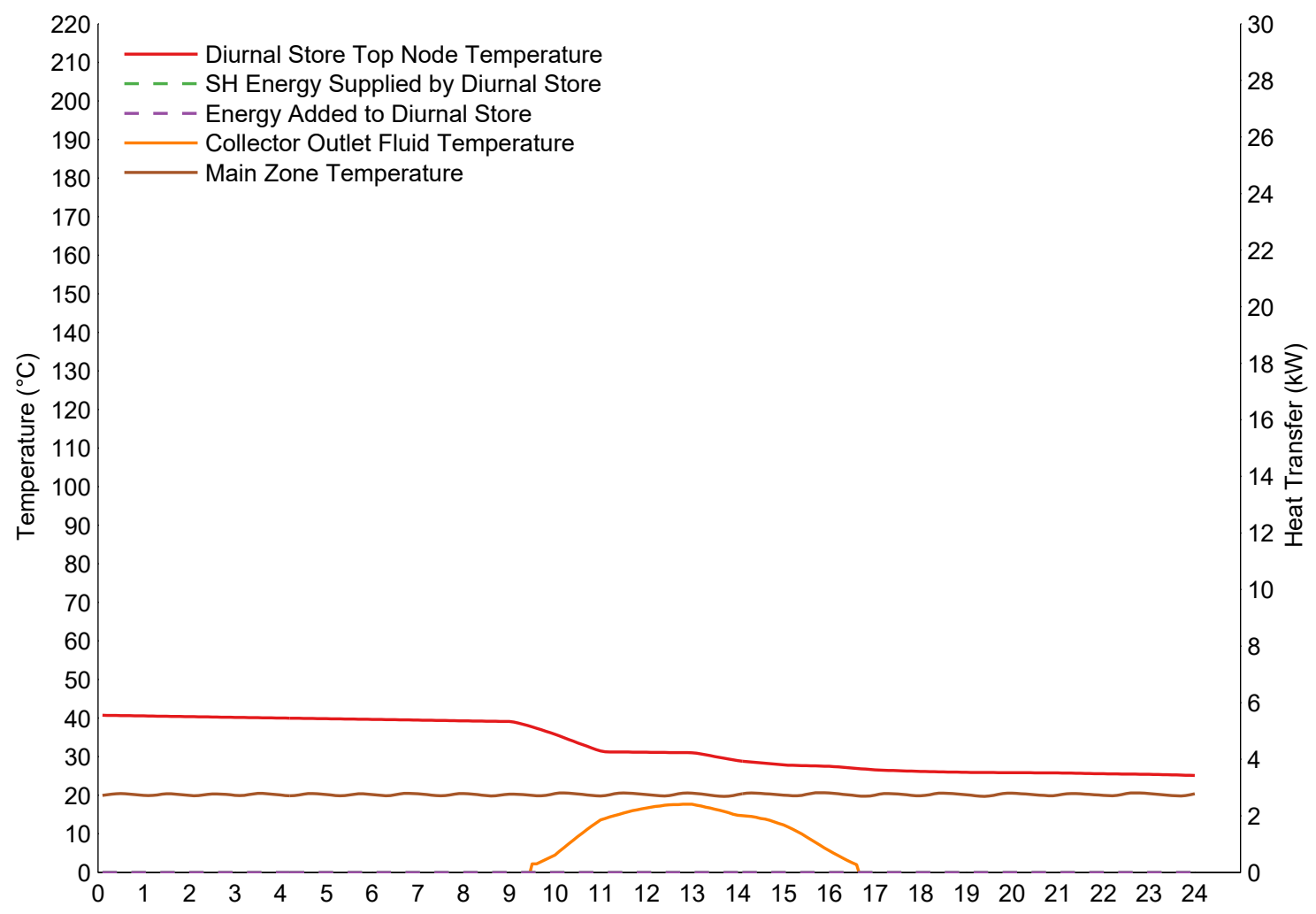

(b) Seasonal

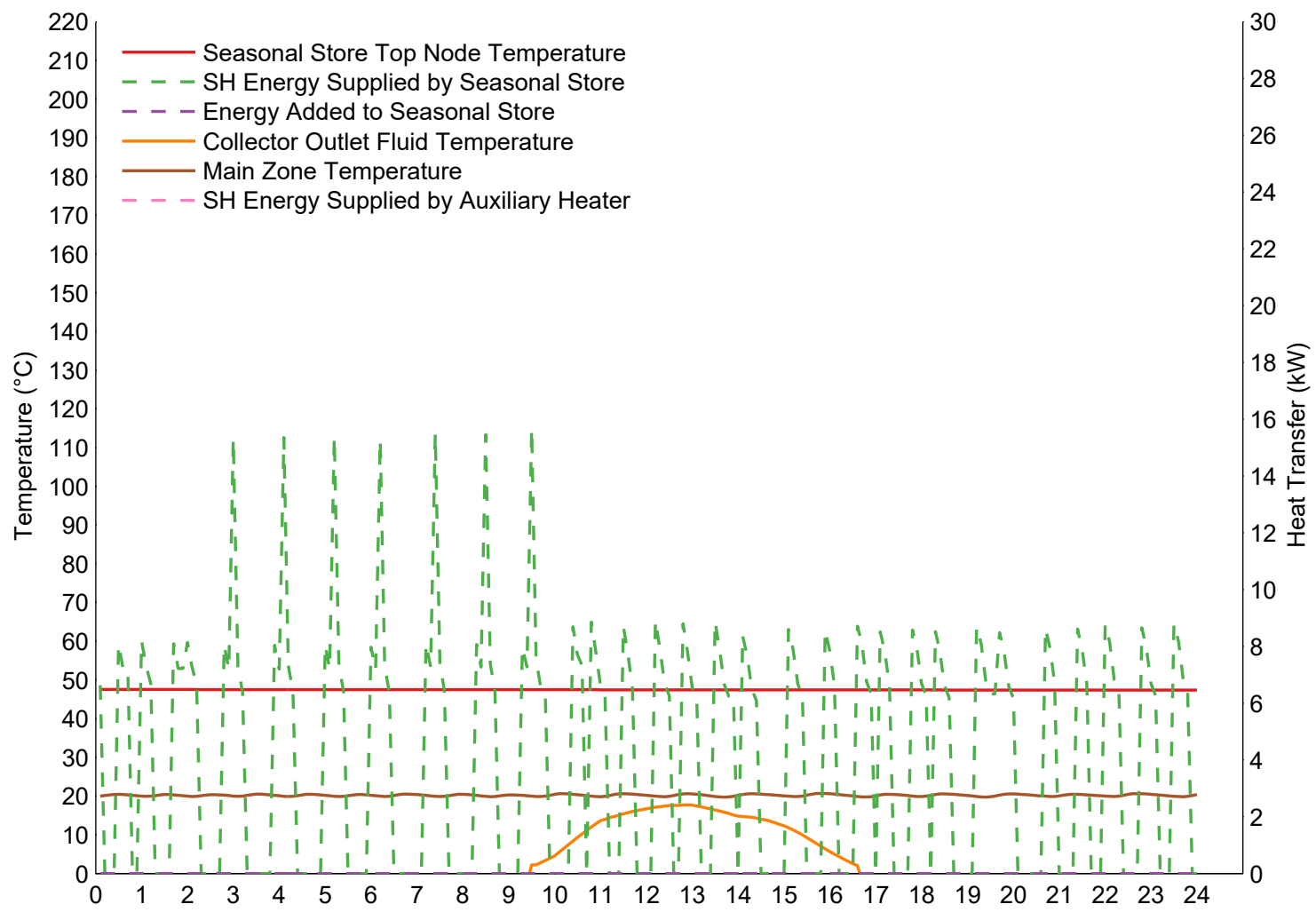

Figure 58: Cloudy Winter Day - Store Behaviour 


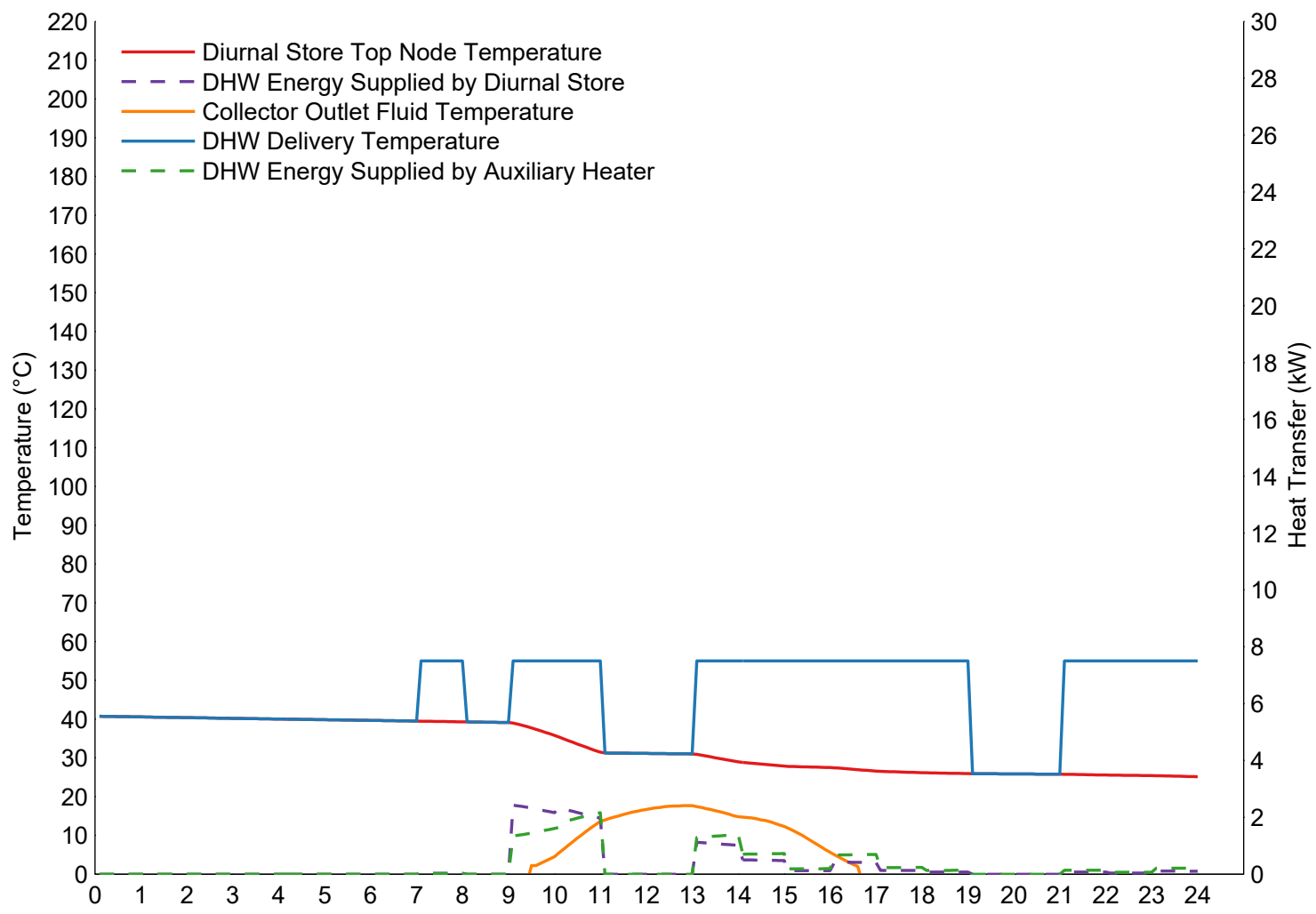

Figure 59: Cloudy Winter Day - DHW Loads

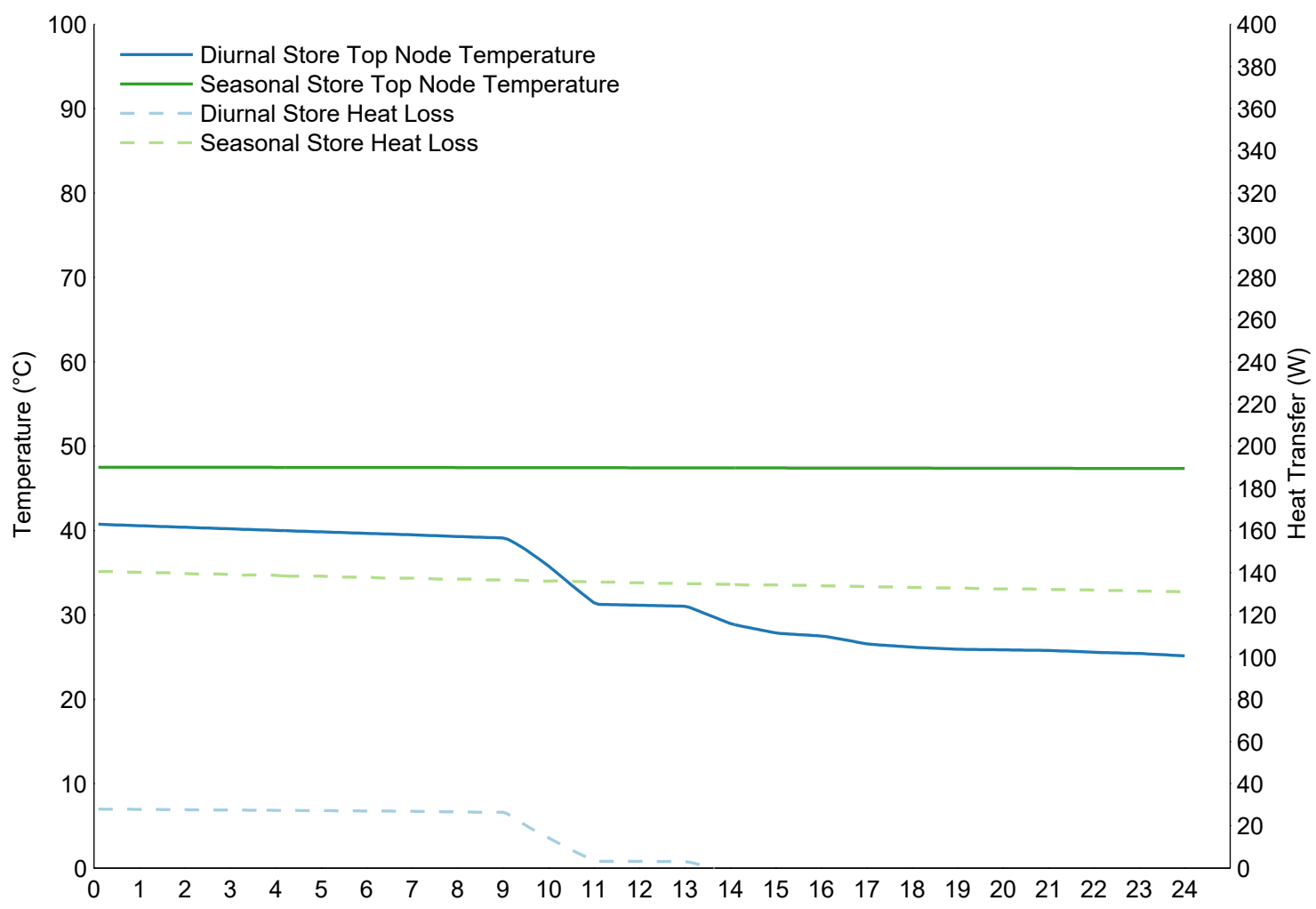

Figure 60: Cloudy Winter Day - Heat Loss 
(a) Diurnal

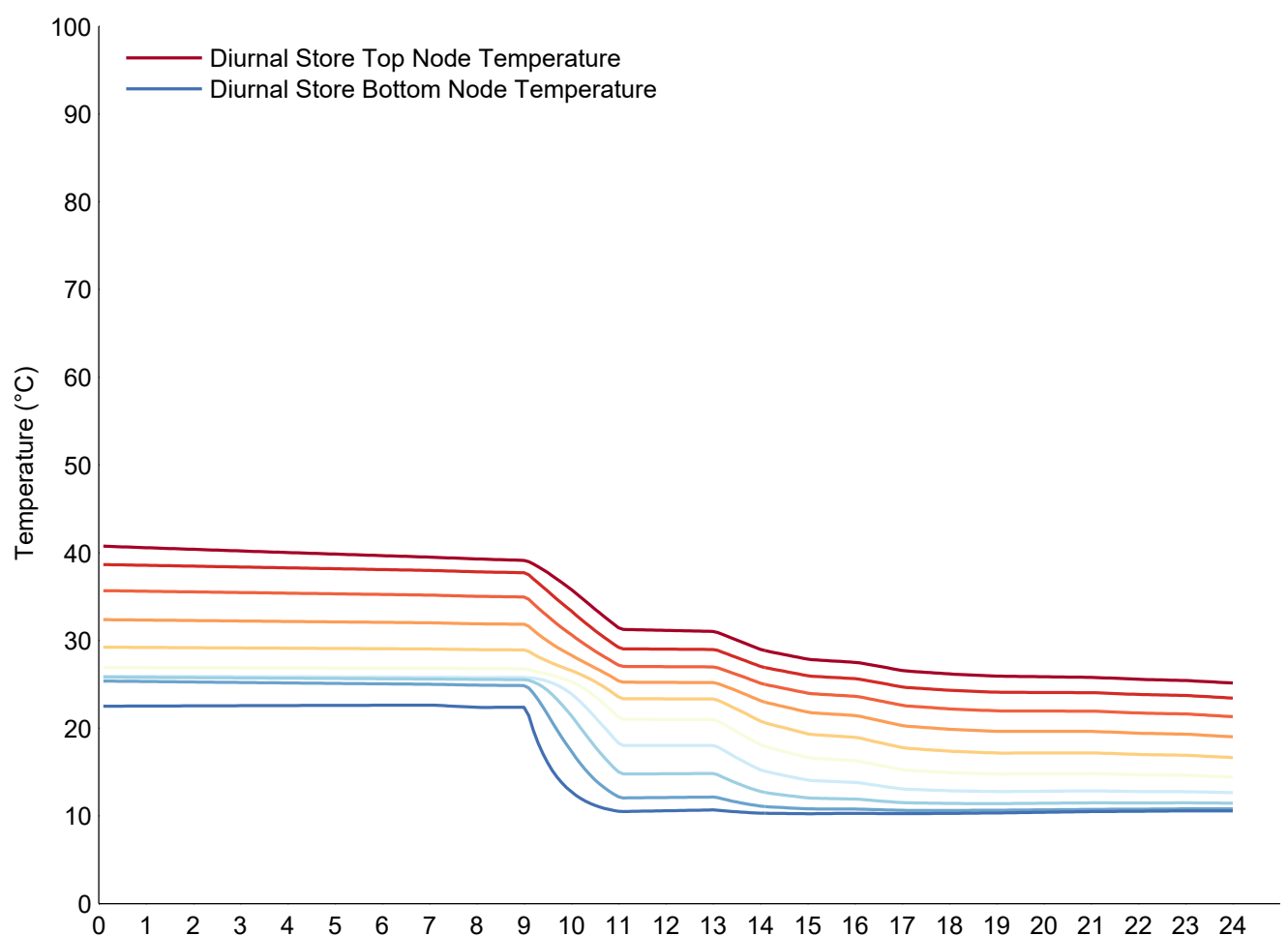

(b) Seasonal

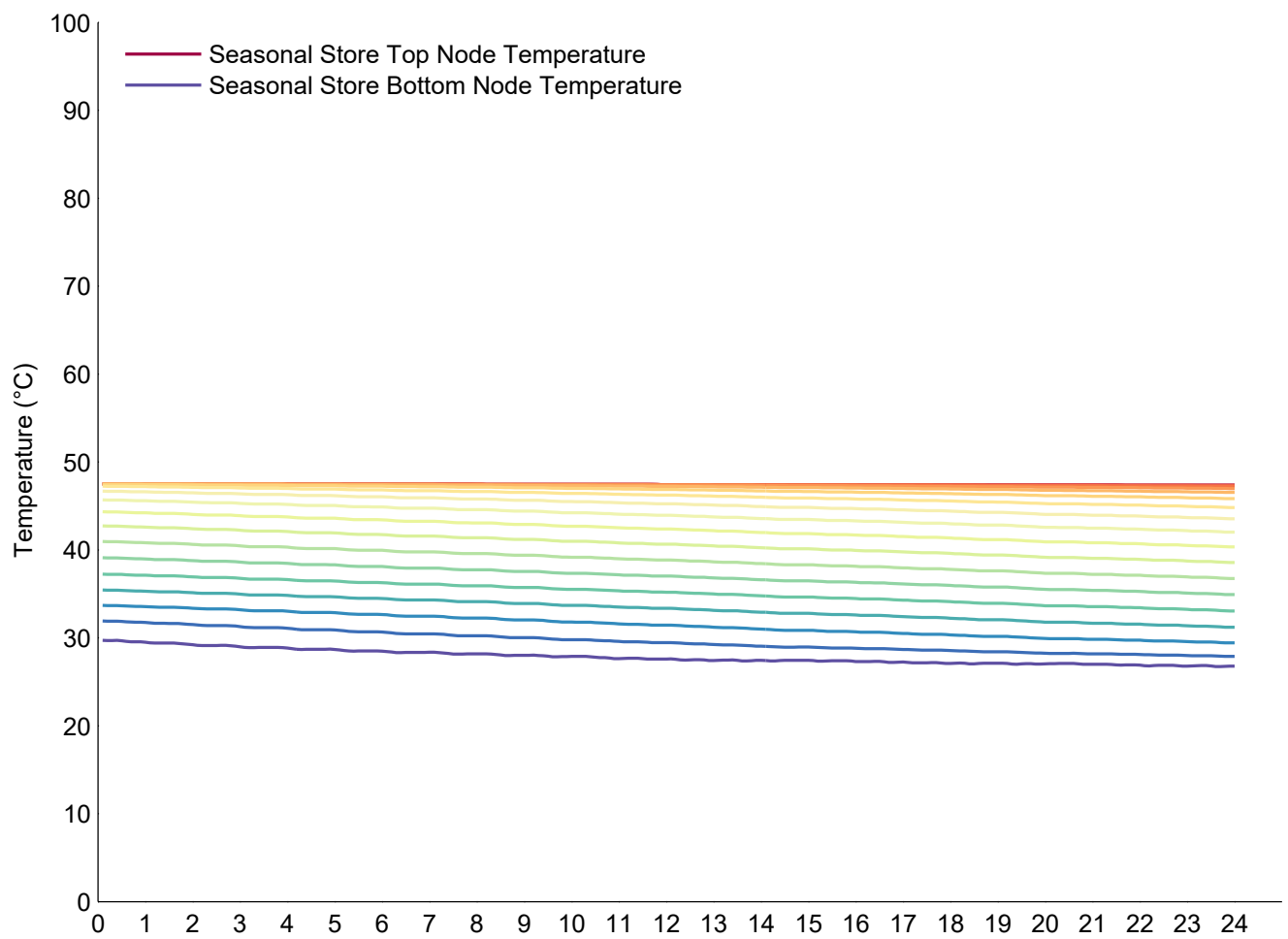

Figure 61: Cloudy Winter Day - Store Stratification 


\section{A.4 Sunny Spring Day - 6 May}

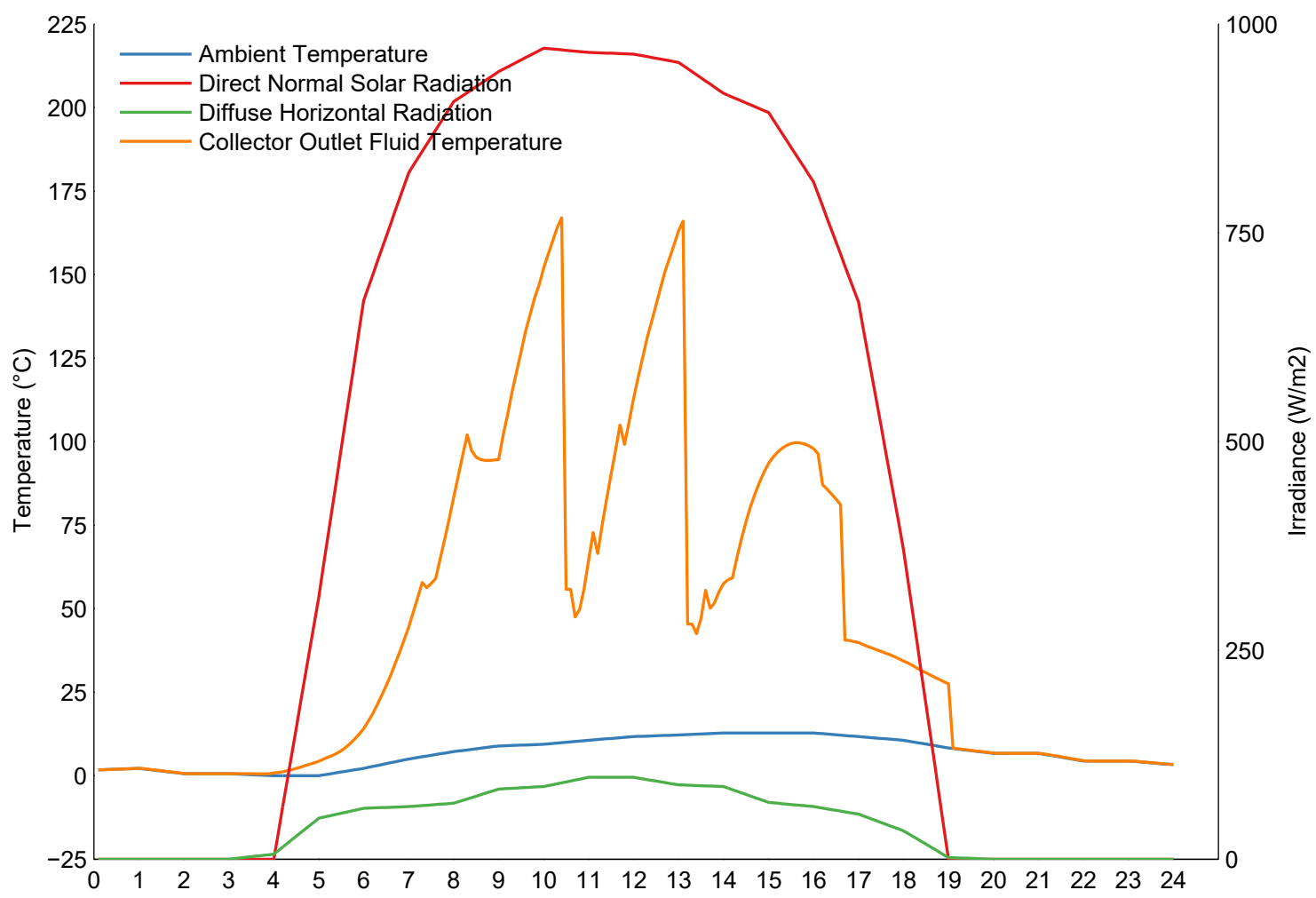

Figure 62: Sunny Spring Day - Ambient Temperature and Irradiance 
(a) Diurnal

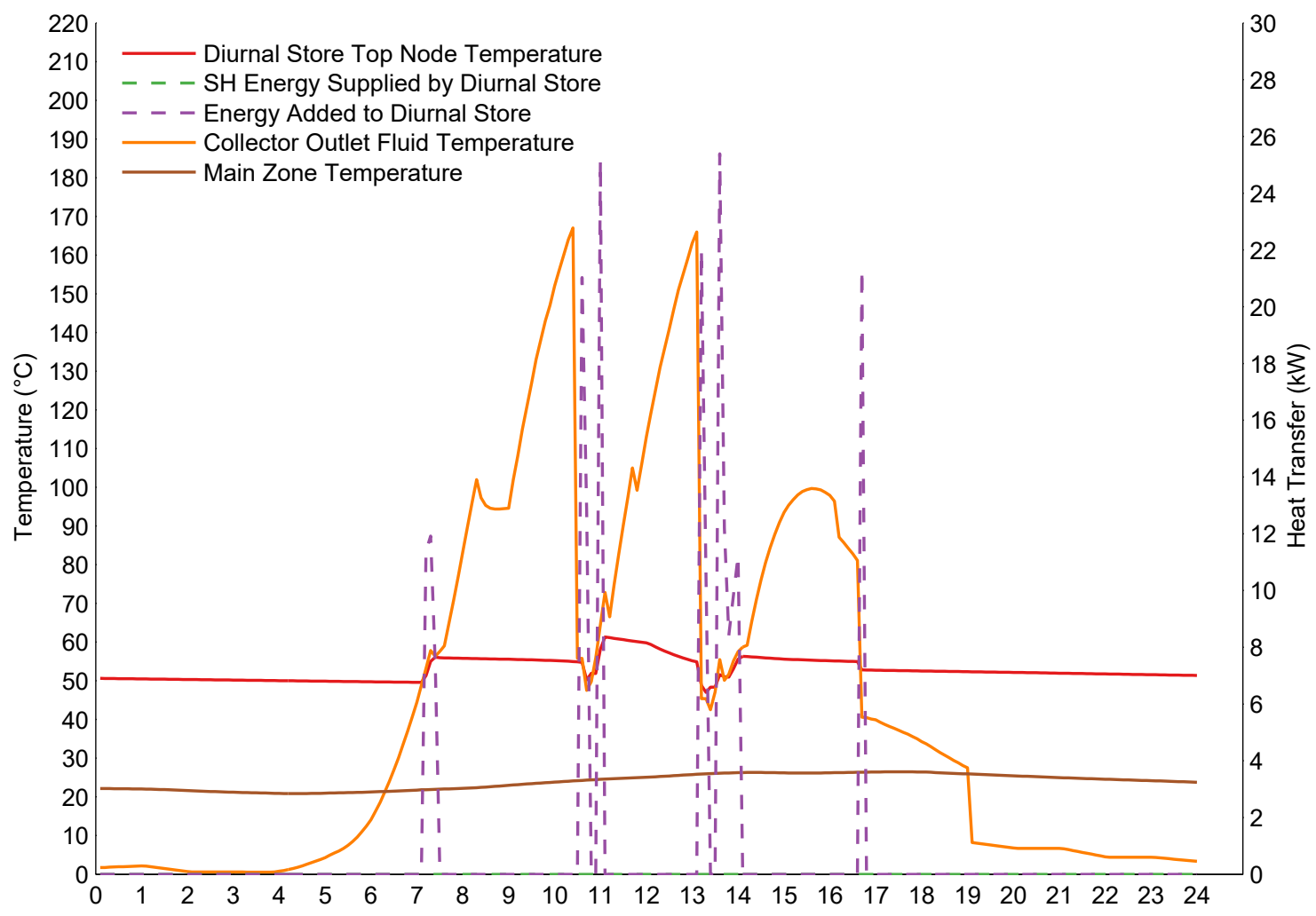

(b) Seasonal

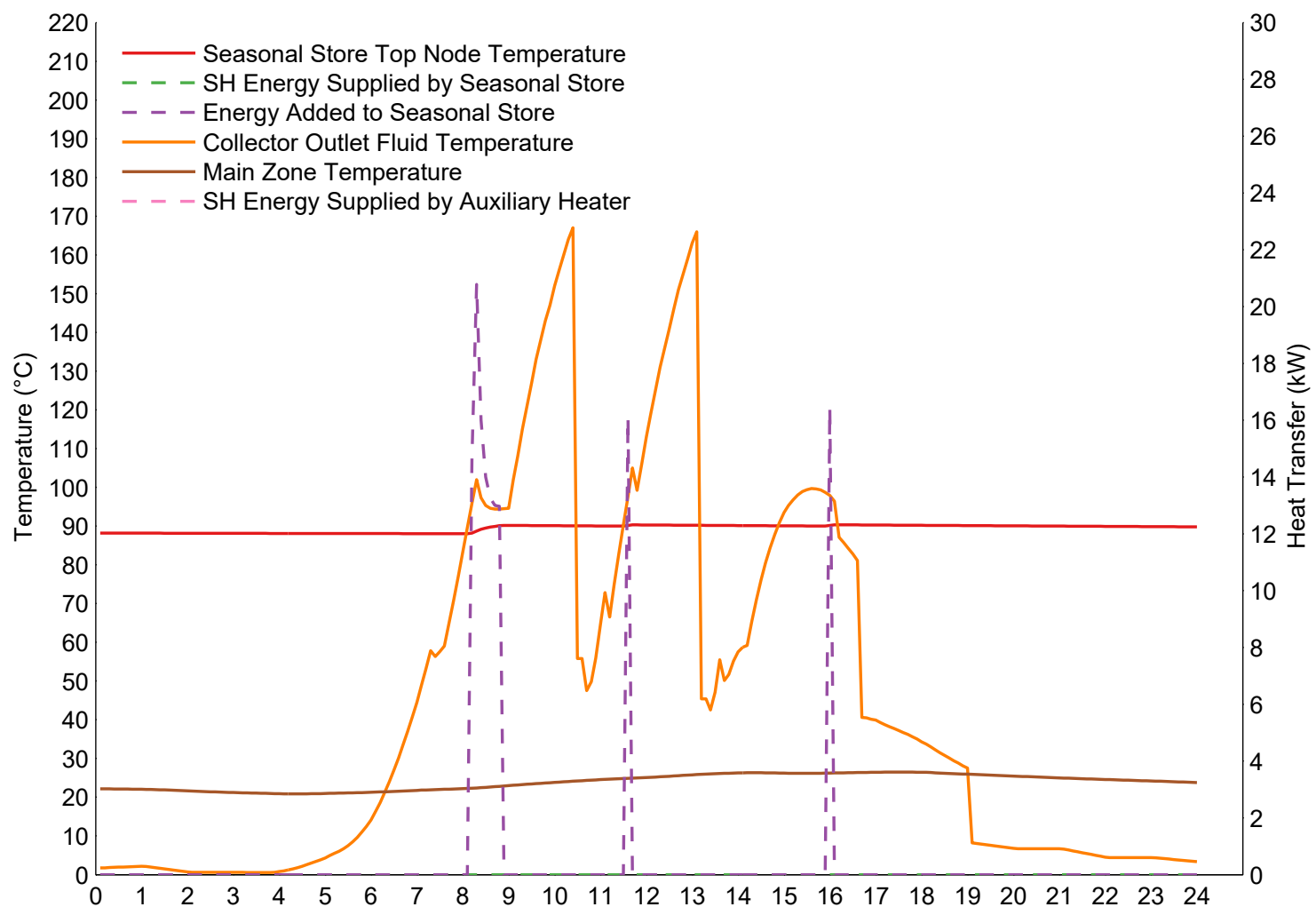

Figure 63: Sunny Spring Day - Store Behaviour 


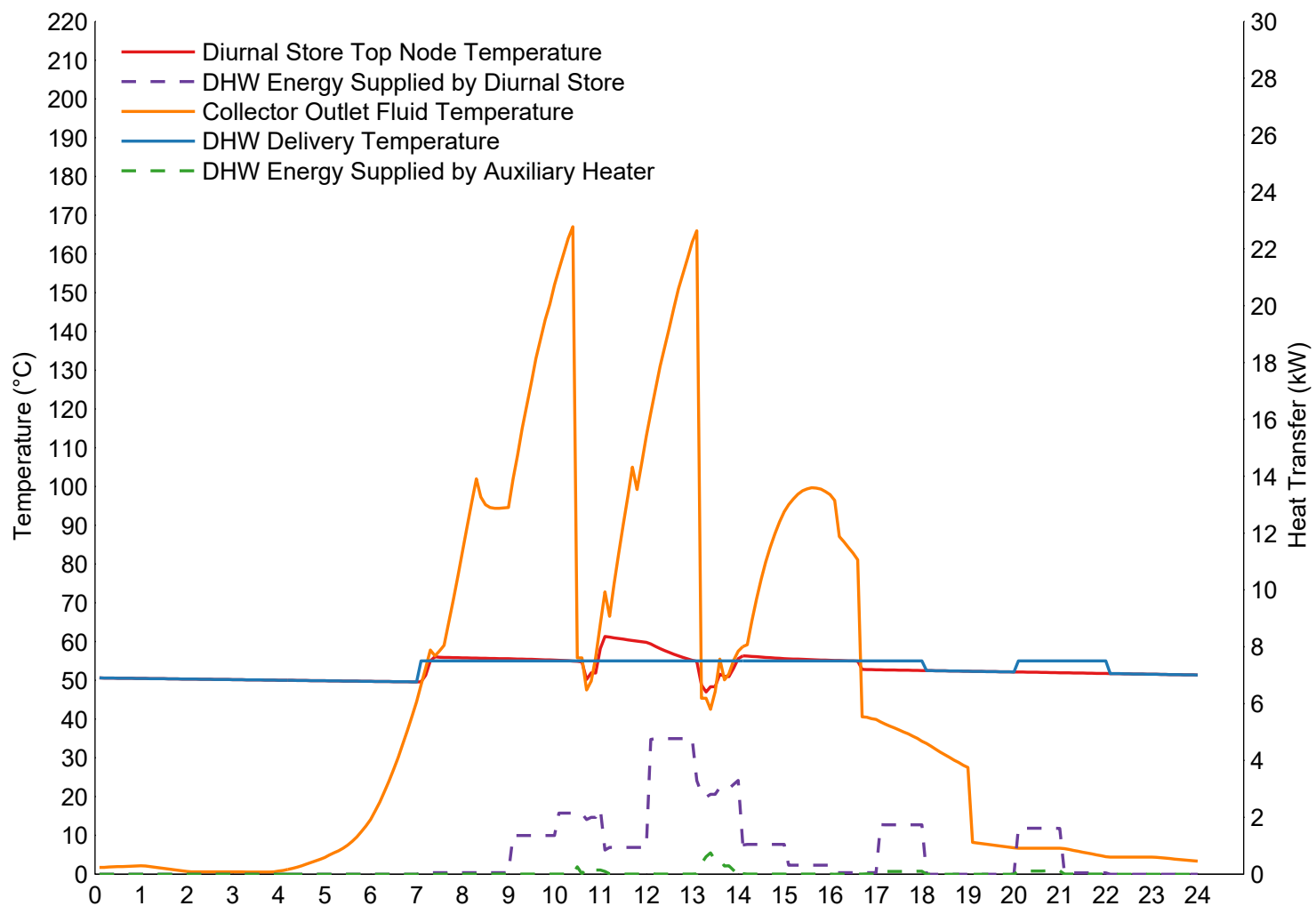

Figure 64: Sunny Spring Day - DHW Loads

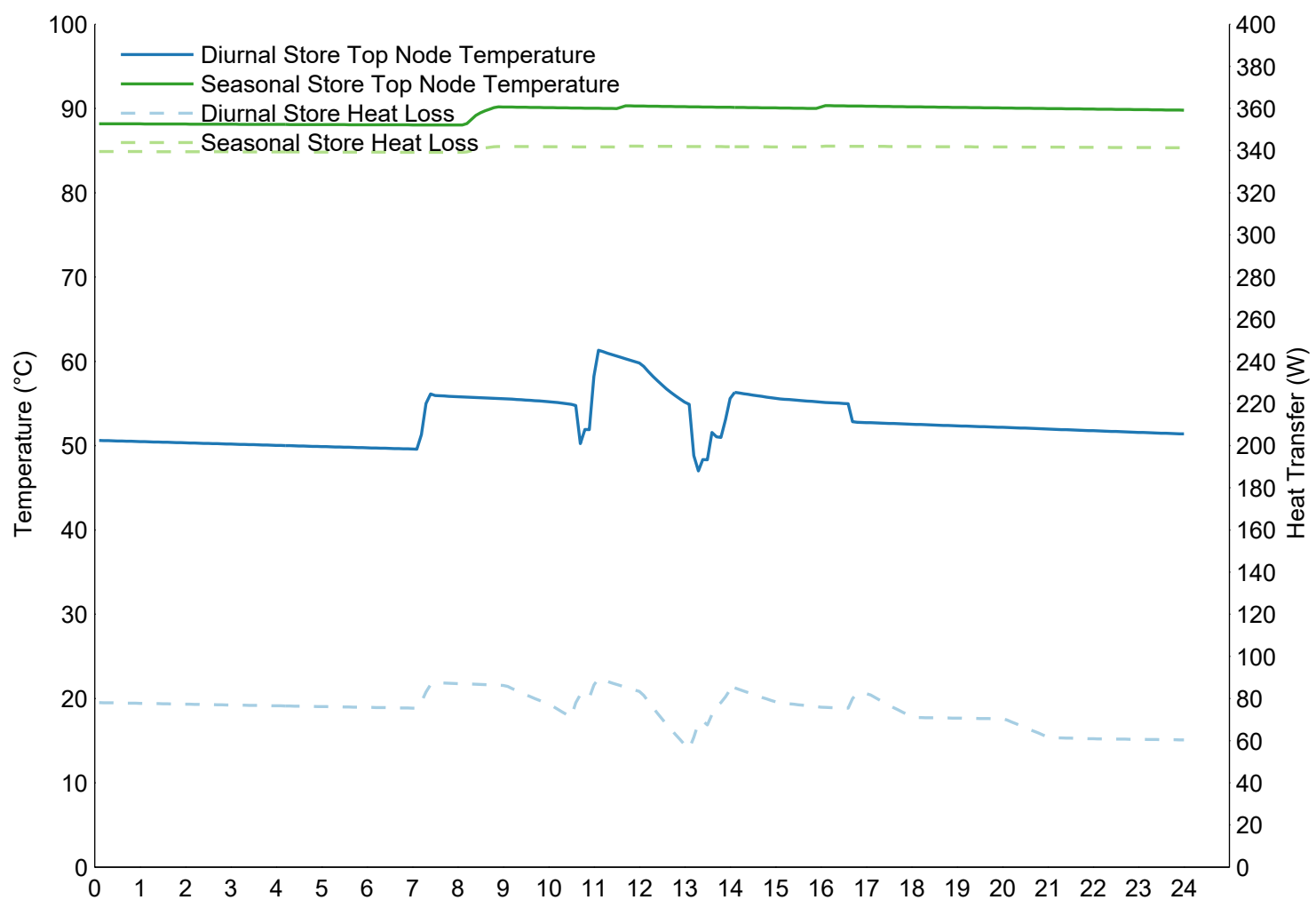

Figure 65: Sunny Spring Day - Heat Loss 
(a) Diurnal

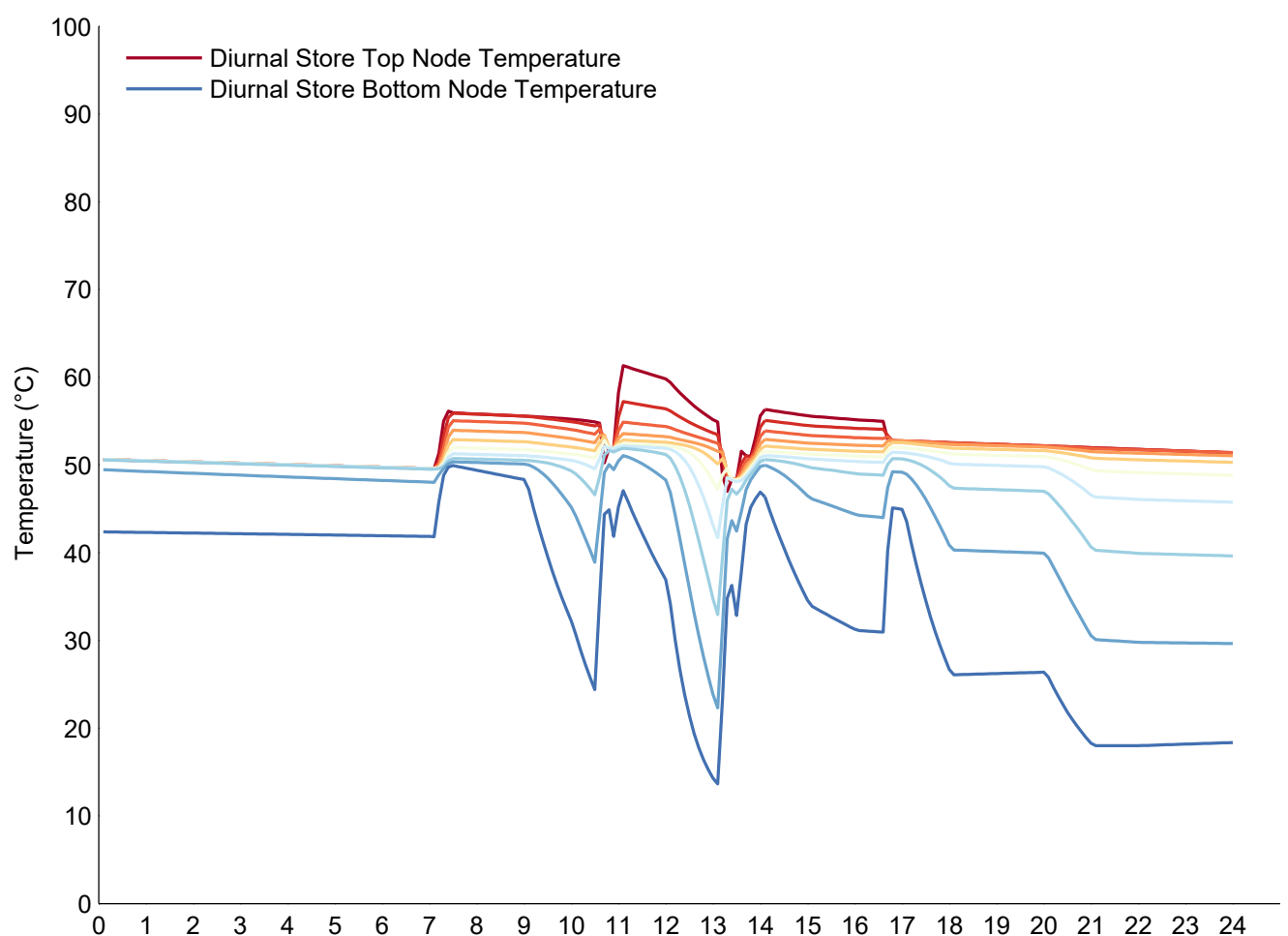

(b) Seasonal

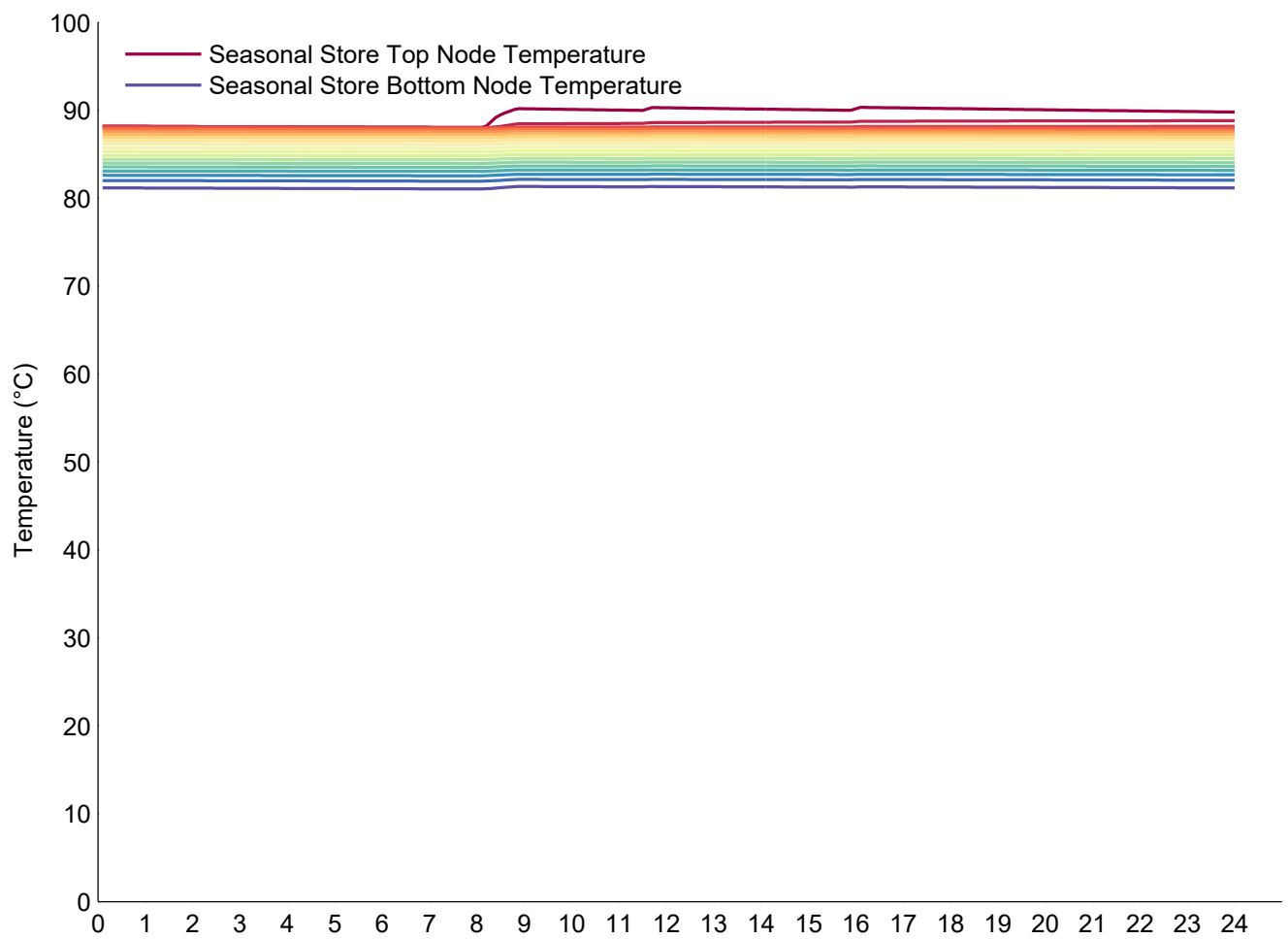

Figure 66: Sunny Spring Day - Store Stratification 


\section{A.5 Sunny Summer Day - 13 August}

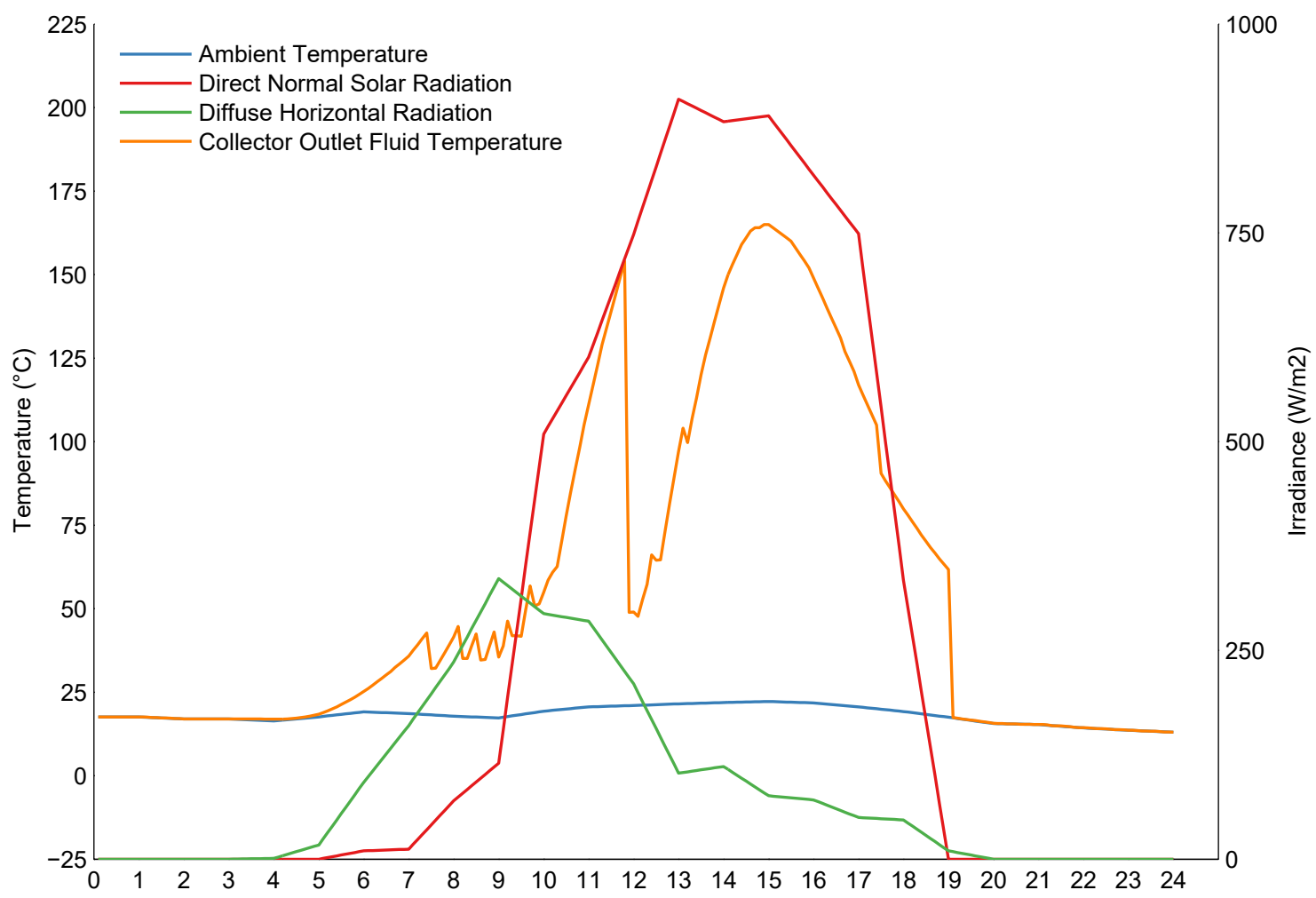

Figure 67: Sunny Summer Day - Ambient Temperature and Irradiance 
(a) Diurnal

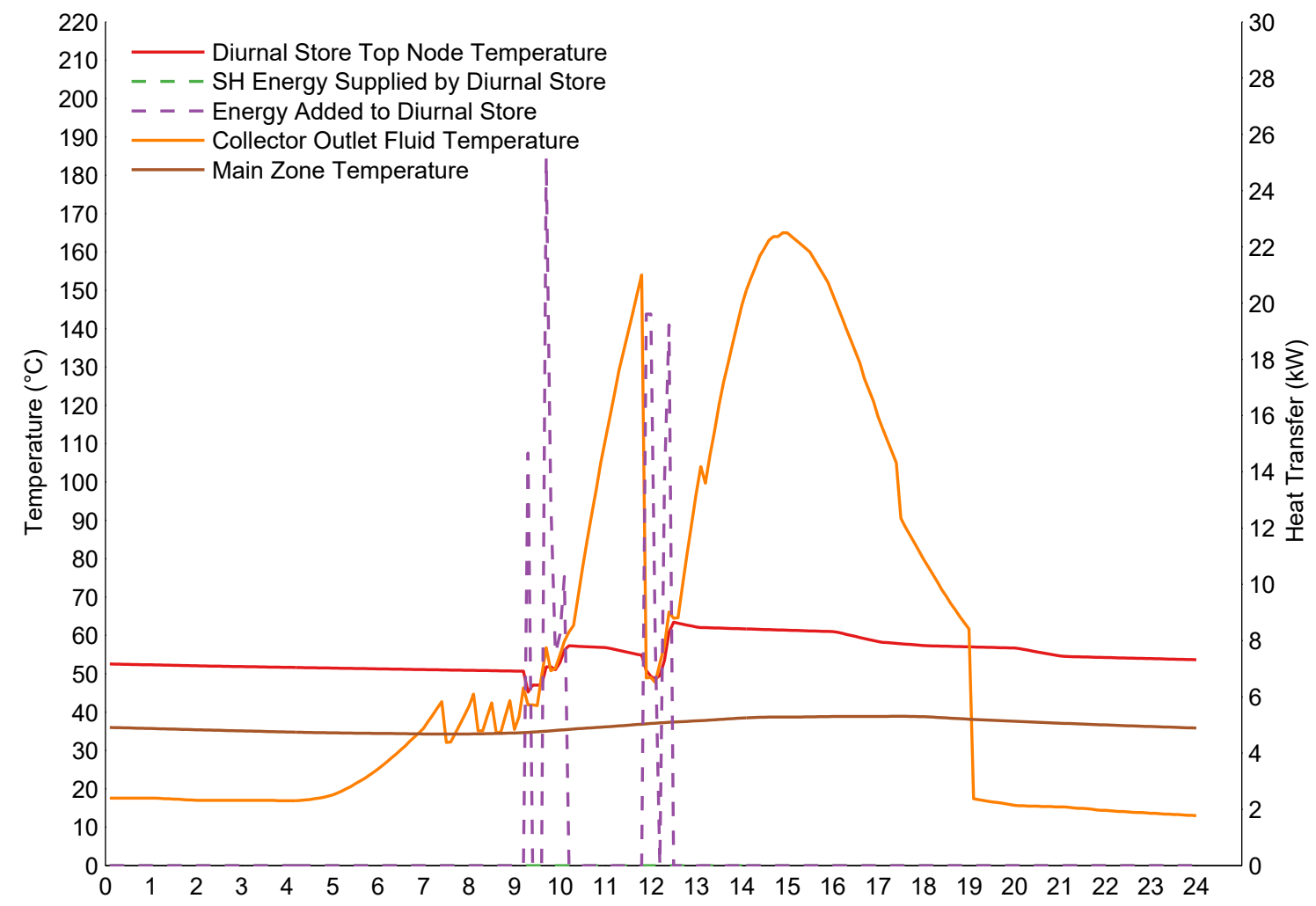

(b) Seasonal

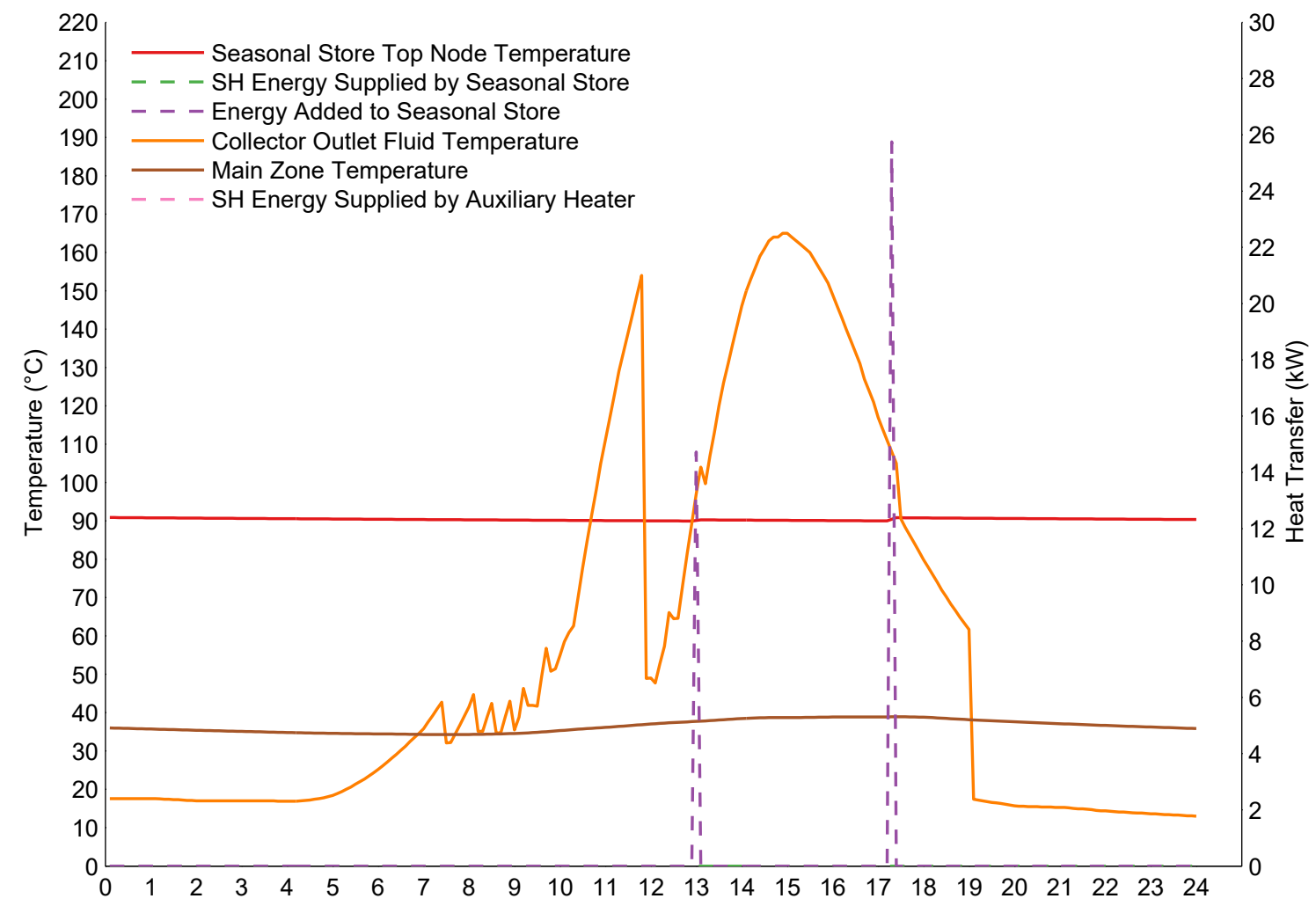

Figure 68: Sunny Summer Day - Store Behaviour 


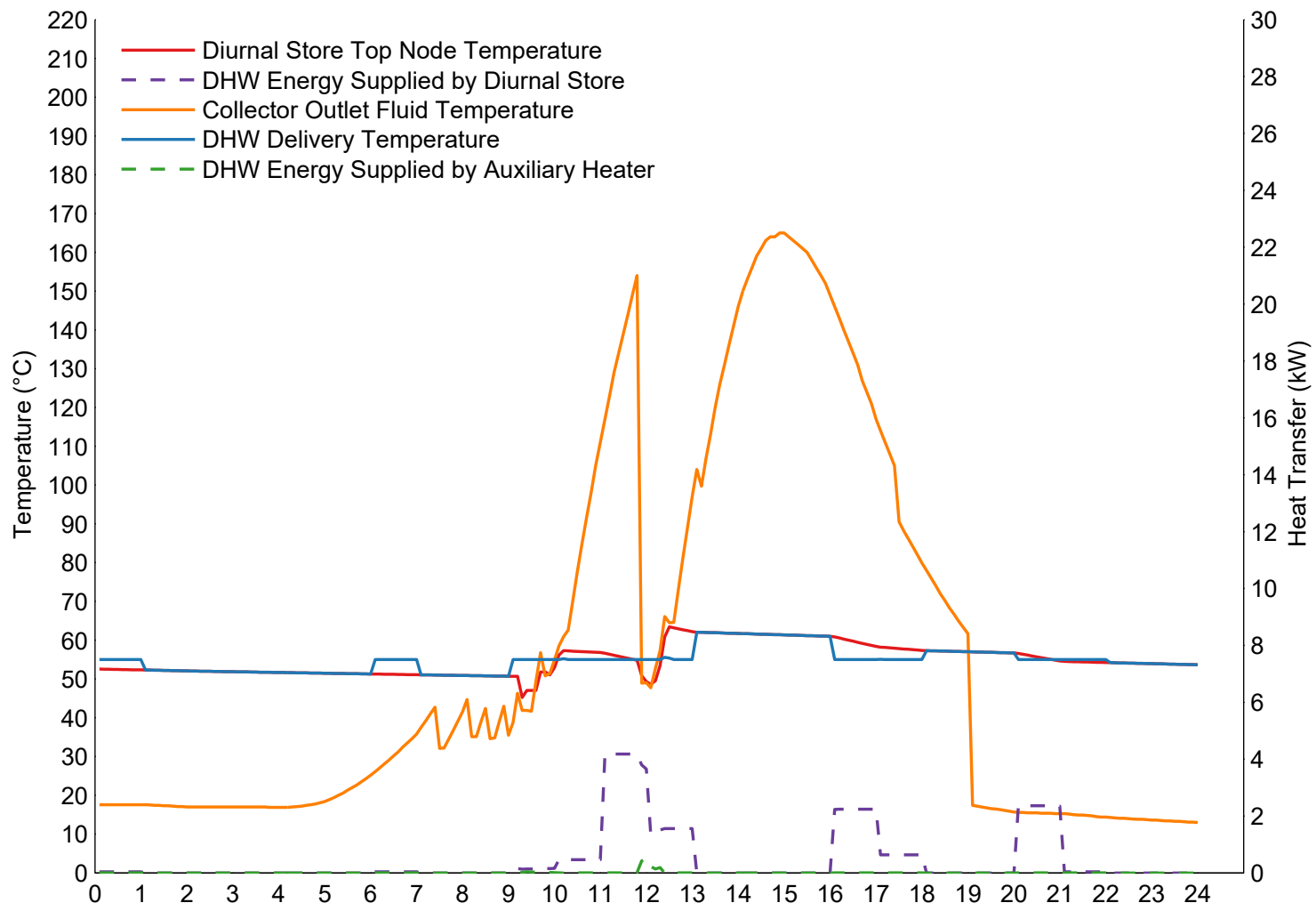

Figure 69: Sunny Summer Day - DHW Loads

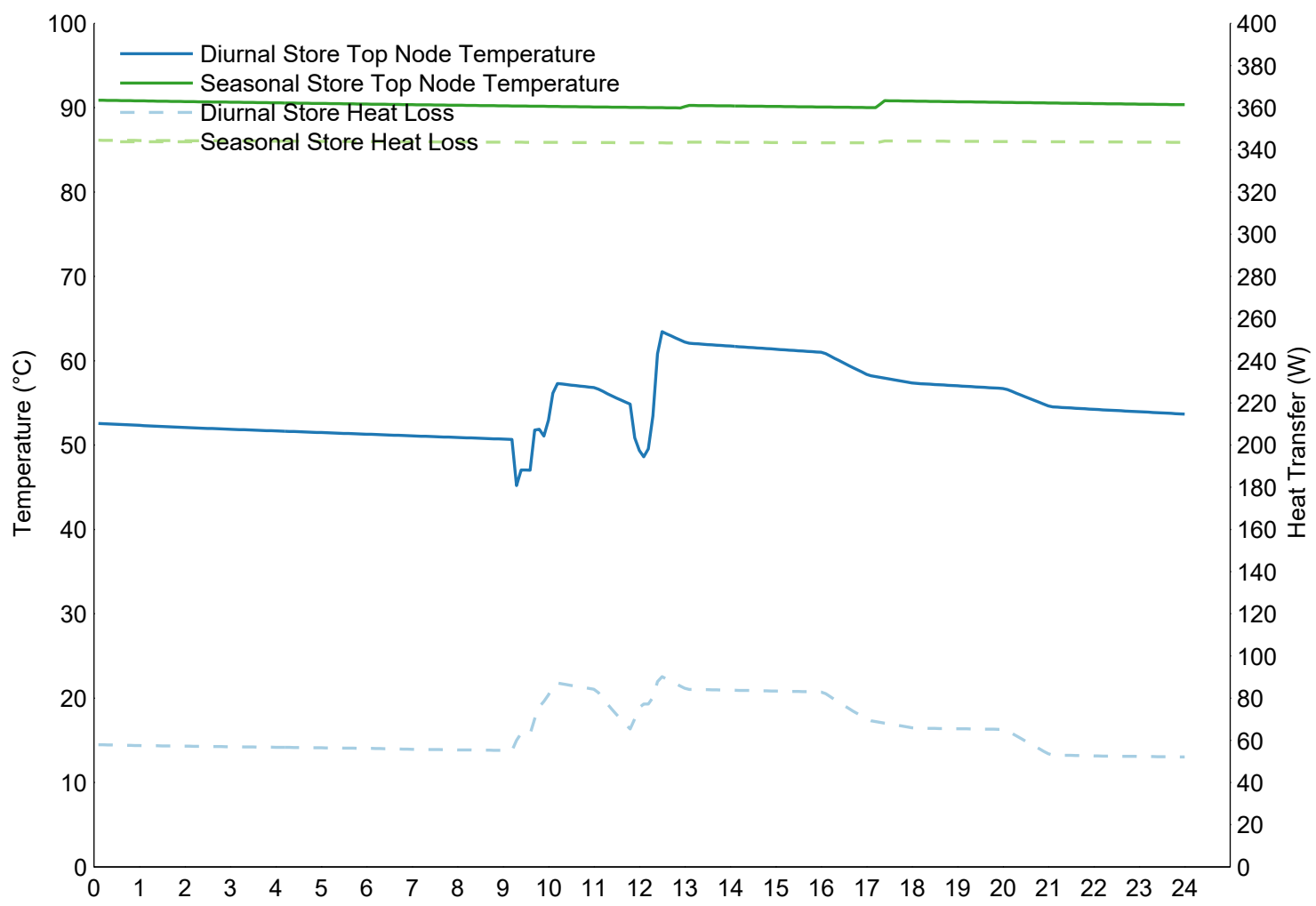

Figure 70: Sunny Summer Day - Heat Loss 
(a) Diurnal

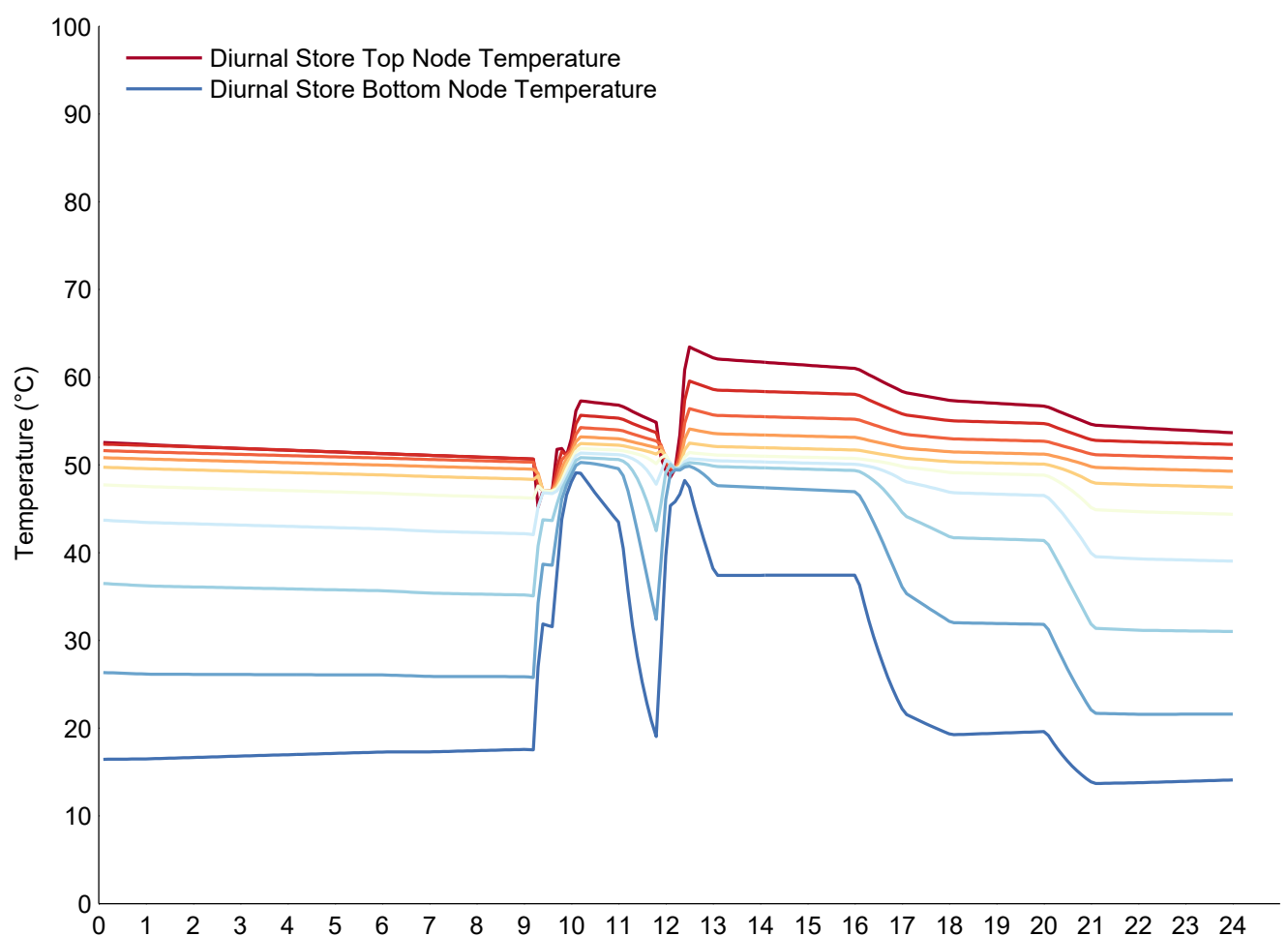

(b) Seasonal

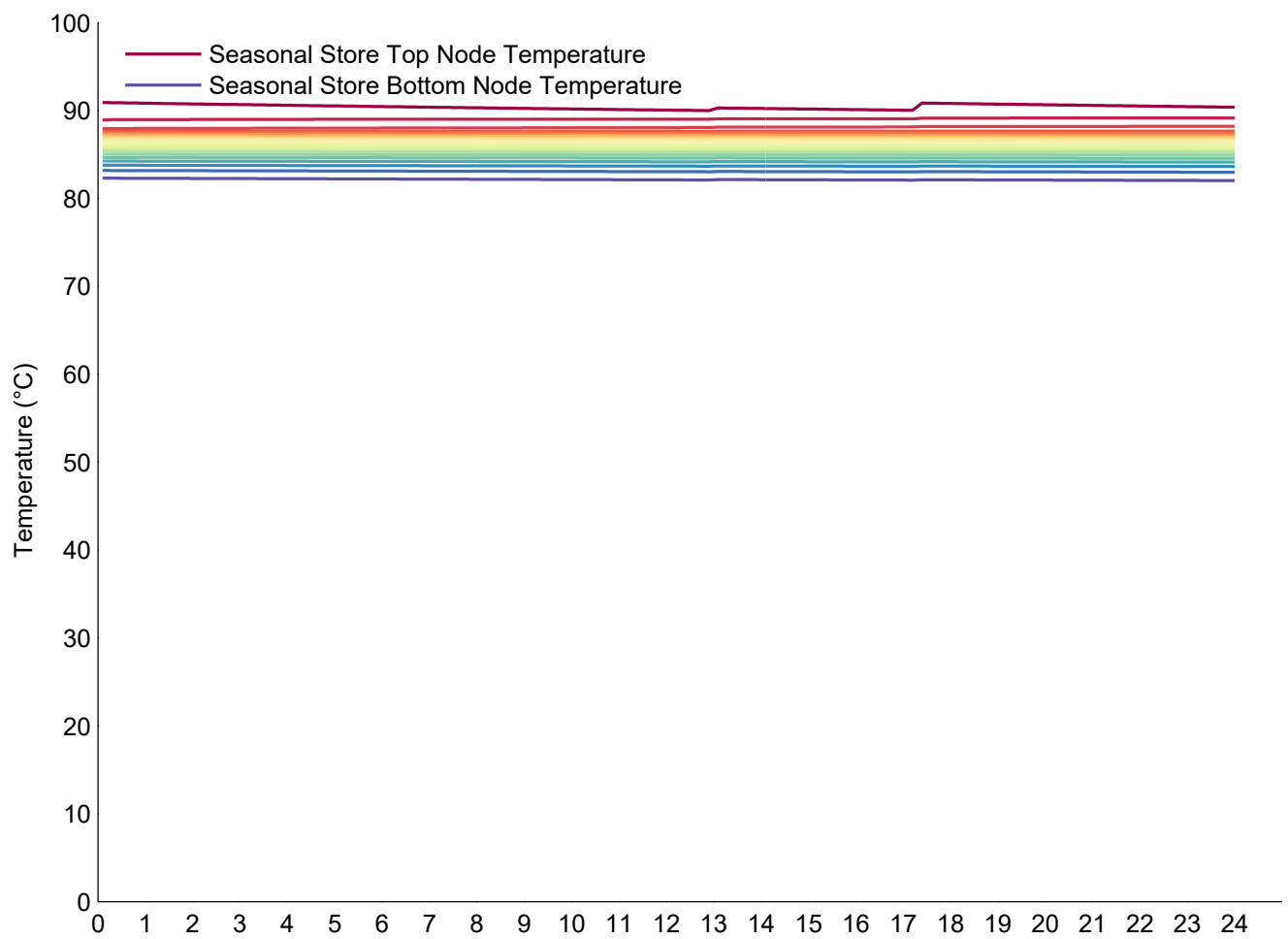

Figure 71: Sunny Summer Day - Store Stratification 


\section{A.6 Sunny Autumn Day - 14 October}

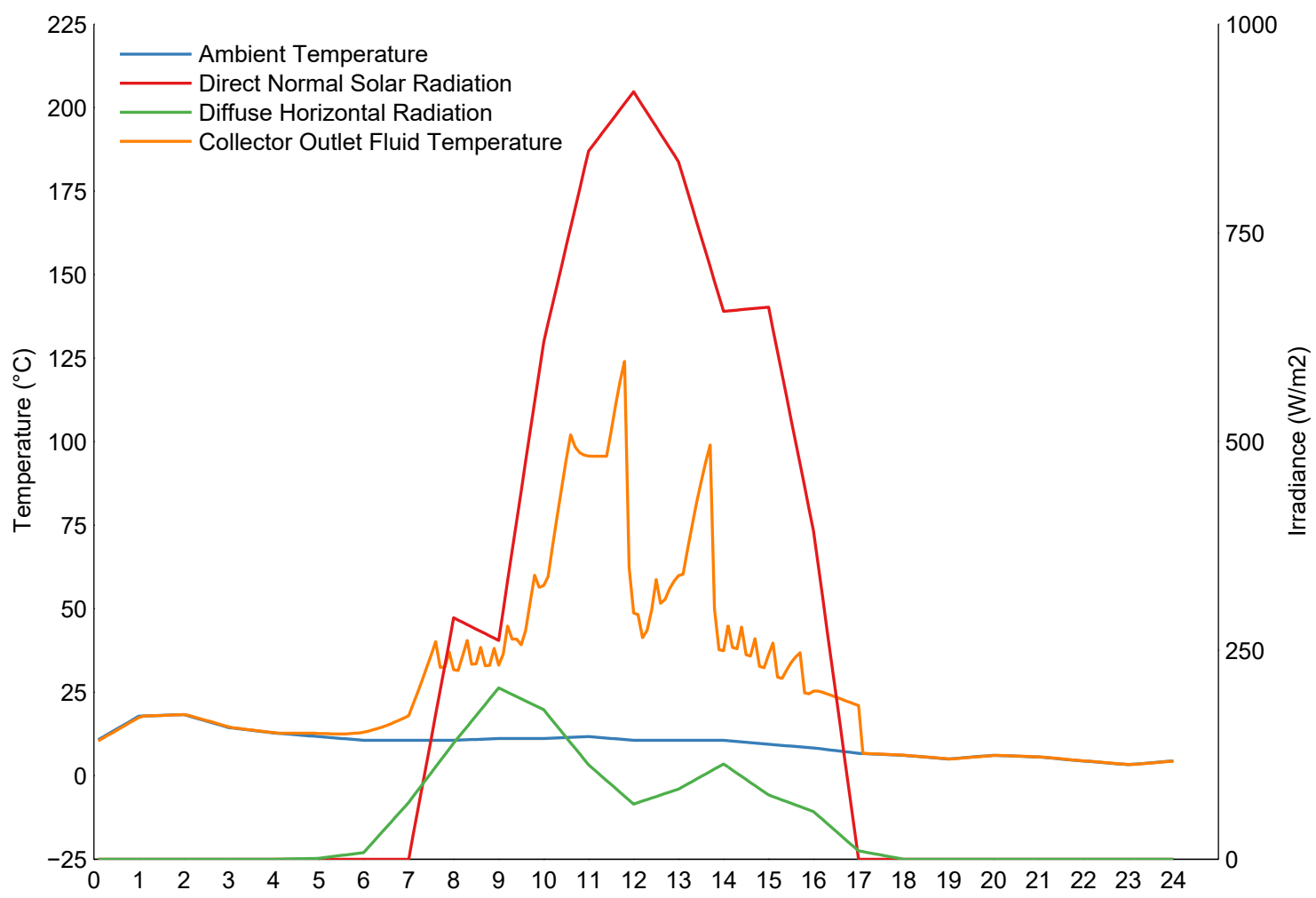

Figure 72: Sunny Autumn Day - Ambient Temperature and Irradiance 
(a) Diurnal

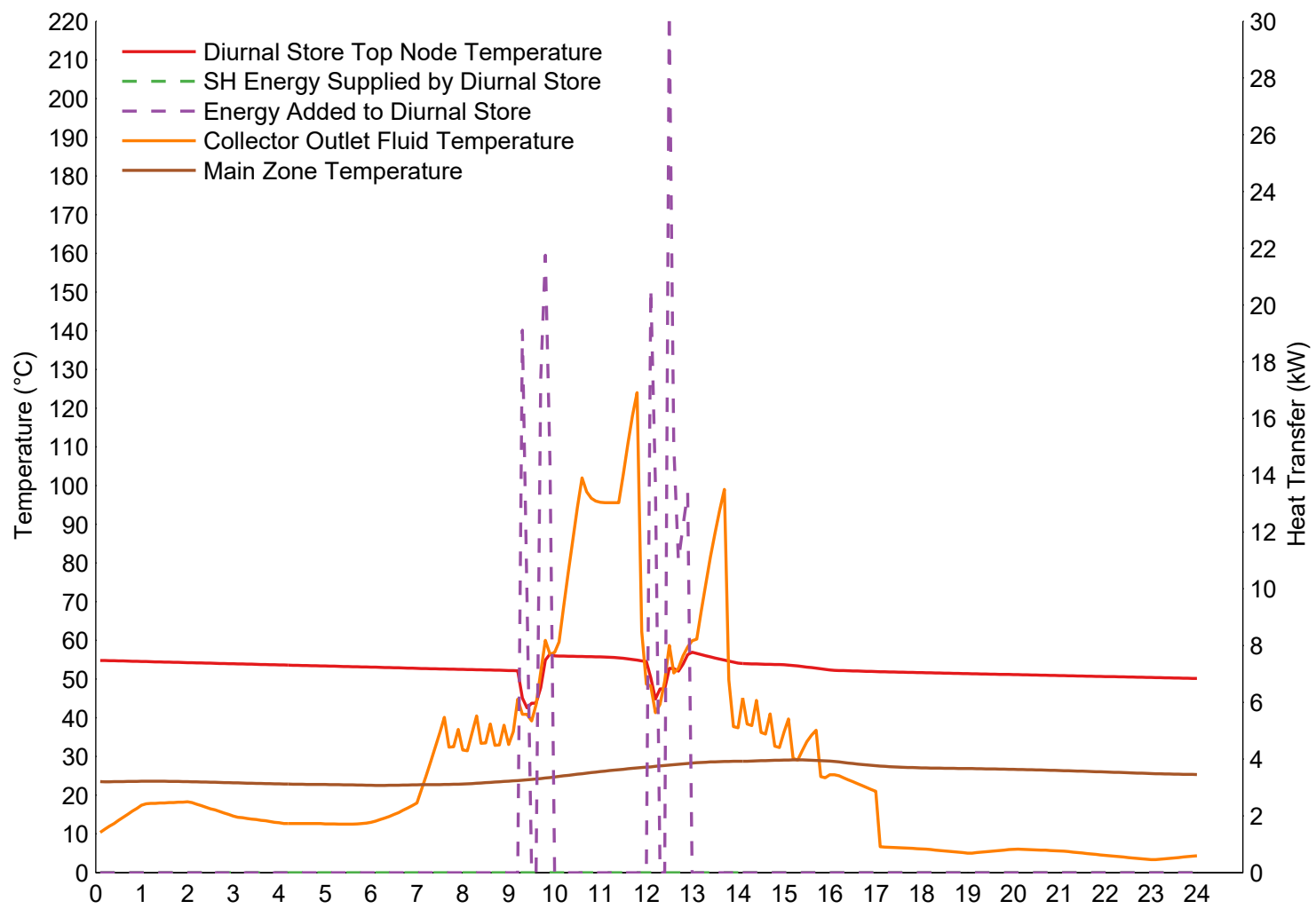

(b) Seasonal

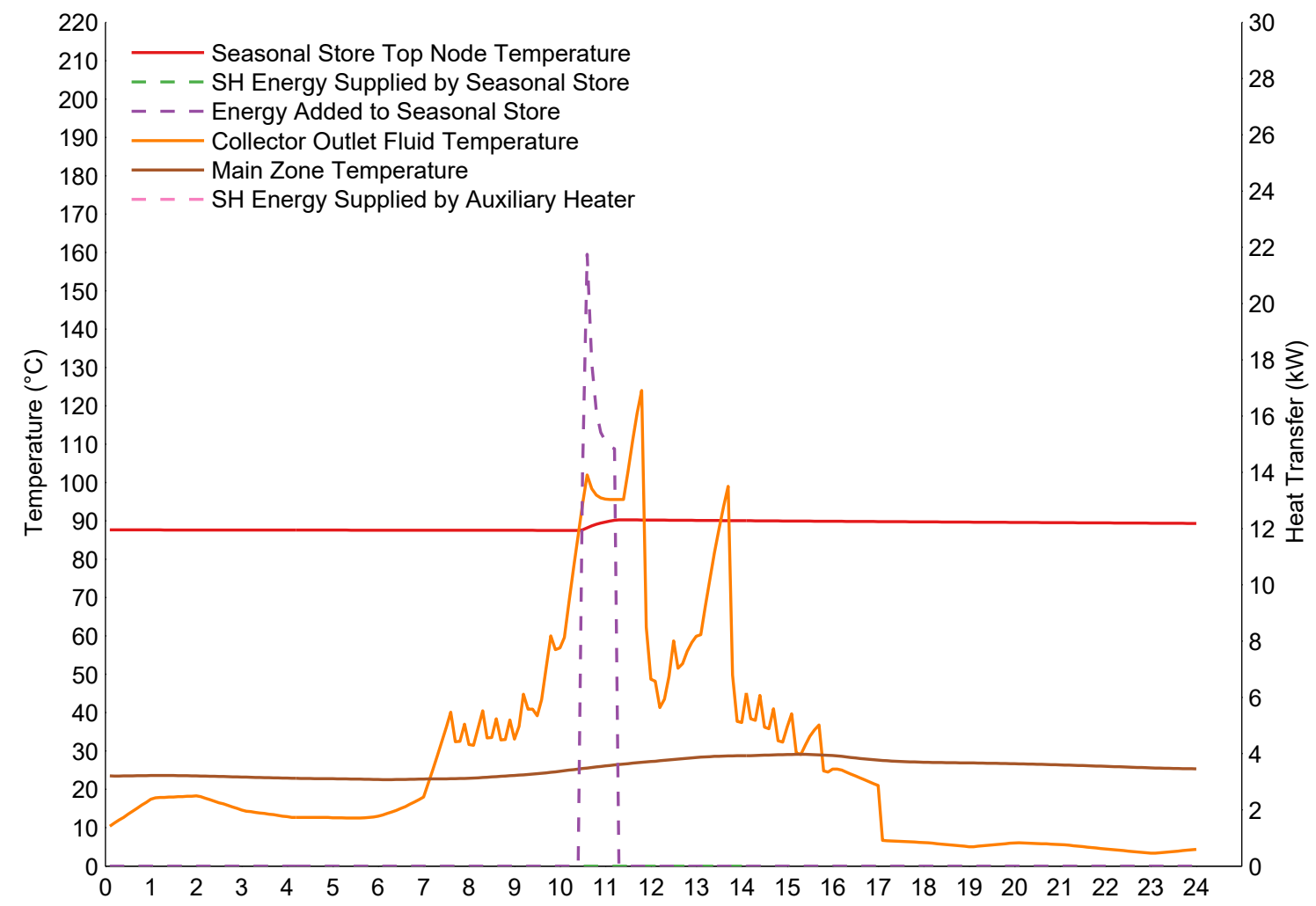

Figure 73: Sunny Autumn Day - Store Behaviour 


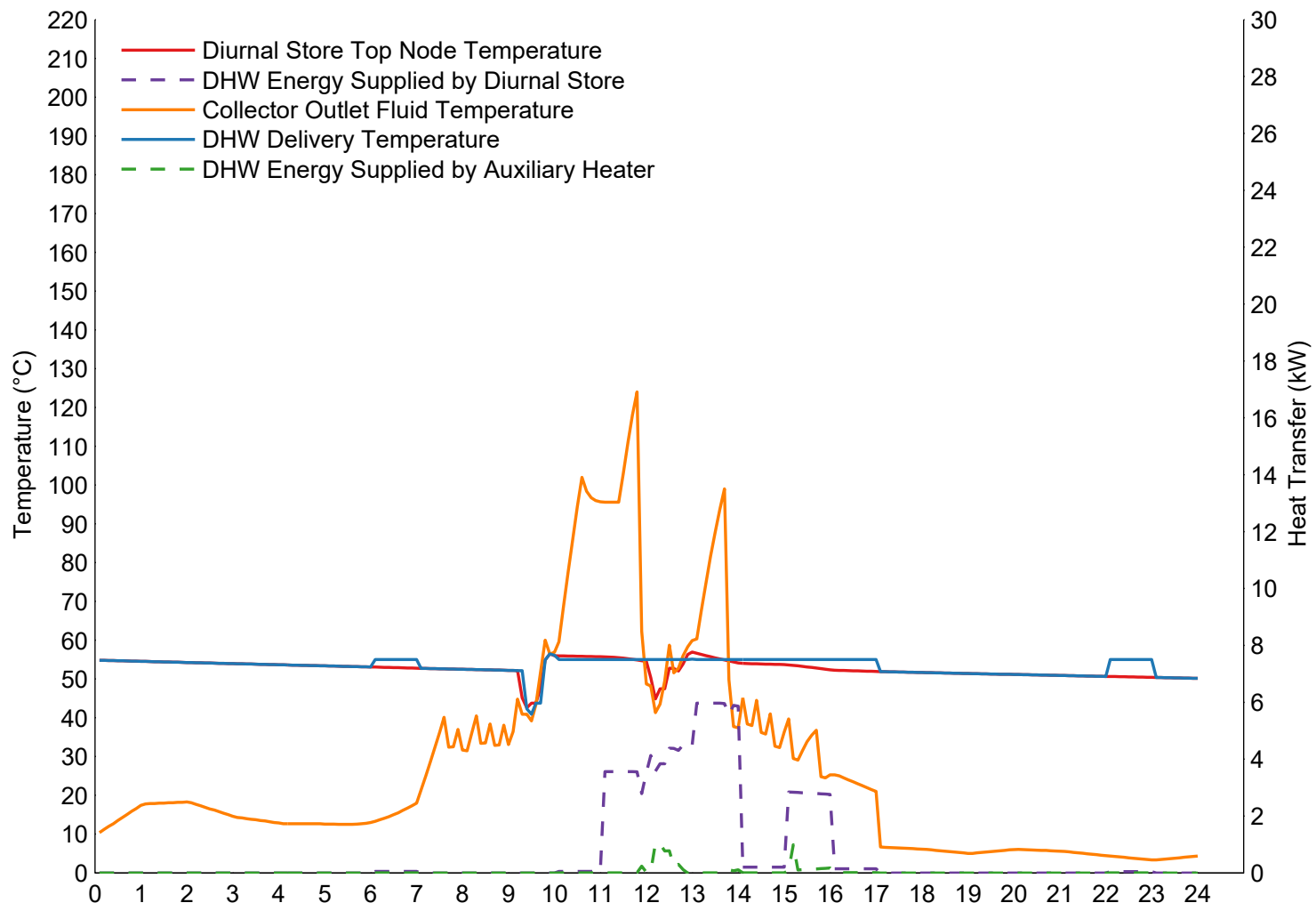

Figure 74: Sunny Autumn Day - DHW Loads

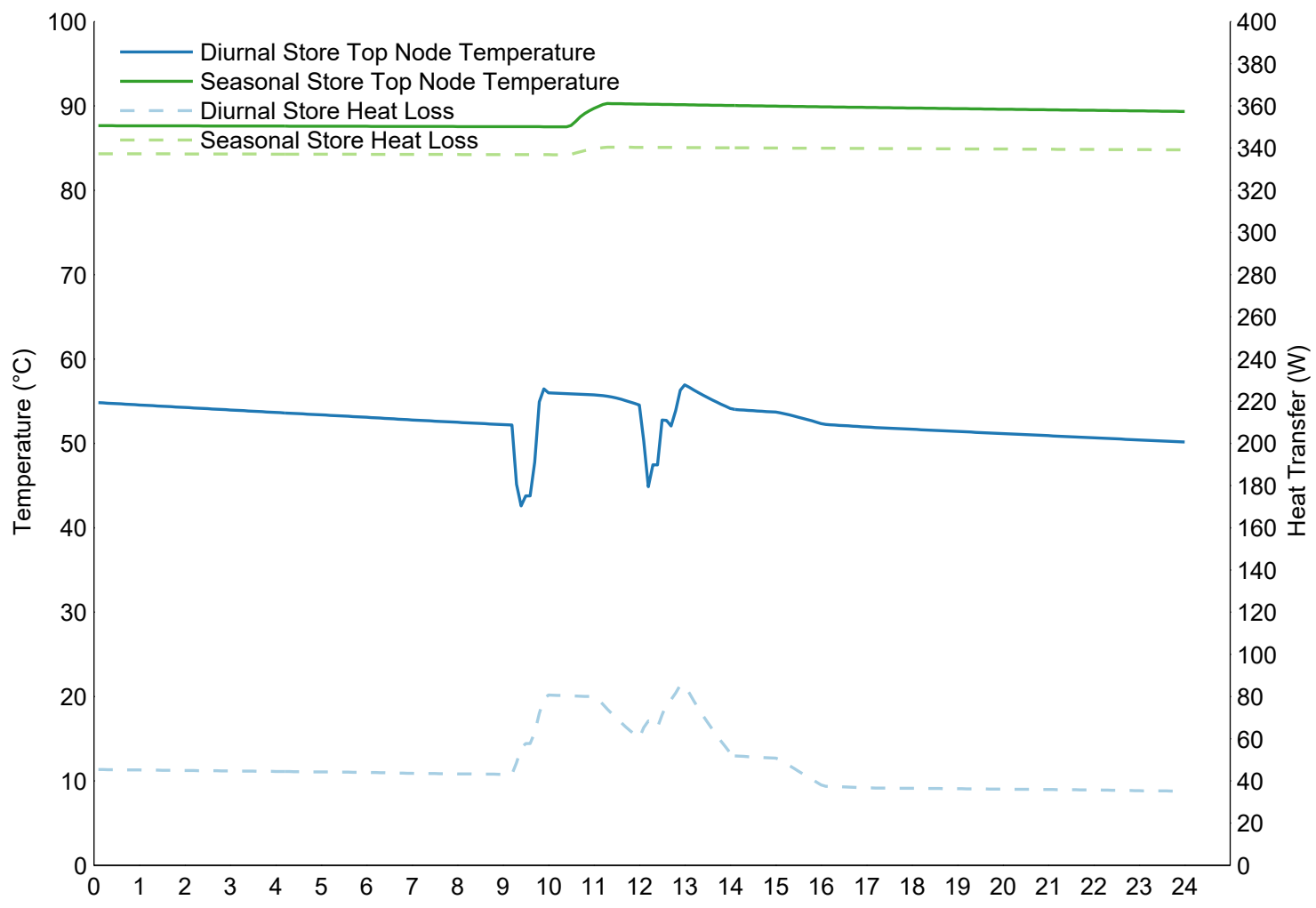

Figure 75: Sunny Autumn Day - Heat Loss 
(a) Diurnal

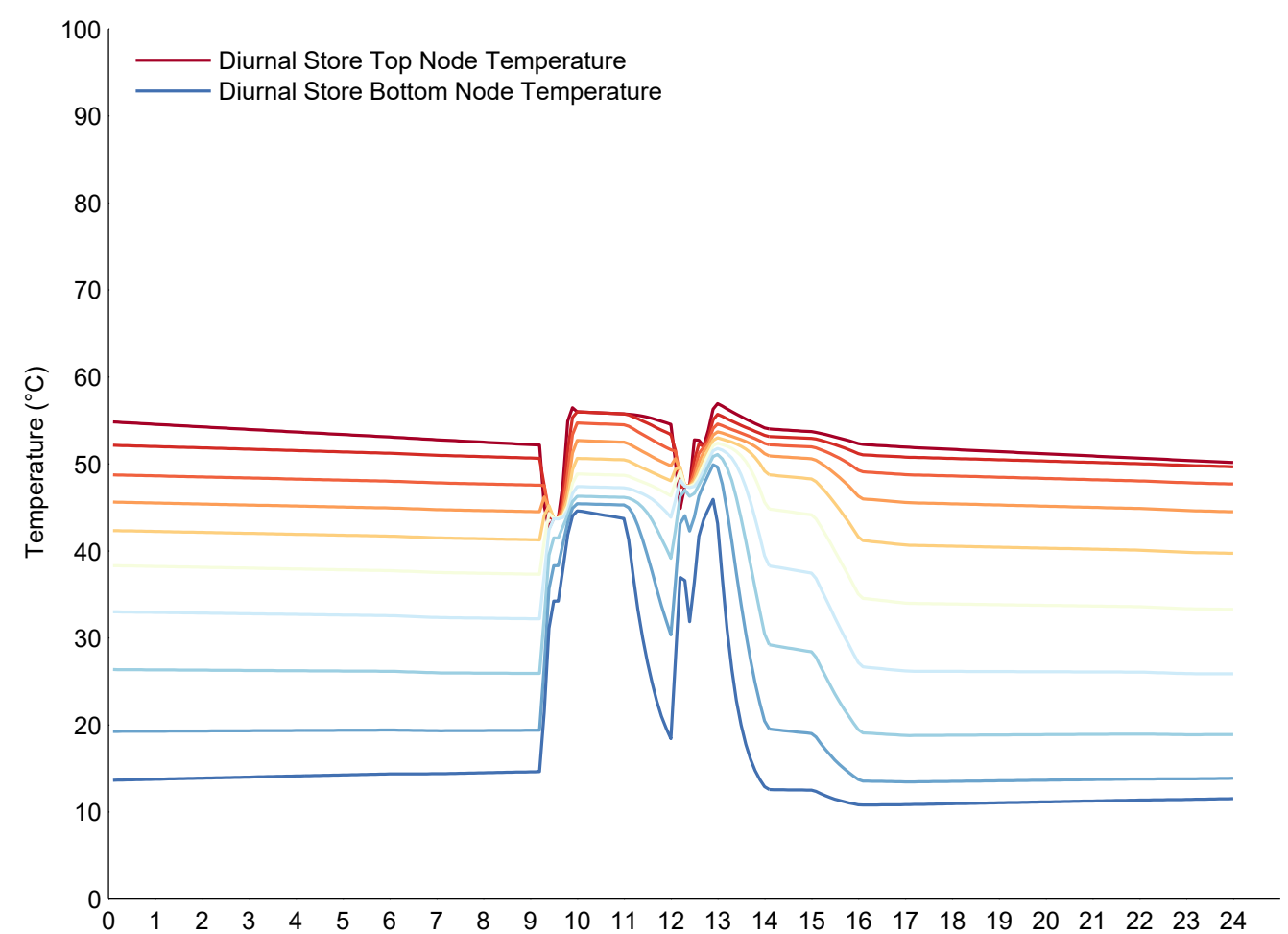

(b) Seasonal

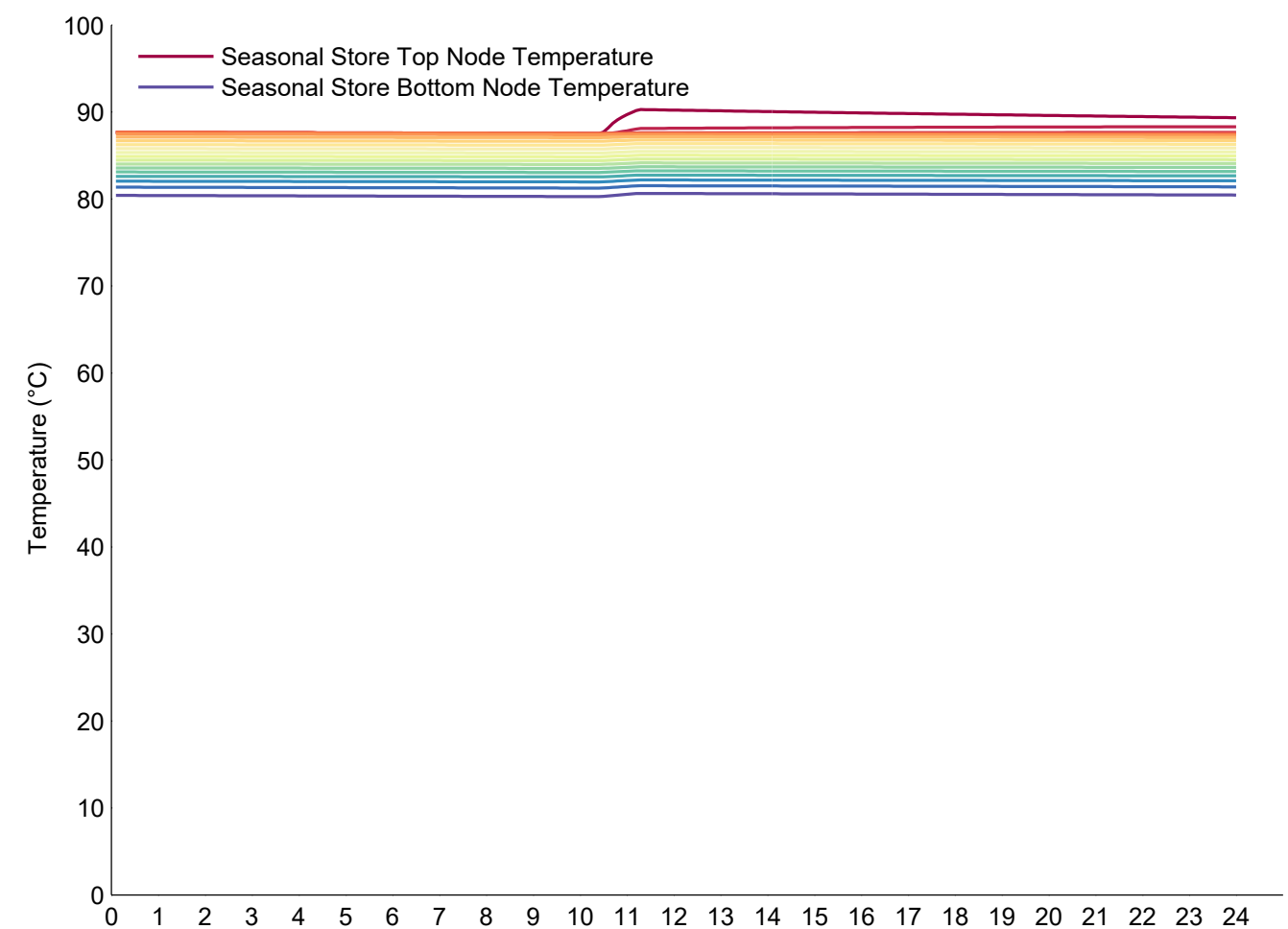

Figure 76: Sunny Autumn Day - Store Stratification 
A.7 STES $\alpha$ and $\beta$ Case Behaviour Comparison 
(a) $\alpha$ Case

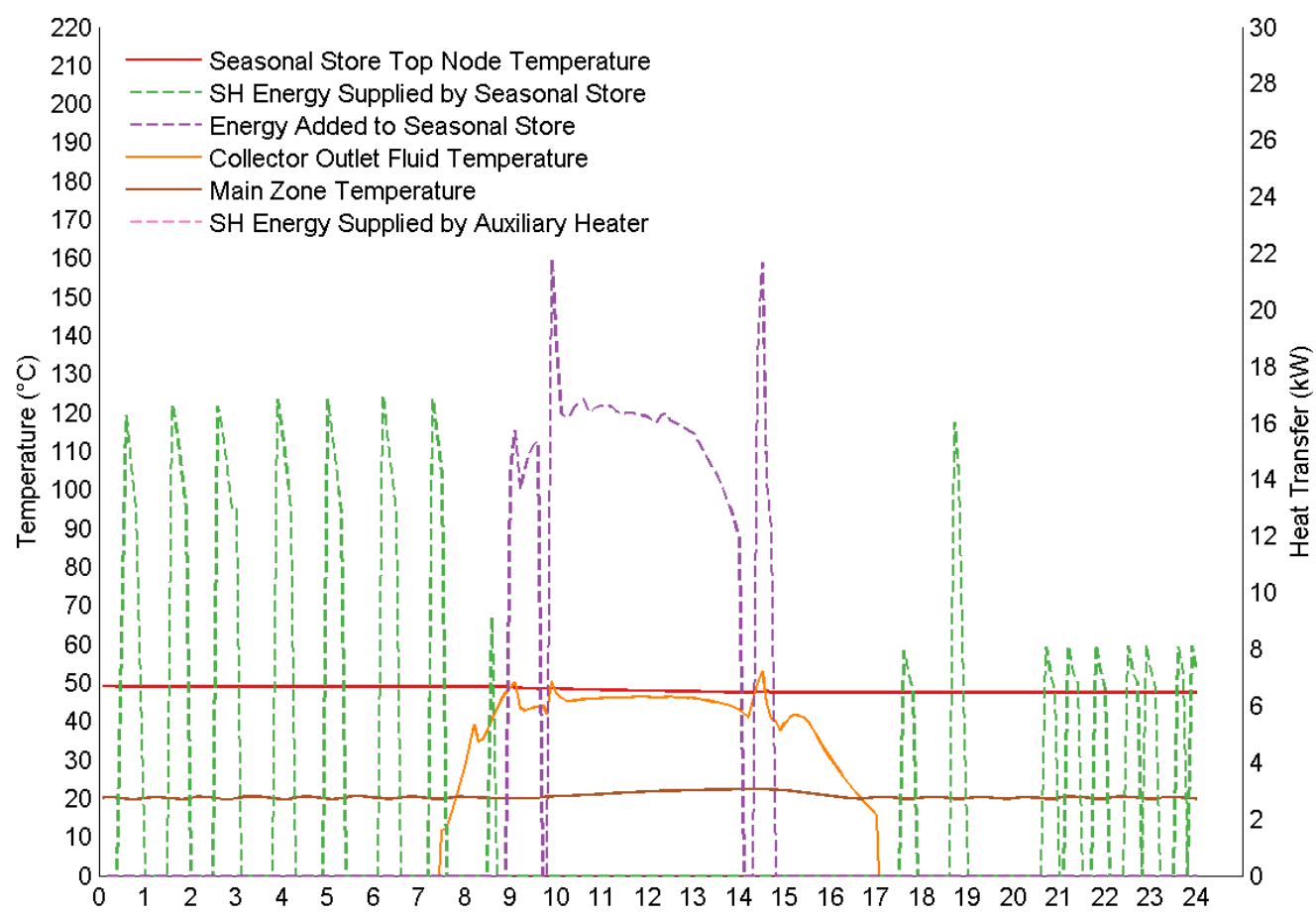

(b) $\beta$ Case

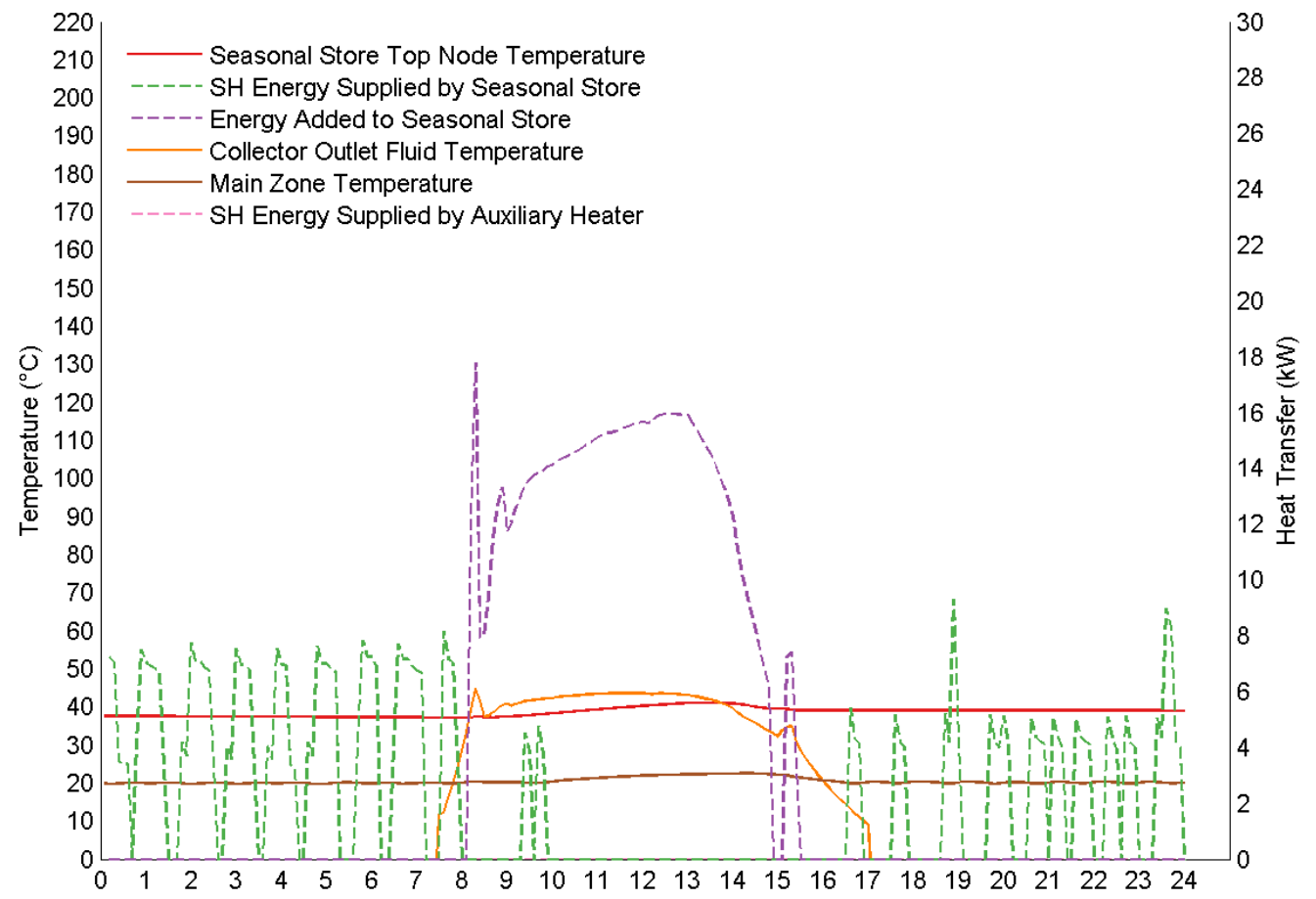

Figure 77: Sunny Winter Day 


\section{Appendix B}

\section{Model Inputs}

\section{B.1 Harmonizer Input File}

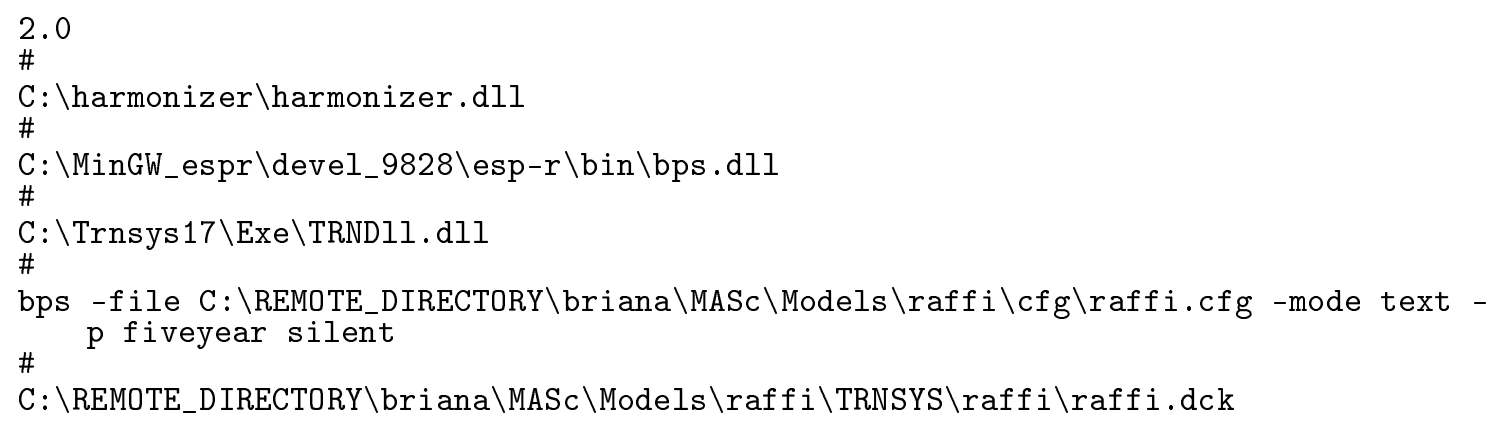




\section{Appendix C}

\section{ESP-r Input Files}

\section{C.1 Configuration}

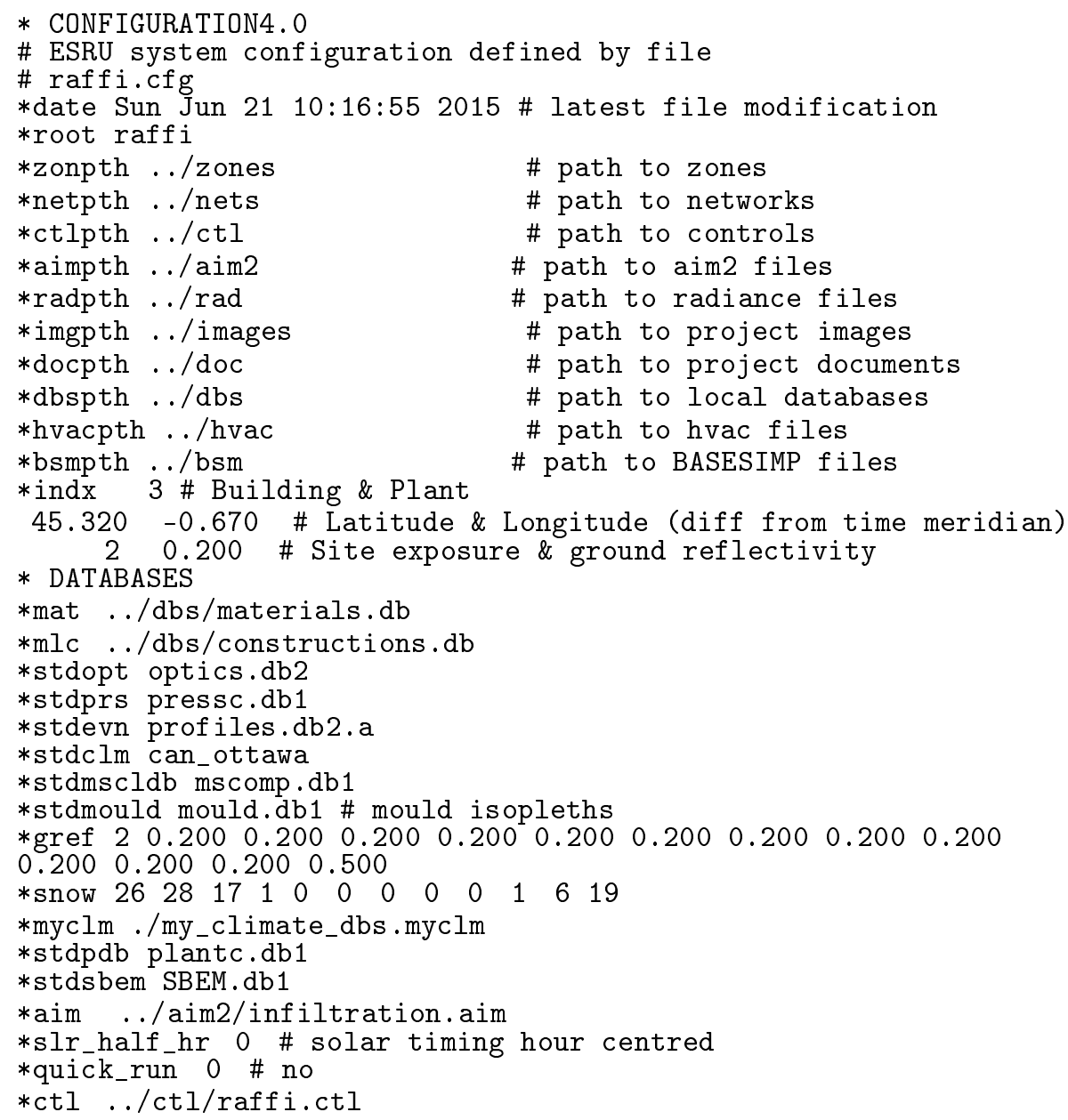




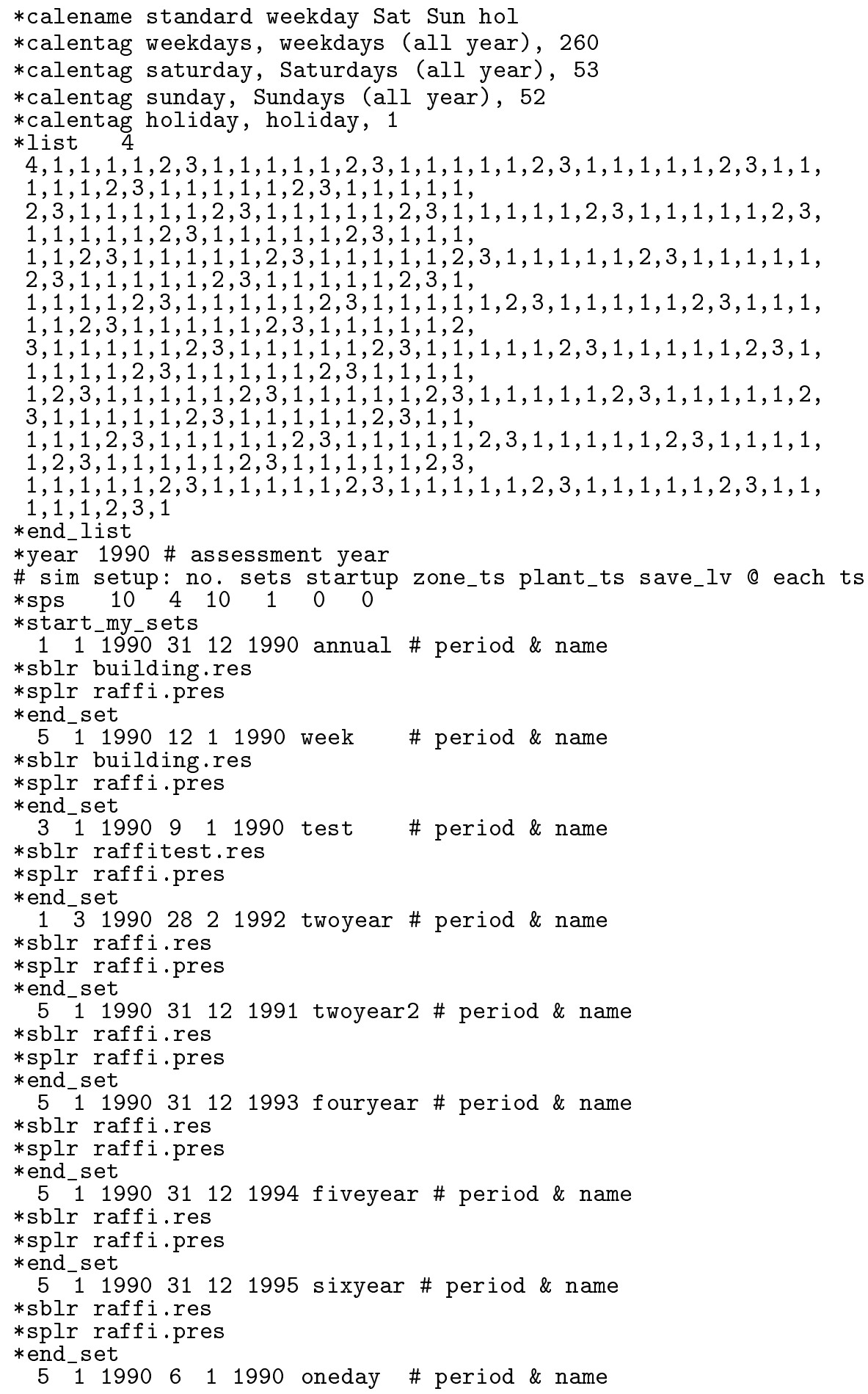




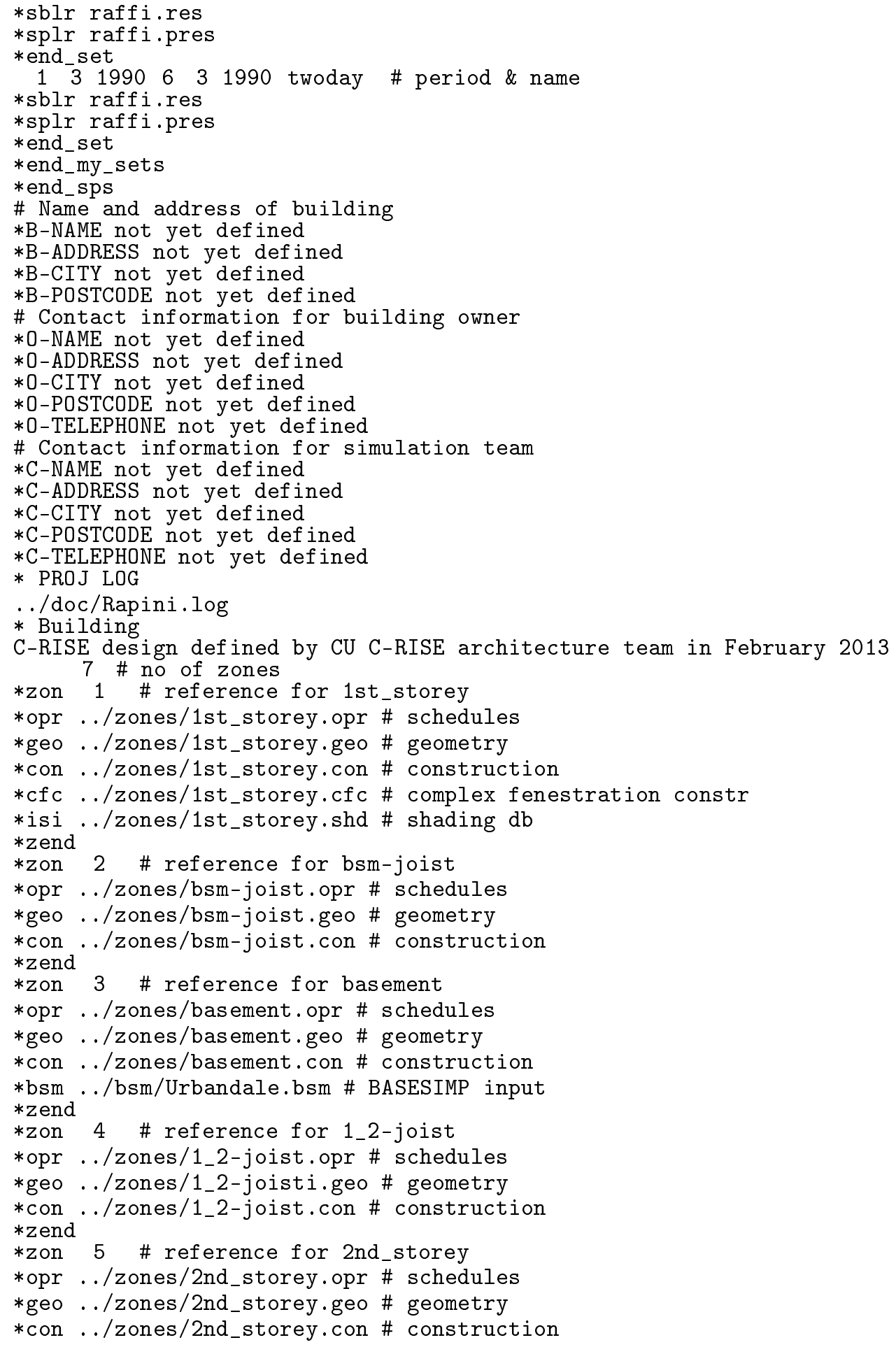


*cfc ../zones/2nd_storey.cfc \# complex fenestration constr *isi.../zones/2nd_storey.shd \# shading db

*zend

*zon 6 \# reference for attic-joist

*opr ../zones/attic-joist.opr \# schedules

*geo .../zones/attic-joist.geo \# geometry

*con .../zones/attic-joist.con \# construction

*zend

*zon 7 \# reference for attic

*opr ../zones/attic.opr \# schedules

*geo .../zones/attic.geo \# geometry

*con .../zones/attic.con \# construction

*zend

*cnn raffi.cnn \# connections

0 \# no fluid flow network

* Plant

../nets/raffi.pln \# plant network description 


\section{C.2 Alberta Infiltration Model}

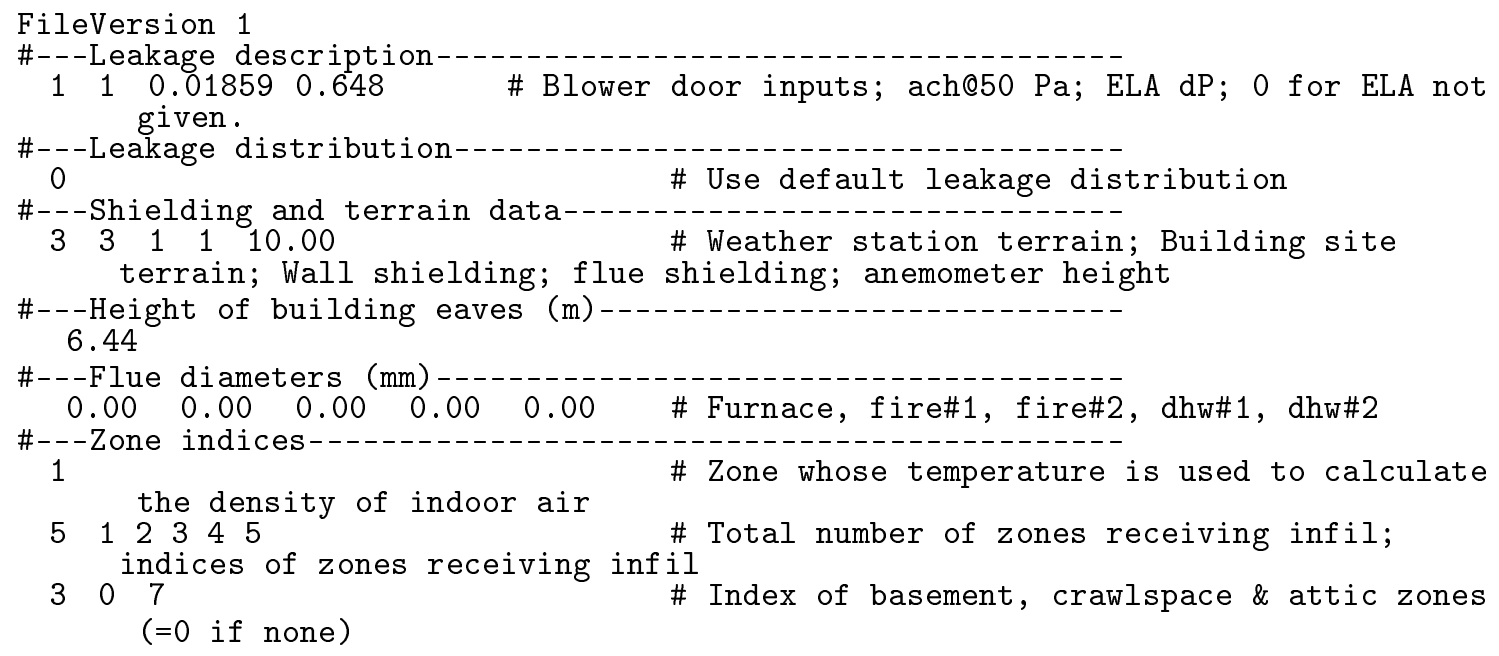

\section{C.3 Control}

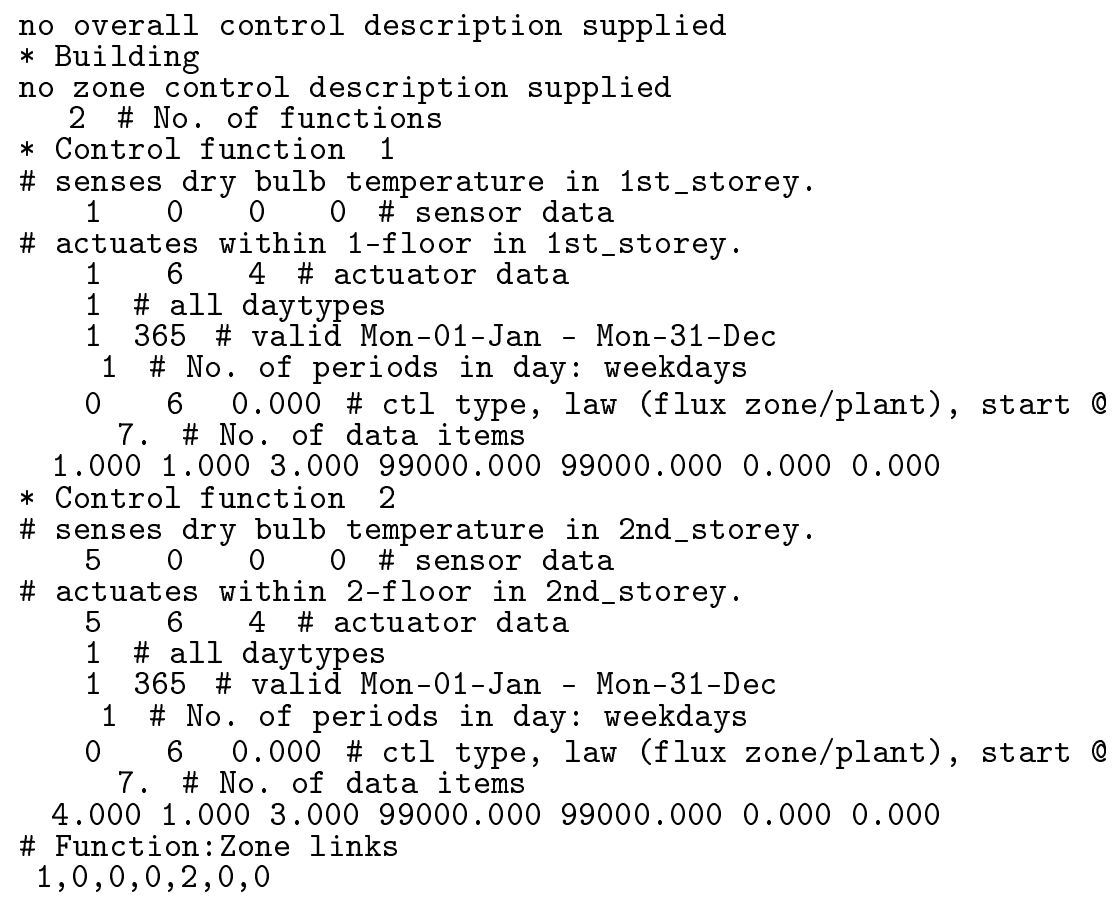




\section{C.4 Plant}

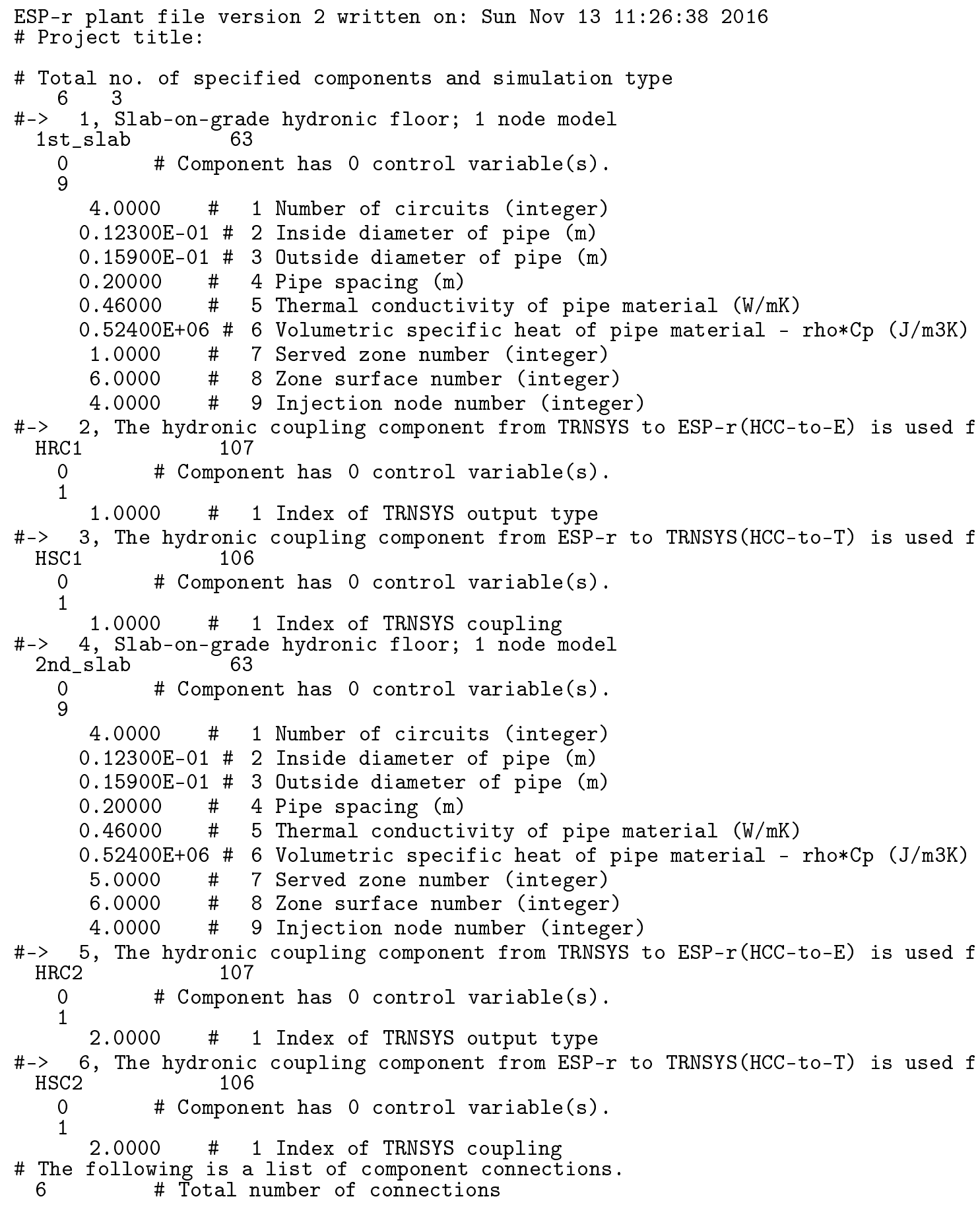




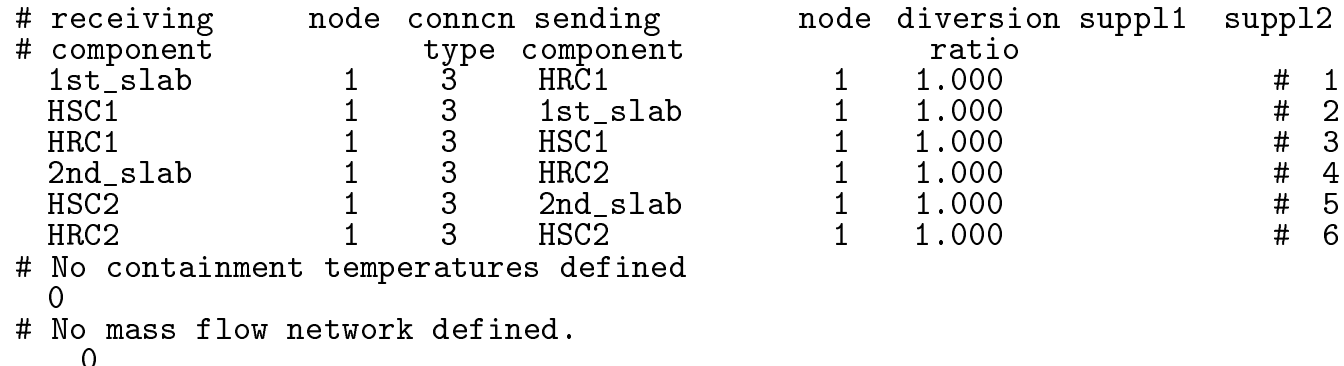

\section{C.5 Air Flow Network}

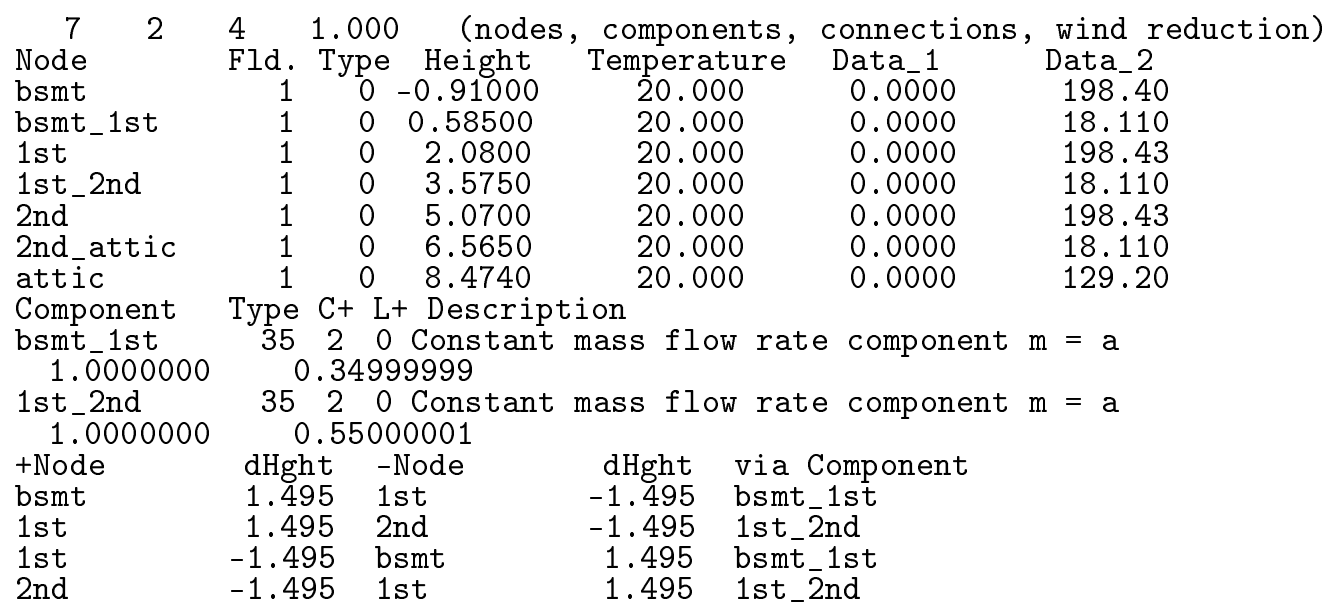

\section{C.6 BASESIMP}

*FileVersion 99.0
2.27
1.71
\# foundation height (m)
\# foundation depth (m)
12.50
\# foundation length (m)
6.40
0.0000
2.1100
\# foundation width (m)
\# insul overlap (for BCCN_1,BCCN_2)
0.8500
10.0000
\# insulation in RSI
\# soil conductivity ( $\mathrm{W} / \mathrm{m} \mathrm{K})$
8.90
14.2
\# water table (m)
0.3691
\# Tg,avg
\# Tg,amp
0 .
\# Ps (Ground temperature phase angle)
\# Above-grade heat-loss factor (Sag) [A.g. surfaces
treated separately with external boundary condition.]
37.729
\# Below-grade average heat-loss factor (Sbg,avg)
12.957
\# Below-grade variable heat-loss factor (Sbg,var)
2.658
\# phase angle (phase) 
Appendix D

Simulation Studio Architecture 


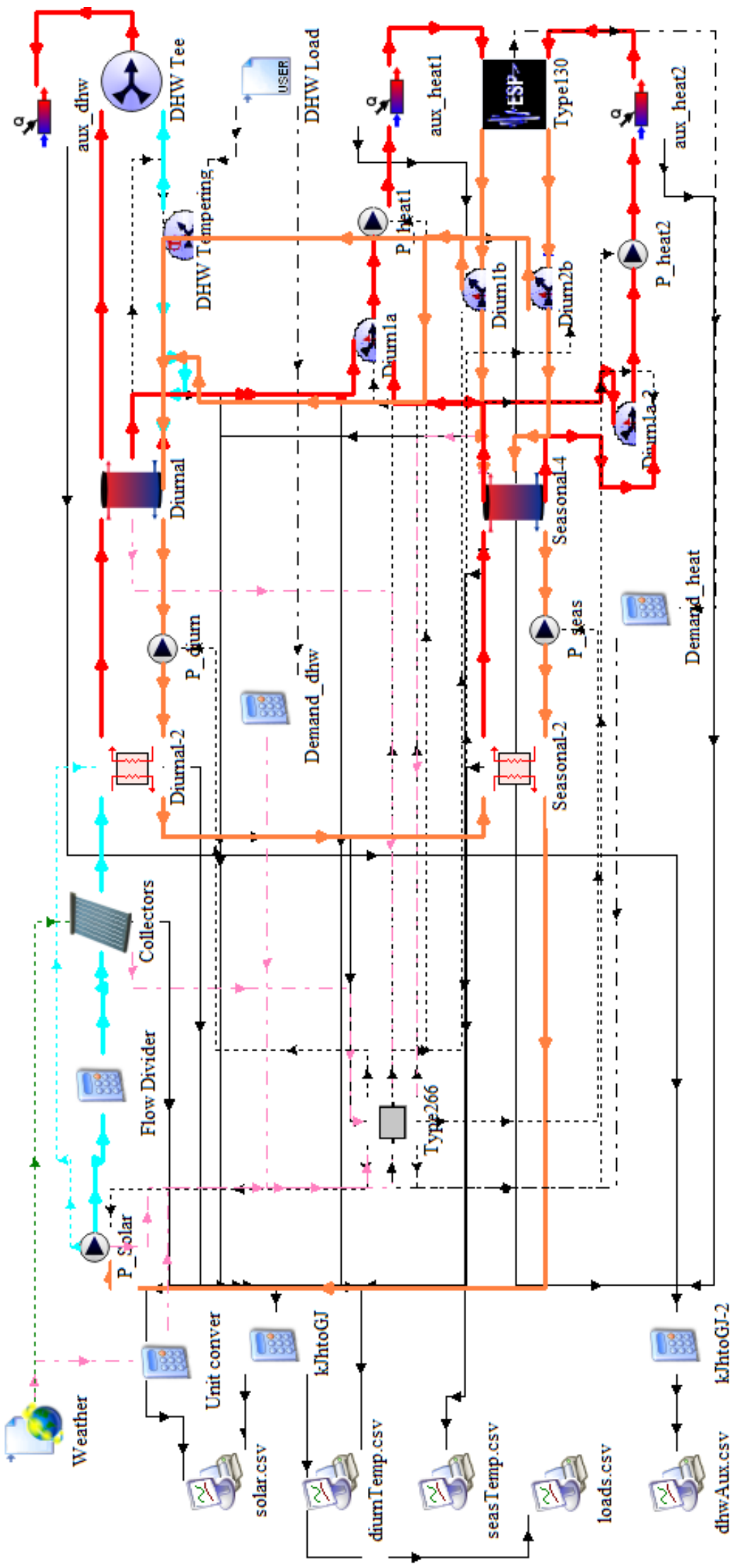

Figure 78: TRNSYS Simulation Studio Architecture 
Appendix E

\section{TRNSYS Input Files}

\section{E.1 Custom Controller Type}

Subroutine Type266

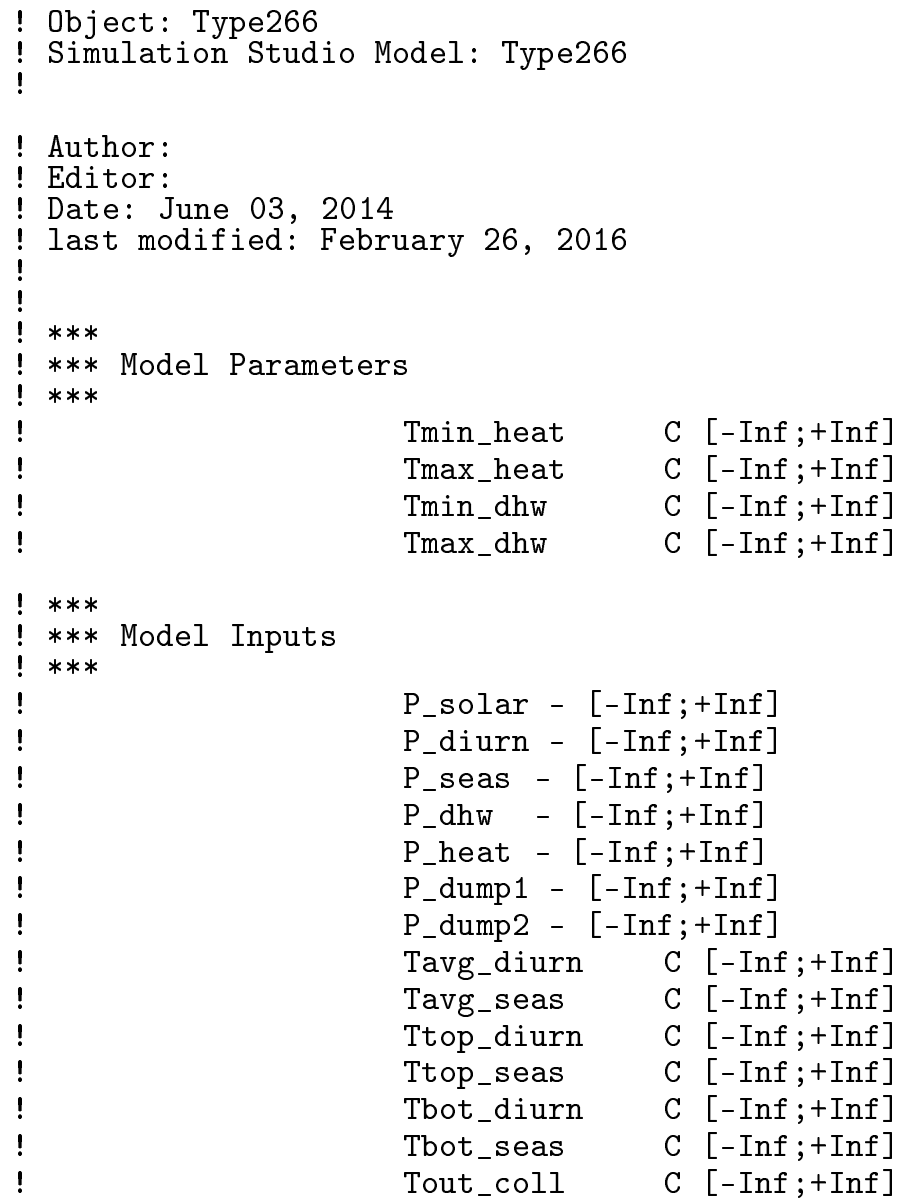




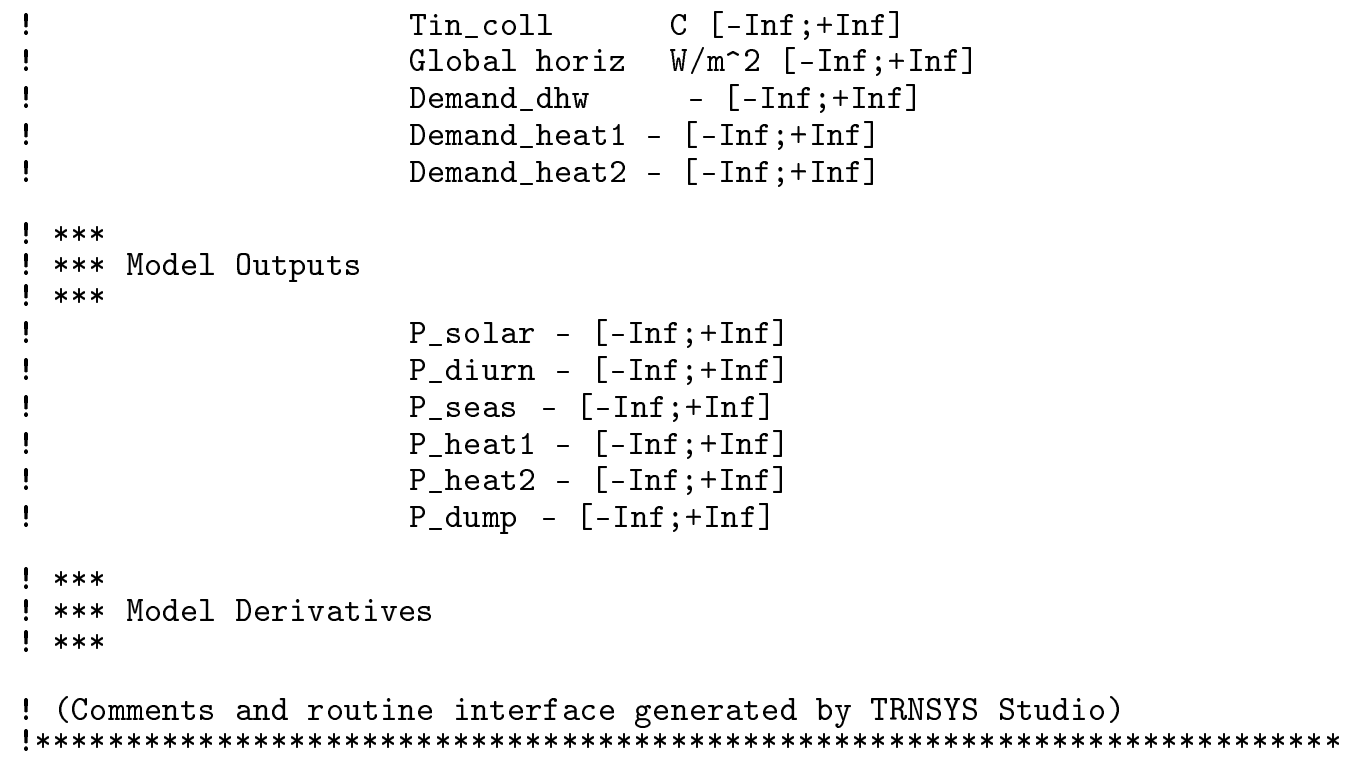

!-

! This TRNSYS component skeleton was generated from the TRNSYS studio based on the user-supplied parameters, inputs,

! outputs, and derivatives. The user should check the component formulation carefully and add the content to transform

! the parameters, inputs and derivatives into outputs. Remember, outputs should be the average value over the timestep

! and not the value at the end of the timestep; although in many models these are exactly the same values. Refer to

! existing types for examples of using advanced features inside the model ( Formats, Labels etc.)

Use TrnsysConstants

Use TrnsysFunctions

!-

!DEC\$Attributes DLLexport : : Type266

! - -

! Trnsys Declarations

Implicit None

Double Precision Timestep, Time

Integer CurrentUnit, Current Type

! PARAMETERS

DOUBLE PRECISION Tmin_heat 
DOUBLE PRECISION Tmax_heat

DOUBLE PRECISION Tmin_dhw

DOUBLE PRECISION Tmax_dhw

! INPUTS

INTEGER P_solar

INTEGER P diurn

INTEGER P_seas

INTEGER P_heat 1

INTEGER P_heat 2

INTEGER P_dump

DOUBLE PRECISION Tavg_diurn

DOUBLE PRECISION Tavg_seas

DOUBLE PRECISION Ttop diurn

DOUBLE PRECISION Ttop_seas

DOUBLE PRECISION Tbot_diurn

DOUBLE PRECISION Tbot_seas

DOUBLE PRECISION Tout_coll

DOUBLE PRECISION Tin coll

DOUBLE PRECISION Global_horiz

INTEGER Demand_dhw

INTEGER Demand_heat1

INTEGER Demand heat2

DOUBLE PRECISIONN Tamb

DOUBLE PRECISION TdiurnHX_outS

! LOCAL VARIABLES

INTEGER stagnating

INTEGER heatDump

INTEGER glycolWarm

INTEGER recirculator

INTEGER diurnCharged

INTEGER seasCharged

INTEGER nstk, icnt, cntold, iosc, totstk

CHARACTER $* 12$ ICNTStr

CHARACTER*160 WarnMsg

! OUTPUTS

DOUBLE PRECISION otpt_P_solar

DOUBLE PRECISION otpt_P_diurn

DOUBLE PRECISION otpt_P_seas

DOUBLE PRECISION otpt_P_heat1

DOUBLE PRECISION otpt_P_heat2

DOUBLE PRECISION otpt_P_dump

DOUBLE PRECISION otpt_recirc

DOUBLE PRECISION diurn rad1

DOUBLE PRECISION diurn rad2

DOUBLE PRECISION otpt_Tmin_heat

DOUBLE PRECISION otpt_Tmax_heat

DOUBLE PRECISION otpt_Tmin_dhw

DOUBLE PRECISION otpt Tmax dhw

DOUBLE PRECISION diurn_split

DOUBLE PRECISION diurn_mix

DOUBLE PRECISION seas_split

DOUBLE PRECISION seas mix

! - -

!Get the Global Trnsys Simulation Variables 


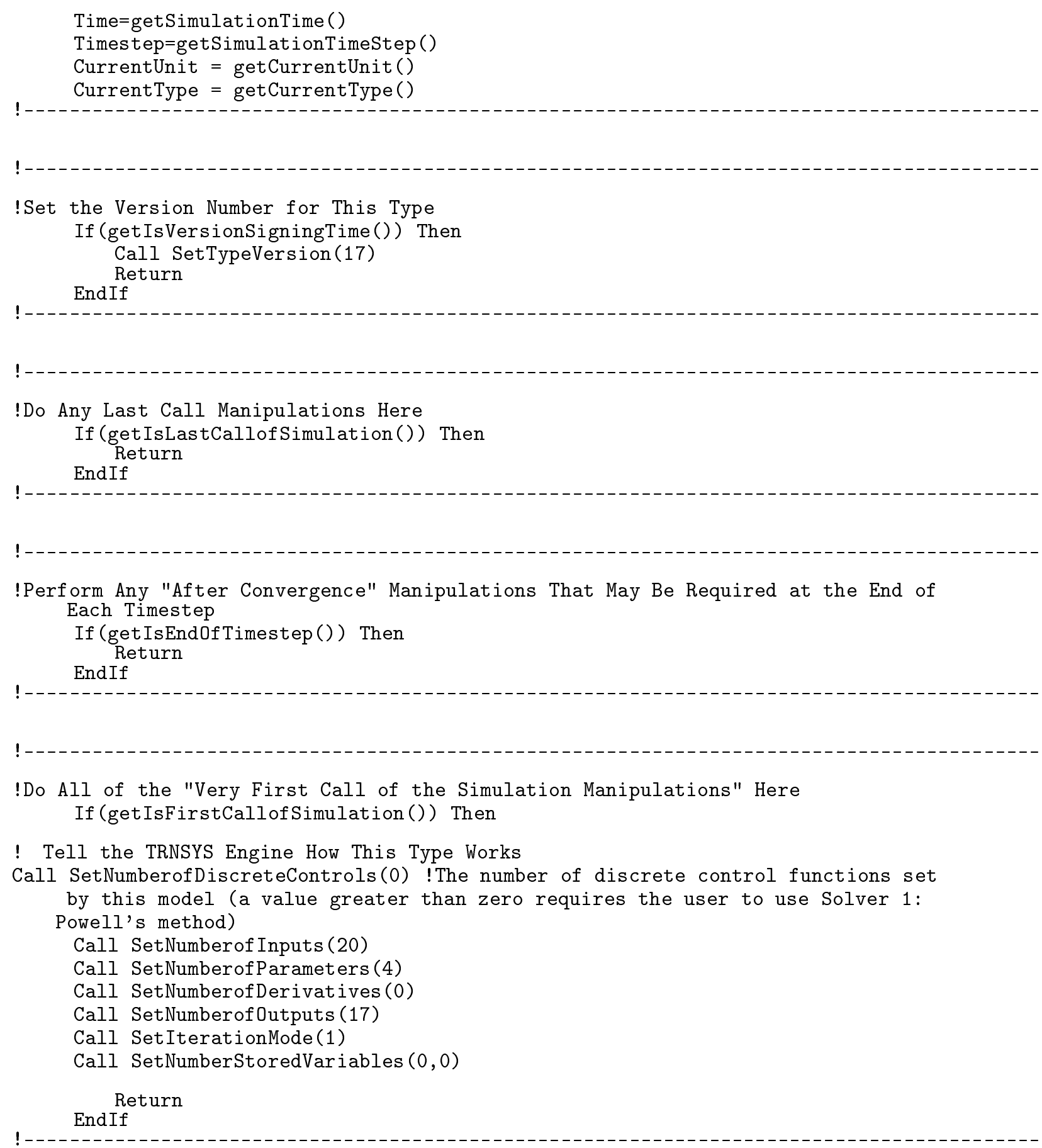


!- -

!Do All of the First Timestep Manipulations Here - There Are No Iterations at the Intial Time

If (getIsStartTime()) Then

Tmin_heat $=$ getParameterValue $(1)$

Tmax_heat $=$ getParameterValue (2)

Tmin_dhw = getParameterValue (3)

Tmax_dhw = getParameterValue(4)

P_solar $=$ GetInputValue $(1)$

P_diurn = GetInputValue (2)

$\mathrm{P}_{\text {_seas }}=$ Get InputValue (3)

P_heat 1 = GetInputValue (4)

P_heat2 = GetInputValue (5)

P_dump = GetInputValue (6)

Tavg_diurn = GetInputValue $(7)$

Tavg_seas = GetInputValue (8)

Ttop_diurn = GetInputValue (9)

Ttop_seas = GetInputValue $(10)$

Tbot_diurn = GetInputValue(11)

Tbot_seas = GetInputValue (12)

Tout_coll = GetInputValue(13)

Tin_coll = GetInputValue (14)

Global_horiz = Get InputValue(15)

Demand_dhw $=$ GetInputValue (16)

Demand_heat1 $=$ Get InputValue(17)

Demand_heat2 = GetInputValue(18)

Tamb = GetInputValue(19)

TdiurnHX_outS = GetInputValue(20)

!Check the Parameters for Problems (\#,ErrorType,Text)

!Sample Code: If ( PAR1 <= 0.) Call FoundBadParameter(1,'Fatal', 'The first parameter provided to this model is not acceptable.')

!Set the Initial Values of the Outputs (\#,Value)

Call SetOutputValue (1, 0) ! P_solar

Call SetOutputValue $(2,0)$ ! P_diurn

Call SetOutputValue (3, 0) ! P_seas

Call SetOutputValue $(4,0)$ ! P_heat1

Call SetOutputValue $(5,0)$ ! P_heat2

Call SetOutputValue $(6,0)$ ! P_dump

Call SetOutputValue $(7,0)$ ! recirculator

Call SetOutputValue $(8,1)$ ! diurn_rad1

Call SetOutputValue $(9,1)$ ! diurn_rad2

Call SetOutputValue $(10,0)$ ! Tmin_heat

Call SetOutputValue $(11,0)$ ! Tmax_heat

Call SetOutputValue $(12,0) !$ Tmin_dhw

Call SetOutputValue $(13,0)$ ! Tmax_dhw

Call SetOutputValue $(14,0)$ ! diurn_split

Call SetOutputValue $(15,0)$ ! dirun_mix

Call SetOutputValue $(16,0)$ ! seas_split 
Call SetOutputValue $(17,0)$ ! seas_mix

!If Needed, Set the Initial Values of the Static Storage Variables (\#, Value)

!Sample Code: SetStaticArrayValue $(1,0 . \mathrm{d} 0)$

! If Needed, Set the Initial Values of the Dynamic Storage Variables (\#, Value)

!Sample Code: Call SetDynamicArrayValueThisIteration(1,20.d0)

! If Needed, Set the Initial Values of the Discrete Controllers (\#,Value)

!Sample Code for Controller 1 Set to Off: Call SetDesiredDiscreteControlState $(1,0)$

Return

EndIf

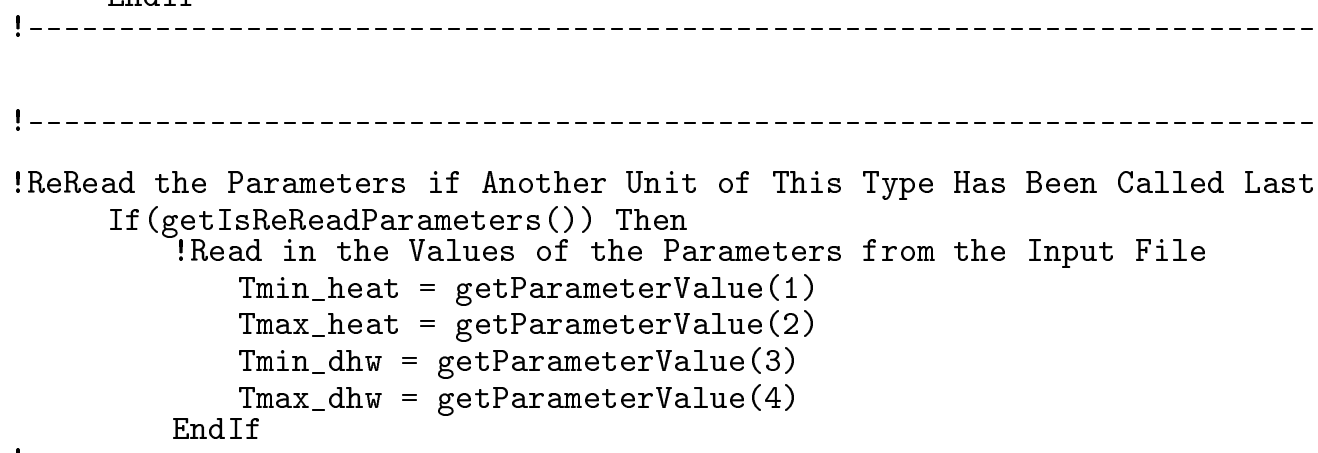


!Check the Inputs for Problems (\#,ErrorType,Text)

!Sample Code: If ( IN1 <= 0.) Call FoundBadInput(1, 'Fatal', The first input provided to this model is not acceptable.')

If (ErrorFound()) Return

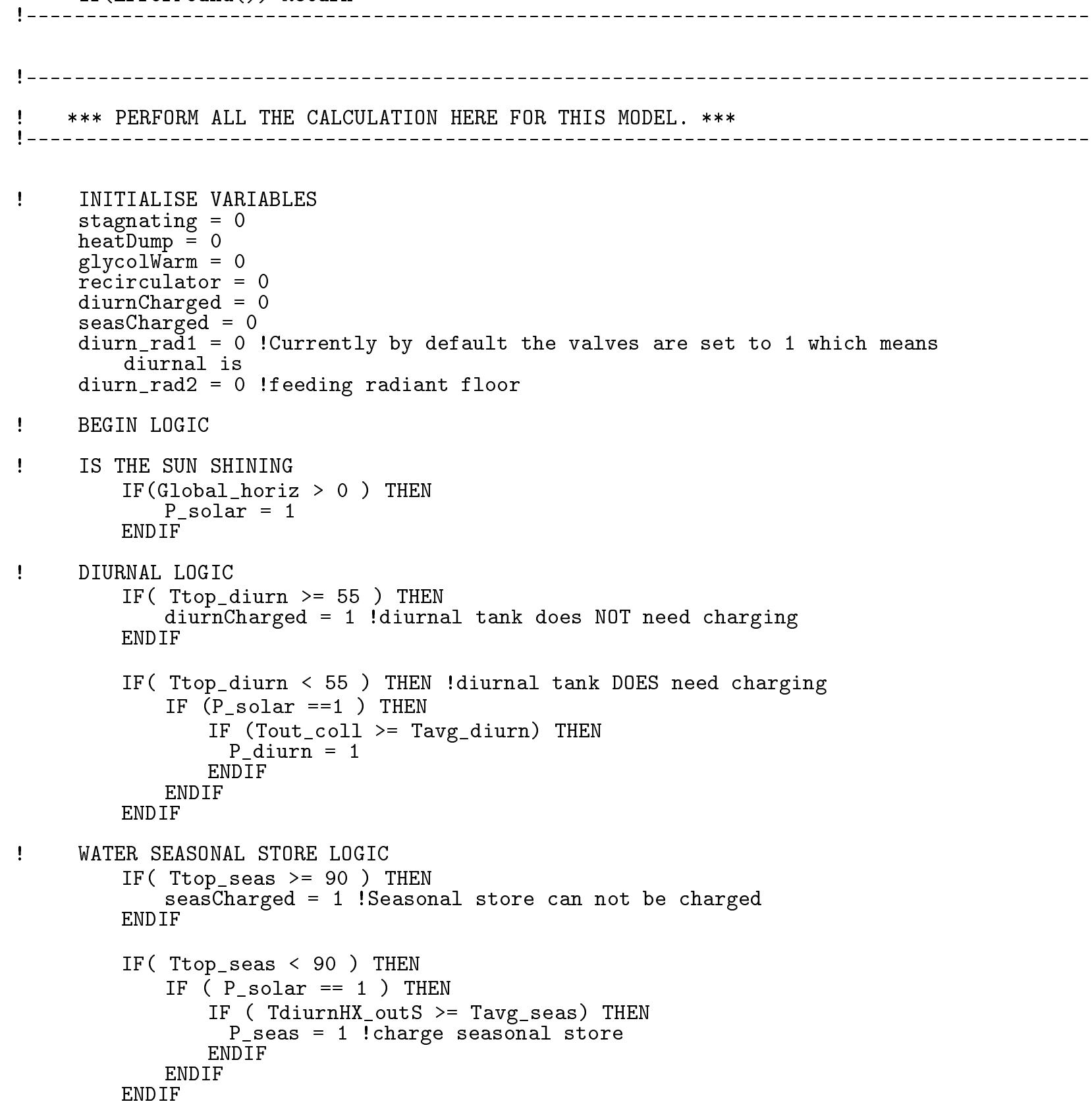

!RADIANT FLOOR LOGIC 


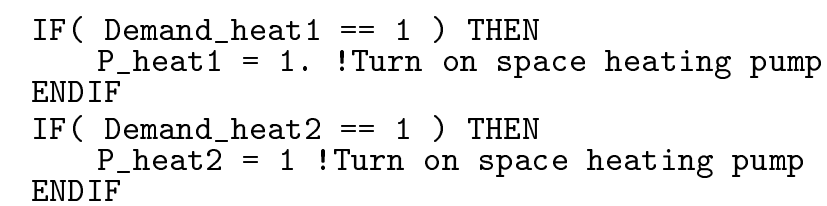

! SEASONAL / DIURNAL TO SUPPLY RADIANT FLOOR

IF ( P_heat1 == 1 ) THEN !main story radiant floor calls for htg IF ( Demand_dhw $==0$. AND. Ttop_diurn > 55) THEN

! REASSIGN INPUT VARIABLES FOR OUTPUTTING

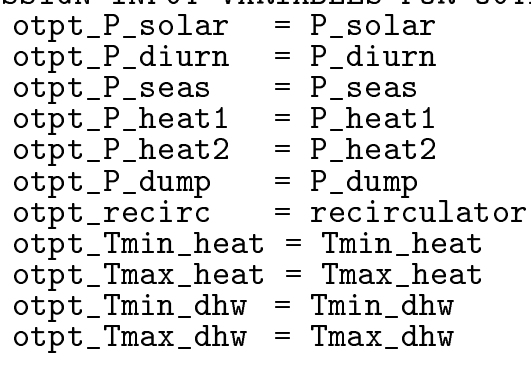

!If Needed, Get the Previous Control States if Discrete Controllers are Being Used (\#)

!Sample Code: CONTROL_LAST=getPreviousControlState (1)

! $-\ldots-\ldots$

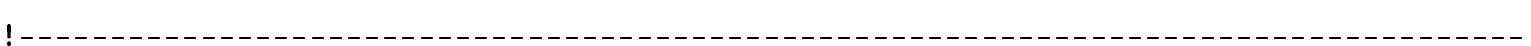

!If Needed, Get the Values from the Global Storage Array for the Static Variables (\#)

!Sample Code: STATIC1=getStaticArrayValue(1)

!

! If Needed, Get the Initial Values of the Dynamic Variables from the Global Storage Array (\#)

!Sample Code: T_INITIAL_1=getDynamicArrayValueLastTimestep (1) 
$!-$

!-

!Perform All of the Calculations Here to Set the Outputs from the Model Based on the Inputs

!Sample Code: OUT1=IN1+PAR1

! If the model requires the solution of numerical derivatives, set these derivatives and get the current solution

!Sample Code: T1=getNumericalSolution(1)

!Sample Code: T2=getNumericalSolution(2)

!Sample Code: DTDT1 $=3 . * \mathrm{~T} 2+7 . * \mathrm{~T} 1-15$.

!Sample Code: DTDT2 $=-2 . * \mathrm{~T} 1+11 . * \mathrm{~T} 2+21$.

!Sample Code: Call SetNumericalDerivative(1,DTDT1)

!Sample Code: Call SetNumericalDerivative(2,DTDT2)

!Set the Outputs from this Model (\#,Value)

Call SetOutputValue(1, otpt_P_solar) ! P_solar

Call SetOutputValue(2, otpt_P_diurn) ! P_diurn

Call SetOutputValue(3, otpt_P_seas) ! P_seas

Call SetOutputValue (4, otpt_P_heat1) ! P_heat1

Call SetOutputValue(5, otpt_P_heat2) ! P_heat2

Call SetOutputValue(6, otpt_P_dump) ! P_dump

Call SetOutputValue(7, otpt_recirc) ! P_dump

Call SetOutputValue(8, diurn_rad1) ! P_dump

Call SetOutputValue(9, diurn_rad2) ! P_dump

Call SetOutputValue(10, otpt_Tmin_heat) ! Tmin_heat

Call SetOutputValue(11, otpt_Tmax_heat) ! Tmax_heat

Call SetOutputValue(12, otpt_Tmin_dhw) ! Tmin_dhw

Call SetOutputValue (13, otpt_Tmax_dhw) ! Tmax_dhw

Call SetOutputValue(14, diurn_split) ! diurn_split

Call SetOutputValue(15, diurn_mix) ! dirun_mix

Call SetOutputValue(16, seas_split) ! seas_split

Call SetOutputValue(17, seas_mix) ! seas_mix

!If Needed, Store the Desired Disceret Control Signal Values for this Iteration (\#,State)

!Sample Code: Call SetDesiredDiscreteControlState $(1,1)$

!- - 
! If Needed, Store the Final value of the Dynamic Variables in the Global Storage Array (\#,Value)

!Sample Code: Call SetValueThisIteration(1,T_FINAL_1)

Return

End

0.8

\section{E.2 TRNSYS Deck}

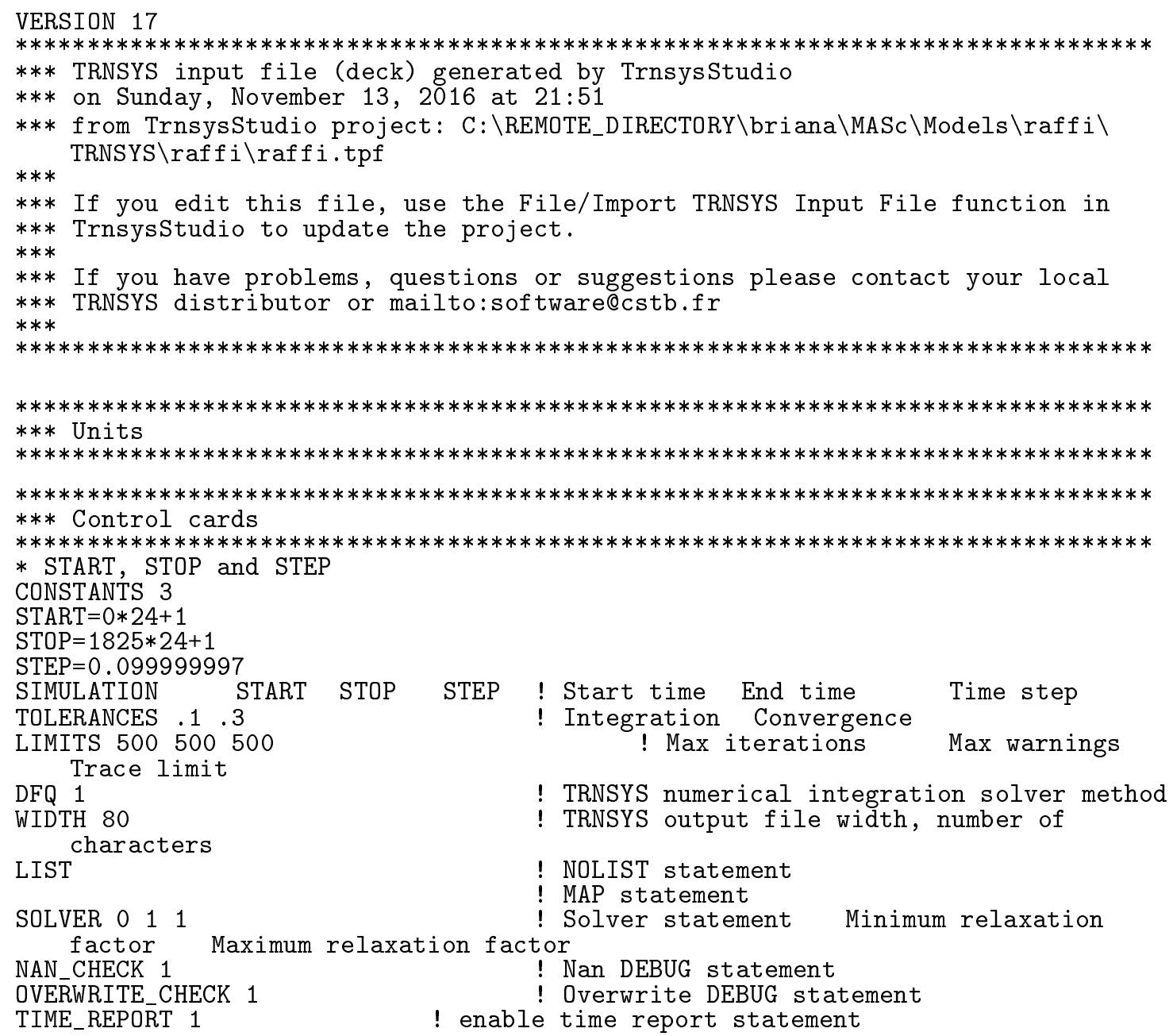


EQSOLVER 0

! EQUATION SOLVER statement

* User defined CONSTANTS

EQUATIONS 24

seas $\mathrm{T}=90$

Vol_seas $=35$

$\mathrm{h}_{-}$seas $=3.048$

tank_insul $=0.272736$

diurn_insul $=2.5675$

ground $\mathrm{T}=10$

diurnT $=55$

Vol_diurn $=0.45$

h_diurn=1.8796

$\operatorname{dh} w \mathrm{~T}=55$

green $\mathrm{Cp}=3.495$

splitF=greenF $/ 2$

greenF=1888

water $\mathrm{Cp}=4.19$

water $\mathrm{F}=900$

ht $\mathrm{gF}=300$

Parallel_num $=2$

Series_num=5

A_collector $=4.158 *$ Series_num

UA_HX=1872.65*3.6

yint $=0.458$

firstCoef $f=4.86324$

secCoeff $=0.013716$

testF $=72$

* Model "Type266" (Type 266)

$*$

UNIT 15 TYPE 266 Type266

*\$UNIT_NAME Type266

*\$MODEL . \C-RISE $\backslash$ Type266 . tmf

*\$POSITION 305265

*\$LAYER Loads \#

PARAMETERS 4

20

55

20

75

INPUTS 20

! 1 Tmin_heat

! 2 Tmax_heat

! 3 Tmin_dhw

0,0

0,0

! 4 Tmax_dhw

0,0

0,0

0,0

0,0

9,9

39,7

9,24

39,21

9,26

39,23

2,1

4,1

! [unconnected] P_solar

! [unconnected] P_diurn

! [unconnected] $\mathrm{P}_{-}$seas

! [unconnected] P_heat1

! [unconnected] P_heat2

! [unconnected] P_dump

! Diurnal:Average tank temperature ->Tavg_diurn

! Seasonal-4:Average tank temperature ->Tavg_seas

! Diurnal:Tank nodal temperature-1 ->Ttop_diurn

! Seasonal-4:Tank nodal temperature-1 ->Ttop_seas

! Diurnal:Tank nodal temperature-3 ->Tbot_diurn

! Seasonal-4:Tank nodal temperature-3 ->Tbot_seas

! Collectors:Outlet temperature ->Tout_coll

Global_Horizontal

Demand_dhw

! P_Solar:Outlet fluid temperature ->Tin_coll

Demand_heat 1

! Unit conver:Global_Horizontal ->Global horiz

! Demand_dhw:Demand_dhw ->Demand_dhw

! Demand_heat:Demand_heat1 ->Demand_heat1 


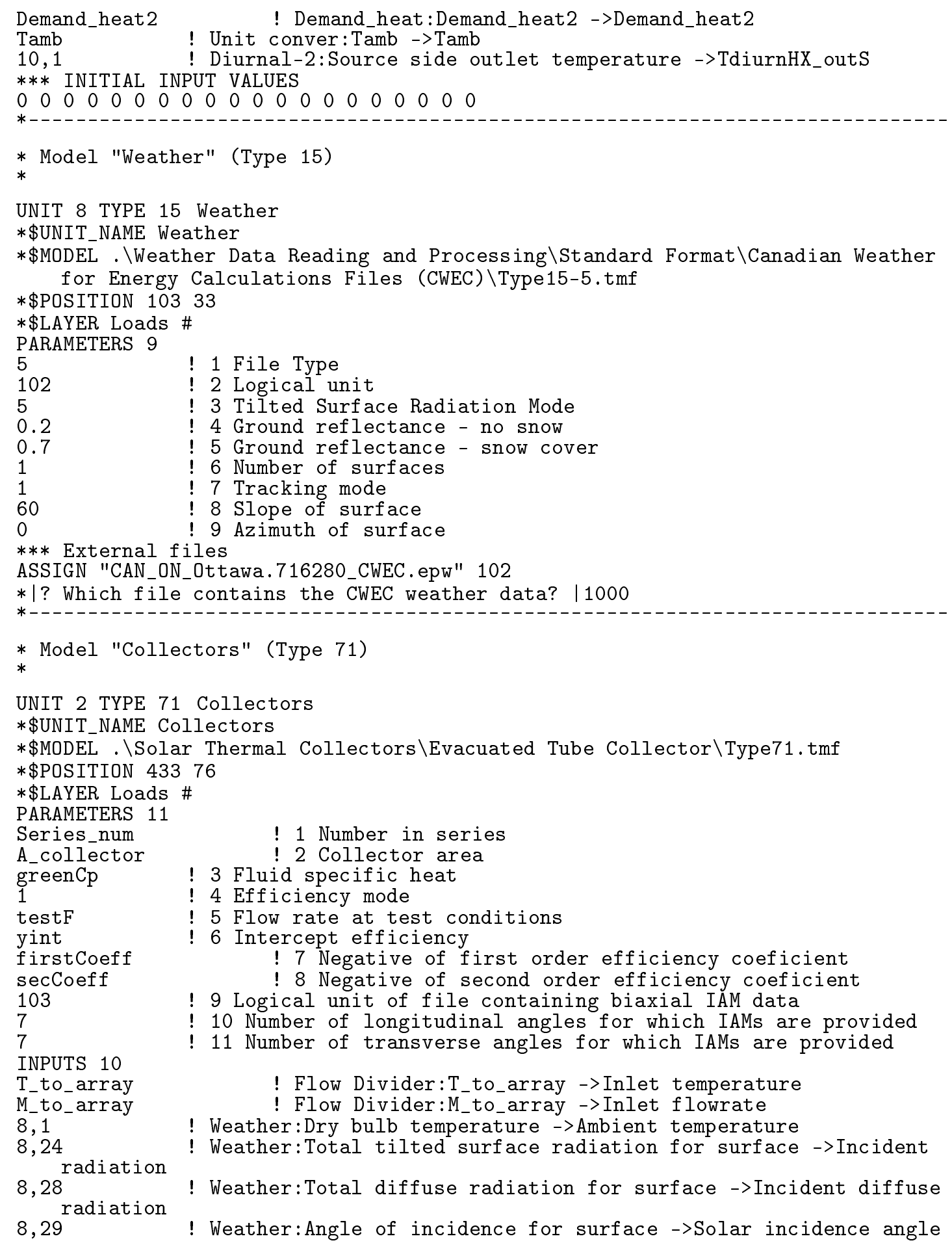




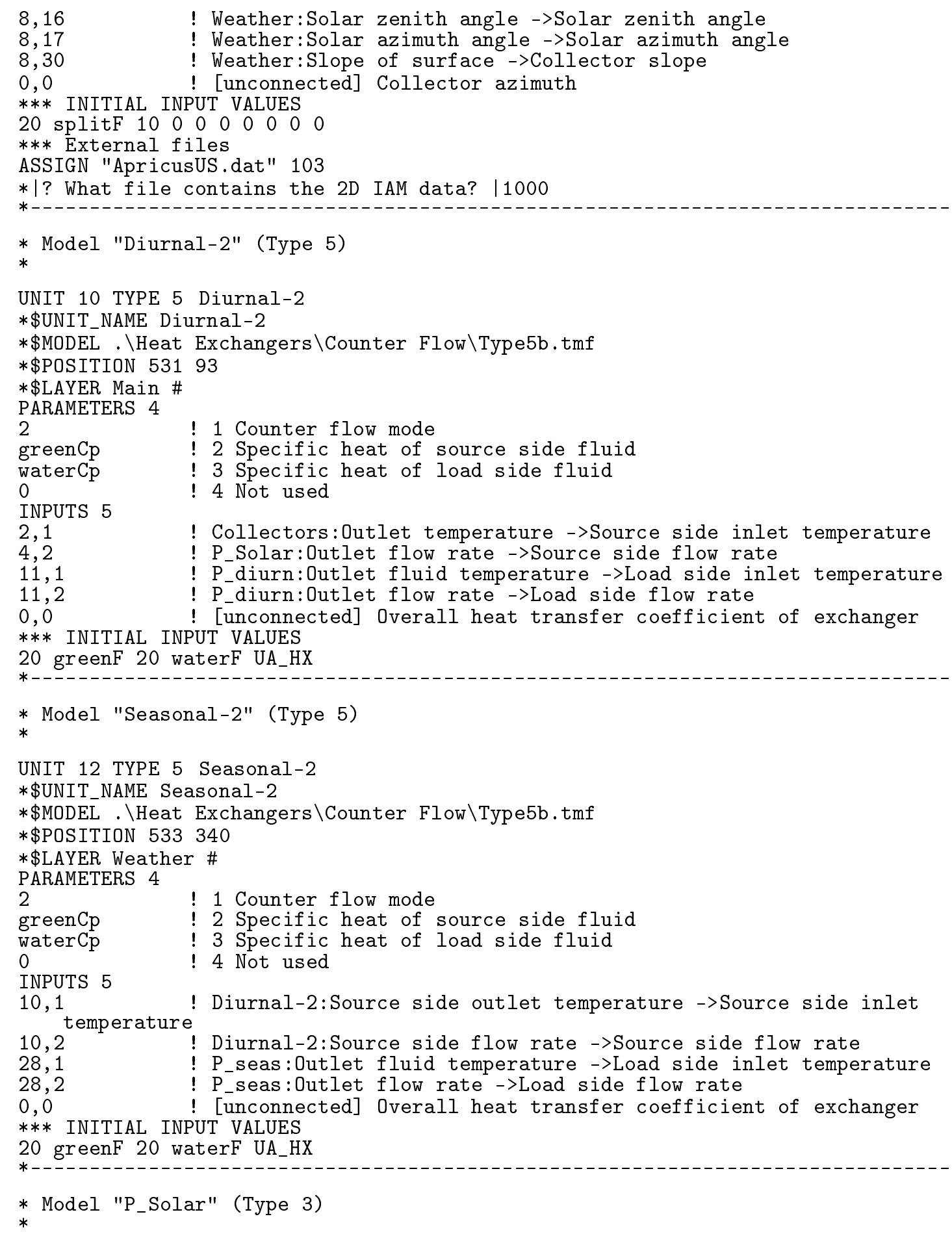




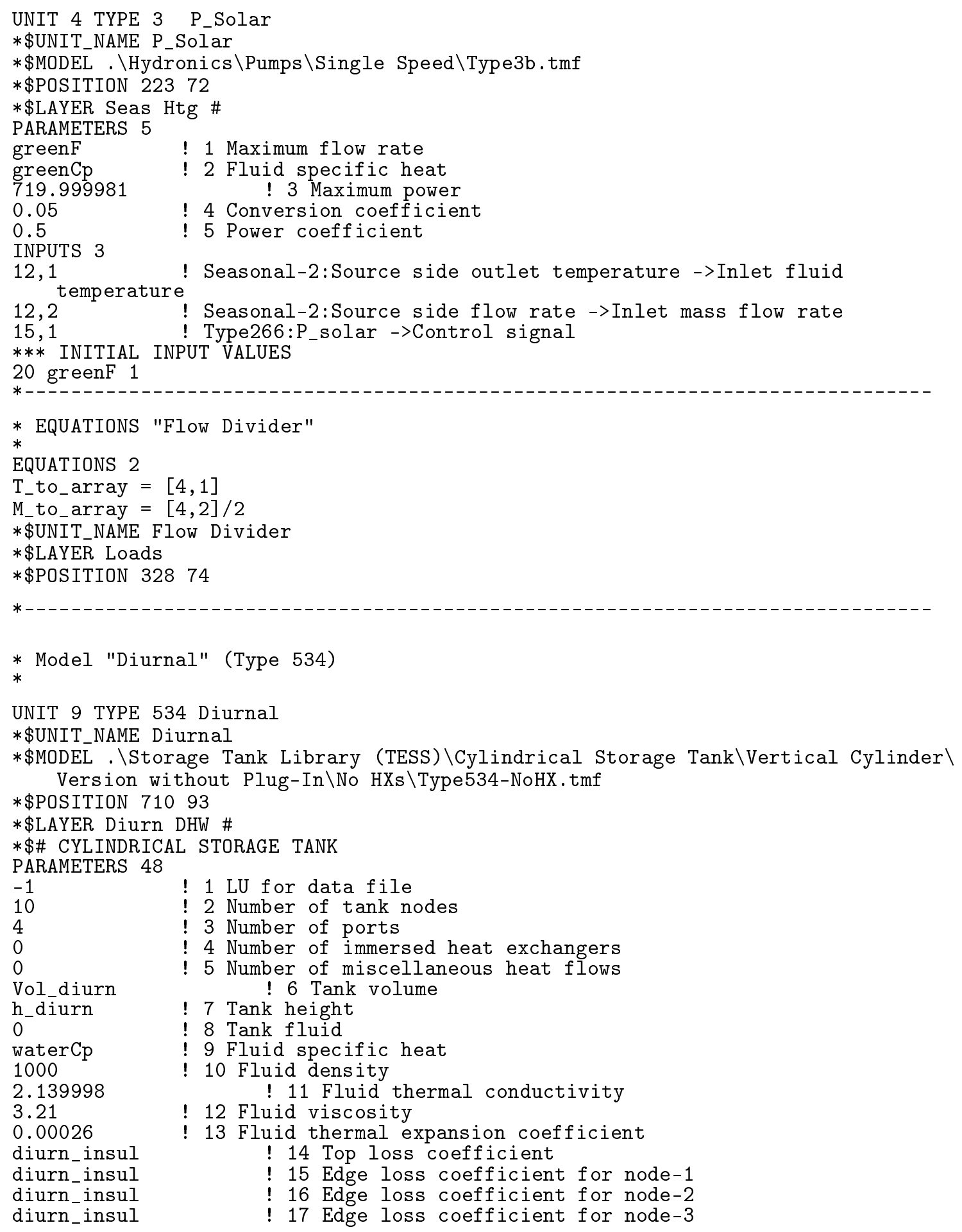




diurn_insul
diurn_insul
diurn_insul
diurn_insul
diurn_insul
diurn_insul
diurn_insul
diurn_insul
0
1
1
10
1
10
1
1
10
1
1
10
1
0
0
0
0
0
0
0
0
0
0
INPUTS 32
10,3
10 port-1
10,4
21,1
21,2
42,1
42,2
45,1
45,2
0,0
0,0
0,0
0,0
0,0
0,0
0,0
0,0
0,0
0,0
0,0
0,0
0,0
0,0
0,0
0,0

! 18 Edge loss coefficient for node-4

! 19 Edge loss coefficient for node-5

! 20 Edge loss coefficient for node-6

! 21 Edge loss coefficient for node-7

! 22 Edge loss coefficient for node-8

! 23 Edge loss coefficient for node-9

! 24 Edge loss coefficient for node-10

! 25 Bottom loss coefficient

! 26 Additional thermal conductivity

! 27 Inlet flow mode-1

! 28 Entry node-1

! 29 Exit node-1

! 30 Inlet flow mode-2

! 31 Entry node-2

! 32 Exit node-2

! 33 Inlet flow mode-3

! 34 Entry node-3

! 35 Exit node-3

! 36 Inlet flow mode-4

! 37 Entry node-4

! 38 Exit node-4

! 39 Flue loss coefficient for node-1

! 40 Flue loss coefficient for node-2

! 41 Flue loss coefficient for node-3

! 42 Flue loss coefficient for node-4

! 43 Flue loss coefficient for node-5

! 44 Flue loss coefficient for node- 6

! 45 Flue loss coefficient for node-7

! 46 Flue loss coefficient for node-8

! 47 Flue loss coefficient for node-9

! 48 Flue loss coefficient for node-10

! Diurnal-2:Load side outlet temperature ->Inlet temperature for

! Diurnal-2:Load side flow rate ->Inlet flow rate for port-1

! DHW Tempering:Temperature at outlet 1 ->Inlet temperature for

! DHW Tempering:Flowrate at outlet 1 ->Inlet flow rate for port-2

! Diurn1b:Temperature at outlet $1->$ Inlet temperature for port-3

! Diurn1b:Flow rate at outlet 1 ->Inlet flow rate for port-3

! Diurn2b:Temperature at outlet 1 - Inlet temperature for port-4

! Diurn2b:Flow rate at outlet 1 ->Inlet flow rate for port-4

! [unconnected] Top loss temperature

! [unconnected] Edge loss temperature for node-1

! [unconnected] Edge loss temperature for node-2

! [unconnected] Edge loss temperature for node-3

! [unconnected] Edge loss temperature for node-4

! [unconnected] Edge loss temperature for node-5

! [unconnected] Edge loss temperature for node-6

! [unconnected] Edge loss temperature for node-7

! [unconnected] Edge loss temperature for node-8

! [unconnected] Edge loss temperature for node-9

! [unconnected] Edge loss temperature for node-10

! [unconnected] Bottom loss temperature

! [unconnected] Gas flue temperature

! [unconnected] Inversion mixing flow rate

! [unconnected] Auxiliary heat input for node-1

! [unconnected] Auxiliary heat input for node-2 


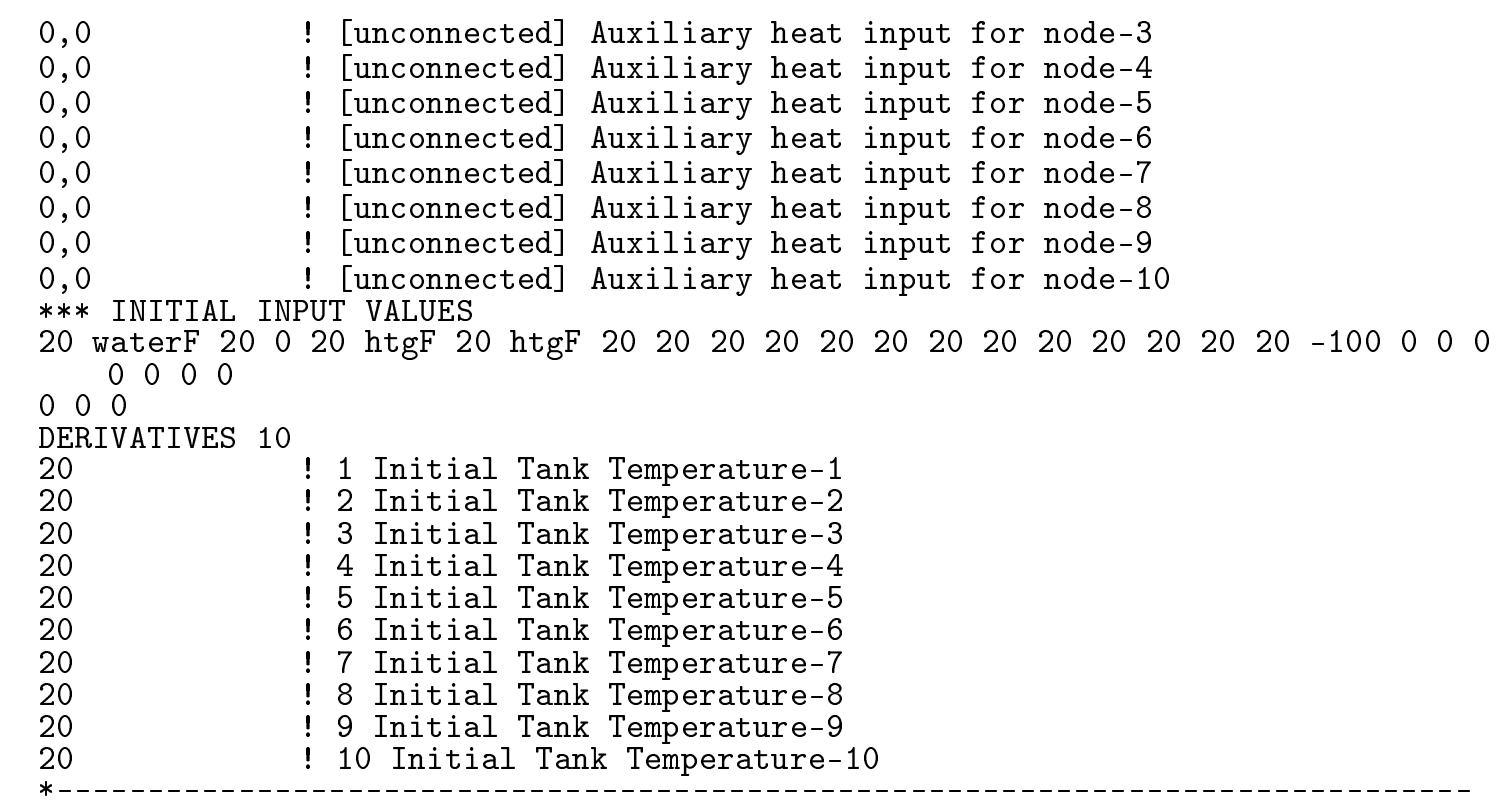

* Model "P_diurn" (Type 3)

UNIT 11 TYPE 3 P_diurn

*\$UNIT_NAME P_diurn

$*$ \$MODEL . \Hydronics $\backslash$ Pumps $\backslash$ Single Speed $\backslash$ Type3b.tmf

*\$POSITION 610116

*\$LAYER Stores \#

PARAMETERS 5

waterF

! 1 Maximum flow rate

waterCp

! 2 Fluid specific heat

719.999981

0.05

! 3 Maximum power

0.5

! 4 Conversion coefficient

INPUTS 3

$\begin{array}{ll}9,1 & ! \text { Diurnal: Temperature at outlet-1 }->\text { Inlet fluid temperature } \\ 9,2 & \text { ! Diurnal:Flow rate at outlet-1 } \rightarrow \text { Inlet mass flow rate }\end{array}$

15,2 ! Type266:P_diurn ->Control signal

$* * *$ INITIAL INPUT VALUES

20 waterF 0

* Model "Seasonal-4" (Type 534)

*

UNIT 39 TYPE $534 \quad$ Seasonal-4

*\$UNIT_NAME Seasonal-4

*\$MODEL . \Storage Tank Library (TESS) \Cylindrical Storage Tank\Vertical Cylinder Version without Plug-In $\backslash$ No HXs $\backslash$ Type534-NoHX.tmf *\$POSITION 702340

*\$LAYER Loads \#

*\$\# CYLINDRICAL STORAGE TANK

PARAMETERS 65

$-1$

! 1 LU for data file 
! 2 Number of tank nodes

! 3 Number of ports

! 4 Number of immersed heat exchangers

! 5 Number of miscellaneous heat flows ! 6 Tank volume

! 7 Tank height

! 8 Tank fluid

! 9 Fluid specific heat

! 10 Fluid density

! 11 Fluid thermal conductivity

! 12 Fluid viscosity

! 13 Fluid thermal expansion coefficient

! 14 Top loss coefficient

! 15 Edge loss coefficient for node-1

! 16 Edge loss coefficient for node-2

! 17 Edge loss coefficient for node-3

! 18 Edge loss coefficient for node-4

! 19 Edge loss coefficient for node-5

! 20 Edge loss coefficient for node-6

! 21 Edge loss coefficient for node-7

! 22 Edge loss coefficient for node-8

! 23 Edge loss coefficient for node-9

! 24 Edge loss coefficient for node-10

! 25 Edge loss coefficient for node-11

! 26 Edge loss coefficient for node-12

! 27 Edge loss coefficient for node-13

! 28 Edge loss coefficient for node-14

! 29 Edge loss coefficient for node-15

! 30 Edge loss coefficient for node-16

! 31 Edge loss coefficient for node-17

! 32 Edge loss coefficient for node-18

! 33 Edge loss coefficient for node-19

! 34 Edge loss coefficient for node-20

! 35 Bottom loss coefficient

! 36 Additional thermal conductivity

! 37 Inlet flow mode-1

! 38 Entry node-1

! 39 Exit node-1

! 40 Inlet flow mode-2

! 41 Entry node-2

! 42 Exit node-2

! 43 Inlet flow mode-3

! 44 Entry node-3

! 45 Exit node-3

! 46 Flue loss coefficient for node-1

! 47 Flue loss coefficient for node-2

! 48 Flue loss coefficient for node-3

! 49 Flue loss coefficient for node-4

! 50 Flue loss coefficient for node-5

! 51 Flue loss coefficient for node-6

! 52 Flue loss coefficient for node-7

! 53 Flue loss coefficient for node-8

! 54 Flue loss coefficient for node-9

! 55 Flue loss coefficient for node-10

! 56 Flue loss coefficient for node-11

! 57 Flue loss coefficient for node-12

! 58 Flue loss coefficient for node-13

! 59 Flue loss coefficient for node-14

! 60 Flue loss coefficient for node-15

! 61 Flue loss coefficient for node-16 


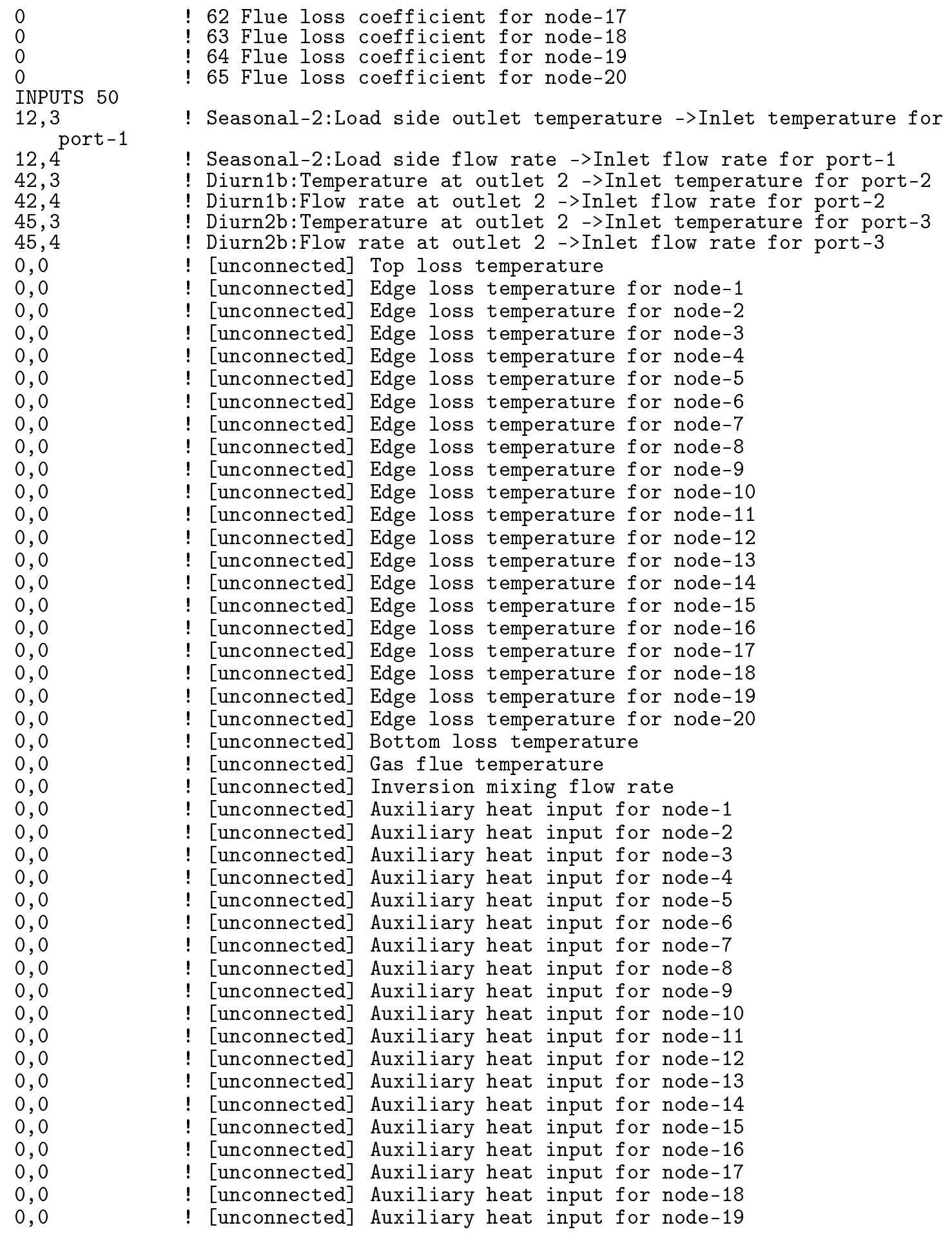




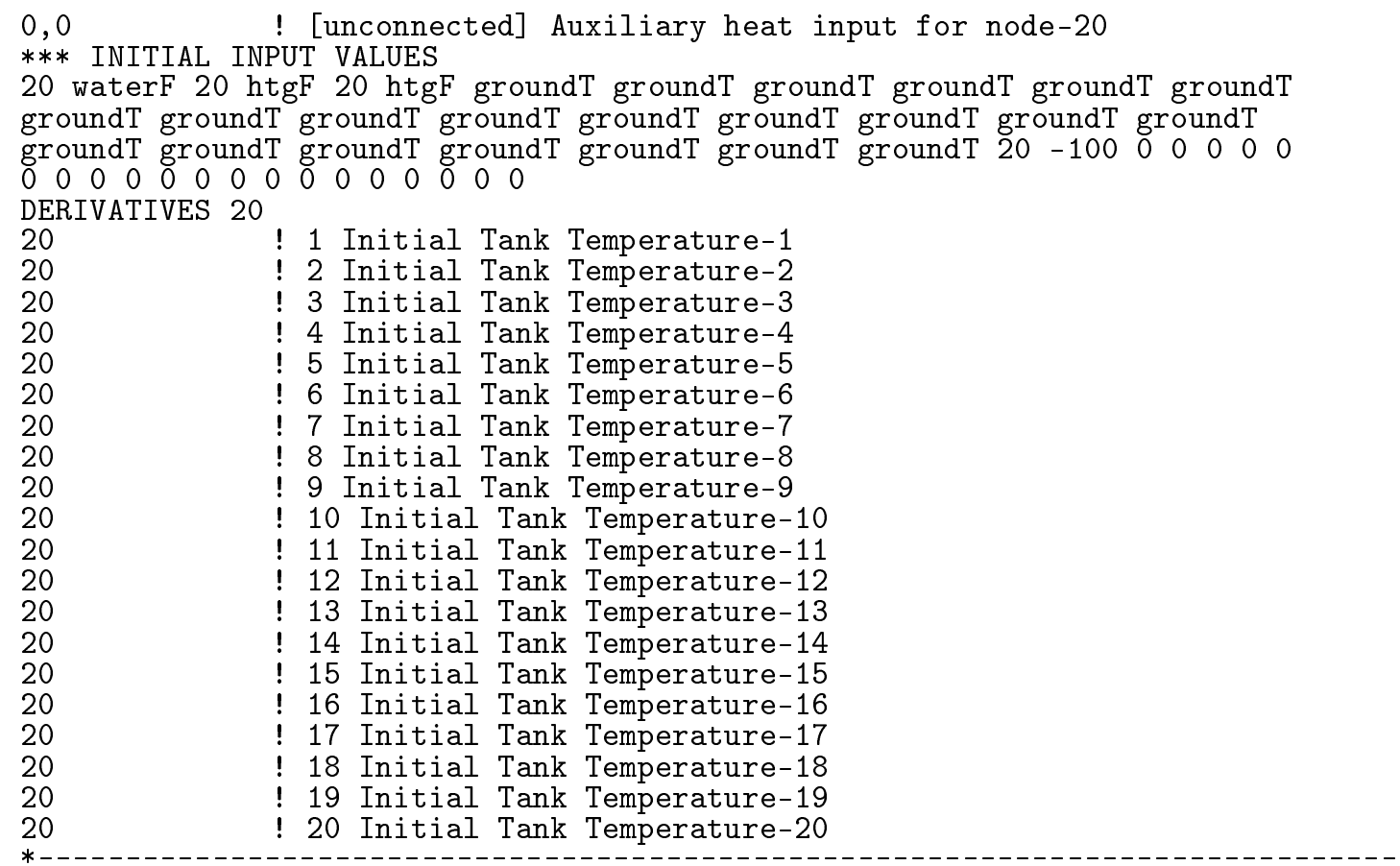

* Model "P_seas" (Type 3)

UNIT 28 TYPE 3 P_seas

*\$UNIT_NAME P_seas

$*$ \$MODEL . \Hydronics $\backslash$ Pumps $\backslash$ Single Speed $\backslash$ Type3b.tmf

*\$POSITION 622363

*\$LAYER Stores \#

PARAMETERS 5

waterF

! 1 Maximum flow rate

waterCp

719.999981

0.05

0.5

! 2 Fluid specific heat ! 3 Maximum power

INPUTS 3

39,1

39,2

15,3

$* * *$ INITIAL INPUT VALUES
20 waterF 0

! 4 Conversion coefficient

! 5 Power coefficient

! Seasonal-4:Temperature at outlet-1 ->Inlet fluid temperature

! Seasonal-4:Flow rate at outlet-1 ->Inlet mass flow rate

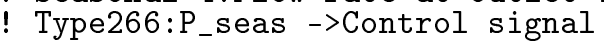

* Model "DHW Load" (Type 9)

UNIT 18 TYPE 9 DHW Load

$*$ \$UNIT_NAME DHW Load

*\$MODEL . \Utility \Data Readers \Generic Data Files $\backslash$ Expert Mode $\backslash$ Free Format $\backslash$ Type9e. tmf

*\$POSITION 980180

*\$LAYER Loads \# 


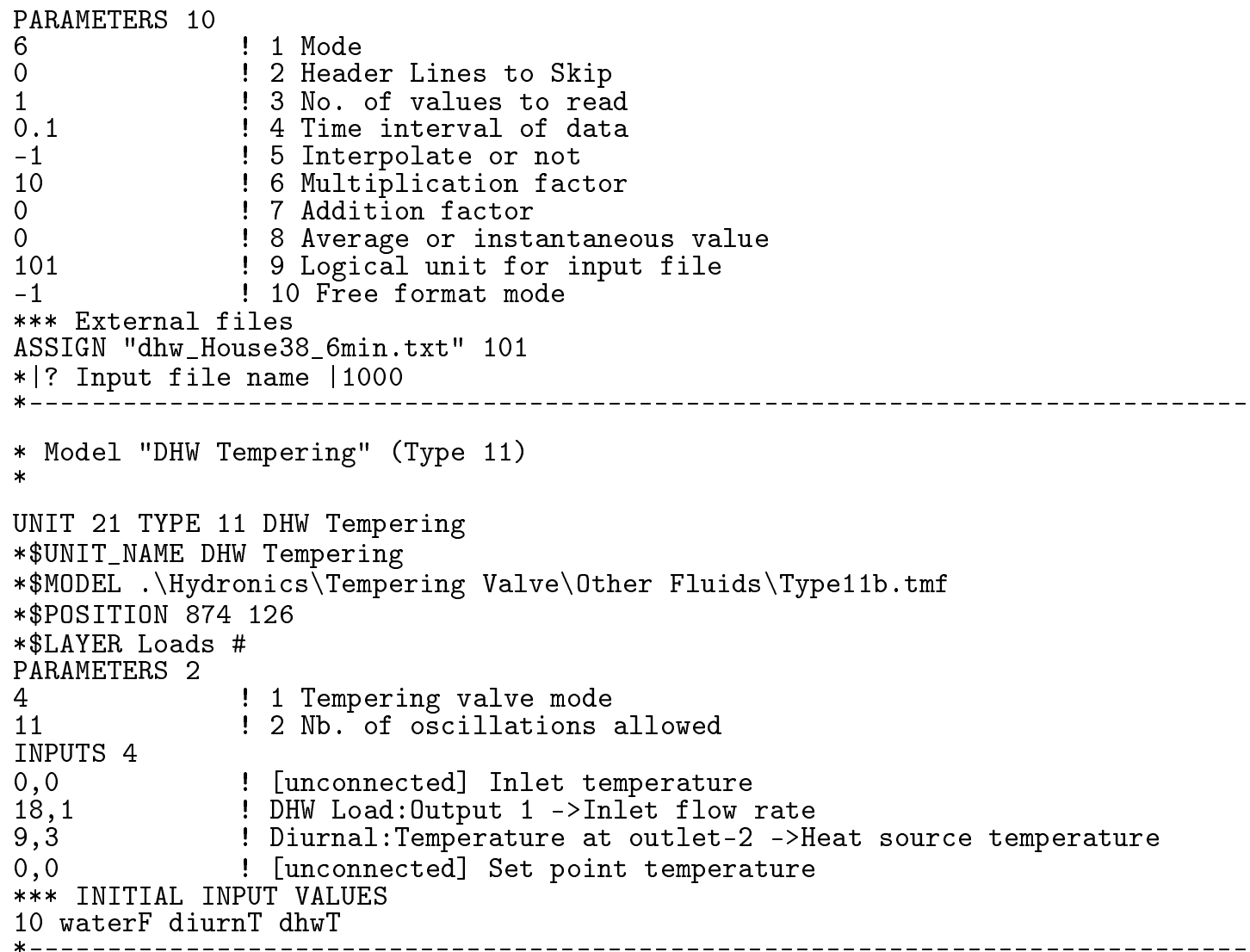

* Model "DHW Tee" (Type 11)

UNIT 22 TYPE 11 DHW Tee

*\$UNIT_NAME DHW Tee

$*$ \$MODEL . $\backslash$ Hydronics $\backslash$ Tee-Piece $\backslash$ Other Fluids $\backslash$ Type11h.tmf

*\$POSITION 97593

*\$LAYER Diurn Htg \#

PARAMETERS 1

1

INPUTS 4

! 1 Tee piece mode

9,3 ! Diurnal:Temperature at outlet-2 ->Temperature at inlet 1

9,4 ! Diurnal:Flow rate at outlet-2 ->Flow rate at inlet 1

21,3 ! DHW Tempering:Temperature at outlet $2->$ Temperature at inlet 2

21,4 ! DHW Tempering:Flow rate at outlet $2->\mathrm{Flow}$ rate at inlet 2

$* * *$ INITIAL INPUT VALUES

20 waterF 20 waterF

* EQUATIONS "Demand_dhw"

*

EQUATIONS 1

Demand_dhw $=\operatorname{GT}([18,1], 0) * 1+(1-\mathrm{GT}([18,1], 0)) * 0$

*\$UNIT_NAME Demand_dhw 


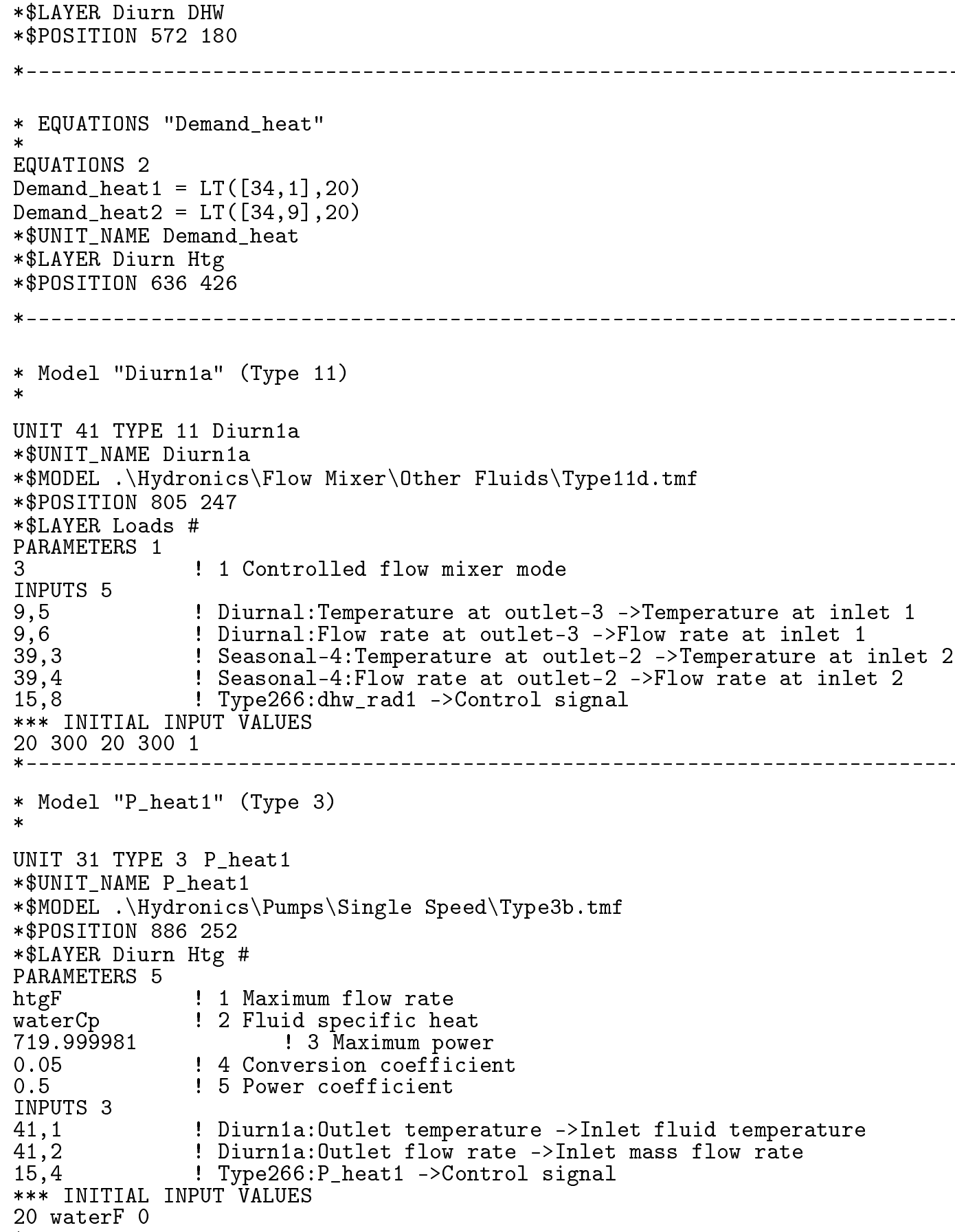


UNIT 36 TYPE 6 aux_heat 1

*\$UNIT_NAME aux_heat1

*\$MODEL . \HVAC \Auxiliary Heaters $\backslash$ Type6.tmf

*\$POSITION 967259

*\$LAYER Loads \#

PARAMETERS 4

107999.992009

waterCp

0

1

INPUTS 5

31,1

31,2

0,0

0,0

0,0

*** INITIAL INPUT VALUES

! 1 Maximum heating rate

! 2 Specific heat of fluid

! 3 Overall loss coefficient for heater during operation

! 4 Efficiency of auxiliary heater

! P_heat1:Outlet fluid temperature ->Inlet fluid temperature

! P_heat 1:Outlet flow rate ->Fluid mass flow rate

! [unconnected] Control Function

! [unconnected] Set point temperature

! [unconnected] Temperature of surroundings

20 htgF 13520

* Model "Type130" (Type 130)

$*$

UNIT 34 TYPE $130 \quad$ Type130

*\$UNIT_NAME Type130

$*$ \$MODEL . \Cosim Espr \Type130.tmf

*\$POSITION 963340

*\$LAYER Diurn DHW \#

PARAMETERS 6

! 1 Mode

! 2 NumZones

! 3 NumHccToTrnsys

! 4 NumHccToEspr

! 5 NumAccToTrnsys

! 6 NumAccToEspr

INPUTS 11

0,0

0,0

! [unconnected] Gains Zone-1

! [unconnected] Gains Zone-2

! [unconnected] Gains Zone-3

0,0

0,0

0,0

0,0

[unconnected] Gains Zone-4

! [unconnected] Gains Zone-5

! [unconnected] Gains Zone-6

0,0

36,1

! [unconnected] Gains Zone-7

! aux_heat 1:Outlet fluid temperature ->THccToEspr-1

36,2

! aux_heat1:Outlet fluid flow rate ->FlowHccToEspr-1

35,1

35,2

*** INITIAL INPUT VALUES

! aux_heat2: Outlet fluid flow rate ->FlowHccToEspr-2

$\begin{array}{lllllllllll}0 & 0 & 0 & 0 & 0 & 0 & 0 & 50 & 300 & 50 & 300\end{array}$

* Model "Diurn1b" (Type 11)

$*$

UNIT 42 TYPE 11 Diurn $1 \mathrm{~b}$

*\$UNIT_NAME Diurn1b

*\$MODEL . \Hydronics $\backslash F$ low Diverter $\backslash$ Other Fluids $\backslash$ Type11f.tmf

*\$POSITION 838318 


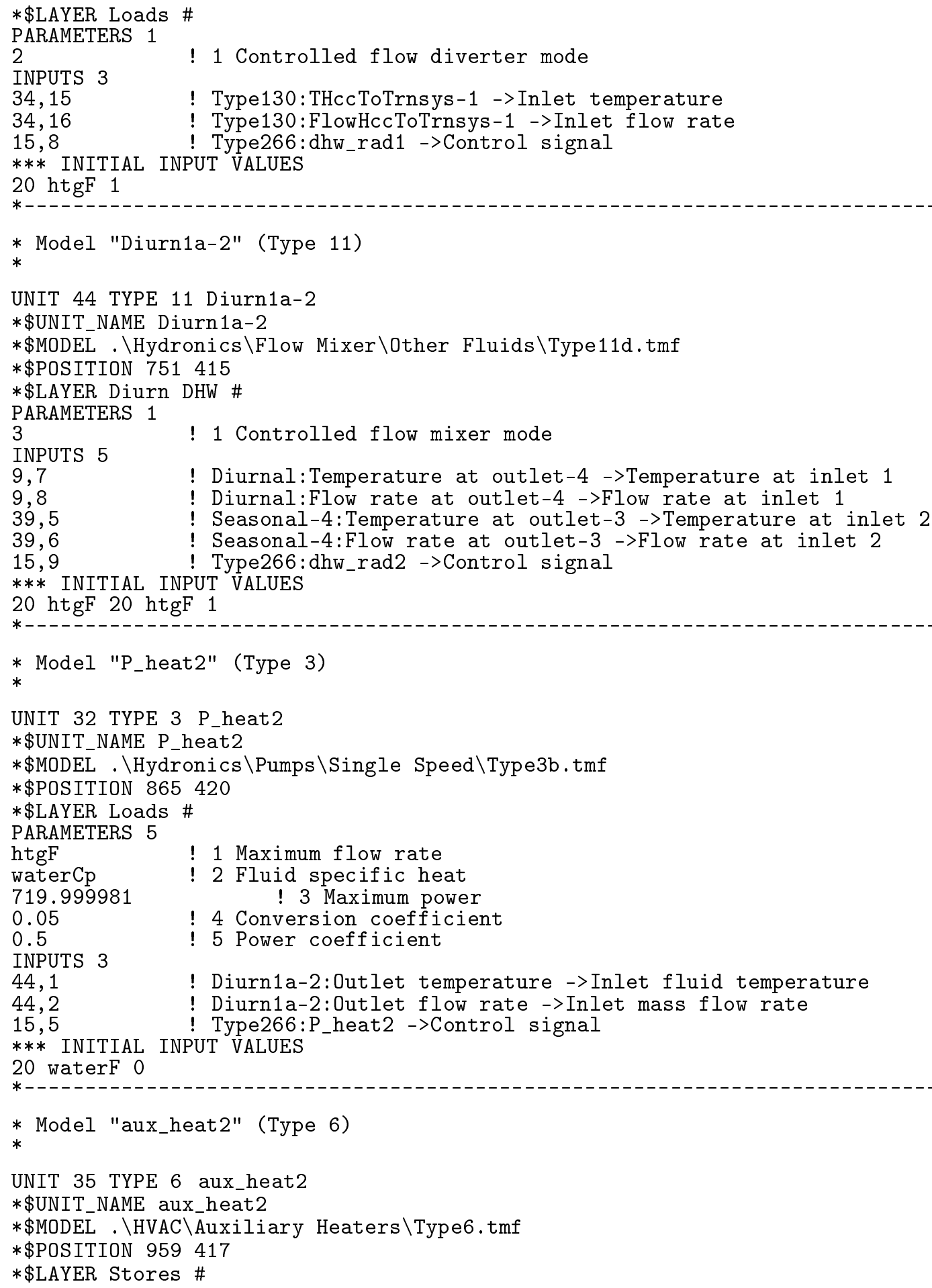




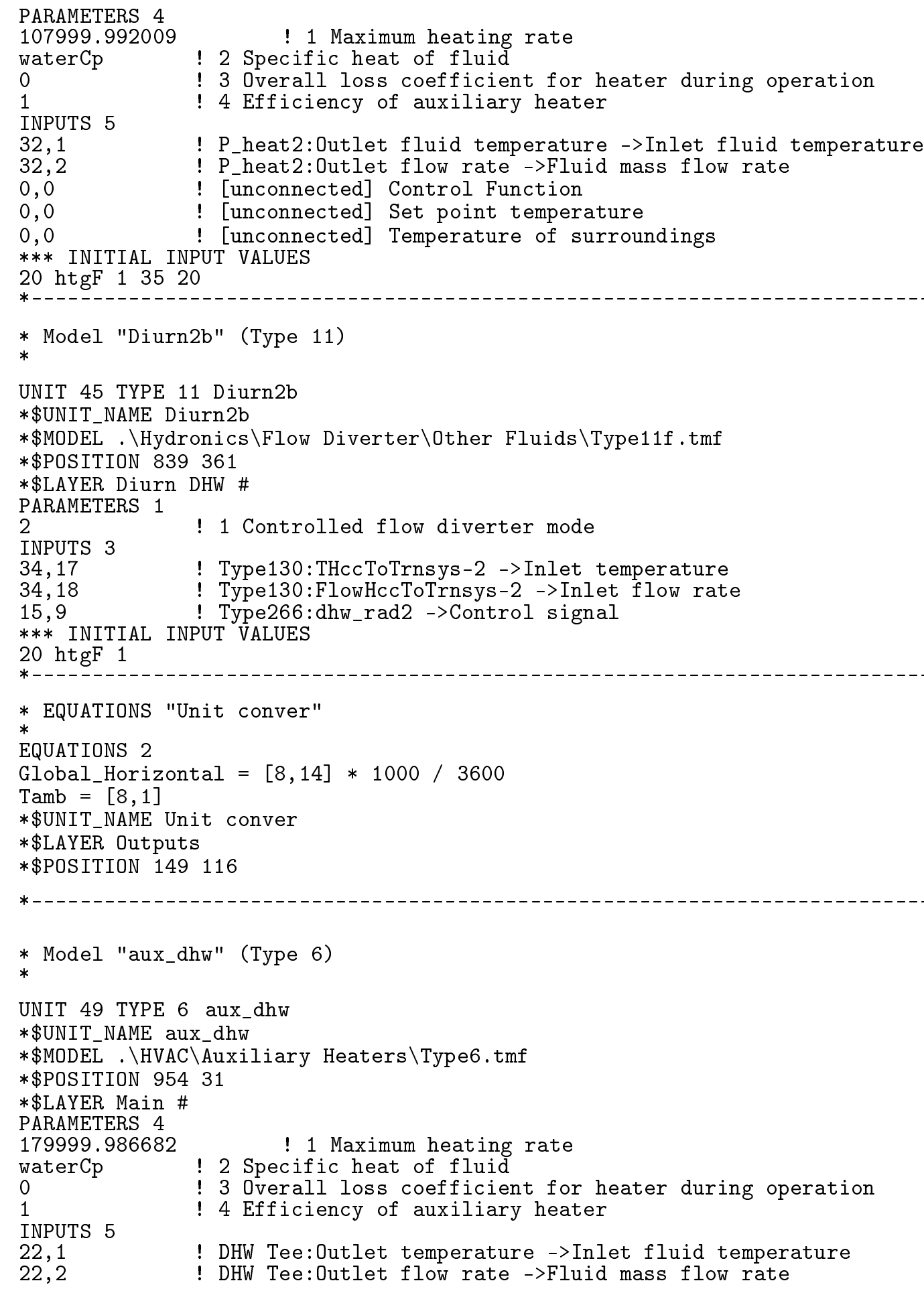




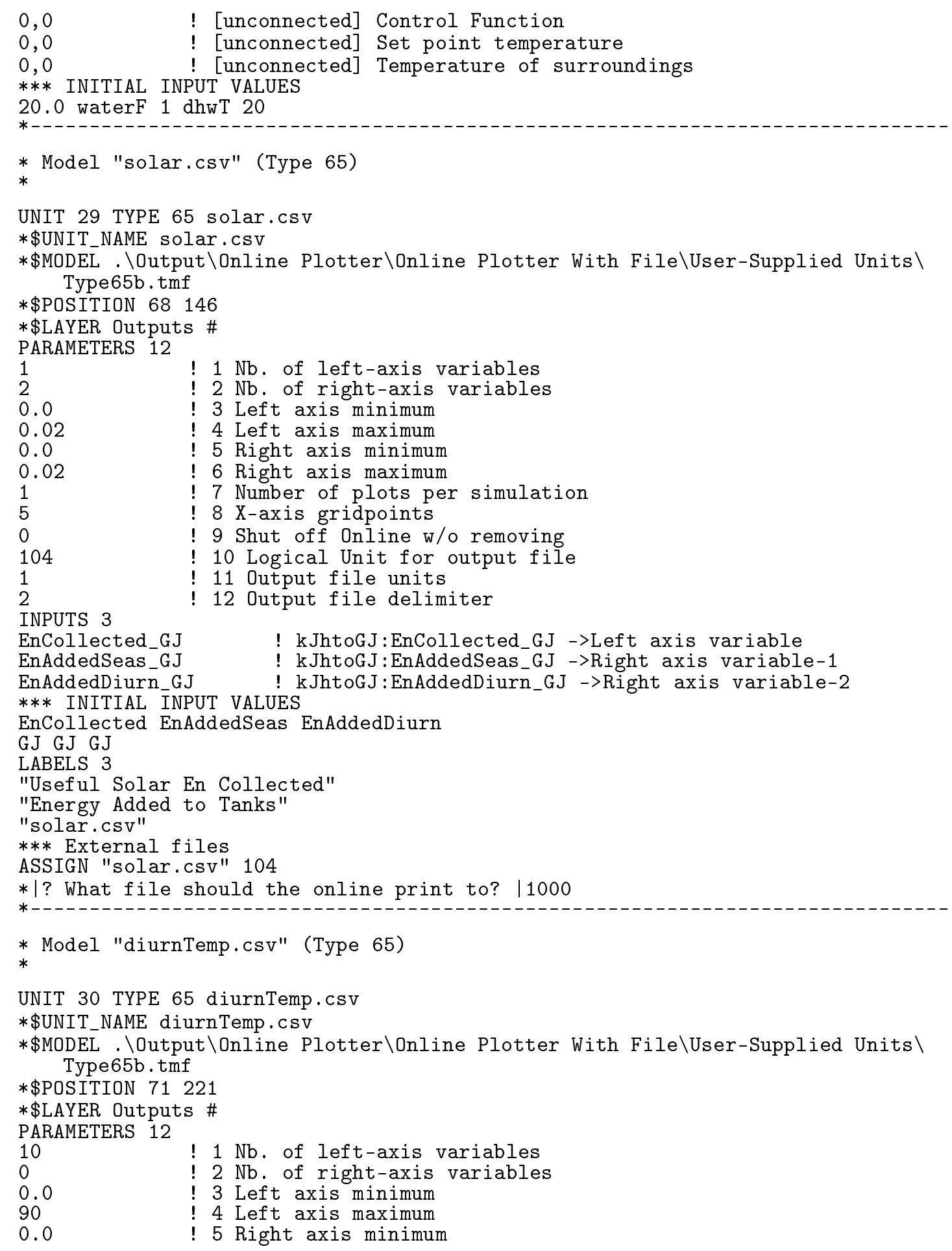




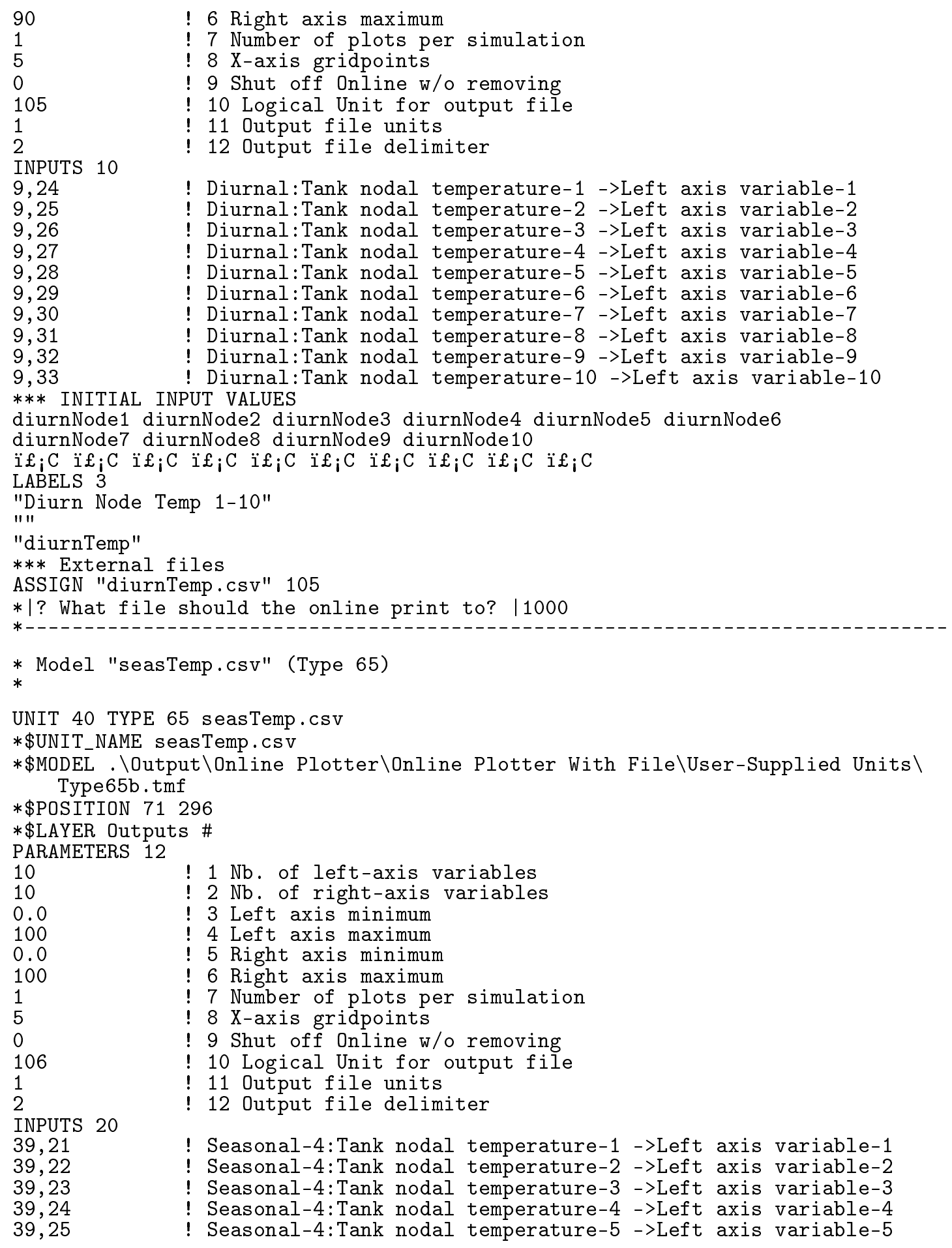




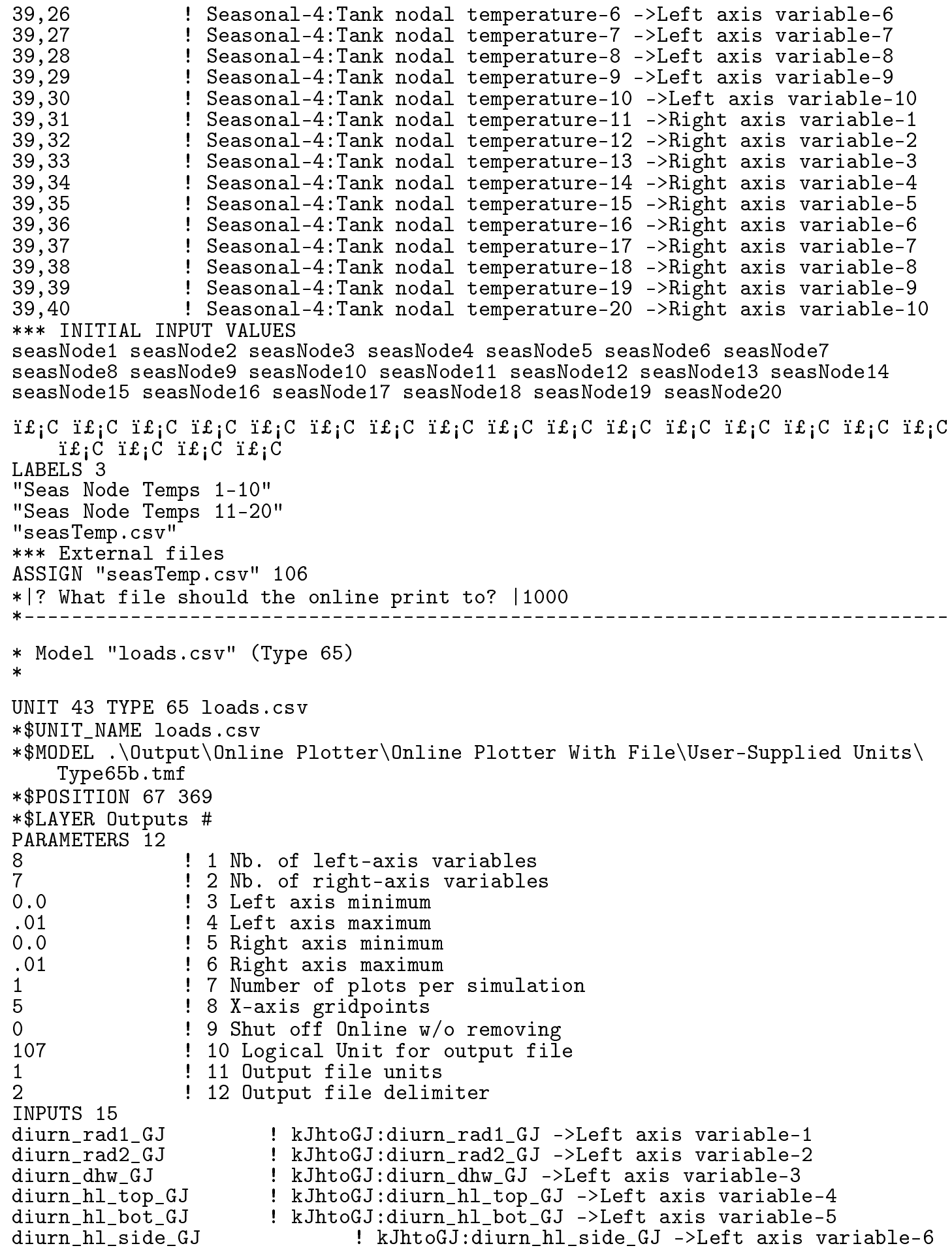




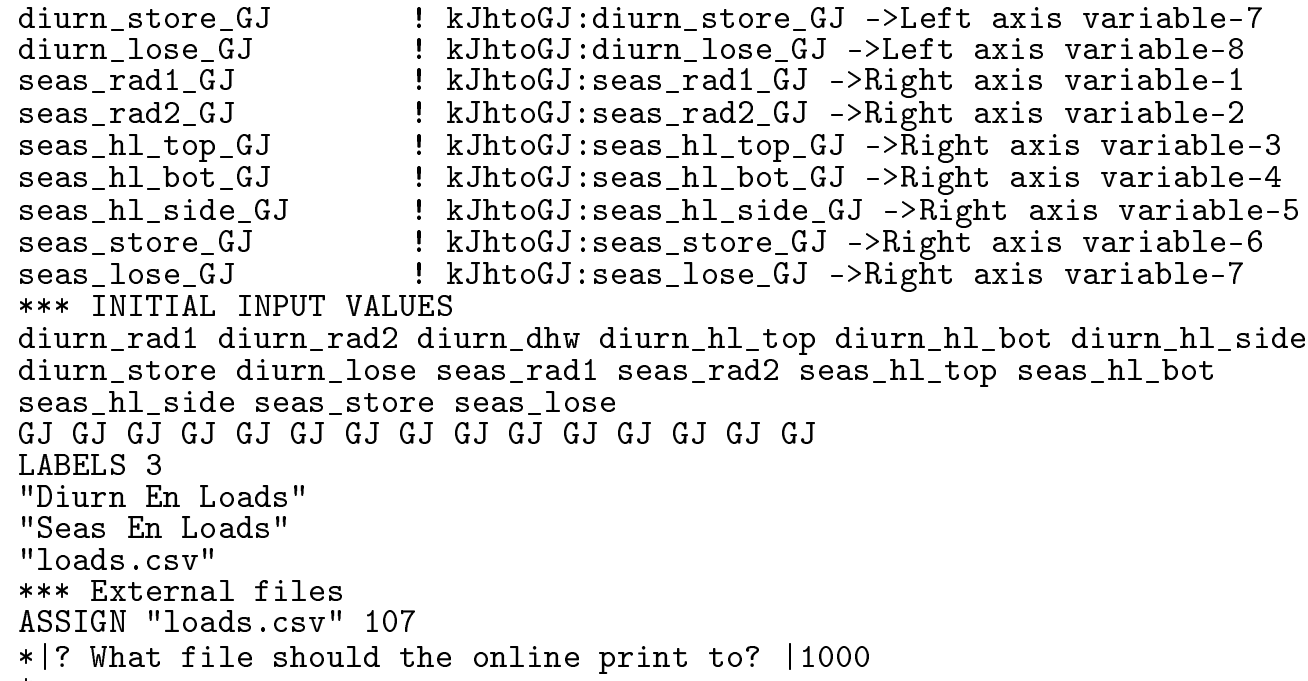


*|? What file should the online print to? | 1000

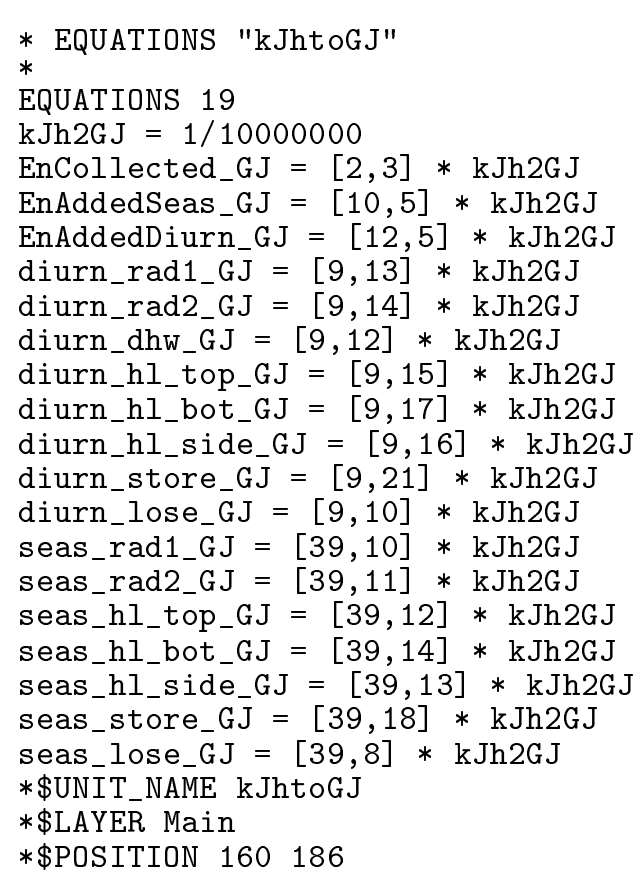

END

0.55 


\section{E.3 Apricus Solar Collectors}

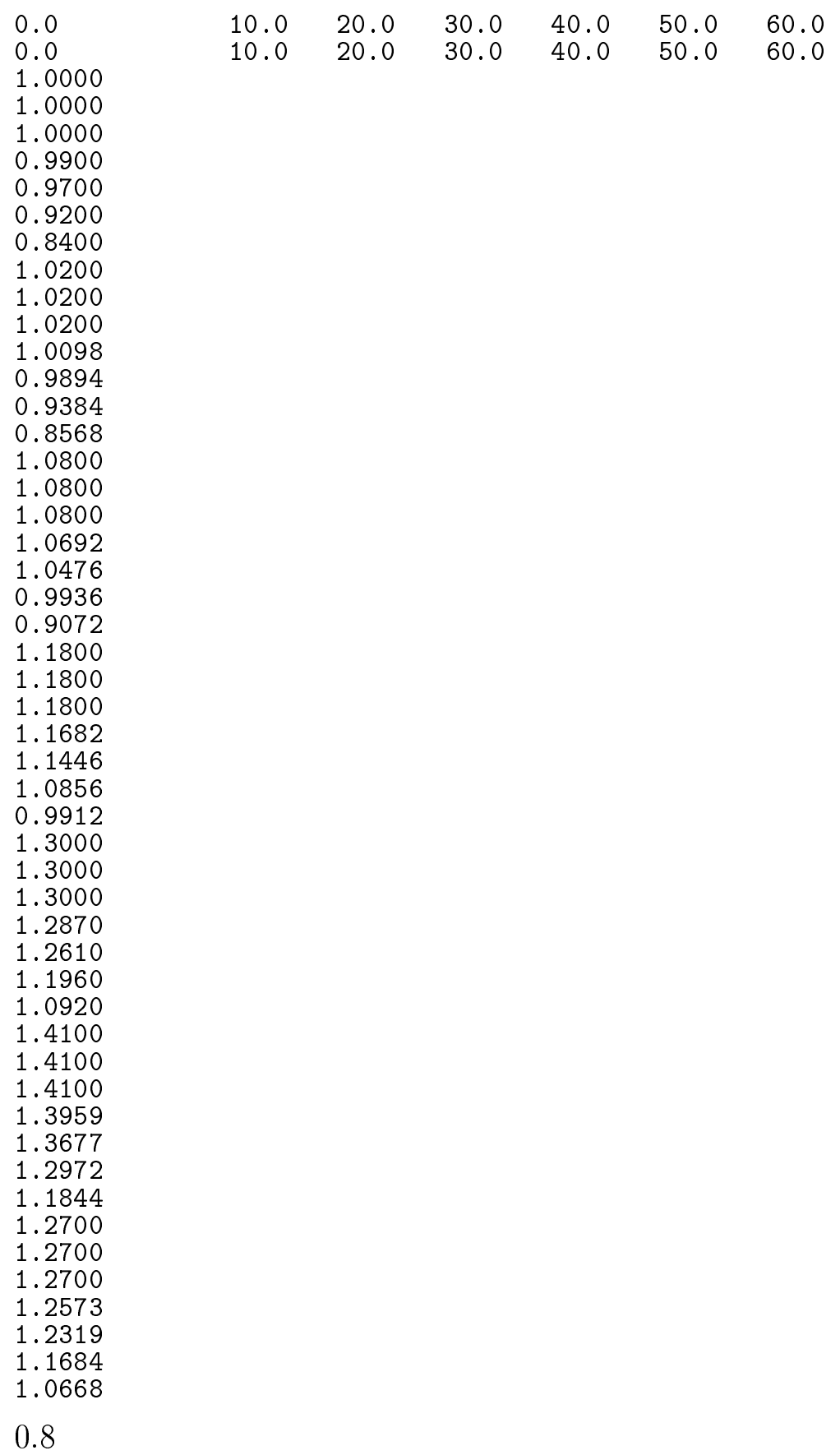

